
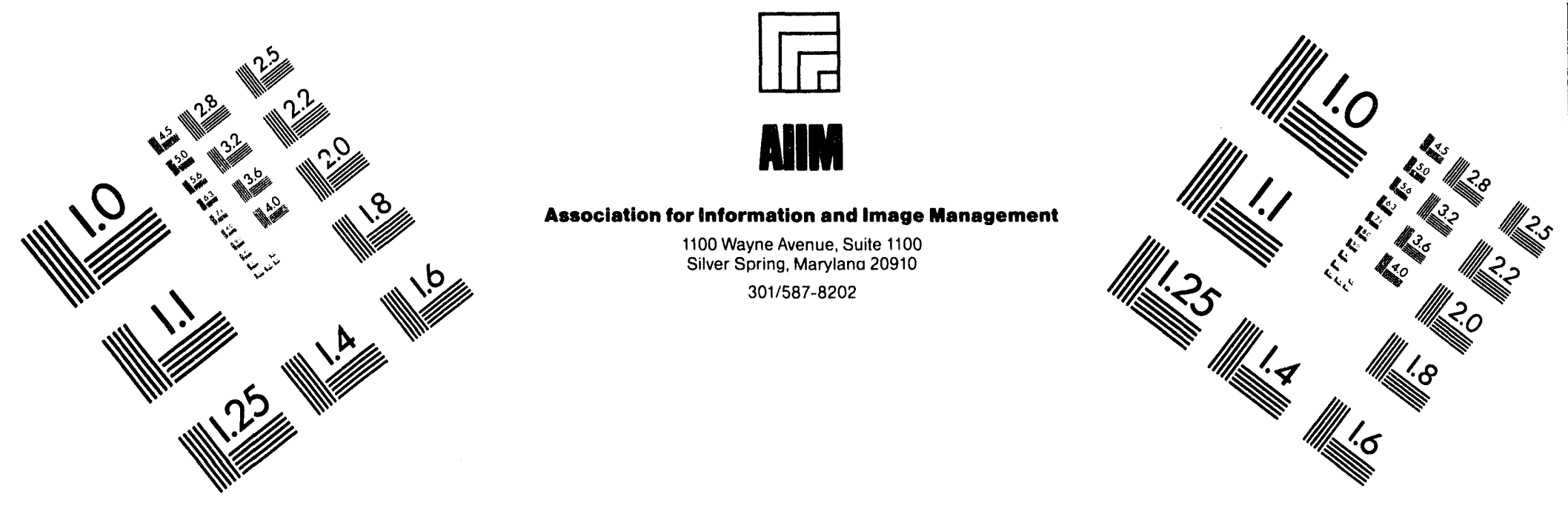

\title{
Centimeter
}

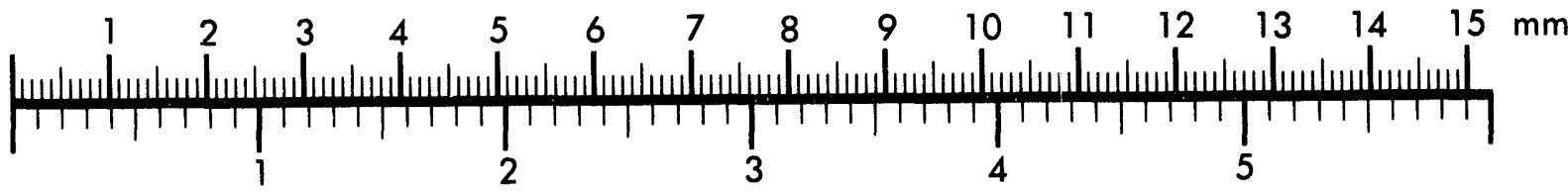
Inches
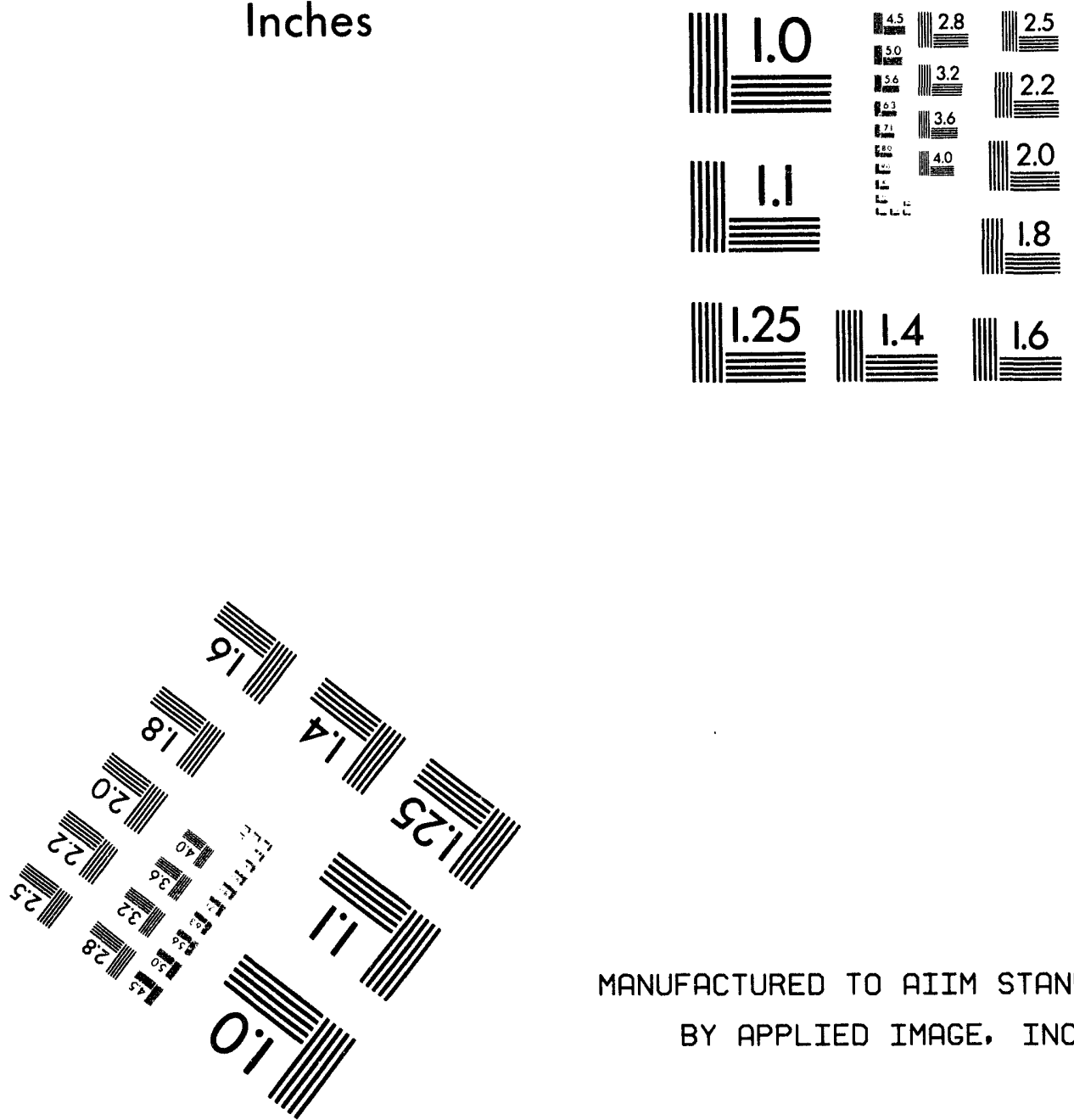

MANUFACTURED TO AIIM STANDARDS

BY APPLIED IMAGE, INC.

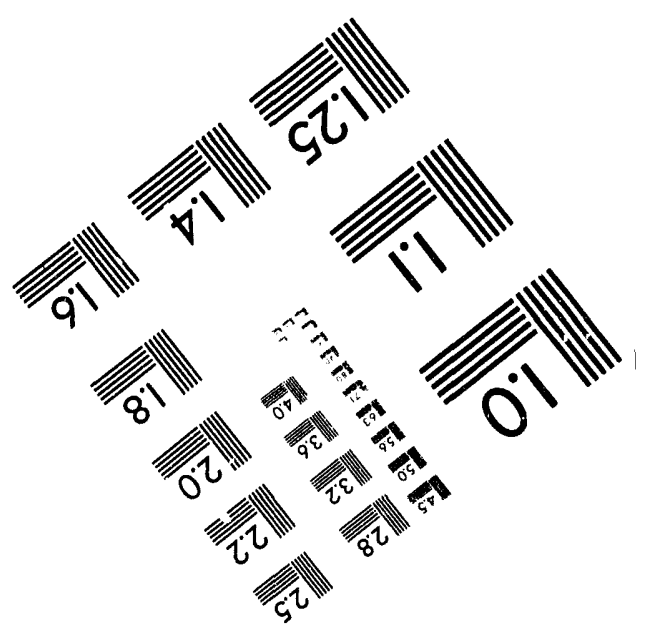



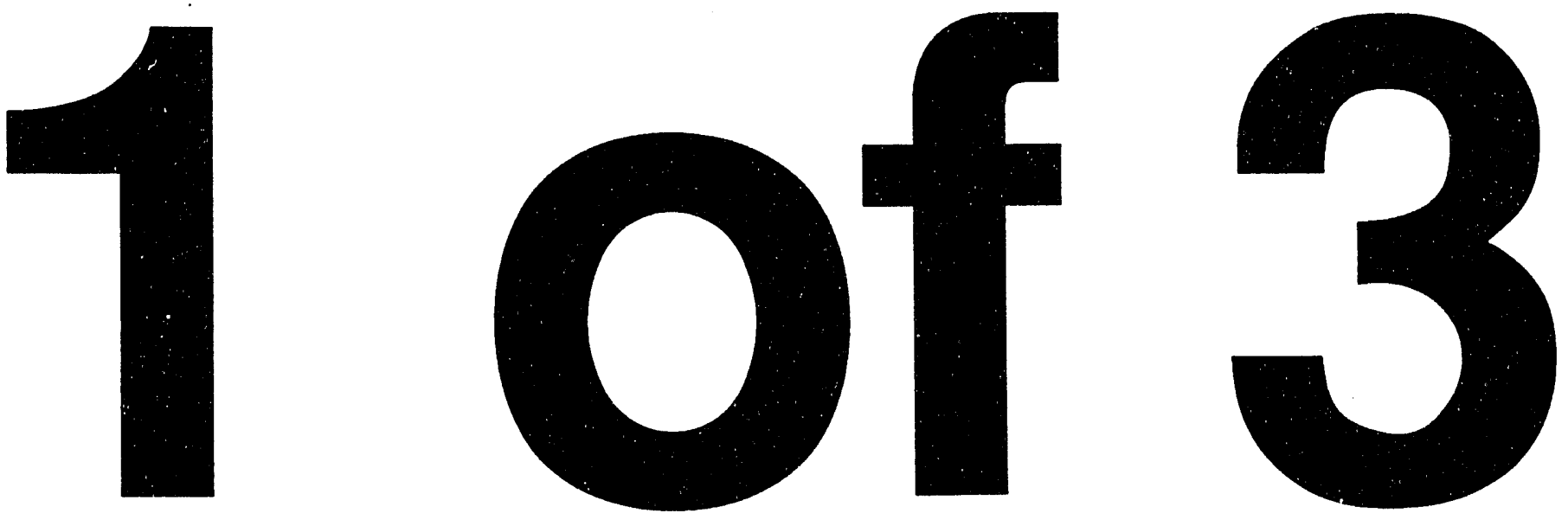


\section{U.S. Department of Energy Public Participation Policy Comment Response Document}

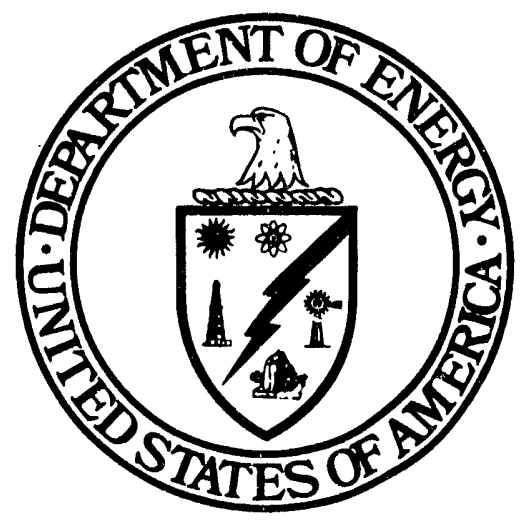

August 1994 


\section{Contents}

1. Public Participation Policy and Implementation Guidance

2. Comment Responses

3. Incoming Comment Letters 
Public Participation Policy

and

\section{Implementation Guidance}




\section{The Secretary of Energy \\ Washington, DC 20585}

JuTy 29,1994

$\begin{array}{ll}\text { MEMORANDUM FOR: } & \text { ALL DOE EMPLOYEES } \\ \text { FROM: } & \text { HAZEL R. O'LEARY } \\ \text { SUBJECT: } & \text { GUIDANCE ON IMPLEMENTATION OF THE DEPARTMENT'S PUBLIC }\end{array}$

Public participation must be a fundamental component of the Department's program operations, planning activities, and decision-making. The business of the Department must be open to the full view and input of those whom it serves, consistent with applicable laws, regulations, and contracts.

To ensure that we operate in this manner, the Department's Public Participation Policy was developed by a cross-cutting team that included field representatives. This policy marks a clear break with past practice by challenging the Department and its contractors to perform to a new standard of openness and service.

Within this policy framework, each site will develop its own public participation program and plans in consultation with stakeholders and with the concurrence of appropriate Headquarters program offices. In achieving the goals of public participation, managers are responsible for:

* identifying, planning, funding, supporting, and implementing the appropriate level and scope of public participation activities in their programs;

* ensuring that public participation principles, values, and processes are fully understood and practiced within their programs and at their sites;

* providing necessary human, information, systems, and financial resources; and,

* ensuring that their staff receive basic communication and public participation training, and where appropriate, advanced public participation training.

To promote teamwork, share the benefits of experience and innovation at individual sites, and avoid unreasonable demands on site personnel or stakeholders, program and staff offices will coordinate public participation activities through the Office of Public and Consumer Affairs at Headquarters or with its counterpart in the field. This coordination in no way limits or dilutes field managers' authority to implement effective public participation programs or program managers' responsibility to plan, fund, and support appropriate levels of public participation in their programs. 
The effectiveness with which each site/program implements the Department's Public Participation Policy will be assessed annually, and these assessments must include the views and recommendations of stakeholders. Stakeholders will also be invited to participate in the processes used to develop criteria and measures for judging effectiveness. The Director of Public and Consumer Affairs will evaluate these annual assessments and recommend changes to improve the effectiveness of the Department's public participation efforts.

While public participation processes must be tailored to meet specific site, program, and stakeholder needs, the following broad guidance provides a framework to assist management in implementing this policy Department-wide. Using the following critical policy elements and implementing actions as a guide, Headquarters and Field Elements should consult with stakeholders to develop appropriate public participation programs and activities.

\section{CRITICAL POLICY ELEMENTS:}

I. The Department recognizes that honesty and forthrightness in dealing with stakeholders, and consistent, credible, quality performance are the bases upon which to build public understanding and trust.

Implementing Actions:

* Department officials will be open, honest, and accurate in their public statements and accountable for diligent follow-up and timely results from the commitments they make.

* Department officials will engage in an open and on-going communication process and consistently listen and respond to suggestions made by the public. The Department will incorporate public input into its decisions where appropriate and feasible and will provide feedback to the public on its reasoning.

* Department officials will recognize and reward leadership and results in the area of public participation.

II. Departmental program development, planning, and decision-making processes will be clearly defined, with regular, easily identified access points for public input.

Implementing actions:

* Senior management will ensure that Department personnel, other Federal, State, and local officials, Tribes, and other stakeholders are appropriately integrated into their planning activities and decision-making processes.

* Stakeholders and field managers will determine and identify pre-decisional access points for public input. 
III. Headquarters, field offices, laboratories, and facilities will operate as an integrated team in planning local and national public participation programs by combining resources, sharing information, and coordinating activities.

Implementing actions:

* Headquarters Elements will coordinate their planning of public participation activities with the Office of Public and Consumer Affairs and with affected sites, including the site Public Affairs/External Relations director.

* Field managers, as those closest to affected communities and stakeholders, will facilitate accommodation between local and national interests.

IV. The Department will establish and support training and education programs to meet evolving public participation needs, both internally and externally.

Implementing actions:

* Senior management, at Headquarters and in the field, will identify and coordinate communication and public participation training on a priority basis until all appropriate headquarters and site personnel are trained.

* In consultation with stakeholders, field managers will make recommendations on the timing and content of needed external education/training programs.

v. The Department will foster candid information exchanges and ongoing two-way communication using a variety of mediums.

Implementing actions:

* Whether formal or informal, all public participation activities will be conducted in a spirit of openness, respect for different perspectives, and a genuine quest for a diversity of information and ideas.

* The Department will work to establish, announce, and manage topical data bases of reliable, timely information available to the public through telephone and computer access.

Attachment 


\section{PUBLIC PARTICIPATION POLICY}

PUBLIC PARTICIPATION:

POLICY:

PURPOSE:

SCOPE:
Public participation is open, ongoing, two-way communication, both formal and informal, between the Department of Energy and its stakeholders. This steady, interactive communication enables each party to learn about and better understand the views and positions of the other. The Department recognizes the many benefits to be derived from public participation, for both stakeholders and DOE. Public participation provides a means for the Department to gather the most diverse collection of opinions, perspectives, and values from the broadest spectrum of the public, enabling the Department to make better, more informed decisions. Public participation benefits stakeholders by creating an opportunity to provide input and influence decisions.

Public participation is a fundamental component in program operations, planning activities, and decision-making within the Department. The public is entitled to play a role in Departmental decision-making.

This policy is intended to ensure that public participation is an integral and effective part of Departmental activities and that decisions are made with the benefit of important public perspectives. This policy provides a mechanism for bringing a broad range of diverse stakeholder viewpoints and values early into the Department's decision-making processes. This early involvement enables the Department to make more informed decisions, improve quality through collaborative efforts, and build mutual understanding and trust between the Department and the public it serves.

This policy is designed to function as a general framework within which all Department programs shall operate. While it applies to all levels of DOE, its intent is development and implementation of effective public participation programs at each site. In conjunction with its stakeholders and field manager, each site shall develop and implement a public participation program that promotes openness and two-way communication and is tailored to meet specific program, site, and stakeholder needs. This policy is not intended to affect legal requirements imposed by law, regulation, or contractual agreement; neither does it modify any legal rights available to the public under current law. 
DEFINITION: $\quad$ Under this policy, the Department actively seeks, considers, and incorporates or otherwise responds in a timely manner to the views of its stakeholders, thereby providing them an opportunity to influence decisions. Stakeholders are defined as those individuals and groups in the public and private sectors who are interested in and/or affected by the Department's activities and decisions. Public participation is defined as open, ongoing two-way communication, both formal and informal, within the DOE Complex and between the Department and its stakeholders. This communication will vary widely in nature and scope and may include, but is not limited to, informal conversations, scheduled meetings and workshops, legally required hearings, and Federal-Statelocal-Tribal agreements.

GOALS: $\quad$ The goals of the Department's Public Participation Policy are:

I. The Department actively seeks and considers public input, and incorporates or otherwise responds to the views of its stakeholders in making its decisions.

II. The public is informed in a timely manner about and empowered to participate in the Department's decision-making processes, which are open, understandable, and consistently followed. Access points for public input are clearly defined from the earliest stages of a decision process and provide adequate time for stakeholders to participate.

III. Credible, effective public participation processes are consistently incorporated into the Department's program operations, planning activities, and decision-making processes, at headquarters and in the field. Every employee within the DOE Complex shares responsibility to promote, practice, and improve public participation.

CORE VALUES: $\quad$ Though program-specific public participation activities may vary throughout the DOE Complex, each program will be characterized by the following core values:

Accessibility: Known avenues to Department leaders who are available, approachable, and open to the public.

Accountability: Responsibility to the public for its decisions and a willingness to provide explanations for the rationales behind its decisions.

Accuracy: Commitment to the truth.

Communication: Open, two-way exchange of information, knowledge, and perspectives between the Department and its stakeholders. 
Consistency: $\quad$ Stakeholder interactions marked by regularity and continuity.

Fairness:

Honesty:

Objectivity and freedom from favor toward any side.

Innovation:

Commitment to fairness, trustworthiness, and straight forwardness.

Openness:

Introduction of new ideas, methods, and approaches.

Peer review: Reexamination of key issues and decisions by internal

Ready accessibility and a willingness to listen to, consider, and respond to stakeholders.

Respect: Consideration and deference in the treatment of and external peers. stakeholders.

Responsiveness: Timely and empathetic consideration of and response to the needs, wants, and concerns of stakeholders.

Scientific credibility: Commitment to the pursuit of sound, dependable, leading edge science.

Sincerity: $\quad$ Openness, frankness, and truthfulness in all stakeholder communications.

Time/Timeliness: Adequate amount of time for stakeholders to participate in Department decision-making processes. Timely responses to stakeholder input and requests. Timely Departmental decision-making processes supported but not hindered or delayed by public participation.

ACCOUNTABILITY: Senior departmental, program, and field managers are accountable for assuring that public participation activities meet the goals of this policy and the needs of stakeholders; are fully coordinated; and reflect Departmental principles and values. Managers are responsible for implementing $p l a n s$ that assure that public participation needs for their programs or projects are identified and satisfied in the decision-making process. Public Participation is a performance element for these managers. 
Comment Responses 
ORGANIZATION

1. City of Oak Ridge, TN

2. Environmental Coalition on Nuclear Power

3. Laborers International Union of North America

4. League of Women Voters

5. Baltimore Gas and Electric

6. Agency for Nuclear Projects Nuclear Waste Project Office

7. Nevada Nuclear Waste Task Force Inc.

8. Nuclear Waste Technical Review Board

9. Nuclear Waste Technical Review Board

10. Commonwealth Edison

11. Public Service Electric and Gas Company

12. GPU Nuclear Corporation

13. Northern States Power

14. Nuclear Information and Resource Service

15. County of Inyo, CA

16. PECO Energy Company

17. Safe Energy Communication Counci1

18. U.S. EPA

19. USCEA

20. Boston Edison

21. Tennessee Valley Authority

22. Nuclear Waste Study Committee

23. Sigma $X_{i}$, The Scientific Research Society
AUTHOR

Jeffrey Broughton, Sity Manager

Judith H. Johnsrud, PhD.

Kenneth D. Smith

Elizabeth Kraft

Elizabeth Bauereis, PhD.

Joe Strolin

Judy Treichel

Paula N. Alford

D. Warner North

Louis 0. DelGeorge

Harold W. Borden, Jr.

P. R. Clark

James Howard

Mary 01 son

Brad Mettam

Gwendolyn S. King

Martin Gelfand

J. William Gunter

Phill ip Bayne

Bernard W. Reznicek

0. D. Kingsley, Jr.

Hal Rogers

John F. Ahearne 
24. Office of Management and Budget

25. Portland General Electric Company

2f. Western Interstate Energy

27. American Society of Civil Engineers

28. U.S. Nuclear Regulatory Commission

29. ADR

30. Eurekz County, NV

31. League of Women Voters of Nevada

32. BNFL

33. Agency for Nuclear Projects

Nuclear Waste Project Office

34. UNLV-Harry Reid Center for

Environmental Studies

35. American Nuclear Society

36. Esmeralda, Lincoln, and

White Pine Counties, NV

37. Science Applications International

Corporation

38. Science Applications International

Corporation

39. Department of Energy

Environmental Management Advisory Committee

40. Vicki Dastillung

41. Shira A. Flax

42. Confederated Tribes and Bands

of the Yakima Indian Nation

43. Ohio EPA

44. Department of Energy

Idaho Communications Division

a. (Comment made by Brett Hayball, Shoshone-Bannock Coordinator and Project Director):

b. (Comment made by Linda Milam, Mayor of Idaho Falls):

c. (Milam)

T.J. Glauthier

Ken Harrison

Douglas Larson

Nancy Wall

John Graham

Bob Loux

Bill Andrews

Dan Burns

Paul Seidler

Shira A. Flax

Russe11 Jim

Connie Nash

Edward 0. Pfrang

Robert M. Bernero

A. David Rossin

Abigail C. Johnson

Edward D. Fuller

Florindo Mariani

James T. Melillo

Vicki Dastillung

Thomas Winston, P.E.

Tribal/DOE 
d. (Comment made by Terry Smith, Public Information Officer, State INEL Oversight Program):

e. (Comment made by Candis Mebb, Department of Energy, Idaho):

f. (Comment made by Ellie Hamilton, Private Citizen):

g. (Webb) :

h. (Smith):

i. (Smith):

45. Department of Energy

Office of Nuclear Energy Daniel Dreyfus

46. Illinois EPA

Stephen K. Davis

47. Department of Energy

Oakland Operations Office

John Belluardo

48. Lawrence Livermore National Laboratories

Harry L. Galles

49. Stanford University Linear Accelerator Center

Kirk Stoddard

50. Sandia National Laboratories

Steve Baca

51. Department of Energy

Chicago Operations Office

Gary L. Pitchford

52. Department of Energy

Human Resources and Administration

Archer Durham

53. Oak Ridge Institute for Science

and Education

James E. Drewry

54. Author Unknown

Author Unknown

55. Energy Research Foundation

Tim Colıner

56. Neighbors in Need

Rev. Dr. Velma Shearer

57. National Renewable Energy Laboratory

Duane N. Sunderman

58. Battelle Pacific Northwest Laboratories

Joseph D. Spencer

59. Continuous Electron Beam Accelerator Facility

James E. Coleman

60. Amarillo Area Office

Tom Williams

61. The Metal Trades Council

Ronnie Payne

62. Lawrence Berkeley Laboratory

Michael Chartock

63. Oregon Department of Energy

Ken Niles

64. Department of Energy

Environmental Health

Lea Ekman 
65. Department of Energy

Environmental Restoration

David Perotti

66. Departmerst of Energy

Environmental Management

Bobbie Smith

67. State of Missouri

Department of Natural Resources

Robert Geller

68. Pantex

Guyon H. Saunders

69. The Peace Farm

Mavis Belisle

70. W.H. O'Brien

H.H. O'Brien

71. Ames Lab

John Eckert

72. Military Production Network

Stephen Schwartz

73. Department of Energy

Defense Programs

Greg Rudy

74. Department of Energy

Office of the Secretary

Dan Reicher

75. City of Oak Ridge, TN

Mayor Edmund A. Nephew

76. Department of Energy

Office of Environmental Management

Cynthia Kelly

77. Stanford University Linear Accelerator Center

Burton Richter

78. Mary Riseley

Mary Riseley

79. Eugene Kovalenkc

Eugene Kovalenko

80. Bonnie Bonneau

Bonnie Bonneau

81. LANL 2000 Subcommittee/Task Force on Policy Formation and the National Economy

82. Vista Control

Author Unknown

83. Gloria Gilmore-House

Gloria Gilmore-House

84. Carolyn and Arnold Keskulla

Carolyn/Arnold Keskulla

85. David Kime

David Kime

86. John Darke

John Darke

87. Erwin Binder

Erwin Binder 
88. Jay Edgeworth

89. DOE-Los Alamos Area Office ES\&H Branch

90. Sig Hecker

91. LANL-Public Affairs

92. John Ussery

93. New Mexico-Radioactive Waste Consultation Task Force

94. DOE-Carlsbad

95. Martin Marietta

96. DOE-UMTRA

97. DOE-Los Alamos Area Office Counsel's Office

98. DOE-Los Alamos Area Office Counsel's Office

99. Concerned Citizens for Nuclear Safety
Jay Edgeworth

Author Unknown

Sig Hecker

Scott Duncan

John Ussery

Anita Lockwood

Patty Baratti-Sallani

Jane Malagon

Albert Chernoff

Lisa Cummings

Author Unknown

Margaret Card 


\section{PUBLIC PARTICIPATION POLICY COMNENT RESPONSE DOCUMENT}

Ninety-nine respondents provided comments to the Department of Energy on its "Draft Public Involvement Policy," dated December 1, 1993. Their comments and the Department's responses are listed below. Virtually all of the comments were accepted and incorporated into the Department's Public Participation Policy, issued to all employees by Secretarial Memorandum of July 29, 1994. We believe the Policy was significantly improved through public comment and thank all those who took time to respond.

Organization

1. City of Oak Ridge, TN

a. No comments at this time.
Author

City Mgr. Jeffrey Broughton

2. Environmental Coalition on Nuclear Power

a. An inadequate amount of time was given to comment on this document.

Several respondents made this point and in response the Department extended the original comment period from January 7 to the end of January, 1994. The issue of Time/Timeliness has been and will continue to be given careful consideration. The importance and complexity of this core value is implicitly acknowledged in the length of its definition in the Policy document. The challenge will always be to balance the need for sufficient time for full public input with the need for timely decision-making by the Department.

b. The policy should state that DOE intends to include public involvement processes in actual decision making.

This change has been incorporated into the policy. Please see the opening paragraph of the Secretary's Guidance on Implementation of the Department's Public Paricicipation Policy.

c. The Secretary should direct all divisions and offices to require actual demonstrations of new policies of openness and real involvement of the public.

Each site's annual assessment of its public participation efforts will, in effect, "demonstrate" the degree of suceess being achieved in implementing this policy. One such demonstration of how future public participation efforts may occur is the public input the Department sought on these policy and guidance documents and the fact that virtually all of the comments were accepted.

d. In the descriptive summary, first section, add after "activities" the words "and in decision making".

Though this section has been rewritten, the spirit of this suggestion has been incorporated into the Policy.

e. The DOE should not define the public to include those private enterprises and individuals who have vested interests in DOE programs and the outcome of agency decisions.

Private enterprises cannot be unilaterally excluded from the public for they are inherently part of the public. The fact that a vested interest may or does exist cannot preclude an individual's or a group's right to be included in that definition. 
f. Don't promise more than can be delivered.

The Department is committed to implement public participation to the best of its ability. As this is a new approach for the Department, the process cannot be implemented overnight and will certainly require continuing refinement. The Department looks to stakeholders, especially in the annual site assessment process, to help it measure its progress and set achievable goals.

g. Goals: Great! How best can we help you carry these goals through to success?

As this Policy was designed as a general framework for the creation and implementation of public participation efforts within the DOE system, individuals and groups can contribute positively in the development and implementation of the program and sitespecific public participation plans as they are created

Department-wide. What works "best" for one site may not be effective at another site.

h. Core Values: Add "humility" to the list. The essence of "humility" has been incorporated within the core values of "fairness," "honesty," "respect," and "sincerity."

i. Responsibilities: By "discrete performance element" DOE must clarify that all staff should bear the responsibility for full and effective implementation, not just senior departmental and program managers.

While all employees are given responsibility in Goal III to promote, practice, and improve public participation within the Department, senior department managers are accountable for ensuring that public participation activities meet the goals laid out in the Policy, as addressed in the "Accountability" section.

j. Responsibilities: The term "effective" should be defined. This section is no longer part of the Policy.

k. The policy statement should prescribe the consequences of failure to abide by these directives; such failures should go well beyond mere reprimands.

This document is intended to provide the overarching philosophy and core values guiding the Department's conduct of public participation. Under this "umbrella policy" individual program offices or sites will develop detailed implementation directives which will include performance criteria and measures.

1. Memo: Paragraph 1, state definitively that public involvement shall be a routine component in operations, activities, and decision making.

The spirit of these suggestions has been incorporated in the memorandum, beginning with the opening sentence.

m. Memo: Paragraph 2, ensure that the term "stakeholders" will not be so narrowly defined and applied as in the past.

The term "stakeholders" has been defined in the Definition section of the Policy.

n. Add that access points for public input must be widely and timely noticed to encourage response.

The spirit of this suggestion has been incorporated into the Policy (Goal II) and in the Secretary's Memorandum (Critical Policy Element II). 
0. The policy should explicitly state that training/education programs are not to be designed to meet the Department's perceived needs (in the PR mode) but are to satisfy the needs of the public. While it is important that the public receive training and education, it is essential that DOE personnel receive training to learn to interact effectively with the public. In all instances this training will be substantive and conducted to provide personnel with the requisite tools for working effectively in the broadest range of public participation activities.

The goal of consensus in matters of radioactive disposal is unrealistic.

The Department agrees. The goal of public participation is open, two-way communication to foster understanding and ensure that the Department makes better, more informed decisions on the basis of "the most diverse collection of opinions, persepctives, and values from the broadest spectrum of the public."

3. Laborers International Union of North America Kenneth D. Smith a. Consider free training seminars for represented and unrepresented parties.

This idea will be given consideration. We recognize that sites will require differing levels of support, including training, to ensure effective public participation.

4. League of Women Voters

Elizabeth Kraft

a. Diversity issues should be addressed throughout the document. The Public Participation and Purpose sections of the Policy discuss the bringing together of a broad range of diverse stakeholder viewpoints and values.

b. Core Values: Add "respect for diversity." The spirit of "respect for diversity" is reflected in the core Values of "fairness," "respect," and "commitment" and al so captured in the first implementing action of Critical Element $V$ in the Secretary's Memorandum.

5. Baltimore Gas and Electric Elizabeth I. Bauereis, PhD. a. Critical Policy Elements: The new benchmark for excellence will be leadership/performance---the two statements that follow do not fit the benchmark qualities for excellence. "Risk-taking" in and of itself does not define excellence and "peer review" should be strengthened. Perhaps, this statement should be modified or part of a larger set of excellence benchmark parameters.

In the revised Policy and Guidance documents, references to "benchmarks of excellence" have been eliminated. Please see the Guidance document's introduction and Critical Policy Element I for further discussion of this concept.

6. Agency for Nuclear Projects

Nuclear Waste Project Office

a. An insufficient amount of time was given to review this document. Please see response \#2.a. 
7. Nevada Nuclear Waste Task Force Inc.

Judy Treichel

a. The comment period for this document was too short.

Please see response \#2.a.

b. Public interest representatives will be surprised if the message of adequate time for public involvement is ever heard by DOE. The Department recognizes that effective public participation requires adequate time for public review and comment. With the implementation of this Policy, every effort will be made to inform the public in a timely manner of pending and upcoming Department decisions, and to provide sufficient time for the public to participate in those decisions.

8. Nuclear Waste Tecinical Review Board

Paula N. Alford

a. There was not enough time allotted for the Board to review this document.

Please see response \#2.a.

9. Nuclear Waste Technical Review Board D. Warner North

a. Senior OCRWM managers should read the final report of the Secretary of Energy Advisory Board (SEAB) Task Force on Radioactive Waste Management, "Earning the Pubic Trust and Confidence: Requisites for Managing Radioactive Waste" and the National Research Council (NRC) Report, "Improving Risk Communication" (1989) as part of implementation of this policy. Your request has been forwarded to senior OCRWM management.

b. The Director of Public and Consumer Affairs can provide useful coordination and training, but should not inhibit initiatives or delay the public involvement process.

The Department agrees. The revised Guidance document defines the role of the Director of Pubic and Consumer Affairs as the primary point of coordination for public participation activities Department-wide. His/her counterpart at each site or field office will serve a similar coordination role at the local level.

10. Commonwealth Edison

Louis 0. DelGeorge

a. The concept of timely and effective consideration of the full range of diverse stakeholder viewpoints and values produced by public involvement should be included in the policy.

These changes have been incorporated in the Policy. Please see the Public Participation, Purpose, and Core Values sections.

b. There must be a clear acknowledgement that the Department will retain accountability for and be focused on timely decision making.

This suggestion has been incorporated into the Public Participation, Purpose, and Scope sections of the Policy.

c. The implication of Goal III, i.e. "empowerment (of the public) to participate in Departmental decision making," may be impossible to achieve, is not contemplated in the Nuclear Waste Policy Act, or legislative history of the Act.

The Goals section has been revised to convey that the Department actively seeks and incorporates input from an informed and knowledgeable public in an open and timely process. 
11. Public Service Electric and Gas Company Harold W. Borden, Jr.

a. The timing of public involvement is also a crucial factor.

The Department agrees. The issue of timing is discussed generally throughout the revised Policy, including the Core Values section. Determinations about the timing of public participation in decision making will be described more specifically in the program- and site-specific public participation plans.

b. The utilities are important stakeholders and should be included. The Department agrees.

12. GPU Nuclear Corporation

P. R. Clark

a. The policy should specifically recognize the need to seek the full range of diverse public views.

This has been done, specifically in its opening paragraph of tine Policy and in the first implementing action of Critical Policy Element $V$ of the Secretary's Memorandum.

b. The policy should assure a balance of diverse views and determine hol' representative each view is.

The Department believes each viewpoint is representative of a specific stakeholder or stakeholder group. The Department will attempt to reach a balance of diverse viewpoints. Please see response \#4.a.

c. In the Secretary's memorandum, under Implementing Actions, the second item, rewrite it to read "Department officials will routinely and consistently listen to and incorporate or respond to public input."

The spirit of this change is reflected in the Memorandum.

13. Northern States Power

James Howard

a. The training component of this policy should specifically address the importance of the type and timing of information intended to be provided to the public.

This is an excellent suggestion and will be taken under consideration in planning and developing training for this Policy.

b. Specifically address how the agency will use the public's involvement in its decision-making processes.

The revised Policy discusses the incorporation of public input into the decisions the Department makes in a variety of places, including Critical Policy Element I under "Implementing actions." Further details about this process, which will vary by site, will be included in site-specific public participation plans.

14. Nuclear Information and Resource Service Mary 01son

a. There was insufficient time given to review the policy. Please see response \#2.a.

b. When will the Department say there has been "public participation," when in fact there was stakeholder participation? The Department defines stakeholders as individuals or groups within the public and private sectors who are interestad in and/or affected by the Department's activities and decisions. Consequently, the Department considers stakeholders to be members of the public who become involved. 
c. There is no defined mechanism for accountability of who has had the opportunity to know about the Department's plans.

site and program managers responsible for public participation are expected to make good faith efforts to provide broad dissemination of information and notifications of upcoming events/decisions.

The diversity of viewpoints on a given issue/decision will be one measure; another can be provided through the annual assessments to be done in conjunction with stakeholders at each site.

d. In the Definition section, there seems to be a mandate to "play it by ear". Who's ear?

The Department disagrees with this interpretation. Though

responsibility for the implementation of this Policy permeates all

levels, senior managers, both at Headquarters and in the field, are specifically responsible (Accountability section).

e. I strongly recommend a proactive articulation of "actively seek". The phrase "actively seek" means that the Department will make good faith efforts to reach all parties who may be interested in specific programs and activities.

f. The DOE should rethink the apparent interchangeable use of the terms "stakeholder" and "public".

The Department has defined "stakeholder" under the Definition section. As discussed in response \#14.b., stakeholders are considered to be members of the public.

g. An appeals process for the public once a decision has been made is absent.

If the public wishes to appeal a Department decision, it should first attempt to do so at the local level. If issue resolution is not possible at the local level, the public can refer the appeal to senior management at Headquarters.

h. Goals section: "A clearly defined decision-making process with known access points for public involvement is routinely followed". This is great. How will this be accomplished?

There is no one answer to this question. These determinations will be made individually in accordance with each site's public participation implementation plan. Specifics of implementation will largely be local decisions.

i. Empowering the public to participate in decision-making is only meaningful if there is recourse for the public to an independent authority.

Please see response \#14.g.

j. Grants should be provided to fund the public and independent researchers so that they may be able to fully join into the dialogue. Commit taxpayer dollars to support taxpayer input. Public participation is to be the responsibility of all DOE employees (Goal III), part of ongoing program and site operations. As such, resources will be provided in the course of regular planning and budgeting processes. The issue of support funding to stakeholder groups is one that will be addressed on a site-and program-specific basis, subject to federal law and regulation.

k. Fund an independent stakeholder board that would be bound by ethics rules and policies.

Many sites are setting up citizen advisory boards. Given the 
decentralized nature of public participation activities, this approach seem preferable to a single national board.

15. County of Inyo, CA

Brad Mettam

a. The need for early public involvement should be explicitly discussed and required.

The Department agrees and anticipates that this topic will be discussed explicitly in individual program and site specific public participation documents. The spirit of this comment is addressed in numerous places in this document.

b. Both the implementation guidance memo and the policy should say that active public involvement includes providing the public with the institutional and technical resources to independently assimilate and evaluate DOE information.

Please see response \#14.j.

16. PECO Energy Company

Gwendolyn S. King

a. No comments.

17. Safe Energy Communication Council

Martin Gelfand

a. To whom did you send this particular request for involvement?

This document was sent to the heads of DOE Headquarters Elements, Field office managers, and national laboratory directors who, in turn, were asked to share it with their stakeholders.

b. Why is the comment period so short?

Please see response \#2.a.

c. Extra time or funds should be provided for this process to enable stakeholders to adequately participate.

Please see responses \#2.a. and \#14.j.

18. U.S. EPA

J. William Gunter

a. The tone of the memo and guidance is "heavy handed".

What may be interpreted as "heavy handedness" is a reflection of the seriousness with which this issue is being presented to those within the DOE Complex. Trying to change a culture of commandand-control to one of openness and public participation requires special attention and emphasis.

b. The policy and guidance should start off with an explanation of why DOE thinks public involvement is important. This explanation should precede the opening policy statement.

The need for public involvement is defined in the guidance document. In addition, an opening Public Participation section has been added in the Policy.

c. The policy stateirent should stress that public involvement will be an open and on-going communication process. Therefore, we suggest eliminating the word "routine" throughout the policy. The Department agrees and has deleted the word "routine."

d. Add a statement or two suggesting that program managers or public affairs staff try to assess the communication needs of stakeholders and others.

For the most part, references to specific personnel positions have been removed from the document to reflect the relevance this 
policy has to every employee within the DOE Complex. It is expected, however, that, site staff will perform these assessments as a result of these policy and guidance documents, and as part of specific public participation programs established at each site.

e. Core Values: Suggest including "communications" and "consultation."

"Communication" as a core value was incorporated into the Policy. "Consultation" was not for it is similar to the combined core values of "communication," "openness," and "responsiveness."

f. Goals: Add "the public's concerns, questions, comments, etc, are addressed."

The spirit of this suggestion has been incorporated throughout the Policy and Guidance Memorandum.

g. Responsibilities: Add a suggestion for a periodic evaluation of the effectiveness of DOE's public involvement processes.

This suggestion has been incorporated into the guidance document. Each program- and site-specific public participation document will be assessed annually.

19. USCEA

Phillip Bayne

a. The policy should say that participants in any policy or program initiative have an obvious and relevant stake in that initiative. "Participants" in any specific DOE policy or program initiative would fit within the larger group of Departmental "stakeholders" who, by definition, are those "interested in and/or affected by the Department's activities and decisions."

b. The policy should also specify that achieving the desired result of a given DOE initiative will also be a measure of leadership and performance

This is a good suggestion. The policy document, however, is not the appropriate place for this criterion. As discussed in the introductory section of the guidance document, the criteria to be used in the policy and program assessments have yet to be defined. The Department invites stakeholders to participate in this process by providing suggestions and recommendations on the creation of these criteria.

20. Boston Edison

Bernard W. Reznicek

a. The policy needs the important element of timely decision making. . . Add timely decision-making to Goal II or as a separate goal. Timeliness is specifically identified as a Core Value, and the importance of timeliness is referenced throughout the document.

b. I underscore the importance of training DOE staff on the elements of public involvement.

Training will be an integral part of many public participation programs within the DOE Complex. It is identified as Critical Policy Element III in the Secretary's Memorandum.

21. Tennessee Valley Authority

0. D. Kingsley, Jr.

a. The policy should clearly recognize the importance of public involvement, but that DOE has ultimate responsibility for efficient decision-making. 
As indicated in the Public Participation and Scope sections of the Policy, the Department is not relinquishing its responsibility for decision making, but rather is requesting stakeholder input to help it make better, more informed decisions.

b. Public involvement must be carefully integrated to achieve program goals in a timely and cost effective manner.

The Department agrees and will make every effort to integrate public participation programs and activities into other management activities to achieve a timely and cost-effective approach to public involvement. These concerns are reflected in both the Policy (Core Values section) and the Secretary's Memorandum.

\section{Nevada Nuclear Waste Study Committee}

a. Not much time was given to review the policy. Please see response \#2.a.

b. Goal I: What degree of authority is needed and how much will be delegated by this paragraph?

All employees throughout the Department system (Goal III) are held generally accountable for supporting and promoting public participation, but managers will be held specifically accountable (Accountability section). Further, under this Policy, sites are the primary developers/implementors of public participation plans and will be responsible with their stakeholders to do yearly assessments of the effectiveness of their efforts.

c. Goal II: Suggested Change - "...for public involvement shall be established for each project and followed by all employees assigned to the project. The public shall be informed of these processes and encouraged and assisted to participate in the decision making process."

The spirit of this suggestion has been incorporated throughout the document. Please see the Scope section and Goal III.

d. Goal III: Suggested Change - "Current, timely information regarding a project's status (technical, community, administrative, and otherwise), shall be presented to the public, and readily available in response to public inquiries.

Misiniormation appearing in the news media shall be corrected prompt 7y."

The Department agrees with the thrust of these suggestions that information should, to the maximum extent possible, be accurate, current, and readily available; misinformation from any source must be corrected as quickly and broadly as possible. The whole thrust of this Policy is to ensure a continuous flow of two-way information and response.

e. Public communication through the news media and prompt correction of misinformation are the keys to current DOE problems of public perception.

Please see response \#22.d.

f. Responsibilities: The requirement for coordination with Public and Consumer Affairs at headquarters and in the field could introduce delays that would inhibit prompt and effective communication with the public at local levels.

The Department agrees. Please see response \#9.b. 
g. Draft Memo: Public communication should be more specifically emphasized.

The Department believes that the spirit of these comments are reflected in the Guidance document.

23. Sigma $X i$, The Scientific Research Society John F. Ahearne

a. Goal I: Do you intend for every employee to be responsible for public involvement, and still coordinate such activities through PC\&A?

While every employee is generally responsible for public involvement, managers will be held specifically accountable. The role of the director of the Office of Public and Consumer Affairs is one of support and facilitation, not program direction or oversight. Please see responses \#9.b. and 22.b.

b. Confusion can result in the public's mind if it is not clear right from the beginning what decision making participation the public is going to have. Therefore, Goal III needs some clarification. Site-specific public participation plans will provide this clarification, as it may vary according to a site's mission and a community's interests/concerns. Please see response \#14.h.

c. "Risk-taking will be rewarded" is not clear.

In this context, "risk-taking" means "innovation". That is, those who use innovative methods for engaging in public communication and participation will be rewarded. Nevertheless, in response to this and similar comments which suggested that the term "risktaking" was problematic, the term has been replaced throughout the document with the more accurate term "innovation."

24. Office of Management and Budget

a. No comments, the document is fine.

T.J. Glauthier

25. Portland General Electric Company

Ken Harrison

a. The goal of this process is not to force consensus, but to understand the options.

The Department agrees. The concept of understanding threads through the entire Policy and especially in the Public Participation and Purpose sections.

b. Developing and agreeing upon participant ground rules in beginning of these processes, and referring back to this agreement when issues arise, helps align expectations.

The Department agrees and encourages sites to consider the use of various agreements and mechanisms to define expectations as they develop their individual site public participation plans.

26. Western Interstate Energy Douglas Larson

a. The coordination of public involvement activities through the office of Public and Consumer Affairs causes some concern, for it add 3 an unriecessary layer in the chain of communication between headquarters and local decision makers.

The Department agrees. Please see responses \#9.b.

b. The policy should build on and expand the direct contact between state personnel and OCRWM. 
This comment has been forwarded to OCRWM for consideration/action.

27. American Society of Civil Engineers

a. No comments.

Edward 0. Pfrang

28. U.S. Nuclear Regulatory Commission

Robert M. Bernero

a. The policy is consistent with the existing NRC/DOE procedural agreement and its focus on information flow between the NRC and $D O E$, timely NRC involvement in DOE's regulatory activities, early identification of potential licensing issues, and participation in NRC'DOE pre-licensing consultations by sites, Indian Tribes, affected units of local government and the public. . Stakeholder involvement is an essential element of the ongoing NRC/DCE technical interchange process.

The Department agrees.

b. We encourage immediate real-time information availability through telephone and computer access points.

This is directed in Critical Policy Element $V$.

29. ADR

A. David Rossin

a. Purpose: Should be amended to "trust between the Department and the public it serves in order that it may more effectively carry out its responsibilities to the nation and its people. The spirit and intent of these words permeate the Policy.

b. Background: Exceptions to this poor history of public involvement are the Civilian Radioactive Waste Management Program and the LowLevel Waste Management Program.

The section of the policy has been deleted from the final drait document.

c. Definition: There is no mention of the responsible parties the state must deal with - states, municipalities, corporations, contractors, etc.

References to specific stakeholders, including responsible parties, will be incorporated in the site-specific and program public participation plans.

d. Memo: Under Critical Policy Element $V$, the following addition should be made to explicitly point to the risks of failure of the department to meet its obligations, (and in a timely manner): "consensus, including the risks to the nation and its people of failure of the Department to carry out its obligations and meet its objectives.

The concept of consencus-building has been removed from the document. Please see response \#25.a.

e. Participation and involvement are confusingly intertwined in both the draft policy statement and the memo.

The word "participation" is used almost exclusively in both documents in the final draft.

f. It is the Department, not the stakeholders, that must make decisions and set policy. The policy shows a serious lack of recognition of responsibility on the part of $D O E$.

The Department disagrees. This document is intended to ensure public participation in the Department's decisions. Still, it has 
ultimate decision making authority, and nowhere is this document does it relinquish that responsibility. See particularly the Public Participation and Scope sections of the Policy.

\section{Eureka County, NV}

Abigail C. Johnson

a. There was an inadequate amount of time to respond.

Please see response \#2.a.

b. The draft does not address the issue of providing adequate scheduling and time for public involvement.

The issue of timeliness is referenced throughout the Policy document. See especially the Core Values section and Goal III.

c. Does the policy apply to public review processes like Environmental Impact Statements and Environmental Assessments? If so, this should be explicitly stated.

This policy applies to legally-required hearings, as noted in the Definition section.

d. The policy does not provide guidance or direction on doing more than listening and responding. Also, the policy should provide some direction on how DOE managers can incorporate input from the public.

The revised draft focuses more attention on incorporating public input; for example, see Critical Policy Element I and its Implementing Actions. Also note the addition of a specific Accountability section in the Policy.

e. We are unsure of the meaning of "risk-taking". Please see response \#23.c.

f. Headquarters will develop clearance procedures for public information materials. What kind of clearance?

This reference has been deleted from the revised document. Public and/or Community Affairs offices, at headquarters or in the field, will provide coordination as described in the Guidance document. Also, please see response \#23.a.

g. In the past it has been difficult for all levels of DOE to work as a team. Is this a new directive? What special steps will be taken so that this effort is successful?

Teaming is part of the Department's overall commitment to quality management principles and strong customer service. All Department personnel are being trained in quality principles which will be applied in public participation activities.

\section{League of Women Voters of Nevada Nancy Mall}

a. There was not enough time to respond with the original deadline given. We appreciate the extension.

Thank you for noting the extension. It reflects the Department's commitment to be flexible in responding to stakeholder input and to learn from and correct inadvertant mistakes.

b. The policy needs to mention the need for allowing the public enough time to comment or participate.

These additions have been made to the policy. The strongest language to this effect may be found in Goal II and the core Values section. 
c. The policy does not address what DOE should do with the public's input other than respond. The policy should detail how Americans will iniluence decisions --listening isn't enough. Please see response \#30.d.

d. The policy should define what is meant by "risk-taking". Please see response \#23.c.

32. BNFL

John Graham

a. The policy lacks specificity in many areas -- it appears to depend on the "public" and stakeholders coming forward; it lacks any effort on behalf of DOE to approach stakeholders on anything other than a formal basis.

It is true that this Policy lacks specificity in a number of areas. As mentioned earlier, the Policy and Guidance Memorandum are designed to serve as a framework within which program- and site-specific public participation plans can be developed.

Details not discussed in these documents will be included in the site-specific and program plans. With respect to your second comment, the Department disagrees. The very first sentence in the Policy, as well as the Definition section, define public participation as "open, ongoing two-way communication, both formal and informal, . . . " including "informal conversations." Indeed, the Department hopes to build open, respectful relationships with its stakeholders that will virtually ensure steady, informal interactions on the widest range of interests and thoughts.

b. Implementing actions appear to gather only stakeholder concurrence for programs al ready engaged.

The Department disagrees. This Policy has been designed to solicit public input as a means of helping the Department make better, more informed decisions. Consequently, the Department hopes to involve the public as early in the decision making process as possible, and well before final decisions are made. Also, it is important to note that concurrence is neither a Department goal nor expectation.

c. American Indian Tribes are mentioned in passing in a couple of places as being an inclusive group within the "public." They are not.

The Department's American Indian Policy recognizes and commits to a government-to-government relationship with all Native American Tribal governments and ensures that their sovereign rights are fully respected. That Policy mandates that all Departmental activities affecting Native American Tribal rights or trust resources be implemented in a knowledgeable and sensitive manner, respectful of Tribal sovereignty. As noted in other responses, this Public Participation Policy is to be implemented in concert with other Departmental initiatives, including its American Indian Policy.

d. How will DOE's new policy affect program "conferences," in light of scientific credibility and peer review?

It is not expected that this Policy will have any effect on conferences. 
e. Implementation plans do not deal with information channels, publications, public reading rooms, speaking programs, school programs, etc..

This is true. Any reference to these programs would be found in program and site-specific public participation plans.

33. Agency for Nuclear Projects

Nuclear Waste Project Office Bob Loux

a. Responsibilities section: Needs to discuss how a decision making process is defined and access points are established.

Please see response \#14.h.

b. Definition section: While two-way communication is an important and essential element in actualizing real public involvement, there is much more to the concept than is stated or implied by the draft policy.

Two-way communication is discussed in greater detail in the revised policy. Please see the Secretary's Guidance Memorandum, Critical Policy Element I, "Implementing Actions," and the Policy under the Core Values and Definition sections, for specific discussions of this concept.

c. The current draft policy does not appear to do anything to assure that the public will, in fact, be able to influence DOE decisions. This Policy anticipates that the public will, in fact, influence the Department's decision making, but we cannot forecast precisely the nature and extent of that influence on every future decision. The revised document, however, discusses this issue extensively. Please see the Definition section, Goal I, and Critical Policy Element I.

d. Meaningful public involvement processes must have an element of empowerment built in.

The Department agrees. Please see Goal II.

e. The draft policy would be strengthened if it contained specific directives designed to break down the wall between public input and DOE decision making. For example, an administrative appeals process available to the public for recourse when decisions are seen as contrary to the public's interest or when they are not consistent with the public's input.

Please see response \#14.g.

f. The policy needs real teeth, in the form of sanctions and systematic follow up. There is nothing to keep DOE from turning the initiative into a public relations tool.

This document is meant to serve as the broad framework for guiding development of specific, detailed public participation plans and efforts. In the Accountability section, there is specific reference to public participation being a performance element for senior departmental, program, and field mangers responsible for implementing public participation.

g. Unless the term "participate" is defined in such a way as to afford real ability to influence decisions, this statement carries little real meaning.

Please see response \#33.c. 
h. The policy presumes a hierarchical structure of organization, where policy directives will flow readily from one level to the next.

This section (Responsibilities section in the $12 / 1 / 93$ version) has been changed to minimize any delays that may result from a hierarchical flow of policy directives. The coordination point for activities for each program and site will be the office of Public Affairs at that site, while the Director of Public and Consumer Affairs will serve as the primary office for Headquarters and Department-wide coordination.

i. The Principal Secretarial Officer and Senior Department Managers will also need training themselves on the fundamentals of public involvement.

This is true and, in fact, has already begun in many Headquarters program areas. The effort will be extended across the complex.

j. Responsibilities section: Having DOE public relations staff coordinating public involvement activities raises the specter of the initiative devolving into a slick public relations campaign aimed at selling DOE programs to uninformed customers.

The Department's public affairs staff will be coordinating public involvement activities. In addition, however, many informed customers are and will be involved in these processes; they will certainly not allow this type of devolution to occur. The annual stakeholder-assisted policy and program assessments will also help ensure that public participation efforts remain a substantive and meaningful part of the Department's decision making processes.

34. UNLV-Harry Reid Center for Environmental Studies

Bill Andrews

a. The policy should be used to develop a "Total Credibility Management" policy that would go far beyond passive stakeholder participation afforded by "listening" and "access points" outlined in the current draft policy, to a fundamental restructuring of how department activities that lead up to a decision making process are conducted.

This is not dissimilar from the efforts proposed within the revised Policy. Public participation is expected to be an interactive process in which the public will be able to play a substantive role in Department decision making.

b. Peer review should be required, not encouraged, to add confidence to the Core Value of scientific credibility.

This suggestion has been incorporated in the Core Values section.

35. American Nuclear Society

Edward D. Fuller

a. Statement of purpose: Amend it to read "trust between the department and the public it serves in order that it may more effectively carry out its responsibilities to the nation and its people. Please see response \#29.a.

b. Background: It would add perspective to mention that notable exceptions to the poor history of public involvement include the office of Civilian Radioactive Waste Management and the Low-Level Waste Management program. 

c. Definitions: It would be helpful to include the responsible parties with which DOE must also deal...states, municipalities, corporations, contractors, etc.
Please see response \#29.c.
d. Memorandum: Paragraph 5 should be amended to read: "consensus, including risks to the nation and its people if the Department fails to carry out its obligations in a timely fashion. Please see response \#29. d.
e. Information and participation are interdependent, but conceptually and practically distinct. The memo and the policy could be improved by recognizing this distinction.
Please see response \#29.e.
f. The policy leaves the issue of $D O E^{\prime} s$ responsibility to make decisions and provide accountability somewhat vague. (It is important that DOE clarify that DOE and not the stakeholders will ultimately make decisions and set policy).
Please see response \#29.f.

36. Esmeralda, Lincoln, and White Pine Counties, NV Florindo Mariani

a. There was not enough time to respond.

Please see response \#2.a.

b. Policy: The concept that DOE public involvement needs to be "routine" suggests that is may be unimaginative, unable to accommodate evolving stakeholder needs, and ultimately and potentially ineffective. An effective public involvement process will permit public participation when and to the degree various publics determine appropriate to their needs.

The Department agrees that effective public participation will be defined by program and stakeholder needs and wants. Use of the word "routine" was intended to convey a sense of regularity. Rather, it conveys the images described in your comment. As a result, it has been removed from the document.

c. Purpose: You might note that the policy is intended to ensure that effective public involvement occurs and that DOE decisions are not made without the benefit of important public perspectives. This is an excellent suggestion and has been incorporated into the Purpose section.

d. Purpose: As this paragraph now stands, the purpose of public involvement is articulated, yet the purpose of the policy on public involvement is not described. You need to indicate the policy's purpose.

This is true. The Purpose section has been revised and a Public Participation section added to reflect these comments.

e. Background: Perhaps what is missing is the important recognition that historically, DOE staff have assumed an "Us and them" approach to dealing with the public.

Though the Background section has been removed from the revised draft, the intent of the Public Participation Policy is to foster a more interactive approach to decision making by involving the public in meaningful ways. 
f. Definition: The concept of demand-driven public involvement rather than an institution of routine may be more appropriate. An effective public involvement initiative should be the means through which $D O E$ decisions are reached, rather than providing a means through which Americans can influence DOE decisions. This definition might also focus less on inducing greater public involvement and more on improving ways DOE can enhance and better use the input the public is willing to offer.

As discussed in earlier responses, the concept of "routine" decision making has been removed from the policy and guidance documents for the reasons mentioned in response \#36.b. The Department hopes that the Policy will accomplish both of these; that public involvement will serve as the means by which Department decisions are reached and the means by which the public can influence Department decisions.

g. Goal I: Needs to be restated to incorporate staff as having an equal responsibility to effect public involvement.

This important point has been written into Goal III in the revised policy.

h. Goals II: Internal decision-making should be reserved for those actions for which the Department has little or no discretion. In areas where there is latitude, an open decision making policy should be devised.

The Department envisions many of its decisions will be made in this manner.

i. Goals III: Might be restated as, "The public is informed in a timely manner about and empowered to participate in all departmental decision-making activities of a discretionary nature."

This Policy is meant to serve as a broad framework for public participation; more specific discussions about the types of issues in which the public will have opportunities to provide input will be included in the program and site-specific public participation plans.

j. Core Values: Others might include transparency, early involvement, health risk minimization, procedural equity, and distributional equity.

Early involvement is discussed throughout the document. Health risk minimization is a priority of the Department; it is being addressed across multiple program offices, as are complex equity issues.

k. Responsibilities: If public involvement is a discrete performance element, how will performance be measured? Who will decide whether goals have been met? Shouldn't the public play a part in evaluating the performance of senior department and program managers with respect to public involvement goals?

As discussed in the guidance memorandum, annual assessments will be made of the Department's public participation efforts. Stakeholders will be encouraged to participate in this review process by providing their views and recommendations on both the policy and implementation efforts. Stakeholders will also be invited to assist the Department is developing the criteria used 
to evaluate effectiveness.

1. The difference between program and staff offices is not clear The Department recognizes the confusion this has created and has revised the Policy to eliminate references to specific program and staff titles. But this in no way diminishes the responsibility of incumbents in these positions for effective public participation.

$m$. What does the term "coordinate" imply?

The Director of Public and Consumer Affairs will serve as the point of contact for public participation activities that occur at the Headquarters level. S/he will ensure that individual programs and sites are aware of each other's activities and share information, resources, and lessons learned as much as feasible.

n. Will approval through the Office of Public and Consumer Affairs be required by field offices to respond to local stakeholder needs? Will this lead to bureaucratic paralysis?

No. Senior, program, and field managers will have the authority to make decisions in response to local stakeholder needs and requests. Moreover, these individual managers will pass that information back through the Director of Public and Consumer Affairs so that the Department can improve its overall understanding, sensitivity, and responsiveness to stakeholders.

0 . The function of the Office of Public and Consumer Affairs is unclear and not justified with regard to effective public involvement. Perhaps this office can act as an Ombudsman to whom the public can go if they feel involvement is inadequate and managers are unresponsive.

The Department envisions that the Office of Public and Consumer Affairs will serve as a conduit for information and support to ensure that public participation efforts are adequate and responsive across the entire Department. In this sense, the office of Public and Consumer Affairs will indeed serve as a kind of unofficial "ombudsman." The Department also has an official ombudsman.

p. Comments on the memorandum - - 1st paragraph, 1st sentence: DOE is encouraged to reconsider the routine nature of its public involvement policy. The term integral might be more appropriate. The Department agrees. The word "routine" has been replaced throughout the Policy and guidance memorandum and replaced with words like "integral."

q. 1st paragraph, 3rd sentence: Does "open to the full view and input" mean if the public becomes aware of a DOE meeting that the public will be entitled to participate therein?

Though this section has been rewritten, it is the intent of the Policy that the public be broadly involved in the Department's decision making from the earliest stages. Program and sitespecific public participation plans will detail this involvement.

$r$. The terms "open", "full view", and "input" need to be defined so that the Secretary's intent is explicit.

The Policy has been rewritten such that the phrase "open to the full view and input" is no longer a part of the revised Policy. However, the scope and timing of public input will be detailed in each site or program's individual public participation plan. 
s. Critical Policy Element \#1, Implementing Actions: Affected and other interested parties should be vested with the responsibility to regularly review and report to the Secretary Departmental performance in meeting agency involvement goals.

Please see the introductory section of the Secretary's Memorandum for discussion of stakeholder participation in each site/program's annual assessment of its public participation efforts.

t. Critical Policy Element \#:- It is important that DOE not confuse public involvement and public information/education initiatives. The Department recognizes the difference and will work to the best of its ability to avoid confusing them.

37. Science Applications International Corporation

Dan Burns

Yucca Mountain Site Characterization Project

a. Definition: Public involvement should also include substantive two-way communication with employees (internal audience).

The Department agrees. This is referenced in the Definition section.

b. Examination of the interchangeable use of "public" and "stakeholder" might be helpful, as would defining each term. Please see the Definition section of the Policy for a definition of "stakeholder." The word "public" is used in its standard English context.

c. Clarify as a goal of the Department to communicate the decision making access points and accessibility of the Department's decision making processes to the public.

The Department has incorporated this suggestion in Goal II.

d. Core Values: Accessibility should be added to the list of 11 core values.

The Department agrees and has added this core value to the 1 is

e. Effective public communication training for Department personnel and contractors is crucial. Training responsibility is listed for Program Managers but is later listed as an implementing action for the Director of Public and Consumer Affairs. The position closest to the public and with the most interactions with the public should be responsible for this.

The Department agrees that communication training is an important and essential tool for communicating effectively with the public. The draft policy has been rewritten so that senior management is responsible for training at the local level.

f. An innovative method of accurately assessing local needs is needed. An effective assessment of public needs may include various types of public opinion research.

Such an option would be appropriate for consideration by each site or program.

g. Further implementing actions should be examined that would transmit accurate and timely information to large segments of the public.

Such examination is appropriate at each individual site. In addition, the Department is addressing the issue of information dissemination extensively in its development and implementation of its Communication and Trust Strategic Plan. All of the 
Department's efforts are intended to be mutually supportive and integrated; no one effort is exclusive of the Department's overall commitment to openness, efficiency, and customer service.

38. Science Applications International Corporation

Paul Seidler

Yucca Mountain Site Characterization Project

a. The policy document lacks a numbering system.

This deficiency has been corrected.

b. A consistent approach to public involvement is neither feasible nor desirable. The approach at each site will be determined by the political environment of that locality and the issues being discussed.

The Department agrees and has made this a central tenet of the Policy and guidance documents. Each site will develop its own public participation plans tailored to meet its specific needs; but all sites will reflect a consistency in philosophy, core values, and goals as enunciated in these framework documents.

c. A more appropriate objective is a consistent understanding of the Department's public involvement philosophy and a commitment to implement it.

The Department agrees, as stated above.

39. Department of Energy

Environmental Management Advisory Committee James T. Melillo

a. (Comment made by Tad McCall, BDM Federal) What is the purpose of the Core Values section? It just seems to sit there.

This section has been expanded to include a brief description of each core value, describing characteristics to be found in each program, regardless of how it is specifically developed.

b. (Comments made by Al Alm, Science Applications International Corporation; Jerry Christean, Mid-Atlantic Public Service; Ron Ross, Western Governors' Association) This is a good plan. The Department agrees.

40. Vicki Dastillung

Vicki Dastillung

a. It would be useful if DOE would clarify who is responsible for public involvement activities at each site or set up one person who could then refer the public to the proper person and procedure (if there is one) in order to have their needs addressed. The Department agrees and expects each site to designate a public participation contact point. As described in the Accountability section, senior management will ensure that appropriate staff is available to serve in this capacity.

b. How will this policy impact the contractors who run many of the sites? Will they be required to adopt this? Contractors are considered part of the Department of Energy and will be expected to implement this Policy.

c. Who will the public contact if it has any complaints about DOE's implementation of the public participation policy? Will DOE provide clear information about the name (and phone number) of this person so they will know the proper place to get such concerns resolved? 
The site public participation contact and/or site manager would be the first level of recourse; if resolution were not possible, the issue would then be referred to the responsible Headquarters Program and up through that chain of command.

d. How will DOE evaluate how well this policy is actually being implemented? Self-evaluation is essential, but should not be the only method of evaluation; the public should be included, as well. The Department agrees. Please see the introductory section of the Secretary's guidance memorandum for a more detailed discussion of this matter.

41. Shira A. Flax

Shira A. Flax

a. Why does the chain of responsibility stop with the Field/Public Affairs/External Relations Directors?

On the contrary, responsibility for public participation extends to every employee within the DOE Complex. Please see Goal III.

b. Does DOE have staff available that can identify the training and support their colleagues need?

Yes. A number of such training programs are ongoing, through Headquarters and at sites and field offices. The Department has compiled an Inventory of Communications/Public Participation Training currently available. This document is available through the Office of Public and Consumer Affairs.

c. How are the Critical Policy Elements integrated in performance evaluations?

Where appropriate, public participation elements will be included in managers' performance standards, and they will be evaluated on the basis of program effectiveness and results.

42. Confederated Tribes and Bands

of the Yakima Indian Nation

Russell Jim

a. I hope there will be training for managers on the implications of Treaty rights of Indigenous people.

Training will largely be site and/or program specific, and will be identified in site/program implementation plans. The Policy envisions that all appropriate training will be provided.

b. The Yakima Natior. considers its status as a sovereign, and does not wish to be lumped in with general public notices. Please see response \#32.c.

43. Ohio EPA

Thomas A. Winston, P.E.

a. Developing a successful public involvement program at each site requires a long-term commitment from top management.

The Department agrees. Indeed, the Policy's strongest supporter is the Secretary of Energy.

b. Responsibilities: Training employees is not enough. DOE needs to evaluate effectiveness, devise improvements, create incentives, and discourage sanctions for inept, 111 -advised, but well intentioned communication.

The spirit of this suggestion has been incorporated into the Policy. Moreover, the Department views all of its new initiatives to improve openness, efficiency, and customer service as linked. 
The commitment to quality management principles now infusing the Department will help ensure ongoing process monitoring and evaluation with a view toward cont inuous improvement. A key reason for the Director of Public and Consumer Affairs' coordination role under this Policy is to assure that experience, "lessons learned," and successes in public participation are broadly shared across the Department, so that all elements are performing to a high level of quality and meeting customer/ stakeholder expectations.

44. Department of Energy

Idaho Communications Division Connie Nash

a. (Comment made by Brett Haybal1, Shoshone-Bannock Tribal/DOE Coordinator and Project Director): I strongly agree that the process must be tailored to specific stakeholder needs and that the policy only be used as a guide based upon the diversity of stakeholders.

The Department agrees. A decentralized approach to public participation is a fundamental tenet of this Policy.

b. (Comment made by Linda Milam, Mayor of Idaho Falls): Too nonspecific in the area of ident ifying stakeholders.

The term "stakeholder" has been defined in the Definition section.

c. (Milam): I hope that DOE's commitment to two-way communication with "other governmental agencies" includes local (city and county) as well as state and tribal officials.

Two-way communication will occur with all interested individuals, groups, and government entities.

d. (Comment made by Terry Smith, Public Information Officer, State INEL Oversight Program): Holding officials accountable and rewarding risk-taking is a step in the right direction.

The Department agrees, though it has changed the term "risktaking" to "innovation" (please see response \#23.c.).

e. (Comment made by Cand is Webb, Department of Energy, Idaho): The Secretary may want to consider issuing a short, separate letter to all DOE employees to emphasize this culture shift and positive aspects of goals.

The Secretary will be issuing a Guidance Memorandum to all employees along with this Policy. And as noted in other responses, this Public Participation Policy is one of many Secretarial initiatives designed to instill a new culture of openness, efficiency, and customer service across the entire Department. Many efforts are underway to assure that employees embrace this new way of doing the Department's business.

f. (Comment made by Ellie Hamilton, Private Citizen): Core Values: Include "accuracy".

This suggestion has been incorporated into the Core Values section.

g. (Webb): The policy should be issued through the DOE Order system, rather than just issued as a policy letter.

The Policy is being issued under the Department's revised Directives System. 
h. (Smith): Let the citizens advise the site manager on which access points are most appropriate.

As discussed in Critical Policy Element II, stakeholders and field managers will determine and identify pre-decisional access points for public input.

i. (Smith): The establishment of a data base of real-time information is wonderful in theory, but is it workable or feasible cost-wise?

Easy access data bases as well as other means of providing efficient, accessible, real-time information are being examined under the Department's efforts to implement its Communication and Trust Strategic Plan. It is hoped that electronic communication will prove both workable and cost-effective in the near-term.

\section{Department of Energy}

Office of Nuclear Energy

Daniel Dreyfus

a. The policy conveys the impression that the public can have daily and unrestricted access to the policy making process and staff in all DOE program offices. This is not feasible.

Daily and unrestricted access to individuals is not the goal; "open, ongoing two-way communication, both formal and informal, between the Department and its stakeholders" is, with the objective of gaining "the most diverse collection of opinions, perspectives, and values from the broadest spectrum of the public, enabling the Department to make better, more informed decisions." Program officials and staff will be expected to be available as necessary to achieve this objective.

b. Certain information from private industry must remain classified, proprietary, or where privileged. language to that iflect should be included in policy.

The Department agrees and has added lariguage to this effect in the Scope section. Program and site spocific public participation plans will include any additiorial language necessary because of the mission/activities of that program and/or site.

c. The Background section is inappropriate because the policy could be around for years.

The Background section has been removed.

d. Goal I: The public cannot practically be involved in "daily program operations."

The point is well taken and the phrase has been removed.

e. Goal III: The public provides input which we use in making decisions. As written, this section implies that the public actually participates in the decisions themselves.

Participation in Department decision making does, indeed, imply that the public actually participates in this process. Though the Department will ultimately make the decisions, the process will include input from the public. The goal is "better, more informed" decisions.

f. Need to clarify or delete the Director of Public Affairs' engaging in clearance procedures. Certain matters should be cleared with Pubic Affairs, but it appears impractical to both increase the involvement of the public as described in the policy and clear 
everything with Public Affairs. This will tend to delay response to the public and convey the wrong impression regarding openness. The role of the director of Public and Consumer Affairs has been clarified in response to numerous comments; his/her function is one of coordination, not clearance.

g. Policy: "routine component of program activities." Please see response \#36.b.

h. "Risk-taking" is not clear. What kind of risk?. Please see response \#23.c.

i. Peer Review is already encouraged. Peer review is now one of the Core Values.

j. Implementing Action \#3 won't work if everything goes through the Director of Public and Consumer Affairs.

Everything will not need to go through the Director of Public and Consumer Affairs; senior, program and field managers will have the authority necessary to carry out effective public participation.

k. Implementing action \#5: Need to clarify what real-time information is.

"Real-time" information has been changed to "timely" information.

46. Illinois EPA

Stephen K. Davis

a. A guidance document or handbook must first be drafted to expand on the newly generated policy.

Program and site-specific public participation plans will serve to expand on and provide details of this new policy.

b. It would be useful for DOE to investigate the community involvement requirements or the specific program of law that it intends to comply with when conducting environmental remediation (RCRA or CERCLA).

This is assumed. The Department is committed to full compliance with all legal requirements under RCRA, CERCLA, and other environmental laws and regulations. This Public Participation Policy is intended to go beyond such legal mandates by supporting open, ongoing two-way communication and public input into the Department's decision making, whether or not required by 1 aw.

c. Definition: It calls for two-way communication between DOE and "those interested in and/or affected by the Department's decisions and activities." This definition should include two other groups: 1) those living or working in the immediate vicinity of a DOE facility who are potentially affected, and 2) those who are not affected but perceive they are affected.

The Department agrees and has produced a broader definition of "stakeholder" than previously used that would include these two groups. Please see the Definition section.

d. The term stakeholders should be changed to reflect something a bit more personal or relative to the public.

The term "stakeholder" has been defined in the Definition section.

e. Responsibilities: Public involvement will be a discrete performance element for senior and program managers. Does this statement mean that these managers will be responsible for public involvement activities, that this responsibility will be measured on their annual performance evaluation, both, or something else? 
This means that senior management will be responsible for public participation activities and will have at least part of their annual performance assessments based on this process.

$\dagger$ Who will be responsible for responding to news media inquiries? This is a decision best decided on an individual basis at each program or site.

g. Who should the IEPA and other government officials contact at DOE about news media inquiries? Issuance of news releases? Approval of quotes from upper management on joint news releases?

Appropriate contacts will be identified in each site and/or program-specific public participation plan. In the interim questions can be directed to the site program and/or public affairs managers.

h. Can IEPA and other government agencies have the opportunity to reiciew and comment on news releases affecting their particular state? Public involvement plans?

Since state government agencies are considered stakeholders, they can certainly review public participation plans. Media issues should be discussed with site public affairs directors.

i. Why are senior level departmental and program managers only responsible for the policy's effective implementation? Should this concept be carried out through the DOE ranks to be implemented?

Please see Goal III. The Policy applies to all DOE employees.

j. Goals: How is the public informed about and empowered to participate in Departmental decision making?

The public will be informed about opportunities to participate in Department decision making through a variety of channels, including the Federal Register, local newspaper and radio announcements, and public meetings. The types of input desired and substantive information on the issue(s) for decision will be provided at the time of the public announcements.

\section{Department of Energy}

\section{Oakland Operations Office}

John Belluardo

a. The policy should stress proactive public involvement activities by $D O E$ rather than reactive actions.

The revised Policy is much more proactive in its approach.

b. Public involvement should be balanced against delays in activities caused by the time needed for consultation. In some cases, it may be better for DOE to consider stakeholders opinions without going through a formal process.

Public participation activities should be designed in such a way that stakeholders are brought into the process as early as is feasible, adequate time is provided for them to participate, and the Department is able to make its decisions on schedule. Public participation, as defined in this Policy is "open, ongoing two-way communication, both formal and informal." This Policy anticipates that much of the day-to-day decision making activity at the site level will be informal.

c. Responsibilities: A commitment of resources should be made explicit. 
Please see the opening section of the Secretary's Guidance Memorandum. Managers are responsible for providing the necessary resources; specific resource requirements, which will vary from site to site and program to program, will be identified and provided through normal planning and budgeting processes.

d. Goal III: Items such as personnel records and classified data that will not be made public should be listed.

Please see response \#45.b.

e. Purpose: Replace "better" decisions with "more informed" or a similar phrase.

The term "more informed" has been added in the Public

Participation and Purpose sections of the Policy.

f. Critical Policy Elements (Implementing Actions): "The new benchmark for excellence will be leadership/performance:

Excellence of what?"

This Implementing Action and the two bullets under it have been deleted from the document.

g. Risk taking should be better defined.

Please see responses \#23.c. and \#47.f.

h. Peer review of what?

Please see response \#47.f.

i. There should be a more direct connections between the policy goals and implementing actions to achieve those goals.

These have been rewritten to correspond more closely.

j. The commitment to provide staff training and resources to achieve goals should be made explicit.

Please see response \#47.c.

k. Public participation is favored over public involvement as more descriptive and accurate.

This suggestion has been incorporated througtsont the document.

1. The issue of assuring a "balanced" or "representative" public is not addressed. The term "public" is used too often and too broadly.

As discussed in an earlier response, the Department believes each viewpoint is representative of a specific stakeholder or stakeholder group. While the Department will make every effort to solicit the broadest range of diverse viewpoints, it should not arbitrarily assert its judgment as to what constitutes "balance" over the collective input of stakeholders at a particular site or on a particular issue. With respect to the use of "public" in the document, since this is a Public Participation Policy, the Department believes that use of the term is not excessive.

m. Public participation seems to vary between the draft policy and guidance. The policy says the public is "empowered to participate in Departmental decision making." The second says the policy is for the public to be involved with the Department in "developing consensus."

The Department's objective is to encourage and empower the public to participate in its decision making; the term "consensus" has been deleted from the guidance document.

$\mathrm{n}$. The policy and guidance should be flexible to meet the different needs of different communities and not place unreasonable demands 
on site personnel or the public.

The Department agrees completely and believes the revised Policy and Guidance provide the needed degree of decentralization and

flexibility. Moreover, this issue could certainly be addressed further, on the basis of experience, in the annual site assessments which are to be done at the local level with stakeholder involvement.

o. The policy is too broad. It also should address who should determine which activities the public should be involved in. This comment would seem to contradict the previous comment regarding the need for flexibility and "not plac[ing] unreasonable demands." The Policy is deliberately broad in nature, providing an overall philosophy, core values and objectives which will guide development of specific implementation plans which will necessarily vary according to site and program needs.

p. The public involvement policy should be coordinated with customer advocate policies and activities to assure consistency.

As referenced in other responses, the Public Participation Policy is consistent and supportive of other Departmental initiatives. Moreover, the annual assessments required in the Policy will provide each site an opportunity for improving alignment as the Department moves forward in several related areas.

q. The policy should tell the Operations Offices "what" rather than "how" as it does on page 2.

Again, the Policy is meant to serve as a general framework, providing philosophy, core values, and goals; at the local level, managers and stakeholders closest to the issues and the community will formulate specifics in their site public participation plans.

$r$. Both the Department and the public need to have a clearly defined understanding of what role public participation will play in Department decision making.

The Department believes that the revised Policy does that. Further definition will come in the program and site-specific public participation plans.

48. Lawrence Livermore National Laboratories Harry L. Galles

a. I am concerned about the degree and extent to which this policy will be implemented. I question the usefulness of actively seeking stakeholder involvement in all aspects of the LLNL's business.

The Secretary intends for this policy to extend to all Department staff and contractors. The scope and nature of the public participation effort at LLNL will be defined in the implementation plan it develops with its stakeholders.

b. This will provide an open door to extremist or environmental groups to "shut down the laboratory."

The Department disagrees. This Policy is predicated on the belief that the broader and more complete the knowledge base, the more informed and hence, better, the decisions will be. Thus, the Department will seek, consider, and incorporate public views in its decision making the the fullest extent appropriate and feasible. But as stated in the Scope section, this Policy "is not 
intended to affect legal requirements" and that includes the Department's ultimate responsibility for decision making.

c. The policy will run counter to DOE's attempt to be more responsive to the competitive needs of U.S. industry.

The Department disagrees. Rather, greater stakeholder involvement is likely to increase our ability to understand and satisfy stakeholders' interests, including those of U.S. industry.

d. If the policy is implemented, all LLNL schedules will have to be revised and costs will rise accordingly.

This is unlikely. While there may be some initial increase in front-end costs, the Department's ability to better understand and respond more quickly to its stakeholders' interests is likely to lead to improved cooperation and stronger partnerships, to the mutual advantage of the Department and its stakeholders.

e. Does DOE really intend for all its programs to interact daily with the stakeholders, as suggested in Goal I?

Please see response \#45.d.

f. I prefer an approach in which DOE and $L L N L$ are fully responsive to and take full consideration of questions, comments, concerns, and opinions volunteered by stakeholders, without instituting a formal process to solicit that input.

A wide variety of means will be used to solicit public input; these will range from the most informal conversations to legally required hearings. "Two-way communication" certainly need not be a "formal process."

g. The issue of how this policy would apply to classified work is not addressed.

This issue is now addressed in the Scope section of the Policy and the opening paragraph of the Secretary's Memorandum.

49. Stanford University Linear Acceleracor Center

Kirk Stoddard

a. There should be a more direct connections between the policy goals and implementing actions to achieve those goals.

Please see response \#47.i.

b. Responsibilities: Commitment of training and resources should be addressed more explicitly.

Please response \#47.c.

c. Risk taking should be clearly defined.

Please see response \#23.c.

d. Purpose: The term "better decisions" is unnecessarily vague.

"Better" should be replaced with "more informed", "more conscientious", or "more thoughtful", or the like.

The phrase "more informed" has been incorporated into the policy.

e. What type of document review process will be involved in coordination of activities at the various levels?

The review process may depend on the nature and contents of a given document; that is, a NEPA document. Coordination activities assigned to the Office of Public and Consumer Affairs under this Policy will be in the nature of facilitation rather than "review" activities.

f. Throughout the document "assure" and "assuring" should be replaced by "ensure" and "ensuring." 
This change has been made.

g. Critical Policy Element V: Replace "real time" with "timely" or define the intended application in more detail.

This change has been made.

h. Critical Policy Element IV: Address the commitment of resources, either combined with training or as a separate item. See response \#47.c.

i. Critical Policy Element II: "Well-known" seems vague here...replace with "well defined" or "well-established". This has been changed to "clearly defined".

50. Sandia National Laboratories Steve Baca

a. Each program manager should commit that program's public involvement dollars in the field and at the laboratories in a way that is both effective and accountable. Public Affairs and External Affairs Offices should, per the implementation funding, receive funding directly from the program managers and should be accountable to the program managers.

Certainly, the Department expects that all expenditures will be effective and prudent. And since public participation is the responsibility of every employee (Goal III) and the special responsibility of cognizant managers (Accountability section), it is expected that all elements in the Department will factor public participation activities into their planning and budgeting processes. It is further expected that in line with quality management principles, related elements in the Department will work as an integrated, effective team in promoting two-way communication and stakeholder input in DOE decision making processes.

b. "Public involvement must be a routine component" in everything we do. If that is the intent, it should be stated in a section on Scope in the policy.

Please see response \#36.b.

c. There is no mention of balance in public involvement. Public involvement must be balanced and include the full range of community views and opinions.

Please see the Public Participation and Definition sections of the Policy, as well as Critical Policy Element $V$ and the first Implementing action under it. The clear intent of this Policy is that the Department gather the broadest, most diverse range of stakeholder viewpoints, values, and perspectives.

d. Core Values: Consider the addition of "Commitment to progress in solving each problem through consensus."

The Department's goal is understanding, not consensus-building.

e. What will be the process for continuously improving the policy and implementation guidance as well as measuring their effectiveness? The annual assessments outlined in the Secretary's Memorandum should provide the opportunity for evaluation and improvement in each site's efforts, as well as a forum for highlighting successes and progress which can then be shared across the DOE Complex. 
51. Department of Energy

Chicago Operations office

Gary L. Pitchford

a. "Risk taking will be rewarded" needs clarification.

Please see response \#23.c.

b. The policy needs to provide more guidance on how it will be implemented and coordinated with other departmental initiatives. The Department believes that this guidance has been provided in the revised policy.

c. The document should be codified as a DOE directive. Please see response \#44.g.

d. References to DOE (Operations Site, Area, Project, Etc) and contractor-operated organizations (Laboratories, production plants, etc) needs to be clarified and made more consistent. An effort to maintain consistency has been incorporated into the Policy.

e. Critical Policy Element IV: Development of performance measures will be critical to the success of this assessment procedure. The Department agrees on the importance of criteria and measures for judging effectiveness. This concept is discussed in the Secretary's Memorandum.

f. Critical Policy Element V: Last paragraph, add the word "prompt" before the phrase "clearance procedures for public information materials." Timeliness in such reviews is critical.

The issue of clearance procedures is no longer part of critical Element $V$.

\section{Department of Energy}

Human Resources and Administration

Archer Durham

a. The broad manner in which the policy is written makes it very adaptable to local situations, but also leaves it open to inconsistent interpretations.

The Department believes that this potential problem has been minimized in the revised draft policy.

b. A general statement of what is excluded from coverage would be helpful.

This has been added in the Scope section of the Policy and the opening paragraph of the Secretary's Memorandum.

c. We do not interpret the program managers' responsibilities to include coordinating procurement rulemakings with your office, as we are interested in streamlining the rulemaking process. You are correct.

d. "...public involvement will be a discrete performance element for senior departmental and program managers directly responsible for its effective implementation." This definition is not clear as to what levels are considered "senior" or what constitutes direct responsibility.

This section has been deleted in the revised policy. Please see the Accountability section for a more detailed discussion of this issue.

e. Our concern is that organizations will request additional resources (FTEs and funding) to meet this requirement. A statement needs to be included either within the actual policy or the 
Secretary's cover letter memorandum which states that the incorporation of this responsibility will be accomplished with existing resources.

Like quality management principles, public participation is a way of doing business that must be incorporated into all of the Department's activities and programs. It is not something separate or apart that would necessarily require additional resources.

53. Oak Ridge Institute for Science and Education James E. Drewry a. Public involvement activities may impact upon legal requirements set forth in the Administrative Procedures Act in Title 5 of the U.S. Code.

Please see the Scope section of the Policy and the opening paragraph of the Secretary's Memorandum. This Policy does not affect existing legal or regulatory requirements on the Department.

54. Author Unknown

a. Comments illegible

Author Unknown

55. Energy Research Foundation

Tim Conner

a. There is little mention of any system by which DOE can determine whether the goals are being accomplished. DOE should add a pledge to measuring its accessibility and responsiveness to meaningful public involvement.

The Department agrees that accessibility and responsiveness are essential. Please see the Core Values and Accountability sections of the Policy as well as the Secretary's Memorandum which discusses the need for annual assessments of the effectiveness of each site or program's public participation plan. Stakeholders are to be involved in formulating criteria and carrying out these assessments.

b. The Director of Public and Consumer Affairs is responsible for annually assessing the effectiveness of DOE's communications efforts. Perhaps this person should also be the appropriate one to evaluate the effectiveness of the overall public involvement policy.

Please see response \#55.a. The Director of Public and Consumer Affairs will evaluate these annual assessments of the site and program participation plans. The Director will also recommend changes to improve the effectiveness of these plans.

c. What should citizens do when they have grievances about the effectiveness or responsiveness of DOE's public involvement policy?

Please see response \#14.g. Good faith efforts should be made to resolve all grievances at the local level, but as necessary may be referred through the chain of command at Headquarters.

d. DOE is in the process of establishing nearly a dozen site-specific advisory boards. These boards may quickly become a central element in many of the DOE's public involvement activities. Perhaps the policy and implementation guidance should indicate how 
these boards will mesh with the other elements of DOE's public involvement program. Also the policy might indicate points of contact for these boards.

The role site-specific advisory boards will play in furthering public participation activities will be defined at the site level. Points of contact for these boards should be, and to the best of our knowledge are, available now at each site with a citizen advisory board.

e. The policy and guidance should contain more details on how officials who are progressive and successful in implementing meaningful public participation will be rewarded.

This issue is referenced in Critical Policy Element $I$ in the Secretary's Memorandum and in the Accountability section of the Policy, which seeks to make effective public participation a normal part of daily operations for the Department. Specific expectations, measures, and rewards for cognizant managers should be detailed in their performance plans.

56. Neighbors in Need

Rev. Dr. Velma M. Shearer

a. Are public involvement plans being designed solely for clean-up and health study activities at DOE weapons sites, or do plans include programs which concern future energy needs as well? Public participation is to be a part of all Department activities and operations, day-to-day; plans will be developed for specific program and site decisions, as necessary.

57. National Renewable Energy Laboratory

Duane N. Sunderman

a. Definition: There should be a major focus or emphasis on interactions with the public and less emphasis on interactions with other government agencies.

The revised draft policy focuses on Department interactions with the public, not government agencies.

b. Goal I states that "every employee shares the responsibility to practice public involvement." This should be addressed in the "guidance" section (it currently is not), and some broad guidelines on employee responsibilities should be provided. Such specifics will be found in the program and site-specific public participation plans. This reference can now be found under Goal III. It has remained in the policy due to the fundamental role it will play in the effective implementation of the policy.

c. Some consolidation of the Core Values list appears to be possible. Because of the overwhelming number of suggestions calling for the inclusion of additional Core values, this list has expanded. Because this is an important area of commitment for the Department, each Core Value is 1 isted sepamately.

d. The term "triggering legal requirements" is ambiguous and should be provided by the policy-setting body.

The issue of legal requirements is now addressed in new language in the Scope section of the Policy and the opening paragraph of the Secretary's Memorandum.

e. A statement should be provided noting the need for protecting business-sensitive information. 
This can be found in the Scope section.

f. A better description of "risk taking" is needed and its boundaries should be included.

Please see response \#23.c.

g. A definition of "program operations" and "planning activities" is needed.

These terms will be defined in the program and site-specific public participation plans, since the terms will vary throughout the DOE Complex.

h. Guidance outlining how public input will be used by the DOE is lacking and should be provided.

The Department is committed to incorporating public input into its decision making processes and to providing feedback to the public on its reasoning for not incorporating input. Language to this effect appears in both the Policy and the Guidance Memorandum.

i. We encourage simple, streamlined clearance procedures that do not overly inhibit the central goal of openness.

The Department agrees.

j. Critical Policy Element IV: The word "external" should not apply to training the public since DOE has a responsibility to help educate but not necessarily train the public.

The Department has a responsibility to make the public participation process efficient and effective. Accomplishing this may in some instances include some level of training to help stakeholders better participate in these processes. This is an issue that will be decided at the local site/program level with input and discussions between the Department and stakeholders.

58. Battelle Pacific Northwest Laboratories Joseph D. Spencer

a. A fourth goal should be considered which would read "The public is informed about how their input influenced Departmental decision making."

This issue is addressed in language in the revised Policy under the Definition section. The Department actively seeks, considers, and incorporates or otherwise responds in a timely manner to the views of its stakeholders.

b. Responsibilities: Departmental program managers' responsibilities also should include "participating" in appropriate levels of public involvement in their programs. These paragraphs should explicitly state this expectation in addition to the identifying, planning, budgeting, and implementing responsibilities already mentioned.

This issue is addressed under language directing program and site managers to be accessible. Under the Core Values section, accessibility is listed and defined as known avenues to Department leaders who are available, approachable, and open to the public. The intent of this language is to encourage and ensure managementlevel involvement in public participation activities.

c. Program managers need to receive "basic public involvement" training, in addition to basic communication training. Critical Policy Element IV and the Responsibilities sections discuss the need for both communication and public participation 
training. Moreover, an Inventory of Communications/Public Participation Training currently available across the Department has been compiled and distributed.

d. All managers need to understand when and how to factor public involvement into their program decision-making processes.

This information would be provided in public participation training sessions. Also, Critical Policy Element II states that stakeholders and field managers will determine and identify predecisional access points for public input.

e. Managers of Field Operations al so need to be reld responsible for "assuring that their staff receive necessary training and participate in appropriate levels of public involvement."

Senior managers throughout the Department are to be responsible for ensuring that staff receive training. References to specific management positions have been eliminated from the Policy because they were confusing to many.

f. Critical Policy Element III: Cooperation "and teamwork" should be rewarded.

This reference to "reward" has been removed from the Guidance Memorandum. While public participation is a performance element for senior managers (Accountability section), cooperation and teamwork in public participation processes are expected from all employees as part of acceptable performance across the DOE Complex (Goal III).

g. Critical Policy Element IV: The Department's communication "and public involvement" efforts should be assessed for effectiveness annually.

This suggestion has been incorporated into the Secretary's Memorandum.

59. Continuous Electron Beam Accelerator Facility James E. Coleman

a. If the public is to be included in planning, and if its participation is to be constructive, the public needs to have a good understanding of risk concepts.

As issues arise and public participation is planned, concepts like "risk" and "equity" will be examined as appropriate. The need for such discussions will be identified at the program and site level.

b. The policy should cultivate and encourage "win-win" decisions and allow responsible, informed stakeholders to be effective team players.

The Department agrees with this suggestion and hopes that this Policy will result in "win-win" solutions for all parties.

c. We request the summary information on the issue of advisory committee requirements referenced in your memorandum (1ast paragraph).

This information has been provided.

60. Amarillo Area Office

Tom Williams

a. I am forwarding to you additional comments provided to us by the Metal Trades Council of Amarillo. . . and we hope you give due consideration to their views.

The comments, which follow, have been given due consideration. 
61. The Metal Trades Council

Ronnie Payne

a. It is a concern to us when an overwhelming majority of the public expresses a viewpoint and a very small minority is allowed to hold up a process. DOE should examine this issue more closely. Please see response \#2.p.

b. Goal 111: Our concern is the word "empowered". How would the public be empowered and to what extent?

These issues are addressed in various parts of the Policy and Guidance Memorandum. Generally, the public will be given information early-on with respect to issues and questions needing resolution, and will be invited/encouraged to offer their various views and values as to the preferred manner of resolution. The Department will incorporate this public input into its decisions, or otherwise account for why input was not accepted.

c. Employees at DOE sites are being left out of the key stakeholder lists.

The Department agrees. Critical Policy Element II contains language directing senior management to ensure that Department personnel are integrated into planning activities and decision making processes.

62. Lawrence Berkeley Laboratory

a. We have no comments.

Michael Chartock

63. Oregon Department of Energy

Ken Niles

a. Reference should be made to the Administration's commitment to streamline and simplify the Freedom of Information Act (FOIA) process and to declassify historical documents.

As noted earlier, this Policy is one of many initiatives tıat, taken together, mark the Department's new way of doing business. Issues affecting openness, including FOIA reform, are being addressed el sewhere.

64. Department of Energy

Environmental Health

Lea Ekman

a. The final draft should contain a graphic depiction of the lines of internal DOE coordination. It would be a useful adjunct to understanding the various responsibilities and lines of authority for the DOE levels described.

The Policy has been restructured and lines of responsibility simplified. Public participation efforts will be driven at the local level, by site and program managers who are vested with the authority necessary to interact effectively with stakeholders on a consistent basis. Internal DOE coordination will be identified and directed from the program or site level.

65. Department of Energy

Environmental Restoration David Perotti

a. The policy should reflect the significant effort expended to date to achieve a publicly supported program. As currently written, it places an undue emphasis on "changing the old culture." 
Several references to the "old culture" have been deleted in favor of streamlining the Policy and focusing attention on the salient issues involved in public participation.

66. Department of Energy

Environmental Management

Bobbie Smith

a. The policy is simplistic and provides few details on how these objectives will be met.

This Policy is mearit to serve as a general framework; the siteand program-specific public participation plans to be developed will include an appropriate level of detail.

b. The terms "public involvement", "public participation", and "public outreach" seem to be used interchangeably within the DOE. These three terms have different connotations. There is a difference between involving and communicating. It may be more palatable to DOE's stakeholders to use the term "public participation" consistently in all DOE documentation. Participation implies a more active, two-way approach.

The Department agrees that public "participation" is more appropriate than "involvement" and has incorporated this change throughout the Policy and Guidance Memorandum.

c. Core Values: It may be more helpful to provide value statements rather than a list of words.

The Department agrees and has provided value statements in the Core Values section.

d. How is headquarters and the field supposed to apply these core values?

Public participation efforts, whether implemented at headquarters or in the field, will be characterized by the values identified in the Core Values section.

e. DOE should not continue to punish itself for the secrecy of the past (Background section).

This recommendation references the Background section which has been removed from the revised Policy.

67. State of Missouri

Department of Natural Resources Robert Geller

a. No comments.

68. Pantex

Guyon H. Saunders

a. The Department is already strangling on public involvement.

The Department disagrees and believes there is much to be gained by involving the public in its decision making processes.

b. There is no imperative that the "public" have a warm, friendly feeling about DOE.

This is not the purpose of public participation. Rather, the goal is "better, more informed decisions" due to a more comprehensive, inclusive decision process.

69. The Peace Farm

Mavis Belisle

a. Core Values: I think there should be some commitment to providing context for decisions. 
This can be found in the Core Values under "Accountability." In addition, this issue is addressed in the Definition section which states that the Department actively seeks, considers, and incorporates or otherwise responds in a timely manner to the views of its stakeholders. Further, this issue is addressed in Critical Policy Element I, bullet \#2. The Department will incorporate public input into its decisions where appropriate and feasible and will provide feedback to the public on its reasoning.

b. In addition to site-based public involvement, the policy should include the same broad-based review of DOE materials designed for use in schools and other educational programs or institutions.

This is an issue to be addressed by other areas of the Department.

c. Critical Policy Element II: Headquarters and field

offices will be responsible for seeing that plant managers are fully included in communications, and have at the earliest moment the information they need to respond to inquiries or iniliate public comment.

The Department agrees that the timely flow of information is essential to the success of public participation.

d. Copy costs are high and reading room hours are not always convenient. DOE should consider making technical and other documents available on a loan basis.

The Department is and will continue to examine more convenient, accessible, efficient ways to offer information to stakeholders.

e. All regulatory permits or permit amendments should be available in the public reading rooms at the same time they are submitted to the state and/or federal regulators.

Consistent with legal requirements, this seems appropriate.

70. W.H. O'Brien

H.H. O'Brien

a. High risk operations should be identified as such.

The Department agrees and will continue to pursue policies of openness and full compliance with all environment, safety, and health standards in its operations.

71. Ames Lab

a. This is a good thing.

\section{John Eckert}

Stephen Schwartz

72. Military Production Network

a. How will officials, especially regional officials and contractor employees, be held accountable for implementing the new policy? What measures will be taken if employees do not follow the policy? All employees are expected to uphold this Policy. Annual reviews will help determine the relative success of public participation efforts at each site. Non-performance under this Policy will be handled in the same manner as non-performance in any other area.

b. Whom can a stakeholder turn to when the inevitable personnel or procedural roadblocks are encountered?

Stakeholders should first turn to local officials (i.e. site/field managers). If a satisfactory resolution cannot be achieved, stakeholders would then press the issue through the chain of command in Headquarters. 
c. How does DOE plan to measure progress in implementing this policy? This is an issue that requires further attention, but the annual assessments are one means. Stakeholders will bc involved in developing site public participation plans, establishing performance criteria and measures, and assessing whether these are being met.

d. What funding mechanisms are envisioned for FY95 and beyond to help implement this proposals?

Sites and programs are to include public participation activities as a part of their regular planning and budgeting processes.

\section{Department of Energy}

Defense Programs

a. Definition: Change "between" to "among".

Greg Rudy

Because the Definition was reworded, "between" is now correct.

b. Definition: The department will genuinely/sincerely seek consider, and respond to the views of its stakeholders.

This suggestion has been incorporat d into the Definition section.

c. Goal III: Delete "empowered to" and change "participate" to "participates".

In the revised Policy, this references Goal II. The Department

feels that the concept of empowerment is an important component of the Policy and as such, has left this part of the goal intact.

d. Responsibilities: Public involvement should not be a discrete performance element for just senior departmental and program managers. The policy says its everyone's responsibility.

While it is true that all employees bear responsibility to support public participation efforts, the Department views Policy

implementation as the responsibility of management. Please see the Accountability section.

e. Replace "basic communication" with "appropriate communication training and public involvement training (delete "and where appropriate, advanced public involvement training").

The Department believes all employees involved in implementing public participation efforts should receive basic communication and public involvement training. For those working more closely with stakeholders, advanced training may be advisable. Please see the introductory section of the Secretary's Memorandum for discussion of this issue.

f. Guidance, second paragraph, second line, add "and legal requirements".

This concept is captured in the Scope section.

g. Critical Policy Element III: Change to "will develop consistent formats and facilitate procedures for public access to information".

This has been deleted from the revised Policy.

74. Department of Energy

Office of the Secretary

Dan Reicher

a. This is well done. 
75. City of Oak Ridge, TN Mayor Edmund A. Nephew

a. A more explicit statement that distinguishes public input from intergovernmental contractual agreements is appropriate.

Please see the Scope section; there is explicit language to this effect.

b. Because elected and appointed officials are legal representatives of the public, it is more accurate to state "Public involvement provides a means for Americans to more directly influence decisions made by their government."

In the revised Policy, this sentence has been deleted.

c. The DOE should receive training on public involvement from experts in that field, rather than relying on public relations contractors.

The Department agrees and is using recognized public participation experts to provide employee training.

76. Department of Energy

Office of Environmental Management

Cynthia Kelly

a. The subject headers in the policy should be less abrupt; they seem very bureaucratic.

The subject headers are meant to be brief, clear, and descriptive.

b. Purpose: The primary purpose of public involvement is working with the public to reach consensus on how to solve problems in a more publicly acceptable way. This goes beyond "building mutual understanding and trust" and should be incorporated into the statement.

The Department disagrees. Public participation is not intended as a tool to build consensus, but as a means to build understanding between the Department and the public and to help the Department make better, more informed and responsive decisions. Please see the Public Participation section in the Policy for a more detailed discussion.

c. Background section: The second sentence should be deleted. The third sentence should read "The focus of DOE's efforts during the Cold War was on national defense through nuclear deterrence; the priority, on design..." Insert after this sentence "This focus resulted in an operating culture that allowed for limited public interaction only."

The Background section has been deleted from the Policy.

d. Background: The second paragraph could be improved by deleting, "from a closed, command-oriented hierarchy."

The Background section has been deleted from the Policy.

e. Background: Second paragraph: In the last sentence delete, "such leadership and change are essential" and insert "this new culture is essential if..."

The Background section has been deleted from the Policy.

f. Definition: Reword lead-in sentence: "Public involvement is participation by interested members of the public in the activities and decision process of the Department, and provides a means for members of the public to influence these decisions."

The spirit of this suggestion has been incorporated. 
g. Definition: Reword last sentence: "The Department will actively seek and consider public input, and will incorporate or otherwise respond to the views of its stakeholders in making decisions."

The spirit of this suggestion has been incorporated.

$h$. The Goal section needs a lead-in sentence and the goals need to be reworded.

The Department agrees. A lead-in sentence has been included and the goals reworked.

i. Core Values: Examples would be very useful, especially in regard to "risk-taking".

Definitions of each core value have been provided. The term "risk-taking" has been replaced with "innovation." (Please see response \#36.b. for comment on this issue.)

j. Responsibilities: What does this coordination consist of? Is this advisory only or will the office of Public and Consumer Affairs be actively involved?

The Office of Public and Consumer Affairs will coordinate public participation activities at the Headquarters level. Local public affairs offices will coordinate their own public participation efforts. As noted earlier, this coordination role is one of facilitation and support, not direction. (Please also see responses $\# 36 \mathrm{~m}$. and 0 .)

k. May need to add another responsibilities section regarding the responsibilities of the Deputy Assistant Secretaries and Office Directors to oversee their program managers and ensure that they are including public involvement in their projects as early as possible.

The Responsibility section was reworked, simplified, and renamed "Accountability." Specific titles were eliminated to avoid confusion; thus, additional designations are unnecessary. The value of early participation, however, is recognized and incorporated throughout the Policy (for example, in Goal II).

1. Guidance Memorandum: The last sentence should be revised to reflect that public involvement plans and activities should be appropriate to the needs of both the program and stakeholders. DOE must be very clear in defining what it needs from the public involvement process in terms of recommendations, alternatives, priorities, etc.

The document is intended to provide a framework for what the public can expect from the Department, although benefits to the Department are also noted in the opening Public Participation section, and elsewhere in the Policy. More specific expectations, on the part of stakeholders and the Department, will likely be identified in site-and program-specific public participation plans.

m. It is not clearly stated that the Director of Public Affairs' coordination role is the need to be consistent and accurate. This role is discussed in further detail in the Guidance Memorandum.

n. Critical Policy Element \#1: Suggest rewording the first bullet under Implementing Actions to clarify what officials will be empowered to do. Possible rewrite could be: "Officials 
representing the Department will be honest, open, and accurate in their public statements, and will assure diligent follow-up and timely results from the commitments they make".

This suggestion was slightly modified and incorporated.

o. Second bullet: Change to read "... routinely solicit public input, consider it in making decisions, and provide timely responses to the public. Responsiveness to public input is critical in building credibility".

While this precise wording was not adopted, the spirit of the comment is clearly reflected in the Policy. For a discussion of the word "routine", please see response \#36.b.

p. Third bullet: This is not an action, either delete or incorporate into the introductory paragraph.

The Department believes that the recognition and reward of leadership in this area is extremely important. This section was rewritten to clarify.

q. Critical Policy Element \#2: Replace "well known access points" with "clearly identified access points".

This sentence was changed to read "with regular, distinguishable access points."

r. Second bullet under Implementing Actions: Insert "...will consult with Project Managers to identify appropriate pre-decisional...". Also, need to clarify what is intended by 'facilitate accommodation between local and national interests". The first sentence of this Implementing Action has been reworded, while the second sentence was deleted.

s. Critical Policy Element \#3: First bullet begs for some clarification or expansion - cooperation should be given in any organization and should not necessarily be "rewarded". If these bullets are to be Implementing Actions (header is missing), it may be better to state this as an action: 'A system will be developed to evaluate and recognize examples of innovative, efficient or cooperative team efforts in public involvement activities. Specific guidelines will be necessary to make this work. This bullet has been deleted.

t. Critical Policy Element \#4: It would be more logical to switch the sequence of the Implementing Action bullets to first list training, then evaluation.

This section has been reworked and simplified, with references to evaluations removed.

u. Critical Policy Element \#5: This is the first time developing consensus has been mentioned in the policy or the implementation memorandum. This should be a greater emphasis in the policy. Effective public involvement activities will seek to build consensus and understood public values, not just exchange information.

Reference to consensus has been deleted. See response \#76.b.

v. Second bullet: Will this be one database? Suggest changing to "...manage appropriate (or topical) databases of real-time information...".

This reference to a database has been expanded; there will be more than one. 
77. Stanford University Linear Accelerator Center Burton Richter

a. Those closest to the community should have as much flexibility as necessary in order to meet local needs. Local needs may vary widely from site to site.

The Department agrees; the Policy supports decentralized, sitedriven efforts.

78. Mary Riseley

a. Definition: Are you only going to conduct "legally Riseley meetings"? I suggest omitting the modifiers as hopefully you will hold other public meetings as well.

The Definition section was rewritten to clarify that legally required meetings are but one of many forms of communication that may occur within the DOE Complex and between the Department and its stakeholders.

b. Responsibilities, second paragraph: This is unclear and sounds cumbersome. What does "coordinate" mean here?

The Responsibilities section has been eliminated. Please see responses \#36.m. and 0 . for an explanation of "coordinate."

c. Guidance on Implementation, last sentence, last paragraph: This statement is patently overstated. "The business" of DOE includes many matters that will never be open to full view. I would hope for a more honest statement with qualifying phrases.

Indeed, the Secretary supports a policy which promotes openness and service within the Department. As such, this statement is not overstated. In response to this and other suggestions, however, the statement was qualified with the phrase "consistent with applicable laws, regulations, and contracts."

79. Eugene Kovalenko

Eugene Kovalenko

a. This policy is a shift from an attitude of domination to an attitude of partnering.

This is true.

80. Bonnie Bonneau

Bonnie Bonneau

a. There was not enough time to respond. I believe that 30-60-90 days notice is more in line with legitimate review processes. Please see response \#2.a.

81. LANL 2000 Subcommittee/Task Force on Policy Formation and the National Economy

a. Background, second paragraph: After "and leadership from the top down", add "and bottom up".

The Background section was el iminated.

b. Definition: Add something at the end about timely responses to comments.

This suggestion has been incorporated in the Core Values section.

c. Is public involvement restricted to non-classified material?

Yes. This is discussed in further detail in the Scope section and the introductory section of the guidance document.

d. Responsibilities: Public involvement will be a "discrete performance elemert... Is this a job requirement? 
Though the Responsibilities section has been eliminated, the Accountability section clearly states that public participation is a performance element for senior departmental, program, and field managers.

e. Will Site Specific Advisory Board members have access to clarification information or will they have to obtain a Q? This Policy in no way affects legal requirements governing classified information.

f. Director of Public and Consumer Affairs: This sounds like a place to bottleneck a project.

The Director of Public and Consumer Affairs will serve as the point of contact for Headquarters coordination, but will have no direct role in local activities. For further discussion, please see responses $36 . \mathrm{m}$. and 0 . as well as other references throughout this Comment Response document.

g. Critical Policy Element \#1: Add "truth" to "honesty and forthrightness."

The Department believes that the concept of truth is inherent within honesty and forthrightness.

h. Critical Policy Element \#1, Implementing Actions: Please rewrite this element in laymen's terms.

The Department hopes that Critical Policy Element \#1 is easier to understand in the revised Policy.

i. Critical Policy Element \#2, Implementing Actions, second bullet: Cite a partnership with the public.

The spirit of this suggestion about a partnership between the Department and the public in the identification of pre-decisional access points may be found in Critical Policy Element \#2 of the revised Policy.

j. Critical Policy Element \#3: Replace "rewarded" with "recognize". Because cooperation is now to be the norm, it will be evaluated as part of regular performance appraisals; consequently, references to "reward" have been removed from the guidance document.

Obviously, quality performance in public participation as in other areas will be recognized in the employee's evaluation.

j. Critical Policy Element \#4: The Director should assess effectiveness on a quarterly basis, not annually.

The Department believes that annual assessments are appropriate as public participation is an evolving process that will require time for implementation and progress.

\section{Vista Control}

\section{Author Unknown}

a. For meaningful participation, it is vital that more than all the relevant information is available. In some areas this will conflict with national security issues and classifications. I did not see this addressed in the document.

This is now addressed in the Scope section.

b. Guidance document, first paragraph: I would like the strategic plan to be particularly called out in the second line. As noted in other references throughout this Comment Response document, the Public Participation Policy is but one of many initiatives to redirect the way the Department does business. The 
Strategic Plan provides the overall roadmap for where the Department is going and how it will get there. Public

Participation fits particularly within the critical success factor of Communication and Trust.

c. In the last line of the same paragraph, and with security issues

in mind, add "of Americans" after "view".

The Department cannot and does not wish to restrict public participation to any particular groups.

d. Critical Policy Element \#1, first Implementing Action: Add "completeness" after "honesty".

The word "accurate" has been inserted, implying completeness.

e. Critical Policy Element \#3: Change "Cooperation will be rewarded" to "cooperation will be recognized."

Please see response \#81.j.

f. Critical Policy Element \#5: Add "and understanding values" after "information and ideas".

The spirit of this suggestion has been incorporated into other parts of the Policy, including the Scope section.

83. Gloria Gilmore-House

Gloria Gilmore-House

a. How deep is the commitment to change? Is it simply a fad or will it continue beyond the present administration?

Both the external and internal events driving Departmental change began during the previous administration and are expected to continue beyond Secretary $0^{\prime}$ Leary's tenure. This Policy, for example, is to become part of the Department's Directives System, which pertains beyond any single incumbent Secretary.

b. Why are risk-taking and peer review the only core values singled out as benchmarks for performance assessment in this document? What about other laudable values like accountability, fairness, openness, respect, sincerity, etc...

This was a shortcoming that has been rectified. As discussed in the Accountability section, effective implementation of this Policy will be a performance element for Department managers. Evaluations, in large part, will be based on the Core Values described in the Policy, including many of the values noted in your suggestion.

84. Carolyn and Arnold Keskulla

Carolyn and Arnold Keskulla

a. No comments pertaining to the DOE Public Participation Policy.

85. David Kime

David Kime

a. So that accurate, effective solutions can be found for contamination clean-up, the public should be given the reasoning behind the contaminants.

As defined in the Core Values section under "Accountability," the Department has a responsibility to explain both its decisions and the rationales for those decisions.

86. John Darke

a. No comments on proposed Policy.

John Darke 
87. Erwin Binder

Erwin Binder

a. I have no confidence that the proposed public involvement process will not be subverted by political considerations.

The Department hopes that its actions over time build public confidence.

88. Jay Edgeworth

Jay Edgeworth

a. The Purpose statement should contain a statement of how more involvement can reduce costs (i.e. it could reduce delays and legal issues later).

The primary purpose of this Policy is not cost-reduction, although this would clearly be a welcome auxiliary benefit if it occurs.

b. Guidance memorandum, Critical policy Element IV, bullet \#2: It is important that all employees are apprised of their responsibilities and be given the instructions necessary to adequately carry out their roles in the new era of openness. This means that everyone should be given public involvement training, not just "appropriate personne?.".

The Department agrees. Both of these suggestions have been incorporated into the introductory section of the guidance memorandum in the second and fourth bullets.

c. The draft seems only to address the roles of public affairs officers and area managers and above. It is a mistake not to empower all employees to respond to the public's concerns since all employees will be dealing with the public on a daily basis. The revised Policy clearly states that all Department employees are responsible for public participation (Goal III).

89. DOE-Los Alamos Area Office ES\&H Branch Author Unknown

a. Why are the Core Values different than the 8 DOE Headquarters uses?

The question is not clear. If the reference is to the core values contained in the Department's Strategic Plan, the core values in this Policy are not so much "different" as they are more specific and focused to the needs of public participation. The two sets of core values are complimentary and reinforcing.

90. Sig Hecker

Sig Hecker

a. With respect to empowering the public to participate, who is the public? Accountability is the flip side of empowerment; how do we get the public to be accountable?

Here, the public consists of that portion of individuals or groups who choose to participate in Department decision making processes. It is presumed that such participants will be responsible and diligent in their efforts. The extent of their influence on the Department's decisions will perhaps be the best measure of their "accountability."

91. LANL-Public Affairs

Scott Duncan

a. As a practical matter, I'm not sure just how we "empower" and "include" the public in the decision making process. 
Under this Policy, the Department is empowering the public to participate in its decision making. Specifics of implementation are deferred to local sites in conjunction with their stakeholders.

92. John Ussery John Ussery

a. Enough time has not allowed for the public to truly respond. Please see response \#2.a.

93. New Mexico-Radioactive Waste Consultation

\section{Task Force}

\section{Anita Lockwood}

a. DOE should carefully review the SEAB report during creation of this policy.

Please see response \#9.a.

b. It is strongly recommended DOE pay particular attention to the implementation of the policy in the field. Often a well-thoughtout plan or policy conceived in good faith fails to achieve its objective because of poor implementation.

The Department agrees. As discussed in the Secretary's Memorandum, annual assessments will be made at each site and for program-specific efforts. Stakeholders will be invited to participate in the process. The Director of Public and Consumer Affairs will then evaluate these assessments, share successes, and recommend improvements at individual sites and across the DOE Complex.

c. We recommend DOE take the necessary steps to monitor and evaluate the effectiveness of its Public Involvement Policy. Please see response \#93.b.

94. DOE-Carlsbad

a. No comments or changes to suggest.

Patty Baratti-Sallani

95. Martin Marietta

Jane Malagon

a. Purpose: Add the following: Public involvement brings a full range of diverse stakeholder viewpoints and values into the Department's decision making early in the process, enabling the Department to make better decisions.

This suggestion has been incorporated into the Purpose section.

b. Goal III: Add the following: The public is informed and encouraged to participate. Also, add final decisions rest with the Department. Goal II now seems to reflect the spirit of the first comment. Additions to the Scope section of the Policy and the opening paragraph of the Secretary's Memorandum address the second comment.

96. DOE-UMTRA

\section{Albert Chernoff}

a. The last sentence under the heading DEFINITION is a strong one. It might be more effectively placed under the first heading "POLICY" (Sentence: "The Department will actively seek, incorporate, or otherwise respond to the views of its stakeholders). 
This sentence remains in the Definition section as it serves to define the what of public participation. Because this concept is fundamental, it appears again in Goal I.

b. Senior management must receive training on the new values and assumptions, and must learn to involve public affairs early at the strategic planning level.

As discussed in the introductory section of the guidance document, training is an important element in the effective implementation of this Policy.

c. Public affairs people with media backgrounds will need to learn new roles with a stronger emphasis in strategic counseling to senior management.

Trained personnel will be utilized to the maximum extent.

d. A resource investment is required to achieve the long-term gain of public involvement.

Managers are expected to identify and provide needed resources through their normal planning and budgeting processes.

97. DOE-Los Alamos Area Office Counse1's Office

Lisa Cummings

a. "Legally required?" What law requires secrecy? Classified information/secrecy is an inherent part of weapons development. This Policy in no way affects legal requirements governing classified information.

b. Definition: What is the difference between individuals and the general public?

Not much. This has been reworded for clarification.

c. Goal III: I am concerned this is too broad a statement; it may promise too much.

Indeed, it does promise much. Public empowerment is, however, at the heart of this Policy.

d. Core Values: Is taking risks a Core Value? How about "Prudence" as a Core Value?

"Risk-taking" is no longer a Core Value. Please see response \#23.c. With respect to "Prudence," the spirit of this value is reflected in the Core Values "accountability," "peer review," and "scientific credibility."

e. Responsibilities, second paragraph: How do you coordinate

"informal conversations" between individuals?

This is, perhaps, being read too literally; informal conversations are not meant to be coordinated, though they are an important part of the overall communication effort that will take place in the course of public participation.

f. Add: Risk-taking which leads to increased public involvement will be rewarded.

For reasons discussed throughout the Comment Response document, the entire concept of risk-taking has been deleted.

98. DOE-Los Alamos Area Office Counsel's Office Author Unknown

a. Background: The last two sentences are not true; classification is not an emphasis, but an inherent part of research and development for weapons. 


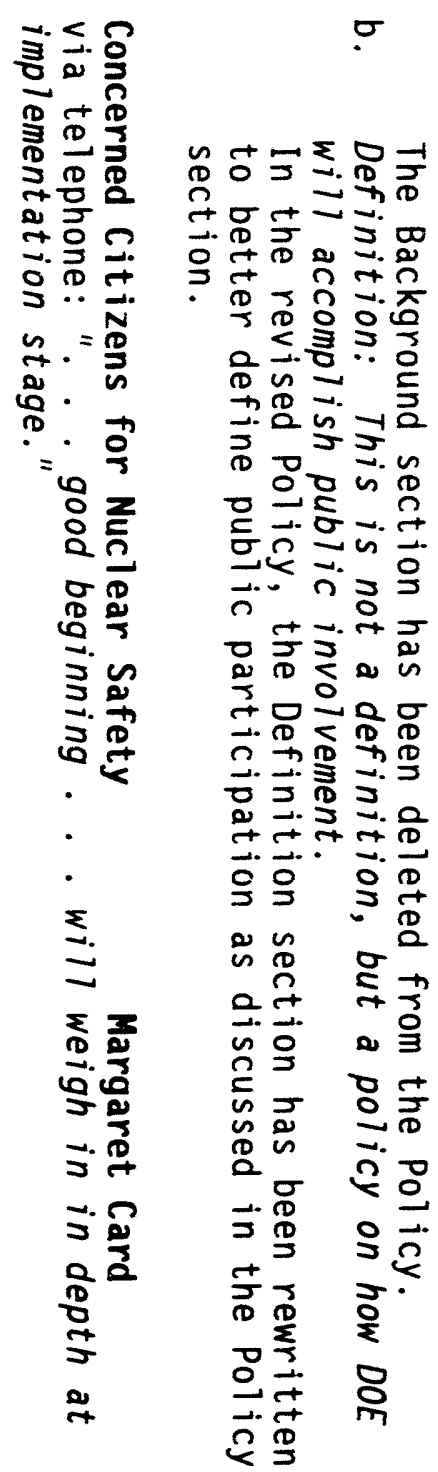




\section{Incoming Comment Letters}


CITY OF

OAK RIDGE

BAX \# 482-8352

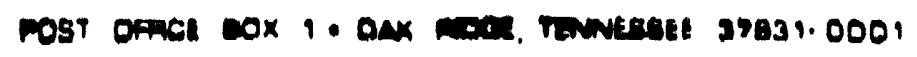
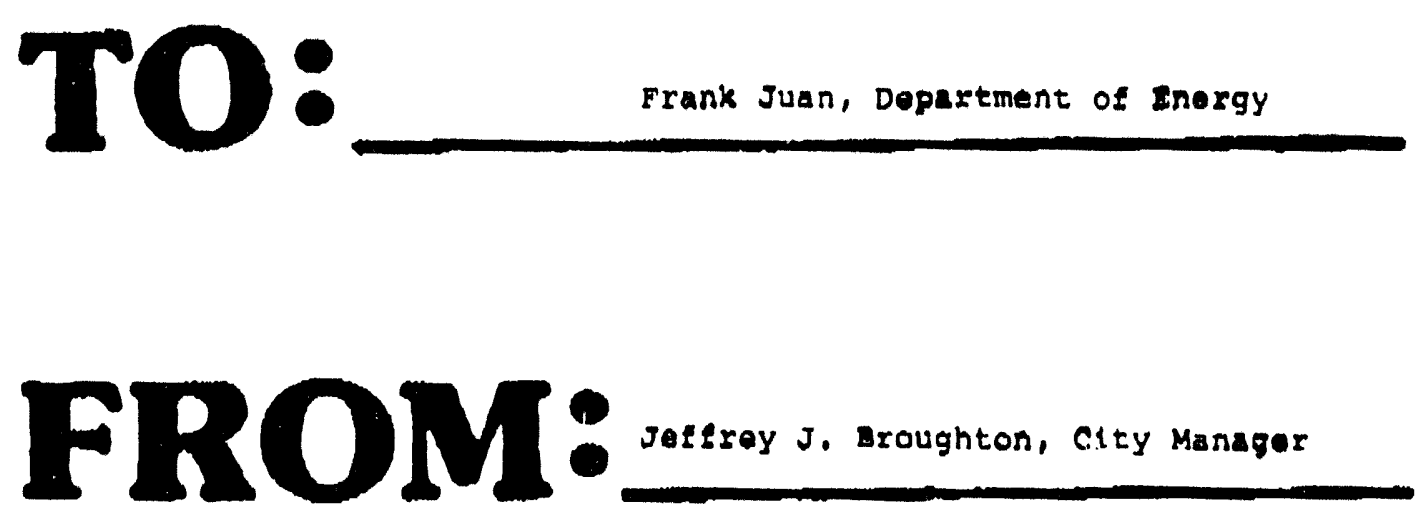

DATE:

January 28,1994
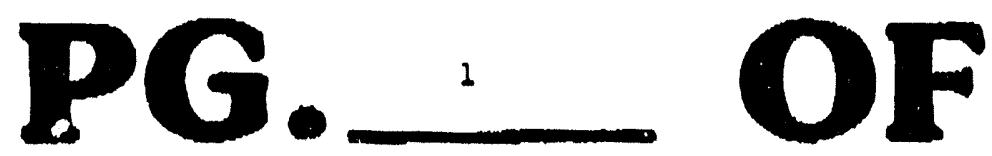

2

NoT: In reapone to your January 26, 1994 fax transmittal ragarding DOE' public Involvement policy, I have roviawed the policy and have no oomments at this time. 
December 23, 1993

Dr. Jerome Saltaman. Director

útibe ot External attaita

U.S. Department of Energy

Wätistion, O.C. 2058 E
RE: Request tos comment on Diatt Futilis lnvolvenent Polloy

Dear Dr. Saltzman:

Thank vou tor ingludiag aus organization in yous reguest tos commentz on the Energy Department's proposed policy on public invoivement. une of the majui concerna I heat voilaed by people in the putllo-Interest communtty has long been the tallure of Federal agencles associated with environmental lgsuea. and especially with issues of nuclear energy. to lncosporate in thelr declsion processes the vlews of the publlc - both those who are directly atrected by agency deations and those who are indlrectly lmpacted by these actions.

There are a great many people who have assumed all theif ilves that these goveinmental bodies. supported by publte runds, have as thelr ilsst prlority the protection of the publia'a Interests in health. satety, and environmental piotertion. unly when their pergonal livez and property are gutte directly and Immediatelv lmpacted by agency declsions do most people become lnvolved. And ot teit. tou late, they itind the gaping chasm between thets concesns and those of the prlvate proplt-orlented corporate or government interests that the agencles Giem devoted to. The deep diatrection or go many Amerlcans toward thelr government is often rooted in thls disllluslonment. And all too ot ten the arrogance or putilic servanta - tor you all are, atter all, our employees - compounds the anger and trustration of the people who are requited to pay your salaries and surter the heavy hand of government.

Becauge the attitude descrlbed atove hag come to be all too prevalent, we

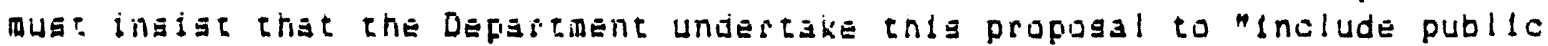
Invoivement procesese as a routine element" not only "throughout ita operstions and fisming activitiea," as you gtate in your liecember 17 th lettes, but much more lmportantly in DOE's declaion-making. Untortunately. reports trom the Auguat loth workshop in Las Vegas indlagted that the commitment did not appeas to be serlous enough to meet the need. We theretore strongly recommend that

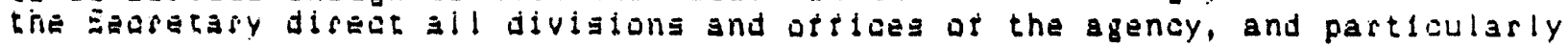
those that deal with weapong-and radioactive waste-related mattera, to give axtiemely high priarity to actual demonstration of these new poltcies of openness and involvement of the publla.

Thus, to turn to yous "Drste Poliay on Public Involvement"

1. At the tisst aection. "Fullicy," please add atrer "activities" the worda "and in debiaion-making," Wa support implementation both at headquarters and in the tield.

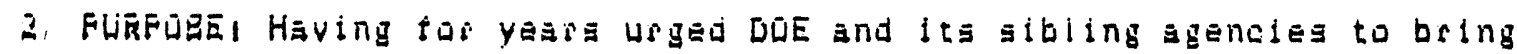

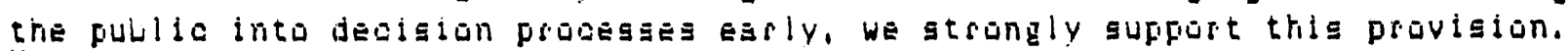

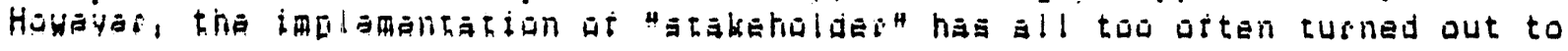
mean a "token enviro" or loeal ofticial or a couple or tarmera os househoiders who live near a tacllity as surrogates ror many others in the publlo whose views are neither sought nor adopted. We recognize this as one of the toughest 


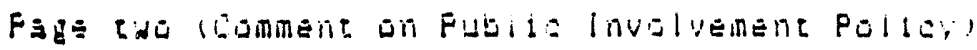

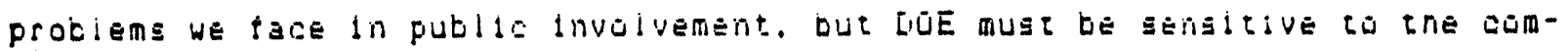

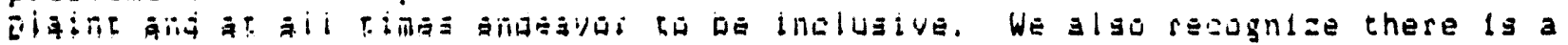
certain level of frustration tor stat: who are disected to reach declelong;

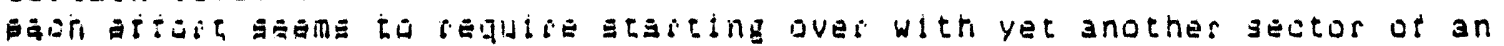
unlnformed or newly aroused angry publlc. Conversely. for thioe in the publta whi haye iong been thvelved, the tiustration wosks the oiner wave having to restate what has been sald many times betore to new DuE statt who are somewhere betwesn the revolving doors. It's enough to try the patience of saints.

3. BACKGROUND: We cannot concur strongly enough with these gtati comments! I tind ot:en that my audiences have no understanding of DOE's obllgations to research, develop. demonstrate, and produce nuclear weapons or to manage highlevel, transuranle, and some low-leve! radluactlve wastes. We would like to look to the Department of Energy to assist us in both the denuclearlaing and demilltatizing of our nation. We commend you on giving emphasis to this aspect of DOE which you propose to change for the better. But historically DOE and It predezessors have so deeply damaged the trust of the American people that there wll! be a speclal need for the Energy Lepartment to bend over very far backward to dedunstrate. With consistency. these changes of pollcy and mission are real and worthy of the public's trust. You therefore must not continue to promcte additional nucleas weapons or more nuclear power reactors.

4. DEFINITION: The wording here sounds good, and we encuurage the gtat to carry ti out consalentlussly. But the cautlon applies about not limlting DoE's concept $0:$ "public stakeholders" to a few well-known or "comitortable" persons or organlzations as surrogates for the lasger population. Almost nothing Irritates a local grassroots group of attected people so much as having someone r rom a national organization Invited by a Federal agency to represent thelr intereste. Which that person mav not even remotely understand or share. We asking that DOE be careful, attentive to these difterences.

5. GLALS: Great! How best can we help you to carsy then through with sucess? Another word of caution: 1 t wlll be prudent for the Department to exercise thls undertaking with prudence and caution. Don't promise more than can be dellvered. The skeptlcal public(s) wlll be all the more cynlcal about DOE (and NRC, DOD. EPA, FDA, et al.) for promising, and then talling.

6. CORE VALUES: Dellghtful words to see in a DOE document. Please add "humility" to the list. We'll probably think of some others.

In order to assure that these comments reach you before January 4 , and because my very young grandson expects me for pre-Chrlstmas Eve dinner tonlght 200 miles irom here -- and that matters to me even more than DOE's public pollcy - - 1'll complete our comments on the remalnder of thle dratt notice upon my return as a supplement to these two pages. Please know that this pollcy is an appreciated holiday package trom DOE.

Sincerely.

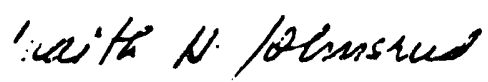

Judlth H. Johnssud. Ph. D.

Director 
Drcember 29, 1993

Dr. Jerome Saltzman, Director

Ostlce of External Astalrs

U.S. Department of Enesgy

Wash!ngton, D.C. 20585

Dear Dr. Saltzmani
RE: Request for comment on Draft Public Involvement Polley

Thle letter repluces our two-page letter of D ceaber 23, 1893. Thank you for Including our orgunization in your request for comments on the Energy Department' draft Po,ley on Publlc involvelwent. the subject 19 of great Importance; we wanted to respond sully. However, four letter, dated December 17, erslued ifterally on the eve of departure for hollday famlly gatherings.

The Department of Energy deserves our careful| consideration of, and oonatructlve responses $t 0$, the issues ralsed. But your closing date of january ath sor publle comment is ear too soon and is totally Inadequate if the Department serlously deslres publlo comments on 1 ta puble pollcy. Therelore, on behals of our organization and others who may not have recelved thls dratt dooument but would like to comment, Lem requesting that the Energy Department extend the publle coment period on the Draft Pol cy on Publle involvenent er in additional 60 days following cormal publicat lon of notlce of avallabllity for cemment in the Fuderal Resleter.

At the very tima that the Energy Department fe admitting to nearly a halt century of eccecy and decoption practlced by DOE and lte predecessor AEC, this brlal window of opportunity for oltlizens t.o respofd to your request ceems yet enother Indication 0:! the contempt of the Energy fepartment (and, we seel, lts tellow Federal agencles assoclated with nuclear oforgy) toward the publle that DOE and they are eupiosed to serve. It yisur agenfy talls to provide tull, notloed cemment perligd on this Important pollcy lfeve, please be aware that you

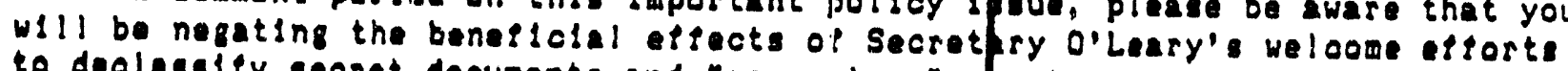
to deolessify ceoret doouments and "come alean" apout radiation experlments and past DOE abuses of power. We can't belleve that he wants that to happen.

A major eoncern that I hear voloed ripeatedly by people in the publdcInterest comaunity is the continuting fallure of fpderal agenoles arioolated whth environmentel lasues, and espeolally nuclear energy, to incorporate in thelr declsion processes the views of the publto - both those who are direotly opportungties for publif comment, those Indireotly lmpeoted by these actions.

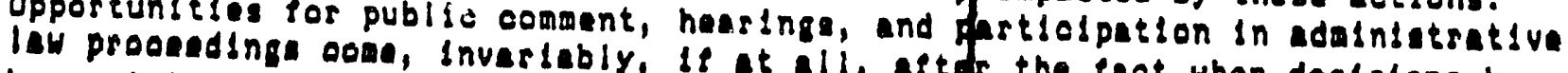
been virtually ilnalized. With rare exoeptions, if the teot when declsions have

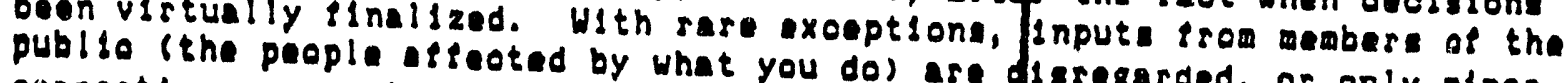
correctlone oocur ir agency programs that are furderegarded, or only alnos

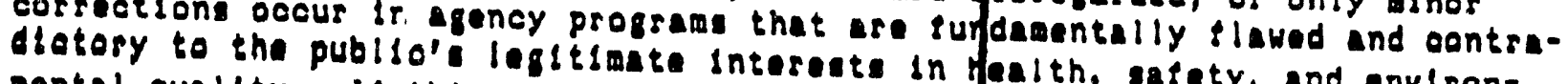
mental quality. If this is the way in which Dos palth, satety, and environins tea publio involvement polloy, the Departoen oont inues to go about presentbullo greates undersitanding and truet" ir partoen is casting lts pallure "to than any Dos has been able to develop for dispos that'll be tar pora durable 
Page two (Comment on Public Involvement Pollcy)

There are areat many people who havi assumep all thals Ilves that governmental agencles, supported by public sunds, have as thelr ilset prlorlty the protaction of oftlzens' interests in health, eatety, and the environment. Only when thels personal lives and property are directify and lmmediately lmpacted by egenoy decislons do wost people become Involved. And often, too late, they IInd the gaping chasm between thelr concerns and hose of the private prolltorlanted oosporate or government interests to whidh the regulatory agencles seen devoted. The duep disalfection of sci many Aferlcans toward thals government is often rooted In thls dislliuglonment. An all too osten, the arrogance of publlc servants -.. for you all are, alter all, our employees -. compounds the anger and erustration of the people who are r quiled to pay your ealarles but suffer the heavy hand of and even injery fromlyour governmental declsions.

Boosure the attltude desorlbed above has been all too prevalent, we must Insist that the Department undartake this pollcy broposal to "Include public lavoluement procesen ar couthe element" not only "throughout ltg operationa and planning actlultles" (as you tate In your Defember 17 th letter), but much more Importantly In DOE's actual dec1sion-naking Untortunately, reports irom the DOE Auguat 10th workshop in Las Vegas indlaafed that the atafl commitment did not appear to be nearly serlous enough to weft thls need. A communlty workshops in whioh and history (as l hive obst exhlblt both 1 gnoralce of thelr agency's actlons Interest partlclpanis do not bode and dlstegard ef recommendations irom publlc-

We therefore strongly and of ilces of the ugency, and particuse the sepretary direct all divistone radtoactlve waste-rlated matters thalaly thos that deal with weapons- and pollcien of openness and real involvemen. of the pul demongtration of the new adequate cormal public notlce and time sigr publit comment of the problating

Involvement." It rour cover descrlption of the noraft pallcy on publlc treatlse. The worda geew reasonable, lor like pn Intelligent achlzophrentc's pleased with the trank disousglon of Energy detfeshing, and one $1 \mathrm{~g}$ lnitlally Background section and with the lofty Goigy Depaftwent els-criticlsu in the But unfortunately, the draft polloy is divorced pratement of Responsibllities. In the Department' Interpretations of 168 statulory the actuality we observe

Include continued researoh and developmint interpretafion of lts misaton and goals sorcing stes tor the torage and disposil of nif nuclear weapons. It lnoludes

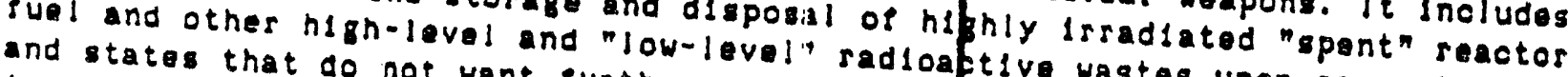
(e.8. WIPP, Yucea Mounteln) surther contianinatiof and damage upon communtties nuolear power reactars, including includis develfprent and demonstration agenoy more radioactive waita, despding ilquld metal bpeedess, that will Isolate nucloar wastes desplte the iact that Dof hasn't that wlll generate hazardoug lite of the waste. deregulation of radloactive wastes in wall recycl of contaminated oontrol for the "background" radlation and wastes in ways that flll be additive materlals and radiation and to Indlvidual" unavoldable addltive to existing 
Page three (Comment on Public Involvement Pollcy)

and other sources of lonlaing radlatlon. The Energy Department has yet to watch Itg commendable slalos of a sood-falth deslra to remedlate sltes with marked actual success in oleaning up the ralloactlu rulnatlon that DOE and its predeceseor and fellow agencles have caused at facllitles natlonwlde.

in true good ealth, we do earnestly urge the spcretary to Insist that all atals undertake the changes of alssion that she profoses by also demongtrating - major change In Ingtltutional and Indluldual attlfude on the part of 11 DOE amployees. These attftudinal changes must be demondtrated in all DOE programs and contacts with tate and local offlclals and mempers ct the public and publle-Interest environmental comounlty. Lip servide to pollcy won't do. Only when those changes of attltude are reflected in reall changes in DOE and 1 ts sotione can the rebuliding of publla trust begin.

We belleve that the ilrst essentlal etep toward regalning trust must be a - tatutory change in the Congressional mandati to Fedpral agencles with respect to the development, uses, and control of nuclear onefgy. We urge the Secretary and all stafs to joln mambers of the publlo in clarlyying to the Congress the desperate need for updating this nation's nuslear en rey polley, which is codifled In the Atomle linergy Act of 1954 as amended at Chapter 1, Section 1 (42 USC 2011-2286). This cowplete statement is as follows:

Section 1. Deciaration.--Atomlc eneirgy ls tapable of application tor peacepul as well as ollitary purposes. Tt is therepore declared to be the pollcy of the Unlted Stated that--

a. the development, use, and control of atguic energy shall be directed os as to make the maximum contribut on to the general weltare, subject at all times to the paramourt objectlve of making the meximum contribution to the common desende and security; and

b. the development, use, and control of atomlo energy shall be direoted so as to promote world peace, loprop the general weliare, Increase the gtandard of 11 ing, and etrengthon tree competition in private enterpidse.

So long as the law requires development and uses op the energy of the atom "to make the maxlmum contribution" without oven wentipning what ought to be the prealer objectlve of nuclear energy pollcy -- vlz., ib protect to the maximum extent the heslth and elety of the publle and of workers and the aus lity of

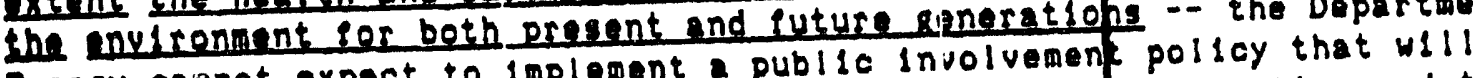
Energy cannot expect to Implement a public lnvolvementeplatration and the sucoesd. When the secretary of Energy has fod thucleaf energy for wllltary and Congress in ending our rellance on the vase of nucleaper greater quantitles of doasests purposes, and thereby and then wlll infor med members of the public radloactlve materlals and wastes, DOE seaks. Only whep DOE's goals watch the be ble to become the prafecting human health erom rad ation damage and for publle's concern rectoring environmental quallty can DOE Implement a successful publto involvement pollor. 
Page sous (Coment on Public Involvament Pallacy)

Environmentalists have prepared some language fo modify the pollcy atatement in the Atomle Ene:" gy Act $s 0$ as to redlrect U.S nuclear energy polley toward the objectlves that oltlzens want: maximlzin protection of health, sasery, and envisonmenis. We look forward to dlscusping these suggested emendments with the Secretary and senlor stat! In the nepr luture, as, we'd Ilke to hope, an early demonstration of the Departmint's nel involvement pollcy.

1. In the descriptlue summary, at the llsst seption, policy, add after "sotlvitles" the word: "and in declgion-making." Welusge rea! Implementation at headquarters and in the rleld.

2. PURPOSE: Having lor years urged DOE and 1 tg gloling agancles to bring the public Into declsion processes carly, we strongly support thls provision. However, DOE's publle "atakeholdeg" has all too of ton turned out to be fugt a "token enulso" or one local offlclal, or a tarmer of householder who llyes near - taclilty as surrogate tor the many others in the public whose vlews are nelther sought nor adepted. We recognize this as fne of the toughest problems we all tace in public involvement, but DOE must be lsensitive to this complaint and at all times endeavor to be inclusive.

We also reoognize there is a certaln lovel of firustration for stalt who are directed to reach conclusions; each efport seeng to requlre starting over with yet another sectes of a seemingly uninsormed or nowly aroused and angry public. Conversely, for those in the public who halve long been involved, the Prustration works the other wayl having to restate what has been sald many times betore to new DCIE stal? who are somenhere belween tho revolving doors. Elther way, it's onougin to try the patsence of salits.

3. BACKGROUND: Wa cannot concur strongly enouth with these observations! I Ind often that my audienoes have no understanding of DOE's statutory obligatlons to research, develop, demonstrate, arid produfe nuclear weapons, or to aanage hlgh-level, transuranle, and low-level radldactive wastes. We commend you for glving emphasis to this aspect of publio plilcy which you propose to chenge tar the better. We would like to lciok to DdE to assist us in both the donuclearlzing and deillitarlzing of our nation. fut historlcally DOE, AEC, and the nuclear Indust:ry have so deeply dalaged th trust of the Amerlcan people that the Energ:' Dopartment must truly chang, and demonstrate, with consistanoy, that these changes of polloy and m1ssion are real and worthy of the public'. trust. You 'heresore aust not continue to premote additional nuclear yeeens or more nucleffe power resctors. But revief, for an exanple of DOE's fallure to change, thil scoping materials por the Pfogramatic Environmental lapact Statement on Rilconiguration of the Nuclear Weapons Program.

4. DEFINITION: The wording here sounds good, find we encourage the stafs to cessy tt out conscien:lously. But the caulion app/10s about not ilalting DOE'. concept of "public stikkeholders" to e law token we 1 -known or "comportable" persons of groups as nurrogates for the larger poppletion. Almost nothing so Iriltates a local graisroots group of affested people as having comeone troa a Washington-based national organization invitted by foderal agency to represent thels Interests, which that person or organization may not oven remotely underatand or share. We'ris asking that DOE be caresul, be very attentlve to these dlferences, and be viastly more inclusive ot the whe range of public concerns. 
We also caution that DOE not perpetuatio the cupton of defining "the ... " to Include thise private enterprlsiss and thdividuals who have vested intereats in DOE progriams and the outcome ot agency declslons. Too often masked conflicte of in:eregt are present in persons chosen to "ropresent" "the publ10" In advlsory or partlclpatory roles sis surrolate stakeholders.

5. GOALS! Great! How best can we help you to garsy these goals through to success? But are you really going to do this? But another word of caution: it wlll be prudent for the Department to exercise this undertaking with both prudence and cautlon. Don't promlse more than can be delluered. The skeptlcal publle(s) w\$ll and by belng all the more cynlcal about DOE (and NRC, DOD, EPA, FDA, t. . ) for promising, and then palling to live up to lts goals. The burden of prool lies squarely with those who have shtitered public confldence.

Wlth respect to DOE's nuclear weapons and wastej responslbllitles, highast priorlty should be glven to full admission a:" what if now known about the doleterlous health eftests of 11 exposures, Includifg low-dose and chronic lowdose exposures, to lonlis Ing radlation. We urge DOE fo Incorporate in 1 ts standards for radiation protection the newest. resear h indings from the tormes USSR (your enemy no lonfer). See Chernobyl Catagtrople, MInsk, 1893, 4 volumes, in Russian; and D.W. Botirdman, M.D., Radiatiein Impace Atome to zysotes, Center tor Atomic Radiation Studles, Cambridge, MA, 1992, pleprint, and lsowhere in the scientlile literature. The essence of these sesparch reaults is that, as the U.S. Natlonal Research Councll's Comittes on the Blologlcal Etsects of lonlzing Radlation admitted in 1990 (BEIR V Report), there is Indood no sate level of exposure, Including that froll naturally-occulring background sources.

The Department must take into eccount these very difserent mechanisus and health conequences of low-dose radiation exposures, pdopt the standard of zaro tolerance above naturally-occurring background, and apandon rellance on r lak assesement. In establlentng rlak-based atandiards. Foporal agencles have salled to include all adverse hoalth and genetlc consequencop, to match rlsk assesament asumptions with roillty, and to ascertaln trom fhose who bear the sisks trom environmental containinants what levels and consepuences of exposures they consider to be an "acceptable rlak" to their "lves, halth, or progeny's wellbelng - or to provide "inmple margins of eafel:y." A feal public involvement pollcy wlll requlre DOE :0 do so, ven at the rlsk of enormously increased costs to achlove the wlsislons with whlch the agency his been charged.

6. CORE VAluES: Deightiul words to see in a Dof document, but only is

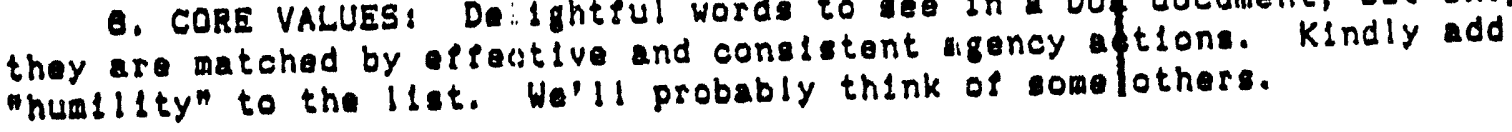

7. RESPONSIBILITIES: By "dlucrete pertormanoe ejement" DOE must clarliy that 11 stalt bear respeinelbllity for full ard eftec lve loplementation, not Just eenlor departmental and program managers. That ferm "etfectlve" should be

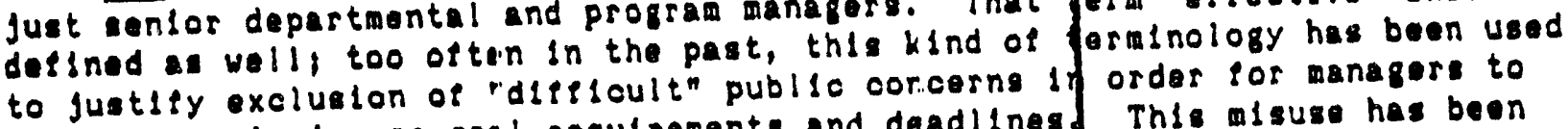
aest other miselon or gos.l requlrements and deadilnes. Thls misuse has been partlcularly offenslue to members of the public when frtiliolally-imposed deadlines (ilke thls janiary 4th oooment deadline) wede used to excuse the Department's iallure or Linwllilngness to tackle tough|lesues. The Dapartment 


$$
\text { Up to here! }
$$

Page Is (Comment on Public Involvement Pollcy)

has an obligation to alake very clear to the politidally motluated Congress the unresolved technical froblems and uncertalnties and length of time requlred for remedlation of contaminated DOE sites and facllitifs, the dismantiling of the nuolear weapons arsensl, and Implementation of technologles for the sate management of all radjoactive wastes generated in his past half century.

Although the goals of coordinating through thl ofilce of Public and Consuner Affalrs seem sensible, we are conciesned tat thls approsoh wlll be or Will become or wlll bu percelved as yet ancither "plbllc relatlons" glmmlek. The good ralth role ol senior Energy Department pofsonnel will have to be to keep a very close watih and be themselves cipen to ho publlo. Another PR program to "sell" the publle on DOE's earnestness flll not surtice.

In paragraphs 3-7 of thls polley description fection, we laud the wandatory language: "are responsible," "wtll ensure, " "are understood and practloed." The polloy atament should prescrlbe the consequences of pallure to ablde by these directlves; such tallure shisuld 80 lell beyond mere reprimands.

We turn nOW to MIIMORANDUM FROM THE SEIRRETARY: GUIDANCE ON IMPLEMENTATION OF THE DEPARTMENT'S PIJBLIC INVOLVEMENT POLICY, and raspectfully subalt the following additlonal somments and recommenidations:

A. At paragraph 1, state desinitively that puplic involvement ghall be a routine component in program operations, planning hetivities, and declstonmeking of the Department of Energy.

B. At paragraph 2, IIne 8, we hope thiat the Spcretary will also take measurea to ensure that the term "stakeholjers" will not be so narrowly dellned and applled as has been the case in the past. (Se comments above.) Clear guldelines on the breadth of the publics to be Invplved should be incorporated In the pollcy, rather than left to the dissretion bf those staff who have in the past iallod to be inclusive.

C. At Critlcal Pollcy Elements, Section 2, aq that access polnts sos publle input must be widely and timely notlced to encourage response. If the request for comment on thls pollcy had been timely lt would be exenplary. We belleve that the stalt does not take Into account the added burdens experlenced by members of the publla, whose lives are Illled with other jobs and obllgatlons, who do not have secretarlal assistance, why are not pald to revlew documents and devote time to preparing comments. We urge the secratary to develop means to sens!tlze DCE statt much more to these adpects of public involvenent.

D. At Section 4, we suggest the polfey staterent explicitly state that training/education programs aro not to be designed to woet the Departaent's percelved needs ( $1 n$ the PR mode) but are to satisyy the needs of the public whose Interests are effected by the Department's docisions and aotions.

E. At Section 5, we caution that a goal of ofnsensus in matters of radioactlve contamination and waste disposal 12 unseal gtic. We have deep concern that some suture Adminlstrations might chcose to fedirect these goals to manlpulato public Involvoment and cltizen partlol ation In ways detrlmental to the very public interests that this secretary is ttenpting to ald. 
F. Also at Sectian 5, we urge the Energy Depaltment to join NRC and EPA In providing toll-iree telephone and computer access o documents and other access polnts for parsons other than Nevada residents. That would be a useful expentlture of our tax dollarg, although, agaln, we onphislze that agency costconsclousness is of great luportance.

Members of the public do need IInanclal asglefance In order to attend DOE meetings and partlclpate fully as envislonid; but fovernmental agencles should arrange to keep those costs minimal -- no nore exp nsive hotele, no hlgh-cost locations; low-cost altarnatives can be arranged. Choose DOE meeting altes on the bages of energy cunservation and eftlclencles, Including both travel and the bulldings in whlch meetings are held. Use pub le meeting places of solar deslgn; digcourage walste in heating, cooling, or f forflclent bullding materlals and design. Agency parsonnel seem to be sol accust med to wastaful environments that they are unaware of, or unwllling to use, les expensive, more approprlate accommodations even 1:: such are avallable. It wou d be good for the Department to seek out and suppo:t small independent public afcommodatlons when and where posalble, rather than costly chaln hotels, to encolrage local small businesses.

Overall, the draft Guldance on Implementation of Pollcy 18 good, and It's sorely needed. It wuist be applied in all alvislon of the Department. We want to encourage the Presldent and VIoe-Presidint, the Secretary, and the Department itafs at all levils to continue to move away rom secrecy, from decoption, arrogance, and neglect of the publlc whom you were elected and hired to serve. This pollcy is refresining and ambltious. We want to to bo wildly successtul, beyond your dreams anis ours. But $1 \mathrm{t}$ must not be ufed to seduce members of the public into supporting surther commltment to the upes of atomlc energy or being torced to choose among unsale means of managing raploactlve wastes, or to accept hlgher expogurias to radiation, denial of juft compensation for injuries, or Incomplete remediation and restoration of contahinated ites.

We recognize that this public involvenent undpraking has potentlal for a huge waste of taxpayers' money -- as occurled, for example, with DOE' unsucceseful search tor a second $h l g h-l e v e l$ wast: repos tory and a volunteer community to take a Monltored Retrlevable Stolage fac|lity. Our country's broke, deeply in debt. Mr. Irumbly tells us elean-up wil cost $11,100,000,000,000$ or more. That is more tian $\$ 4000$ for each oni of us - for the ind 1 gent, the Intirm, the aged, the newborn bables, all. And thpse costs will sise disproportlonately as quantitios of radioactive iaterlal and waste continue to increase. That is only one of the major ruasons that the Department must bring to a halt the generation of more radioactive mater als and wastes, end adopt a pollcy of maintalning offectlve control in isolatipn srom the blosystom of all of the contaminated materials and wastes that have already been produced.

The secretasy wuist not allow any subordinates to mishandle these assigned responsibllities, or in any way to undermline this program to recreate basls for publlo truet in the Department of Enerily. But this pollcy is golng to become errectlve only when, and $1 \mathrm{f}$, the Congress rep aces the Federal andate to promote nuclear energ: with a upreme objective to provide maximum protection trom radiation to proinote health, sapety, und onvi fonmental qualstyi is the entire agency has refirmed and proven its dedicatibn to that latter mandate; 
Page elght (Coment on Public involvement Polloy)

18 the generation of addltional quantftles of radipactive aaterlals and wastes has ceased; and the Dipartment of Energy hus domon trated Its orlginal reason for belng: nawely, to provide thls natlon with an hergy pollcy based on conservation, offlolenoy, and alternatlve renewabl sources -- energy that is cape, olean, and sugtalnable. That linal goel wil require vast changes in Amertcan soclety and values, wany sacrlslcris, perhlps sowe pain and dislocatlon. But a pollcy of public Involvement in seekl 8 the solutions that will be required is worthy, Is desperately noeded, and will be welcomed.

Although our comalents may seem harsh (as well las redundantly repotitlve), they're meant to be pesitive, supportive of the changes that, at long last, the Department of Energy is proposing to adopt. Please know that our organization and others in environmental and public health comminlties will do overything we can to further the Improvements that the Secretary has proposed, but we'11 also remain your sternest oritics it you waver.

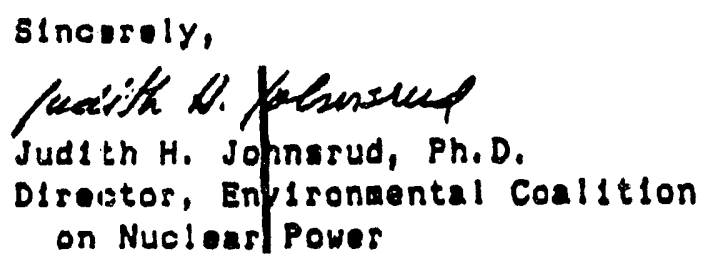

For Identisleation purposes onlys

This commenter has served In 1992-3 as Chaly of the Slerra Club Natlonal Energy Commlttel, and expects to remain un 1ta Nuclear Subcomaltteas and is an Honorary Truateo of the Now England Coalstion on Nuclaar Pollution 


\section{LABORERS' INTERNATIONAL UNION OF NORTH AMERICA}

Kenneth D. Smith Secrotary-Treasurer and Business Manager
LOCAL 872

AFFILIATED WITH THE AFH-CIO

1200 EAST BONANZA ROAD

LAS VEGAS, NEVADA 89110

(702) 452.4440

FAX 452.4262

80
George Dunckhurst

President

and Field Agent

December 27,1993

Mr. Allen Benson

Director of Program Relations Division,

office of Civilian Radioactive Waste Management

1000 Independence Ave., S.W.

Mail Stop RW 5.2

Washington, D.C. 20585

RE: Draft Public Involvement Policy

Dear Mr. Benson:

I have worked directly with a D.O.E. contractor for quite some time now, and may I say, your core values are long overdue. However, you have to start somewhere and I commend you on starting with this draft policy.

I feel it will be difficult for management to be open, honest, and sincere. They are use to the "pass the buck" system. However, you have many outstanding people in your organization who can and will meet the challenge.

I also feel training is the key to all organizations. You may want to consider the implementation of free training seminars to represented and unrepresented parties.

The Yucca Mountain Project Labor Agreement, if negotiated and singed by D.O.E., will show sincerity and honesty, as well as all other elements described in your draft policy. Show your sincerity by sitting down and negotiating this agreement with us.

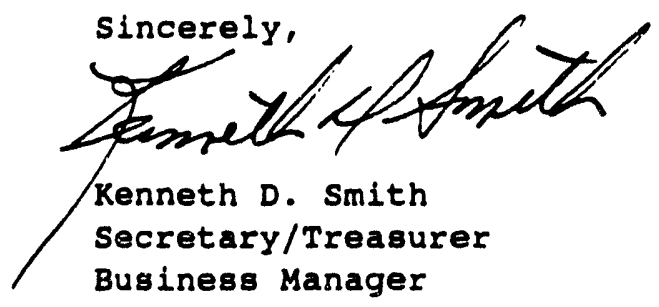

IDS/a Iw 
December 27, 1993

Jerry Saltzman

Director

st Ham Werlin::.. Department of Energy

Office of External Relations

$1, \ldots .1 \mathrm{in.} \cdot 1$

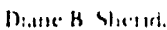

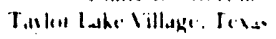

Washington, DC 20585

Dear Mr. Saltzman:

Proin lut

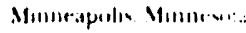

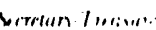

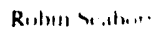

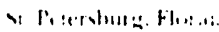

In..... I'،: $B_{1} \ldots$

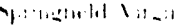

Yortine t fis

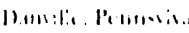

$1.111 \times 1 . .1: 1$

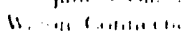

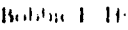

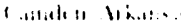

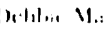

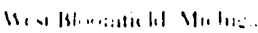

Bull, h Wh hi.

II I., If

1 111.. 11, .

1..... V. 11.

$\backslash \therefore, i, \ldots$

I $14.1,1$.

1..., $11 \ldots 11$ :

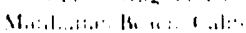

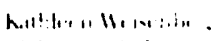

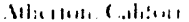

twutu, lu. C.161.1 V H: ...

Thank-you for the opportunity to review your public participation plan. Overall it seems comprehensive, with one omission.

You should specifically address diversity issues throughout the overall document. It is not enough to simply use such terms as "respect for all positions" or "stakeholders." The set of stakeholders that are traditionally up front: industry, environmentalists, local communities, the states, already occupy the psychic space these words offer. If you don't directly address these issues at the senior level, your field staff will not have the tools and training they need. The issues will be skirted and this will lead to problems in the future.

The diversity issues of most significance to your program are ethnic, racial, tribal, gender and income. Respect for diversity should be one of your "core values". A "policy element" and a set of "implementing actions" should be developed. The topic is a tough one and people have a hard time dealing with it. Fear and prejudice are hard to overcome but much can be achieved if the right resources are brought in.

I'm sending you a copy of two recent issues of the National Voter, the membership magazine of the League of Women Voters that addressed diversity issues.

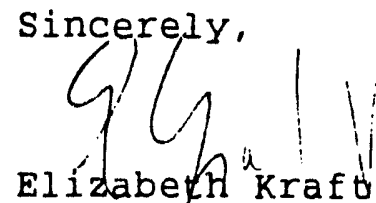

Manager of Natural Resource Programs 


\section{Mr. Allen Benson}

Director of Program Relations Division

Office of Clvillan Radloactivis Waste Management

To: Mr. Allen Benson

From: Ellzabeth I. Bauereis, Ph.D

Director of Environrnental Affairs

Subject: Department of Energy's Pollcy on Public Involvement

Thank you for the opportunity to comment on the proposed policy. I am responding at the request of Mr. Christian H. Poindexter, Chairman and Chief Executive Officer, Baltimore Gas And Electric Company who received the letter from Mr. Jerome Saltzman.

I have only two mincr comments on this proposerd policy. In the memorandum entitled "Guidance on Implementaticn of the Department's Public Involvement Folley" under the Section 1. CRITICAL POLICY ELEN ENTS, Imolementing ections:: -- The new benchmark for excellence will be lesdership/performance.....the two statements that follow do not fit the benchmark qualities for excellence. Ceitainly, risk-taking is importart but by liself without any other supporting benchmark criter $a$ is rather frightening and to reward risk-taking for the act alone is definitely not excellence. Purhaps, this statement should be modified or part of a larger set of excellence benchmark parameters. The second statement concerning peer review should be strengthened to read ".Peer roview should be the rule anid lack of peer review should be justified." Scientific serutlny is imperative for scientiflc escellence in decision making.

igain, thank you for the opportunity to comment.

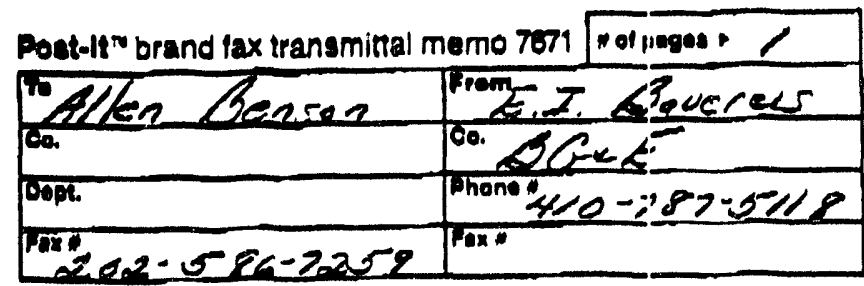

Elizabeth I. Bauereis, Ph.D

Director of Environmental Affairs

Baltimore Gas and Electric Company 


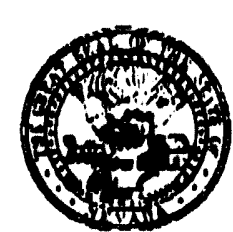

\section{AGENCY FOR NUCLEAR PROJECTS NUCLEAR WASTE PROJE:CT OFFICE \\ Capitol Complex \\ Caraon City. Nevada 89710 \\ Telephone: (702) 687.\$744 \\ Fax: (702) 687.827?}

\section{HEORARDOA}

TO: Allen Benson

U.S. Departiment of Energy

FROM: Joe strolin

DATE: December 29, 1993

suBJECr: Draft Publi.c Involvement Pollcy

We are in recelpt of Jerry saltzman's letter transmitting DOE's draft Public Involvement Policy for comment. This office intends to provide comments.

The comment deadline of January 4, 1994 does not provide sueficient time to seview the document and develop appropriate comments, especially since we did nct receive the draft until December 27, 1993. We are therefore asking that the deadilne be extended at least until January $14 \mathrm{th}$. In any case, the state of Nevada comments will not be submitted before the 14 th.

Thank you for your attention to this matter.

JCS/js

cc Bob Loux 


\title{
NEVADA NUCLEAR WASTE TASK FORCE, INCORPORATED ${ }^{7}$
}

\author{
Alamo Plaza \\ 4550 W. Oakey BIvd. \\ Suite 111 \\ Los Vegas, NV 89108 \\ $702-878-1885$ \\ FAX 708-878-0832 \\ $800-227-9809$
}

December 29, 1993

Jerome Saltzman, Director

Office of External Relations

Department of Energy

washington, DC 20585

Dear Mr. Saltzman,

The December 17, 1993 draft copy of the Department of Energy's (DOE) new public involvement policy arrived at my office on December 23, 1993, with a request for comments to be provided by January $4,1994$.

Public interest participants in general and especially Nevadans have come to expect difficulty in participating in meaningful ways in DOE policies and decisions that vitally affect their lives, their children and their future. Probably the best recent example we've seen of this elusive process is the comment period for this document. Our opportunity for submission of comments amounts to four business days or less - in the midst of the holiday season.

Ever since Nevada was painted with the waste repository target sign, we have been requesting, insisting and demanding more access to the DOE process and a greater degree of fairness. We were vocal at all of the secretary of Energy Advisory Board meetings focused on public trust and confidence. The consistent message was that we were not treated as a genuine, important or equal entity in the process. After years of meetings and testimony, the board's report is to be delivered to the Nuclear waste Technical Review Board next month. It's safe to assume that it will recommend giving the public adequate time and opportunity for significant participation. Public interest representatives will be surprised if this message is ever heard and comprehensively enacted by DOE and the office of Civilian Radioactive Waste Management. 
I have frequent dealings with many government agencies, especially DOE and related entities. It is unusual when I am able to get a simple answer to a simple verbal question by phone or fax within four days. I've never asked DOE to comment on any written proposal or policy spawned in my office but it would be enlightening in many ways to do that, especially to note the time factor that would no doubt be required.

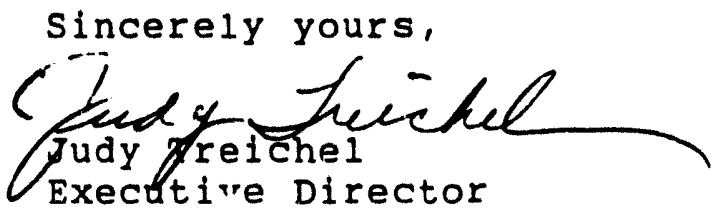

CC: Daniel Dreyfus

Allen Benson 


\author{
UNITED STATES \\ NUCLEAF. WASTE TECHNICAL REVIEW BOARD \\ 1100 Wilson Boulevard. Suite 910 \\ Arlingion, VA 2.220?
}

December 30, 1993

\author{
Mr. Allen Benson \\ Director \\ Program Relations Division \\ Office of Civilian Radioactive \\ Waste Maragement \\ Department of Energy \\ Washington, D.C. 20585
}

Dear Mr. Benson:

Thank you for forwarding a copy of the Department's new policy on public involvement, which we received on December 23 . While we appreciate your desire to receive comments by January 4, there is not enough time for the Board to review this document, particularly with the holjdays upon us. We are, however, including it in the Board's briefing books as an information item at their January 10-12 Board meeting. Should the Board have any comments to make following this meeting, we would be happy to forward them to yciu.

The Nuclear Waste Technical Review Board is specifically charged with providing scientific and technical revie's of the OCRWM program to characterize the Yucca Mountain Site. Consequently, the Board has not been significantly involved to date in studying or reviewing policie; or processes addressing; public involvement. Based on our four years of experience, however, the Board has stated its belief that scientific and technical credibility and public acceptance must both be present in any project to site a permanent underground repusitory. In this spirit, the: Board applauds Secretary O'Leary's efforts to create a more open environment at the Department of Energy. We will be particularly interestec' to see how OCRWM iraplements this policy in its efforts to scek stakeholder involvement.

Thank you for this opportunity to comment. 'We look forward to receiving your draft report from the August 10, 1993 stakeholders workshop.

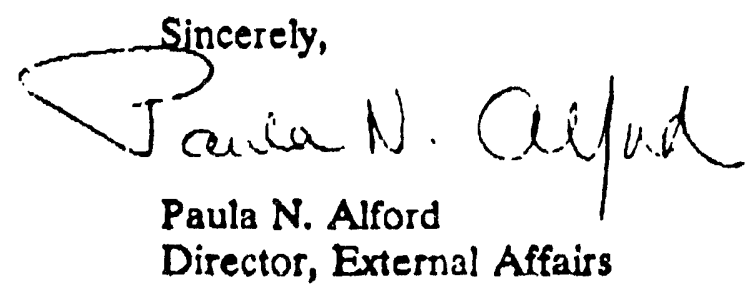




\section{UNITED STATES}

NUCLEAR WASTE TECHNICAI, REVIEW BOARD

1100 Wilson Boulevard, isuite 910

Arlington, VA 222:J9

January 3, 1994

Via Fax: $202 / 586-7259$

Mr. Allen Benson

Director of Program Relation3 Division

Office of Civilian Radioactive' Waste Management

U.S. Department of Energy

Washington, D.C. 20585

Dear Mr. Berson:

Thank you for inviting rne to comment on the draft of the Department of Energy's draft policy on public involvement. I am responding as an individial who presently serves on the Nuclear Waste Technical Review Board (NWTRB). In view of the response deadline of January 4, there has not been time for NINTRI to discuss the draft policy on public involvement. I concur with the comments provided for the NWTRB by Paula Alford. The additional conments provided in this letter represent my ow'n thinking, based upon r.ny professional work in the field of risk analysis.

I strongly support the draft policy and its goals as stated. DOE should have a policy of involving the public in its program operations and planning, at headquarters and in the field. Particularly in the area of radioactive waste management, DOE has very serious problems in establishing and maintaining public trust and confidence. The cultural legacy that has led to these problems is succinctly summarized in the "Background" section of the draft policy. The final report of the Secretary of Energy Advisory Board (SEAB) Task Force on Radioactive Waste Maragement, "Earning the Public Trust and Confidence: Requisites for Managing Radioactive Waste," provides a much more detailed discussion that is specific to OCRWM. The National Research Council (NRC) Report, "Improving Risk Comrunicalion" (1989) provided its viewpoint on OCRWM, concluding:

Given the knowledge today of the cavalier treatment of facts concerning its activitics in the past and the tremendous opportunity for uncertainty to enter its analysis and for its analysis to be akewed, the DOE faces tremendous credibility difficulties.

I attach a copy of the full paragraph on page 120 from which this sentence is taken. (While I was a member of the committie that authored this report, I was not present on the day that Tom Isaacs and Ben Ruche made their presentation, and I will not claim authorship for the words on 
Page 2

page 120, which were writter before I became a member of the NWTRB.) I cite these words as evidence that $O C R W M$ has ar extreme credibility problem, which has perhaps improved slightly over the past five years. I enidorse both the NRC report and the SEAB report as a useful start towards diagnosis and describing methods for ameliorating this problem. I urge that both documents be read carefully by senior OCRWM managers as part of implementing the draft policy on public involvement:

Given the severity of the problem, the achievement of the goals in the draft policy will require a commitment to cultural change by senior management, "special attention and leadership from the top down" as stated in the "Background" section of the draft policy. The Director of Public and Consumer Affairs can provide useful coordination and training, but should not inhibit initiatives or delay the public involvement process. This office must not be perceived as a traditional public relations function or as an impediment to improved communications between DOE managers and the pülic. The needed cultural change must occur with individual headquarters and field manakrers and their staffs. Acccmplishing such a cultural change will be a great challenge to these inc.ividuals and to DOE as in organization.

NWTRB has provided throughh its meetings a public forum for critical review of the technical aspects of the Yucca Mountain Project and of storage and transportation issues associated with spent nuclear fuel and high-l $\epsilon$ vel nuclear waste. As a member of NWTRB since its inception five years ago, I am proud of our contribution toward encoviraging public involvement in OCRWM's activities. I believe that the nuembers of NWTRB will vrelcome further opportunity to comment on the details of how OCFIWM can accomplish the goals of the draft policy on public involvement within the area of NWTRB's statutory authority.

Sincerely,

D. Wammen korte

D. Warner North

Member, Nuclear Waste Technical Review Board

Past President, Society for Risk Analysis

Attachment 
surrounding the ovents at IJove Canul, the result was considerable controversy'. Five independent revitws of the chromosome study were submitted to the EPA, two requested by federal agencies and three by the scientist conducting the study. All emphasized the limited infigrences thet could be drapin due to the lack of a control group. The reviows commisaioned by federal agencien criticized the interpretation of the data on chromosome damage in the study, while those requested by the scientiat conducting the study were more favorable concerning the data interpretation. Although this example is extreme. scientific studies are subject to strict examination of their methods of date collection and interpretation. This examination is usually severe when the atudies are used to support controversial public policy decisions.

\section{Reputation for Deceit, Misrepresentation, or Coercion}

Perhaps the most difficult problem for credibility is a past record of decoit, misrepresentation, or coe:"cion. For example, as was acknowledged to us by officials from tibe U.S. Department of Energy (DOE), one of the biggeat problems confronting the civilian radioective wastu program at DOE is the legacy of the Atomic Energy Commission and oven earlier government programs (Laacs, 1987). The attrilsution during the 1950 s of fallout in St. Louis to Russian sources when in fact it was known tol como from tests in Nevada was a blatant abuse of public trust, the repercusaions of which the DOE must live with today. When the responsible government organizations havi been proven to lie, it is not surprising that people want independunt verification. One year of being honest with the people is not enc ugh. Given the knowledge today of the cavalier treatment of facts concerning its activities in the past and the tremendous opportunity for uncertainty to enter its analyses and for its analyses to be skewed, the DOE faces tremendous credibility difficulties. Even the slight est indication of less than complete candor and honesty will probably lead many people to rejer:t whatever position the agency takes. Given the highly politicized isoues that DOE's program addresses, this legacy adds to an excerdingly difficult challenge.

The aituation is somewhat diffierent for nongovernment organizations. Private corporations, advosacy groups, and private citizens are commonly expected to interpret the facts of the aituation in ways that support their aims and goals. This is part of the reason corporationll and their messages are cliatrusted. Despite the difficulty 
Dear Mr. Benson:

At the request of our Chairman, Mr. Jamus J. O'Connor, I am providing comments from Commonwealth Edison Company in response to the inquiry from Mr. Jerome Saltzman dated December 17, 1993. We appreciate this opportunity to comment on your draft Policy on Public Involvement in the Civilian R:dioactive Waste Program. We support the view that timely, credib.e, and effective public involvement in the Civilian Radioactive Waste Program should be a goal of the Program Office. The timely and effective consideration by the Program Office of the full range of diverse stakeholder viewpoints and values produced by public involvement, should enhance decision-making by the Office.

However, the Office of Civilian Radioactive Waste cannot be expected to address all inpuls that the public has already or may in the future tender. While public involvement and effective on-going comsnunication with the various interested stakeholder groups should receive a high level of attenion by all decision-makers in the Program Office, effective public involvement will not substitute for effective decision-naking in the Program Office..

As you are doubtless aware, there is a Corigressional mandate to complete the development and deployment of a civilian high level waste repository in a safe and timely manner. In fact, the Department of Energy has contracted with my Company to begin accepting high level waste for disposal in 1998. Our nuclear facility operations and our Company financial planning relies on the Program Office fulfilling that contractual obligation.

As an interested stakeholder in this issue and as a Corporate citizen representing the interests of our rate payers, we support a policy of timely, credible and effective public involvement. We also strongly urge the Program Office to meet its contractual obligations, using inpul from the public in support of timely and effective decision-making. 
In this regard, wis strongly recommend that you include the concept of timeliness of decision-making in the public involvement policy. Furthermore, we strongly suggest Goal III be reworded to assure there is clear acknowledgernent that the Department will retain accountability for and be forused on timely decision-making. The implication of Goal III, i.e. "empowerment (of the public) to participate in Departmental decision-making, " may be interpreted as creating a "consensus" decision-making process that may be impossible to achieve, and which is not contemplated by the Nuclear Waste Policy Act, or legislative history of The Act.

If we can be of further assistance in refining this policy recommendation, or in any other way to support the effective performance of the Office of Civilian Radioactive Waste, please contact me directly.

Very truly yours,

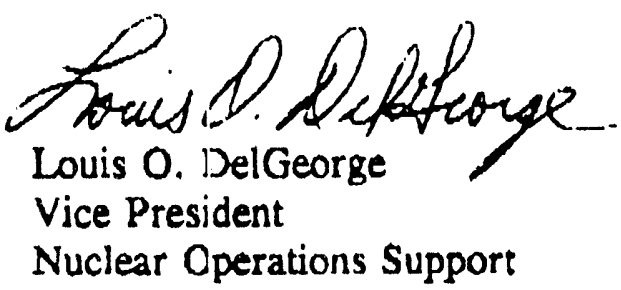

cc: J. J. O'Connor 


\title{
January 3, 1994
}

\author{
Mr. Allen Benson \\ Director \\ Program Relations Division \\ Office of Civilian Radioactive Waste Management \\ U.S. Department of Energy \\ Washington, D.C. 20585
}

Dear Mr. Benson:

I am writing in response to your invitation to share our views on the new public involvement policy developed by the U. S. Department of Energy (DOE). We are supportive of that policy, and are convinced that greater public and stakeholder involvement is vital to the success of the civilian radioactive waste management program.

As the policy statement recognizes, the weak commitment of DOE to public involvement in the past can be traced to the origins and mission of the agency. It is hardly remarkable that an agency whose primary mission was production of nuclear weapons during the Cold war would display a decided lack of enthusiasm for public involvement in its decision-making. The secretary and staff of DOE should be commended for this and other steps it is taking to change the culture of the agency to adjust to new missions and new realities.

The program that can perhaps benefit most from this new policy is the civilian radioactive waste management program. Missteps taken by program management created the perception by many Nevadans that DOE is not open to public views, that there is no role for the public in decision-making, that information is not shared and that the rules that govern public participation are unfair. To the extent these perceptions have fostered public support for bitter opponents of site characterization and encouraged litigation, program delays can be attributed to the failure by DOE to establish a credible, effective process for public involvement in the civilian radioactive waste management program.

We believe this new policy has potential to reduce the level of hostility and suspicion by citizens in Nevada, and instead, foster the belief that DOE is open to their views. At present, some citizens in Nevada believe that the only effective form of public participation in the program is litigation. They must instead be 
convinced the most effective means of participation is involvement in the DOE decision-making process. The timing of public involvement is also a crucial factor. To the extent that public participation is strengthened at earlier stages in DOE's decisionmaking process, there may be less frequent resort to litigation and other procedural tactics, and the many delays that have marked the history of the program may not recur.

The public involvement policy also envisions reinforced contacts with stakeholders in the civilian radioactive waste management program other than Nevadans, such as electric utilities. This is equally important, since on certain key policy issues related to the program, utilitis do not share common views.

As a final note, we are aware that bureaucracies in both the private and public sector are often resistant to change. It is vital that this important policy be effectively implemented.

Thank you for the opportunity to comment on the draft policy.

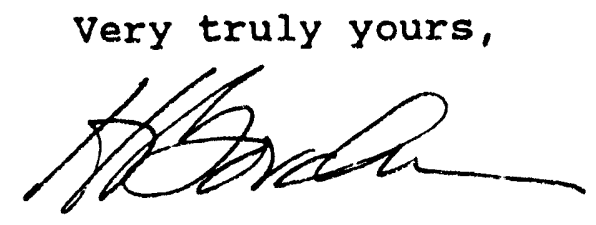


January 3, 1994

Mr. Allen Benson

Director of Program Relatior:s

Office of Civilian Radioactive Waste Management

Department of Energy

Washington, DC 20585

Dear Mr. Benson:

This is in response to Mr. Saltzman's letter of December 17, 1993 which requested comments on a draft DOE policy on public involvement. The following comments are offered:

1) The policy should specifically recognize the need to seek the full range of diverse public views. This is perhaps the most difficult aspect of implementing the policy. It will be easy to allow a few individuals claiming to represent the public to provide an unbalanced view. The policy should require specific attention to assuring a balance of diverse views and determining how representative each view is.

2) In the proposed statement by the Secretary - the second item under Implementing Action could be improved and made more directly consistent with the policy by inserting "to" between listen and, and inserting "incorporate or" between and and respond. The item would then read:

"Department officials will routinely and consistently listen to and incorporate or respond to public input."

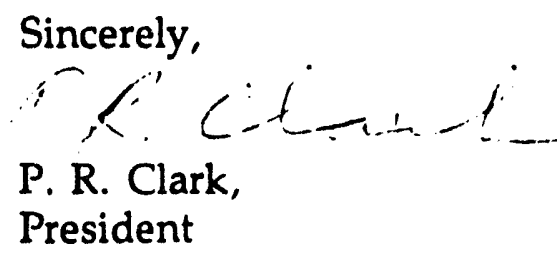

Imes

cc: Prs. C. Clawson - Director, Communications (GPUN) 
Northern States Power Company

414 Nicoiel Mall

Minnearalis Minnesota 55401-1993

Telepnone 1612$) 330.7707$

January 3, 1994
James J. Howard

Chairman and Chiel Executive Officer

Mr. Allen Benson

Director of Program Relations Division

Office of Civilian Radioactive Waste Management

U. S. Department of Energy

1000 Independence Avenue S.W.

Washington, D.C. 20585

RE: Public Involvement Policy

Mr. Benson:

Thank you for the opportunity to comment on the DOE's proposed Policy on Public Involvement. An effective external relations policy is an essential element of any business strategy having a material public impact. We believe the proposed policy codifies the Department's current community relations practices under this Secretary. Moreover, the policy has appropriate goals, strategies and responsibilities necessary for its effective implementation.

Proper presentation of information is critical to encouraging meaningful involvement. In particular, the formulation of alternatives, the communication of risks and a framework for evaluating the information are all essential elements of a public involvement policy, especially in licensing or policy matters. I recommend that the training component of this policy specifically address the importance of the type and timing of information intended to be provided to the public. 
Allen Benson

Department of Energy

January 3, 1994

Page 2

I would also recommend you specifically address how the agency will use the public's involvement in its decision making process. Careful use of public involvement has been shown to enhance the chances for a successful outcome by developing alternatives and encouraging future public participation. At the same time, the use of public involvement in the decision making process should not serve to unnecessarily delay decisions or impair the effectiveness of the Department.

We look forward to the continuation of public involvement in DOE's decision making process. Please contact me if we can provide any additional comments.

Sincerely,
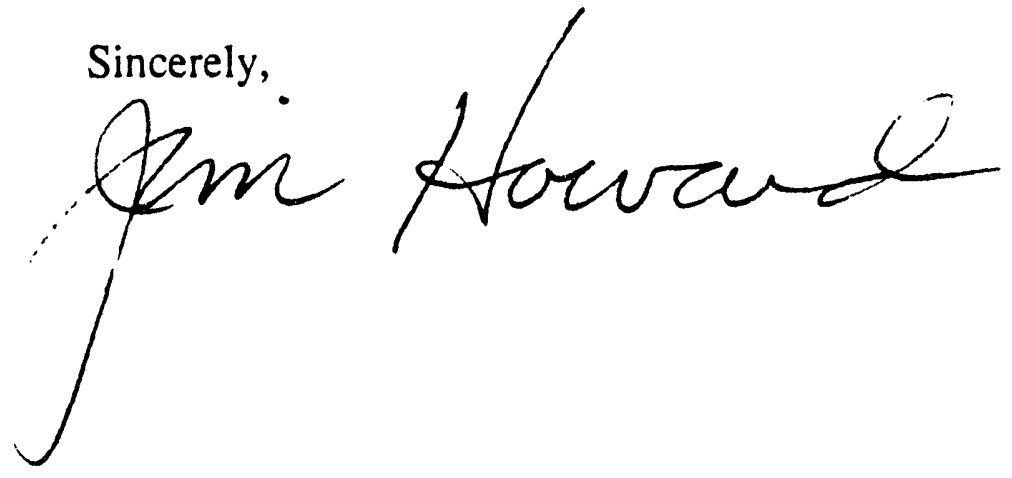


\title{
NIRS NUCLEAR INFORMATION \& RESOURCE SERVICE
}

\author{
1+2t 16th Street NW Siste 601 Washington, DC 20036 \\ voice (202)328-0002 fax (202) $+62-2163$
}

Submitted by facsimile $1 / 494$

To: Allen Benson, Director of Program Relations

OCRW.M, L'.S. Department of Energy

Washington, DC 20585

From: Mary Olson, Radioactive Waste Project

Nuclear Information and Resource Service

Re: Draft DOE Policy on Pub ic Participation

Dear .Mr. Benson.

I have been asked to comment on the Department's Draft Policy on Public Participation. If I take this invitation and the manner in which it was proffered as any indication of what the Department means by "participation." I am not rery hopeful about the meaningfulness or immediate success of this proposal..

It is helpful to be notified, to receive the proposed Draft ?olicy to my attention. however the notification while very friendly and informative -- signed by Jerome Saltzman. dated 121793 -arrived on Christmas Eve. The comment deadline was fixed as January 4 . This allowed me at best 4 working day's to comment on the document. This is less time than I allow a co-worker to review a major position stater ent within my own office! On checking with colleagues who are concerned with OCRWM progsrams and who have an interest and have regularly participated. it is somewhat of a mystery why some people received the draft policy and others did not.

I do take this opportunity to comment on the Draft Policy as a form of public participation -- an extremely vital one which must be done well. If you could at this point establish an open and credible process it would become the foundation for all that follows. Issuing an invitation that arrives just before the major holidar's observed in this culture and then requiring inmmediate response does not create such a vehicle. In fact. it sugge its just the reverse: an extraordinary piece of timing to preclude, exclude and obviate participation.

To be open and credible the dipartment would have needed to: Publish the proposed policy. The Federal Register should be viewed as the barest minimum -- rery few members of the public have access to it, or even know of ir -- but provides an outlet cf sorts. For a major policy such as this. focused on the public and integral to the effort to change the DOE 'culture' of secrecy. it would be important to seek the wider press as well. A mix of straight journalism and the critique of the altermative public interest sector press would be an extrer.1ely interesting change. This would be 


\section{NIRS Comment $1494 \mathrm{pg}-2$}

for the duel purpose of puttin!n out the word that 'things are changing' and also to notifi. a broader public about how to get a cop! of the draft policy and thi: length of the comment period.

The comment period on an important policy such as this one should be a minimum of sixty day.s-preferably 90. This allows some opportunit for the organizations and groups that are affected and those that are broadly concerned. to utilize their own network and communications structures to allow an even wider range of people to participate in giving in-put on this pirotal policy which will affect them as members of the public

The Department also needs to reach out to the individuals and groups that have already made the effort to participate eren before any policy comes from the Department itself. I see that this has been done to the extent that it was mailed directly to me. and a few of my colleagues. It is not clear what system was used to identifi those who receive it. or that it is a comprehensive distribution list that encompassies all of the current "stakeholders."

I applaud the Department in making the effort to "open the doors" and address the issues of culture in as large an entity as the Department of Energy: It is vital that these steps are taken. at the same time. it is meaningless to simply posture.

While it is understandable that there must be a broad policy statement upon which specific articulation and implementation rest. it is rery. difficult to take such a broad statement with no definition or example of its application and expression. The stated policy opens the door to real concems about acccuntability .- when will the Department say that there has been 'public participation.' when in fact. there was 'stakeholder' participation which reflected only the financial interests and gave no concem ithat-so-erer to equity issues. environmental justice.

inter-generational responsibilits. etc. There is not defined mechanism for accourtability of who has had the opportunity to evel know about the Departm ent's plans. let alone access to the levels of participation that some stakeholders may enjor. Perhaps there is a way to work this out. but in the "Definition" section. there "rould seem to be a fairly large mandate to simply. 'play it by ear.' Who's ear?

Perhaps the ker here is in the phrase "actively seek." I would strongly recommend a proactive articulation of "actively seek." It is time and past time thet the Department pay closest attention in setting new policy and making decisions to those who are already most affected by the Department's current program:i. I would urge the Departnent to rethink the apparent interchangeable use of the termis "stakeholder" and "public." This is not appropriate. stakeholder might be appropriate for sorting out issues among contrastors and other agents such as States. It is not appropriate to delegate the people of this country to tieing one or a small number of 'interests' who are then made stakeholde-s on "equal" footing with for-profit corporations who stand to win or loose financially. The dollar should not be the mediun: of exchange in policy making that has the potential to affect the future of the planet. Here. people. ordinary people's roices must be heard on the same terms as the Declaration of Independence. Indeed. the actions of the Department do affect the lives. the libertr. and the ability to pursue happiness of the citizens of this land. This is what a polic about Public Participation must be about. I see little recognition of this understanding in the Draft Policy: 


\section{NIRS Comment $1494 \mathrm{pg}-3$}

Certainly an open door is the first step. In-put on decisions may in fact begin to effect change. if in fact those who's voices are clear have the opportunity to be hears. Nonetheless. from the broad swath. one feature which is obvious for its absence is any mention of recourse or appeal for the public once a decision has been made by the Departmenti with or without 'participation.'). W'e are invited to imagine benerolencs: but it is still a case of absiolute rule without the possibility of hearings -. which must be full. adjudicatory procedures (not to be confused with a public meeting). judicial review of kiy decisions all clearly spelled out such that the Department is no longer the sole arbiter of Department decisions. Finally. there must be the provision for citizen suites that are vital in the situation where the stated polic:' and the actual implementation situation diverge and efforts to seek reniedy from the Deparment fail. This is necessary to put out front.

In the Goals section. it is stated that "a clearly defined coherent decision-making process with known access points for public involvement is routinely followed." This is great. How will this be accomplished? will it be unique to each branch of the Department? To each policy maker? How will orerall accessibility be acisomplished? "...public is empower to participate in Department decision-making" this is only rneaningful if. in fact. there is recourse to an independent authoritr.

In order for truly meaningful frarticipation to happen. it becomes necessary in the highly technical nature of much of the issues the Department is involved in. for there to be a level of support provided for the public and inclependent researchers in order to be able to fully join in the dialogue. Some level of facility and technical assistance grants should be mandated as a Tational Endowment for the Social Responsibility of Nuclear Science... or some other moniker. There could be a range of programs. Extemal. peer-review grarts are needed for community-based projects in affected and potentially affected areas -- granted outside of the channels of those considering such programs (IIRS. IIPC. etc.). There are a number of teclunological resources such as the fly-orer monitoring helicopters that could be made available for independent project much as the space shuttle serries many projects. The possibilities are endless. Many affected communities have their own p:oposals and others will soon. These comments are not intended to override those of any other parti on the profile of this idia.

The bottom line is that although the dollar must not be this medium of exchange. unless some of the taxpayer dollars are deroted to supporting the taxpay'er's in-put. the unfair burden placed on affected communities is compisunded repeatedly. As those members of the general public who have bome the burden of impact from DOE facilities -- or will in the future -- they are the few. who are "activated." They have leamed bout the issues and concems not because ther wanted to. but because they had to. Now they are invited to 'participate.' If they choose to. it is at their own expense or with nominal support for travel or personal expenses. Mlost of these folks participate because they feel a sense of moral obligation to the peop.e of their country: who ther represent. not by choice, but because if they are going to be rictims. they may as well make their roice count. DOE. now is your chance. One level of true change would be to create a sy'stem of real. fair support for affected, and fotentially affected individuals and communities and their representatives. Indeed. some level of resource should be available to those who are muly "members of the public at larg z" any. of whom it is truly. in their interest at citizens to participate in affecting the course of the Deprartment. 

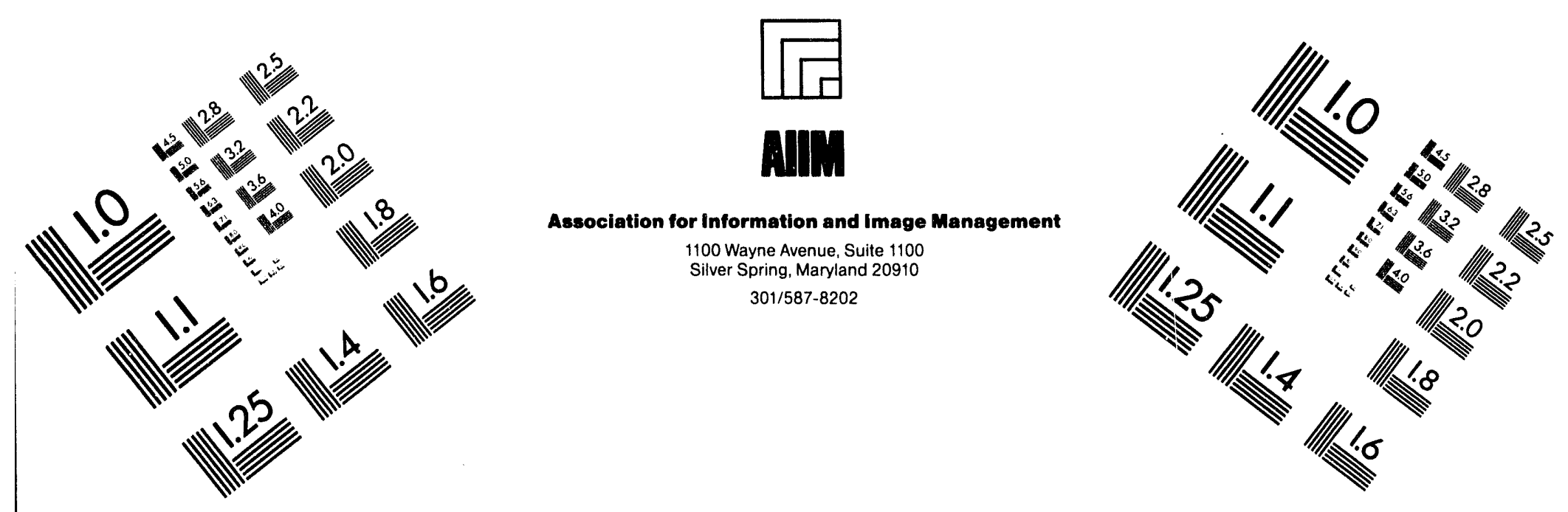

\section{Centimeter}

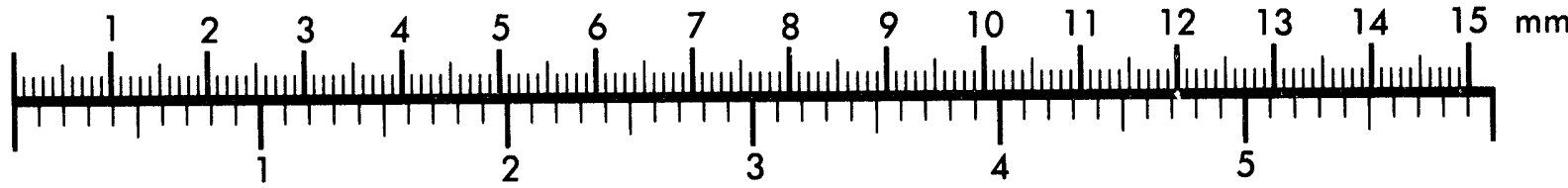
Inches
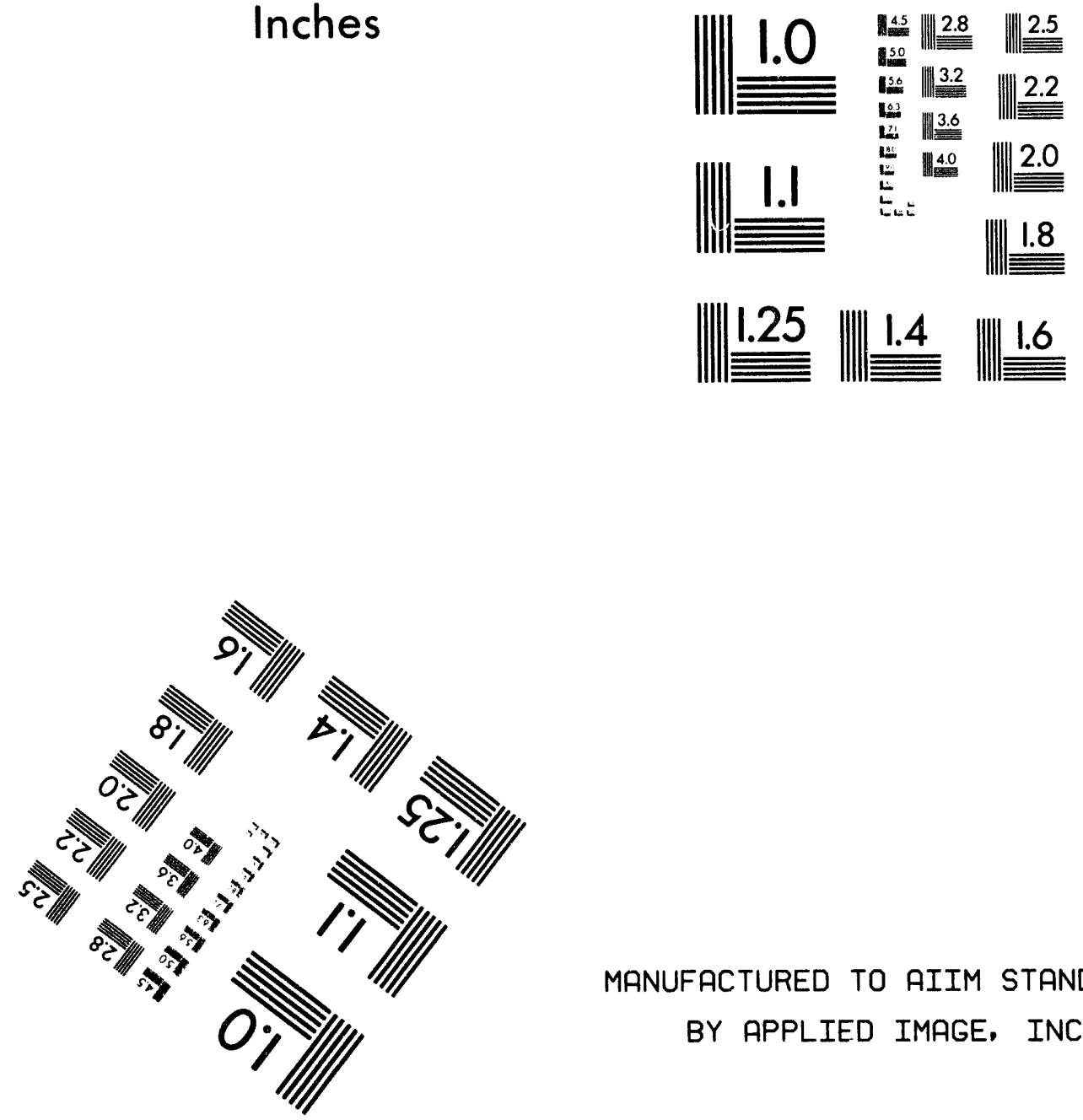

MANUFACTURED TO AIIM STANDARDS

BY APPLIED IMAGE, INC.

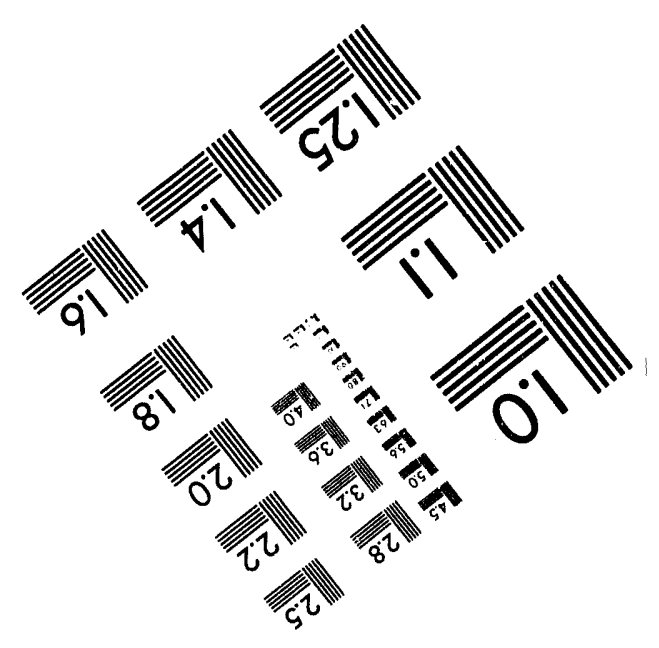



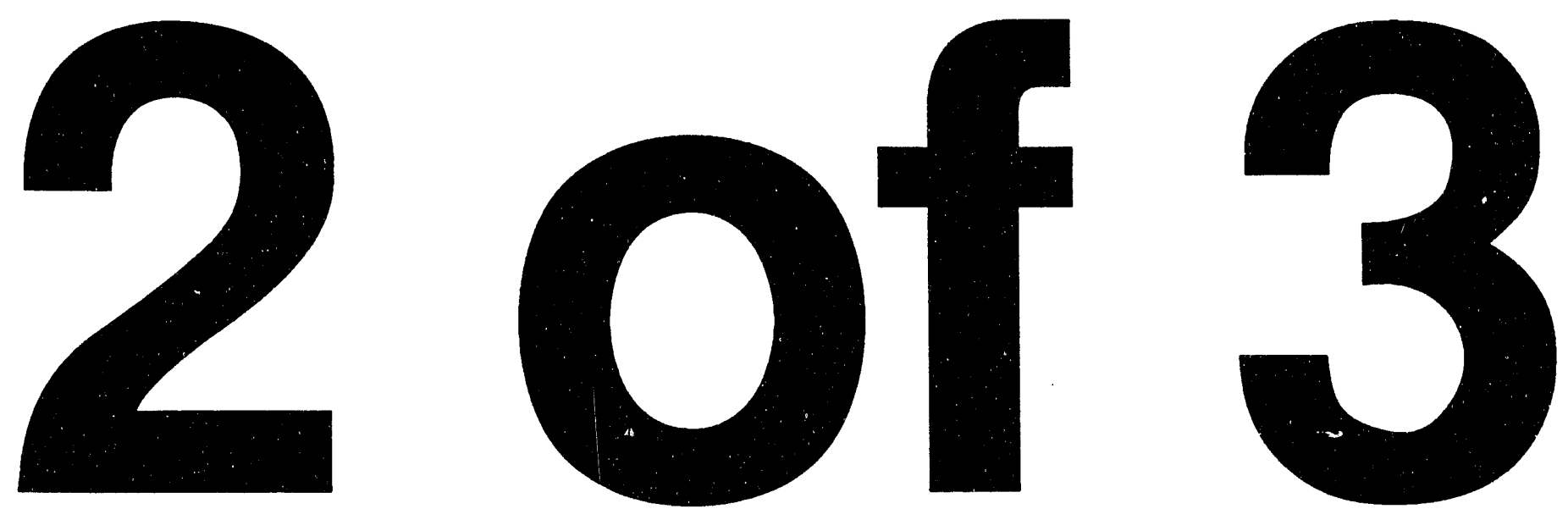


\section{.IRS Comment 1:4 94 pg-4}

In order for such funding to be credible, it most likely should be issued in block to an independent. perhaps "stakeholder" board that would be bound by ethiss rules and policies that uphold the rights of the Constitution for distribution.

I question that the Site . Manager is the right agent to med ate betwieen local and national interests. What about local and state officials?

I sincerely hope that these brief and somewhat hurried comments are useful to you. Next time have the courtesy to offer me al least a few weeks. I an certian that you enjoy a larger staff, and yet I rather think that you would have trouble honoring a 4 day turn-around if our positions were reversed!

In Cooperation,

Mar. Olson

Radioactive W'aste Project 


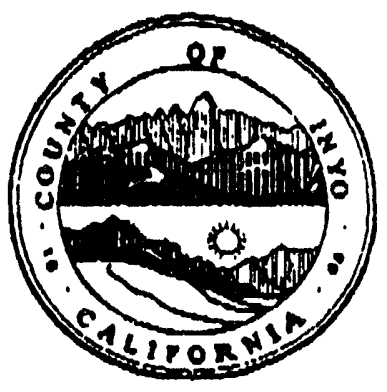

\section{COUNTY OF INYO PLANNING DEPARTMENT Yucca Mountair Repository Assessment Office \\ P.O. Drawer L, Indeperidence, Califomia 93526 \\ Telephone (619) 878-0380 FAX (619) 878-0382 \\ Brad Mettam, Project Coordinator}

January 4, 1993

Mr. Allen Benson

Dircetor of Proyram Relatioris Division

Office of Civilian Radioactive Waste Management

U. S. Department of Encrgy

Washington, DC. 20585

Dear Mr. Benson:

Listed below are my commints on the Department of Encrgy's new public involvement policy'. Please be aware that I have not had sufficient time to revicu and reflect on this draft, and I consider my coinments to be preliminary. based on a cursury revicw of the document. With that in mind, the following comments are presented for your cons dcration:

- A key issue that is not clearly addressed in the draft policy is the timing of public involvement. In order to actively coun "cract the "Decide, Auvounce, Defend" public involvenent methods of the past, the need for early public involvement should be explicirly discussed and required.

- The recognition (in paragraph three under "Responsibilities") that support resources "human, information, systems, arid financial" are ussential is appropriate, and would bear repeating. "Old School" managers may have difficully with the concept that actively encouraging public involvement means more than just having the information available, should sonkone ask. It is probably necessan to explain that active public involvement includes providing the public with the institutional and tiochnical resources to independently assimilate and cvaluate the Department's infonnation. This point should be made in the implementation guidance memorandum, as well as in the policy itsclf.

These two key points: the exrly involvement of the public, and the provision of resources to "even the playing field" are essential elements of the public involvement program. They should be clearly' and cmphatically stated in both the policy and the impler entation guidance memorandum. Thank you for this opportunity to cemment on these documents. If there arc any questions please contact me at (619) 878-0380.

Sincerely,

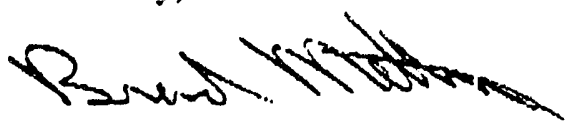

Brad Mcllam

Yucca Mountain Project Cocrdinator 
Mr. Jerome Saltzman, Director

January 4, 1994

Office of External Relations

Department of Energy

Washington, DC 20585

Dear Mr. Saltzman:

Thank you for your letter of December 17, 1993 to our Chairman, Joseph F. Paquette, Jr. which included the draft of your Department's new public involvement policy.

As a former federal employee anci the current Senior Officer responsible for external relations at PECO Energy, I am delighted with the trust, direction and scope of your new policy. We are a large urban utility concerned about corporate social responsibility and public trust. We would be delighted to participate in this new public involvement effort of the Department of Energy and would be pleased to assist in any way as you unfold this bold initiative to increase public participation in the Department's decision-making process.

Specifically the three goals outlined in the draft policy are a breath of fresh air for those of us concerned about ongoing communication and information-sharing with the Department of Energy. We applaud the core values contained in the draft, as they are quite consistent with our own.

My department of Corporate and Public Affairs here at PECO Energy, will be happy to serve as your point of contact. I can be reached at the above number. In Washington, David Brown of my staff is available at 202/789-5599.

We look forward to working with you as you finalize your public involvement policy and to hearing from you in the very near future.

Sincerely,

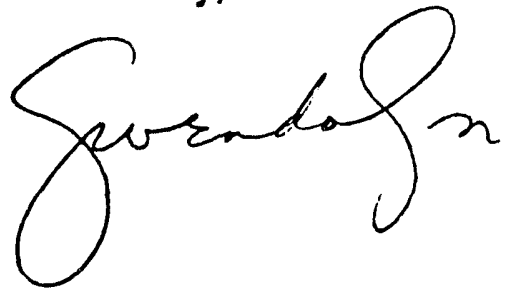

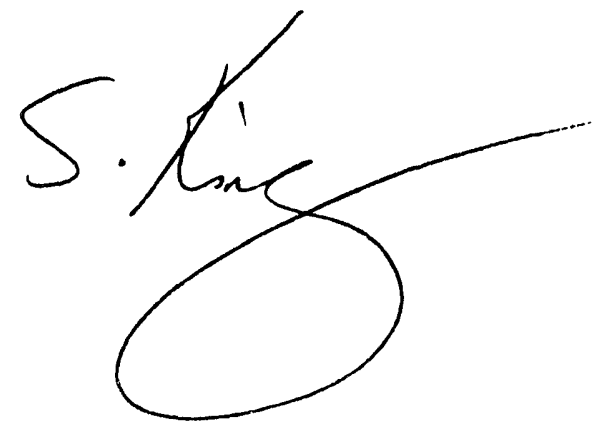




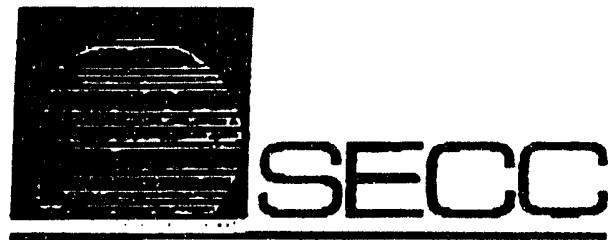

Sed Enargy Cammunication Cormall

DIV Mancohusetts Are NW

Suth 805

Wantogton DC 20036

(207) 483849

FAX. (202) 2349194

January 4, 1994

Mir. Allen Benson

Director of Program Felations Division

Office of Civilian Radioactive Waste Management

U.S. Department of Energy

1000 Independence Arenue, SW

Washington, DC 20585

Dear Mr. Benson,

I received a lettler from Jerome Saltzman dated December 17, 1993, asking for response to the proposed policy on public involvement and the related directive from the Secretary of Energy that were enclosed with the letter.

The Safe Energr Communication Courcil (SECC) believes that the proposed policy expresses the right rhetoric. We agree "that public involvement must be a routine component in program operations and planning activities." SECC applauds the Secretary's desire to include greater public participation in the Deparment of Energy (DOE) decision-making process.

Unfortunately, it apparently is not so simple to change a "50 year old culture from a closed, command-oriented hierarchy into an open, participatory culture that values diversity and innovation." The fact that we were sent a correspondence immediately before Christmas to which we are required to respond irnmediately after New Years (January 4, 1994), is an example of the difficulty thiat the Office of Civilian Radioactive Waste Management (OCRWIM) seems to be experiencing in instituting the necessary cultural change. It is difficult for SECC to adiress the proposed policy change in a thoughtful, carefill manner when the method and time-frame for comments seem to preclude such response. 


\section{Mr. Allen Benson, Page 2}

Nevertheless, SECC is committed to greater public participation in the DOE decision-making frocess in general, and XCRWM's process in particular. Therefore, please consider the following questions:

(1) To whom, aniong the public and public interest groups, did you send this particular request for involvement? Is your list inclusive of the many environmental stakeholders across the country who are concerned about radioactive waste? Has a methodology been instituted to ensure that all environmental stakeholders are included in th.e proposed public participation process? If this has not been done, perhaps SECC could help OCRWM compile a list that is truly inclusive of the many environmental stakeholders that want a greater voice in OCRWM's decisicn-making process.

(2) Why is the period for comments so short? Two weeks, under ordinary circumstances. are insufficient for a comment period. The fact that the two weeks that you chose for a comment period include Christmas and New Years, indicates to us a lack of sincerity on the part of OCRWM.

SECC recommends that OCRWM expard the comment period for this particular issue to April 4, 1994. In addition, ill public comment periods should be at least three months, but up to five: or six months or even longer if the subject matter is of a techrical nature and additional research is needed.

Please always keep in mind that individluals, citizen groups and small businesses do not have any funds allocated to do the research and writing that "public comments" require. Therefore, extra time or funds should be provided for this proceiss to enable such stakeholders to adequately participate.

(3) Is OCRWM axamining its questionable cultural assumptions as well as its public participation policy as a means to accomplish cultural change? While the official mission of OCRWIM is "to manage and dispose of the Nation's spent nuclear fuel and high-level. radioactive waste," a not so "hidder agenda" was described in the Bush Administration FY 1993 DOE Posture Statement. "As enunciated in the NES, solving the problem of permanent disposal of nuclear waste will contribute to ... removing a barrier to the further developinent of nuclear power."

While the first Clinton Administration Budget Highlights removed this language, the culture at OCRWM seems to retain this policy. At a December 8 and 9, 1993, OCRWM meeting I attended by invitation on a nuclear waste system architecture value framawork, one of the assumptions brought forward by OCRWM was that the "inupact on the construction of new 
Mr. Allen Benson, Pagie 3

nuclear power plants" would be a range of between " 0 to 3 years" after the implementation of the system. In other words, the general assumption of the Bush Administration DOE appears to have been carried over by OCRWM without the Clinton ArIministration's publicly expressed approval.

Other examples of OCRWMS cultural and policy assumptions appeared to be operative during the meeting. While the language of the proposed policy change:s appear to be positive from a public interest standpoint, thetoric dows not automatically translate into policy change. It will take a more basic uquestioning of the assumptions within the culture at OCRWM to have a rea. impact.

SECC has called on the Clinton Administration to immediately initiate a comprehensive and inclependent review of the United States' nuclear waste programs. Along witt. seven other national environmental organizations, SECC sent a letter to President Clinton on August 4, 1993 that details the rationale for the review. To date, SECC and the other organizations have not received a reply. A coply of the letter is enclosed for your further consideration.

SECC hopes that OCRWM is sincere about the proposed changes in its public participation policy. We believe that OCRWM could take a step in this direction by extending the comment period on its policy for public involvement, expanding its list of environmental stakeholders and funding public interest participition. In addition, it would send a positive signal if the DOE and the Clinton Administration responded to the August 4, 1993, letter and meet with the signatories to discuss the need for a comprehensive and independent review of the nation's radioactive waste policies.

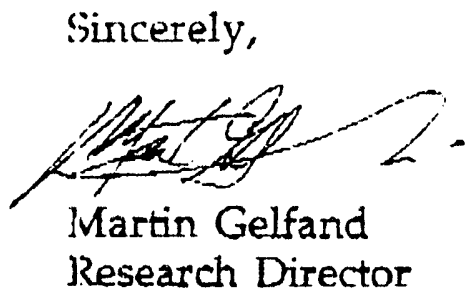

cc Jerome Saltzman

Dwight Shelor

Hon. D. Warner North

Hon. Daniel Reicher

Hon Daniel Dreyfus

enclosure

Hon Hazel OLeiary 


\section{FCR INFC. TLLY}

August 4, 1993

President William J. Clinton

The White House

Washington, D.C 20501

Dear President Clintorl,

We are writing oday to ask you to immediately initiate a comprehensive and independent review of the United States' nuclear waste programs. Secretary of Energy Hazel O'Leary recently announced her intention to conduct a review of the financial issues regarding the high-level radioactive waste program. We seek to ensure that this review will be broadly defined to encompass all aspects of the civilian high level waste progran, as part of a larger comprehensive examination of all radioactive waste generated in both the civilian sector anid weapons complex. Furthermore, examinaion of the systems of waste classification which currently define waste as "high" or "low" level should be a prerequisite for a inearingful reassessment of the current "high-level" waste program. The broad eraluation is ne:essary in addition to the limited inquiry into the financing of the high-level radioactive waste program.

To ensure that the evaluation process vill be designed and conducted in an unbiased and apolitical manner, we urge that an independent commission be established separate from the Department of Energy (DOE). The membership of said commission should include a majority of members who are not affiliated with nor have a vested interest in the utility, nuclear power and radioactive waste management inilustries. To prevent further waste of taxpayers' furids, we recommend that the program activities at the Yuce Mountain site bis suspended for the duration of this review.

Problems with the Yucea Mountain Project

Specifically, with regard to the high-level waste program, there is increasing consensus that the policy directing the conduct of the civilian high-level nuclear waste managennent prograun under DOE's Office of Givilian Radioactive hiaste Management (OCRWMD should be thoroughly and independently reviewed and reevaluatec. This need has been recogrized by the U.S. General Accounting Office (GAO); the Nuclear Wiaste Techrical Review Board (NWTRB) which is a statutory Federal Advisory Committee; Representative Phil Sharp, Chaimnan of the House Subcommittee on Energy and Power; Representative Richard Lehunan, chairman of the Subcoinmittee for Energy and Mineral Resources; and numerous independent: analysts such as Keeney and von Winterfeldt at the University of Southerr. California. 
President Clinfon

August 4, 1993

Page 2

On May 21, 199:, the GAO reported to Congress the results of its sthidy: Nuclear Waste: Yace Mountain Project Behind Schedule and Facing Major Scientific Uncentinties. The GAO specifically recommended to Congress:

In view of the current status of the disposal program, we recommend that: the Congress defer consideration of legislation that would change how funds are provided to DOE from the Nuclear Waste Find for use on the disjosal program until (1) the Secretary of Energy has completed the review of the program that we recominended; (2) an indepencent review of the program, such as that recommended by the Nuclear Waste Technical Review Board, has been completed; and (3) appropriate legijiative policy, and/or programmatic changes to the program have been implemented." "GAO/RCED-93-124, p. 48)

The recessity of an independent evaluation and a curtailment of current site activities are of timely importance because the DOE program to characterize Yucca Mo untain, Nevada, as the only deef geologic high-level nuclear waste disposal site is about to initiate large, irreversible expenditures at the site that may prove imprudent after objective review.

Two specific activities are inminent. (I) final purchasing of a large, multi-million dollar tunnel boring machine to excavate 25-30 foot diameter repository tunnels benisath Yucce Mountain; and (2) further work on excavation of the starter hole for the 5-mile underground Exploratory Situdies Facility (ESF) which is iesigned to be the first istage of repository construction by the turnel boring machine described above. The estimated cost of the ESF over the rext five years, is $\$ 850$ million, with FY-93 ESF costs budgeted in excess of $\$ 49$ million, a portion of which has aiready been spent.

It is clear that the DOE Yucca Mountain project managers are proceeding with great speed to commit as much as possible to irreversible expenditures before the: project is subjected to executive scrutiny that may result in a redirection of the program In simple tems, this type of effort would assure that 'the tail wags the dog.'

While DOE maniggers insist that these large expenditures are necessary to meet the goal of having a repository operational by 2010, it is clear to most observers, including thi? GAO and the NWTRJ3, that this rigorous and demanding schedule is both unrealistic and il-adviseci. Yucce Mountain's 
President Clinton

August 4, 1993

Page 3

suitability for safe disposal of radioactive wastt: has yet to be determined by DOE, and there is no contingency plan should the site prove unsuitabie or unable to receive a license from the Nuclear Fegulatory Commission subsequent to the DOE's determination of viability.

In reference to girestions related to statutory compliance, Secretary OLeary has the legal alithority to order an imnediate halt to these two major flnancial commitments at Yucca Mountain befise any further FY-93 funds are expended, and throughust the period that a review is taking place

\section{Comprehensive Revievr Needed}

It is urgent that tie prudent decision be made to defer the very nearterm commitments to lisge expenditures at Yucca Mountain until a comprehensive; indeperident review of the nuclear waste programs and policies can be completed. In consideration of this request, we believe that it is important to rememoer that high-level waste financial issues are but one subset of the larger, overall problems confonting the nation's civilian and weapons waste progran:5. Establishing an independent commission to completely re-evaluate [J.S. radioactive waste ciassification, technological options, economics, insitutional framework, rigulation, regulation of longlived wastes and fundinis needs is necessary to responsibly address the country's nuclear waste dilemma.

Please let us knou if we can be of any assistance or provide additional information. $W=$ look fcrward to the opportunity to discuss this issue soon with you and your staff.

\section{Sincerely,}

Scott Denmar

Executive Director

Safe Energy Comnunication Counci]

Diane DiArrigo

Radioactive Waste Froject Director

Nuclear Information \& Fesource Service
Arna Aurilio

Stiff Scientist

U.S. Public Interest Researcin Group

Biil Magavern

Director, Critical Mass Energy Project Public Citizer 
President Clinton

August 4, 1993

Page 4

Harvey Wasserman

Senior Advisor to the Nuclear Program

Greenpeace

Angela Park

Program Associate

Center for Policy Alternatives
Brent Blackwelder

Vice President for Policy

Friends of the Earth

Daniel Becker

Director, Global Warming \&

Energy Program

Sierra Club

c. Vice President Albert Gore

Secretary of Energy Hazel O'Leary

Ms. Kathleen Mi.Ginty, Director White House Office of Environmental Policy

Dr. John H Gibbuns, Director, White Hciuse Office of Science \& Technology Policy

Mr. T.J. Glauthier, Associate Director for Natural Resources, Energy \& Science, Office of Management \& Budget 
Mr. Allen Benson

Director of Program Relations Division

Office of Civilian Radioactive Waste Management

U.S. Department uf Energy

Washington, DC 20585

Dear Mr. Benson:

Thank you for the opportunity to comment on DOE's drait policy on public invclvement. Overall, we agree with the policy and think it is similar to EPA's philosophy towards public involvement (although we have not seen it written down in this kind of detal1). However, we have gineral concern that the tone is a little "heavy-handed" for a program area that requires staff to be thoughtfil and sensitive to the public's needs. One suggestion to try to soften the tone would be start off with an explanation of why DCE thinks public 1nvolvement is important. This explanation ought to precede the opening policy statement: "The policy of the DCIE is that public involvement must be a routine component in program operations and planning activities, at headquarters and in the field." our more specific comments follow.

Firet, we feel that the policy statement should stress that public involvement will be an open and on-going communication process. Therefore, we would suggest eliminating the word "routine" throughout the policy since that could be construed as meaning any periodlc basis, frequent or infrequent. As public servants, we feel that it is important to communicate with the public as much as thay feel is necessary, not necessarily according to our "routine." Related to this, you may want to conslder ading a sentence or two suggesting that program managers or public affalrs ctafe try to assess the communications needs of stakeholders and othors. This is something my office did in trying to devilop our WIPP communications/public outreach program. We conductis in-depth interviews with about 25 New Mexicans with an Intareat in the WIPP to try to ldentify their major concerne and communications needs. We have been using the results of hose intarviews to develop an effective communica ne outreach plan. 
In the "Core Values" section we suggest Including the words "communications" and "consultation" since they are the basis for any communications pollicy. DOE (and EFA as well) should etrlve to maintain open Iine:s of communication with the public and to frequently consult with affected stakeholders on the issues.

We suggest adding one more goal ir. the "Goals" section: The public's concerns, quistions, comments, etc., are addressed.

In the section on responsibilities we recommend adding a suggestion for periodic evaluation of the effectlveness of DOE's public involvement process.

Again, we appreclate the opportunity to comment on the policy and look forsact to reviewing tre draft report on your public involvement workshop when it becomes avallable.

sincerely,

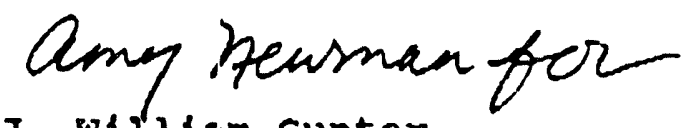

J. W1Iliam Gunter

Director, Criteria and

standards Division 


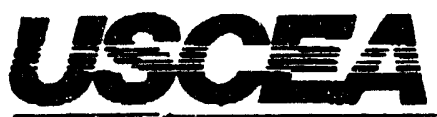

U.S. Couneil to: Ereigy Awareness

\section{VIA EACSIMILE}

January 4, 1994

Mr. Allen Benson

Direcinr, Program Relations Division

Office of Civilian Radioactive Waste Management

U.S. Department of Energy

Washington, DC 20585

Dear Mr. Benson:

This is in response to the Dei:ember 17 letter from Mr. Jerome Saltzman, soliciting our comments on the DOE's dralt public-involvement poliby.

Overall, let me commend the Department for inplementing what we consider to be a thoughtful and timely policy initiative. As the DOE adapts to significant changes in its mission, there is nothing nuore essential than fublic trust and confidence in the Department's efforts. We believe the public-involvement policy, as outlined, has the potential for building and maintaining a real sense of equity among the Diparment's miany stakeholders.

As with any such policy initiative, the proof lies not sc much in the words as in the inplementation. I would offier a few words of caution in that regard.

* Public involvement nust have realistic goals and conditions. An open-ended commitment to building consensus on each and every DOE initiative cuuld lead to paralysis.

* The final policy should rrake clear that participants in any given policy or programmatic initiative have an obvious anil relevant stake in that injtiative.

* The guidance memo to DOE managers and nperaticns offices asserts that the benchmark for excellence will be leadership.'performance; in addition ro risk-taking and peer review, the policy' should also specify that achieving the desired result of a given DOE initiative will also be a measure of leadership and performance.

We will continue to follow the evolution of the public-involvement policy with great interest, and would be pleased to assist the Department in any way we can.

Sincerely,

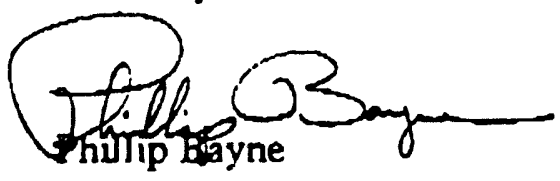




\section{DOSTON EDISON \\ Exoeutive Offlees \\ 200 Boylston Street \\ Baston, Massachusms 021199}

Domard W. Reznicak

Chaiman and Chief Executive Otticer

January 4, 1994

Mr. Jerome Seltzman, Directior

Office of External Relations

Department of Eneray

Washington, DC 20585

Dear Mr. Saltzman:

Thank you for your Decembus 17 letter and the opportunity to comment on your draft polley statement on publlc iivolvement.

Overall, I support the purposie and goals as outlined In the draft. However, In reading $t t_{\text {, }}$ as well as the draft memorandum from the Secretary isf Energy to heads of hesdquarters elements mangers and manugers of DOE operations offices, I find no mention of one of the most important eloments, and that is timely decision inaking. While I fully support public involvement and balleve firmly that the results of olmost any undertaking are better when the views and interests of diverse stakeholders are reflected in the decision making process, I would be zoncerned if the process hiself became the focus instead of focusing on the intended ottcome. Therefore, I would recommend adding elther a further goal to assure timely decisisn making or adding that element to Goal II.

As one of the evaluation fastors for the annual revlew, I would suggest including an assessment of timellness. I would also underscore this importance of training DOE staff members on the elements of public involvement, as well as the importance of producing decisions in a timely manner.

Thank you for the opporturity to comment.

Sincerely,

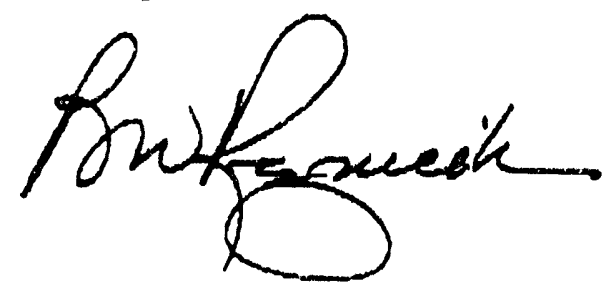




\section{IVA}

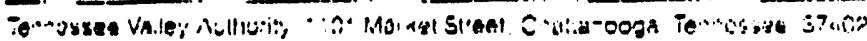

Oliver D Kingsiey, ip

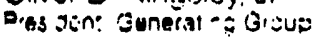

January 4, 1994

Mr. Jerome Saltzmaiz, Director

Office of External Relations

Department of Ererizy

Washington, DC 205 i3s

Dear Mr. Saltzman:

Thank you for the draft of the Department of Energy's (DOE) public involvemene policy which you recently forwarded to Chairman Crowell. Tennessee Valley Aluthority endorses the goal of bringing diverse views and values into the DOE decision-making process in order to make better decisions and bulld greater publ:-c understanding and trust. In addition, we believe that significant accomplishments and sustained progress toward program goals are essential elements to achieving public support.

To this end, we would offer two comment: relative to the new public involvement policy. First, the policy should clearly recognize that public involvement is essential, but that DOE has ulcimate responsibilicy for efficient decision making. Second, the policy should stress that public involvement must be carefuliy incegraced with other management activicies in order to achieve program goals in a timely and cost-effective manner.

We look forward to your drafe report the.t will set forth the program's implementation plar.s for public involventent.

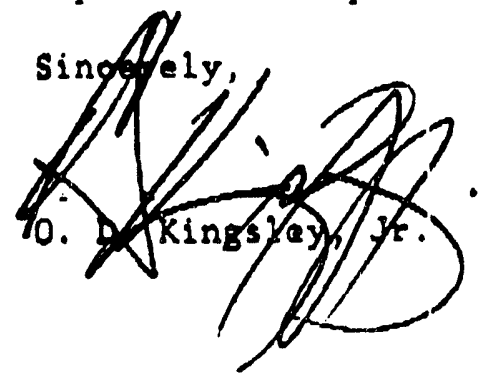




\title{
Nevada Nuclear Waste Study Committee 22
}

\author{
Northern Nevada Activities \\ 1029-1 Brooktree Drive, Sparks NV 89434
}

(702) 331-1228

January 5, 1994

Mr. Allen Benson, Director

Program Relations Division

Office of Civilian Radioactive Waste Management

Department of Energy

Washington, DC 20585

Subject: Draft Policy on Public Involvement

Dear Mr. Benson:

Mr. Jerome Saltzman's letter of December 17 and the subject draft were received today. . . evidently delayed in the holiday mails. I hope that our rather hurried review of the draft policy will be received in time to be useful.

Our comments on the draft policy are as follows:

1. Policy through and including Definition paragraph - no specific comment.

2. Goals:

Goal I: If every employee is delegated responsibility to practice and improve public involvement, they must also be delegated the authority necessary to carry out these responsibilities. What degree or span of authority is being delegated by this paragraph? Can we expect that "every employee" can make public involvement decisions? Does every employee have to coordinate these decisions/actions with the local Public and Consumers Affairs representative? This goal needs to be more clearly defined.

Goal II: Suggested change (also, see new Goal III):

". . for public involvement shall be established for each project and followed by all employees assigned to the project. The public shall be informed of these processes and encouraged and assisted to participate in the decision making process."

Goal III: A major problem in DOE public information policy has been the failure to respond to misinformation appearing in the news media and other public forums. For example, regarding the Yucca Mt. project, Nevada's Robert Loux has frequent op-ed pieces in Nevada papers containing grossly misleading statements or even technical errors; yet, there is seldom, if ever, a correction by DOE. This is frequently noted in our conversations with the public; if DOE or other 
authority does not correct the record, the public assumes the misinformation is true.

Therefore, we suggest the following for Goal III:

Goal III: Current, timely information regarding a project's status (technical, community, administrative, and otherwise), shall be presented to the public, and readily available in response to public inquiries. Misinformation appearing in the news media shall be corrected promptly.

This policy element should be implemented via the news media, regular and well publicized local presentations, by providing guest speakers, communications with state and other governmental and tribal entities and non-government stakeholder organizations, and by other means, in all geographic areas significantly affected by a project.

Our Committee believes that public communication through means readily available to the public -- the news media -and prompt correction of misinformation, are the keys to current DOE problems of public perception.

3. Responsibilities - 2nd \& 5th pp: The requirement for coordination with Public and Consumer Affairs (P\&CA) at Headquarters and in the field, is well taken. However, this requirement could introduce delays that would inhibit prompt and effective communication with the public at local levels. This kind of "red tape" must not occur. Public confidence and support depends on prompt, open and frank communications - fast reaction time -- not news that is several days or weeks old!

4. Draft Memorandum - Generally, we have no suggestions except that public communication should be more specifically emphasized.

Summary:

In general, we believe that the concept of the policy is good, and the terms of the policy as expressed in the draft are doable. However, as expressed in our comments, we believe that greater emphasis on public communication is imperative, especially the prompt correction of misinformation, whatever the source.

Many of us feel that prompt and effective communications with the public are much more important in project acceptance than public participation in decision making, regardless of the expressed desires of some so-called citizen's organizations! 
Please do not hesitate to contact us if we can be of further assistance in these matters.

sincerely,

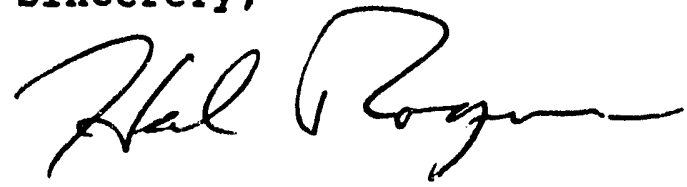

Hal Rogers

Co-chairman, Northern Nevada Activities

Nevada Nuclear Waste study Committee

copy: Hugh Anderson, Co-chair, So. Nevada Activities

NNWSC staff 
Mr. Allen Benson

Director of Program

Relations Division

office of Clvilian Radioactive

Waste Management

U.8. Department of Erergy

Washington, D.C. 20585

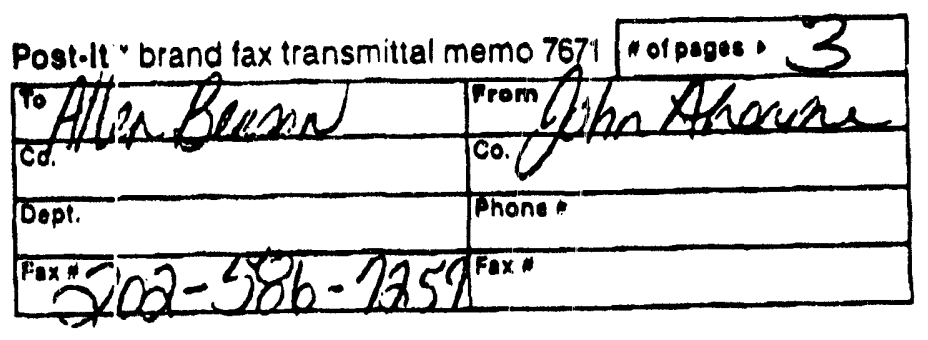

Dear Mr. Benson:

Warner North has sent me a copy of Jerome Saltzman's letter to North of 17 December asking for comments by yesterday on your draft pollcy. Although I was not askeld to comment and I only recelved these last right, I will provide a few comments. These are from three perspectives:

(a) as Chalrman of the National Academy Committee on Risk Perception and Communication, whlch authored the report Improving Risk Cummunication, published by the National Academy in 1989 (Tom Grumbly was a member of the study);

(b) as Chairman of the Department of Energy's Committee on Nuclear Facility Safety from 1989 through 1991; and

(c) as a former Chaldman of the Nuclear Regulatory Commission.

The goals and specitics in the draft are excellent. secretary o'Leary and Mr. Grumbily are making major changes in the openness of the Department and these are all excellent steps outilned in your drait.

I only ralse a couple of issues which you may wish to address because they could laad to some confusion or some difficulties.

In your policy, goal I includes "with every employee sharing responsibility to practice and improve pubilc involvement". However, under Responsibilitles, it lists: "To asaure a consistent approach t:hroughout the agency... Program and staff offices will coordinate their public involvement activities through the office of: Public and Consumer Affairs...." Do you intend that every employee, taking it upon himsele or herself this responsibility j:or public involvement, nevertheless 
Mr. Allen Benson

January 5, 1994

Page 2

continuously coordinate any such activities through the office of Public and Consumer Affairs? In other words, the way the policy is currently written could be viewed, particularly by any local manager who is not interested in $1 \mathrm{mplemented} \mathrm{the}$ policy fully, as a reguirement to constirain the employees rather than to empower them.

Furthermore, the requirement to coordinate all the activities does seem to be a chilling factor. I suggest that, instead of leading off with this under the Responsibilities, put it farther down in the Responsibilities suction and stress that it would be appropriate or advantageous, as opposed to the way it is currently worded, which sounds a bil: like the old Watkins approach. This was: don't do anything until headquarters or the field office has approved. In the past, that was used as a cover to avoid or prevent a local DOE liacility dealing with the public.

Under the goals, III is that "The public is...empowered to participate in departmental decision-making." One of the important issues the National Academy Committee on Risk Perception and Commurication addressed was the confusion that can come in the public's mind if it is not clear right from the beginning what declsion-making participation the public is going to have. When you start discussing with the public, you should be clear, for example, are you going to let them have an equal vote or are yol: going to require consensus before a decision is taken. In the end, this turns out to be the critical issue, becalise most people, in addition to wanting to be sure that their vjews are heard, want to have those views weighed in the final decision. of course, the best way, from the public's view, to insure that adequate welght is given is to allow the public t:o have a vote. If that is not going to be possible, then that sihould be made very clear right in the beginning. Therefork, your third goal needs some clarification somewhere in the rest: of the document.

The memo from the secretary includes under "Implementing actions" one of the Core Values; "Risk-taking will be rewarded". This is not clear. Taking risks is what got many of the reactor operators and other faclilty operators into deep trouble. They took risks with the public health and safety. It is not obvious what you mean by risk-taking. Some clarification would be quite helpful. 
Mr. Allen Benson

January 5, 1994

Page 3

In conclusion, I stringly support the concepts presented and it continues the fresh alr that has been let into the Department by the new Administrition.

JFA: cm/ 492

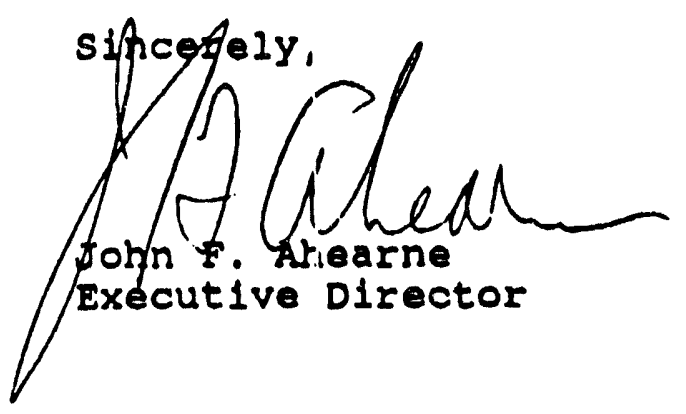

cc: Jerome Saltzman

Warner North 
Mr. Jerome Salteman

JAN 61994

Director

Office of External Relations

Department of Energy

Washington, D.C. 20585

Dear Mr. Saltzman:

Thank you for sending me a draft of the Department of Energy's (DOE's) new public involvement policy. This statement takes a critical step in a needed direction; I have no specific comments and think it is fine as is.

Overall, I applaud your efforts to bring more diverse views and values into DOEs decision-making processes by committing the Department to include public involvement processes as a routine element throughout its operation.

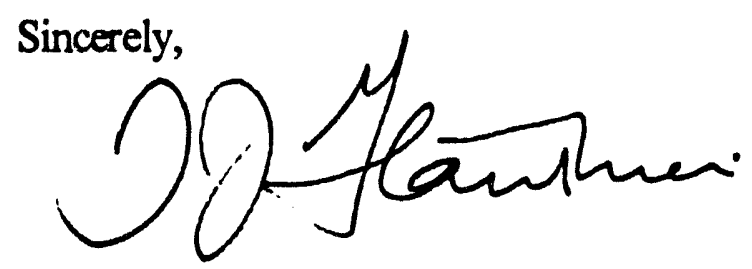

T.J. Glauthier

Associate Director

Natural Resources,

Energy and Science

cc: 'Allen Benson

Director of Program Relations Division

Office of Civilian Radioactive Waste Management 
KENL. HARRISON CHAIRMAN OF THE BOARD AND CHIEF EXECUTIVE OFFICER
Portland General Electric Company

ONE WORLD TRADE CENTER

121 S.W. SALMON STREET

PORTLAND, ORECON 97204

(503) 464.8825

January 6, 1994

\begin{abstract}
Allen Benson
Director of Program Relations Division

Office of Civilian Radioactive Waste Management

Department of Energy

Washington DC 20585
\end{abstract}

Dear Mr. Benson:

Thank you for the opportunity to comment on the Department of Energy's draft public involvement policy. We applaud youx desire to include a wide range of public sentimert in an issue such as radioactive waste management - an issue that can be so polarizing to the citizenry.

As the leader of a utility that, one year ago this week, announced the early closure of an 1,100-MW nuclear power plant, I can attest to the value a participatory process brings to decision-making. This decision was part of an integrated resource plan that was developed with as diverse an assemblage of advocacy groups, state agencies, and customers as was ever assembled by a utility.

Your draft policy articulates the most important characteristics of public involvement: the spirit of openness and respect of differing opinions. I have never believed the goal of these processes is to force consensus, but rather to understand the options and perspectives that should be considered when making decisions. However, making DOE staff accountable for the accuracy of their public statements and thoroughness in their follow-up to the commitments they make, will go far in building trust with your constituents, if not full agreement.

We have also found that developing and agreeing upon participant ground rules at the beginning of such a process, and referring back to this agreement when issues arise, helps align expectations. Developing mutual respect with your public takes time, but the time is well worth the gain in credibility.

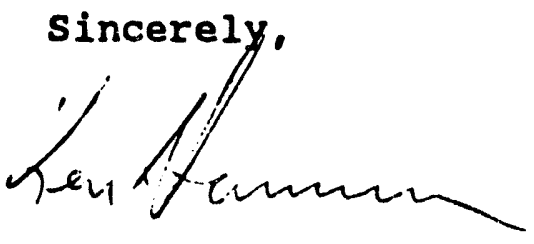




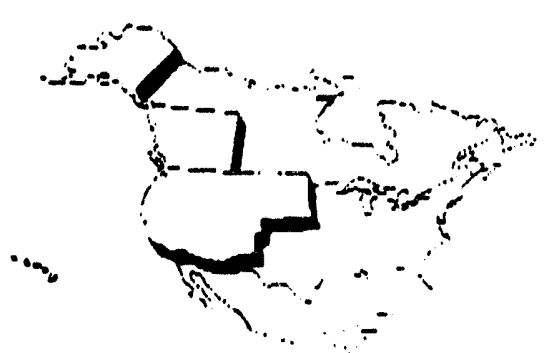

Western Interstate Energy

January 6. 1994
Aberta

Arizona

British Columbia

Californio

Coloraan

Hanvaii

Monsana

Nebraske

Nevada

Now Mexico

North Dukore

Oregon

Uiah

Washinglon

Wyoming

Anila l.ockwood Chair

Douglas C. Larson Executive Director
Mr. Allen Benson

Diroctor of Program Relations Division

Office of Civilian R.adioactive Wastc Manaycmint

Department of Encrg:

Washington, D.C. 20585

Dear Mr. Benson:

A Decomber 17 letter from Jert. Saltrmian requests comments on the Department's draft publis in olvewent policy. The Secretary s policy to embrace a new culture of openness and scricice is clcarly a step in the right direction. There are many elements of the draft policy on public involvenent which will improve the Department's ability to understand and be responsive to their employcrs, the citizens of the country. Howevor. onc element of the dran policy - coordination of public involvement activities through the Office of Public: and Consumer Affairs - causes some concem. This element bas the potential of adding an unnecessar laycr in the chain of communication betwecn state decision-makcrs and decision-makers at the Onice of Civilian Radioactive Waste Manjgement (OCRWM).

As you may know, western stales, thro dgh the Board's High-Level Radic active Wastc Coninittce, have worked hard to cultivate a productive working relationship with OCRWM's experts on spent fuel and HLW trassportation issucs. The sucecss of this working relationsh $\mathrm{p}$ has been the direct communication between state personnel and OCRWM rechnical and policy personnel (and, wherc appropriate. OCRWM contractors). Such direcl discussions are an essential element of productive intergovemnental relations and have enhanced the states' and DOE's understanding of key issues.

The Comritlce believes that any public involvement policy implemented by OCRWM should tuild on and expand the direst contact between state personnel and OCRWM personne!. Trust and understanding are the products of direct discussions.

I hope thesie comments are responsive.

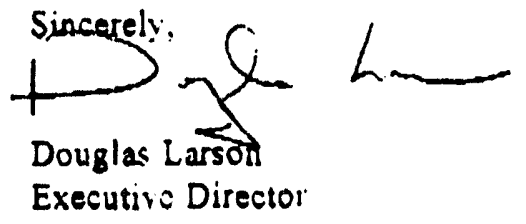

cc: Elissa Turnce, OCRWM

HLW Conmittee Co-Chairmon 
345 Eant 47th Streat

Now York, NY 10017

(212) 705-7496

7 January 1994

Mr. Allen Benson

Director of Program Relations Division

office of Civilian Radijactive Wagte Managamant (OCRWM)

U.S. Department of anerigy

Washington, DC 20585

Reference: Letter -- Siltzman to Pfrang, dat:ed 17 December 1993

Dear Mr. Benson:

In response to the riferenced letter, the American society of civil Engineers (ASCE) is pleaned to be invited to comment on the draft of the Department of Energy': (DOE) now public involvement pelicy. Asce enjoys a long-term relationship with DOE and its OCRWM Progiam, particularly with regard to the management of the annual International High Level Radioactive Waste Management (IHLRWM) Conference, :or which DOE servell as cooperating organization. In fact, rolative to thi dratt policy, educational activities, such as the conference, serve to fioster a greater undesstanding and trust amongst DOE, the solentific, engineering and educational communities and the public ar large.

The draft DOE policy speaks further to thisi issue, and we feel the policy will have positive impact on DOE' current and future programs. The example of the IHLRw conference might be looked at dis case otudy towards facilitating the acceptance of a rational solution cif a controversial problem. The conference provides arl educational forum for the discuseion of forging a cooperative seientific and social sciences approach towarde addressing a controversial national. (and international) problem, and thus facilitates ecceptance towards a solution.

In short, ASCE applauds the draft policy, ard stands ready to assist DOE in its implementation efforts. ASCE has expertise in developing technical programs which facilitate information exchange, technology transfer, team decisionmaking, public involvement, etc. ASCE also has a peer-roview program, public communications program, and other activities which can serve well any public involvement inltiative. Asce would wolcome discussing these programs with DOE.

Should you wish to discuss this further, please contact Mr. George L. De Fels, Manager, AsCs Confererce Marketing pregrans, at tel. 212-705-7290; fax. 212-705-7975. Mx. De Iais has worked closely with DOE on the IhLRws conference during the past five yeara.

sincerely,

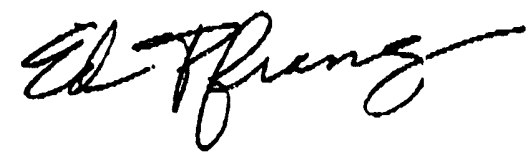

Edward 0 . Perang

Executive Director

Ce: O.L. De Reis 


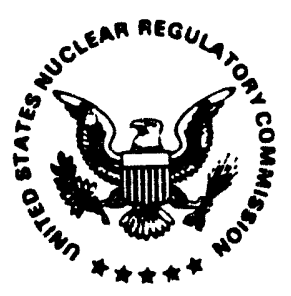

\section{UNITED STATES}

NUCLEAR REGULATORY COMMISSION

WASHINGTON, D.C. 20656-0001

JAN 0.71994

Mr. Jerome D. Saltzman, Director

Office of External Relations

U.S. Department of Energy

Forrestal Building, RK' 5

Washington, D.C. 20585

Dear Mr. Saltzman:

SUBJECT: RESPONSE TO THE U.S. DEPARTMENT OF ENERGY'S (DOE'S) REQUEST FOR COMMENTS ON DRAFT PUBLIC INVOLVEMENT POLICY

As you requested in your letter of December 17, 1993, we reviewed DOE's draft description of a new public involvement policy and have the following comments:

- We support the very worthwhile goal of the rew policy, to increase public involvement in DOE decision-making on civilian high-level radioactive waste managemerit activities.

- We view the new policy as consistent with the existing NRC/DOE procedural agreement and the agreement's related objectives of adequate information flow between NRC and DOE, timely NRC involvement in DOE's activities of a regulatory interest, early identification of potential licensing issues, and participation in NRC/DOE prelicensing consultations by states, Indian Tribes, affected units of local governmerit and the public. Such involvement is and will continue to be an essential element of the ongoing NRC/DOE technical interchange process.

- As in the past, we encourage immediate steps by DOE to implement the data base described in Critical Policy Element 5 , to make real-time inforration available through telephone and computer access points.

We appreciate the opportunity to review the draft public involvement policy. Should you have follow-up questions or comments, please contact Bill Reamer of my staff (301-504-3391).

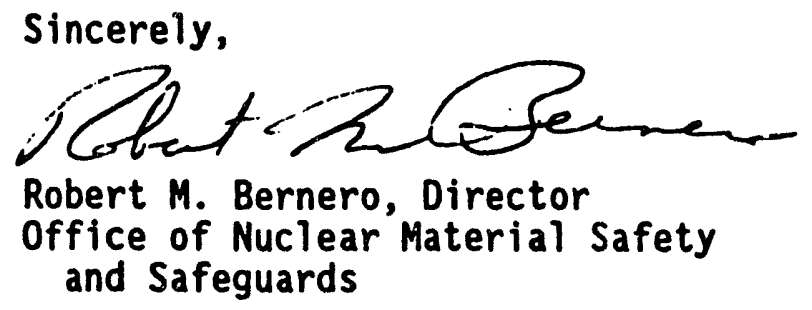

cc: Mr. Allen Benson 


\section{ADR FAX $\gg \gg>$

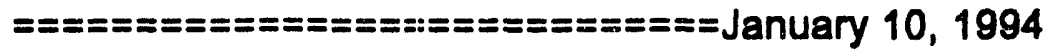

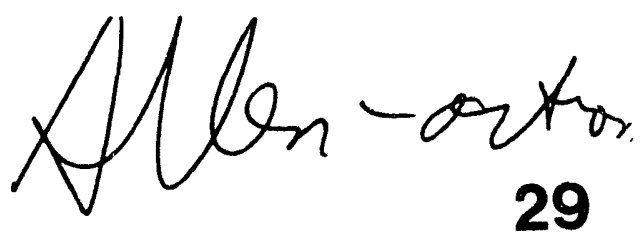

FAX TO: JEROME SALZMAN

FAX PHONE NO. 1-202-586-7259 (ALAN BENSON)

TOTAL PAGES: 1

FROM: A. DAVID ROSSIN

24129 HILLVIEW DRIVE

LOS ALTOS HILLS, CA 94024

(415) 948-7939 FAX (415) 941-7849

DEAR JERRY,

I GOT A COPY OF YOUR DEC. 17 LETTIER ON PUBLIC INVOLVEMENT. THESE COMMENTS ARE MY OWN. THERE MAY HAVE BEEN AN OMISSION IN DRAFTING THE POLICY AND THE MEMO OF THE SECRETARY WITH RESPECT TO THE FOLLOWING POINT:

NOWHERE IN EITHER DRAFT DOCUMENT CAN I FIND ANY REFERENCE TO THE NEED FOR THE [IEPARTMENT OF ENERGY TO FULFILL ITS OBLIGATIONS TO THE NATION AND ITS PEOPLE. FOR EXAMPLE, THE PURPOSE STATEMENT SHOULD BE AMENDED TO READ:

... trust between the Department and the public it serves in order that it may more effectively carry out its respor sibilities to the nation and its people.

IN ADDITION:

IN THE BACKGROUND SECTION, THERE SHOULD BE MENTION OF THE FACT THAT OBVIOUS EXCEPTIONS TO THE RATHER SOUR RECITATION OF THE HISTORY OF PUELIC INVOLVEMENT ARE THE CIVILIAN WASTE MANAGEMENT PROGRAM AND THE LOW-LEVEL WASTE MANAGEIMENT PROGRAM.

UNDER DEFINITION, THERE IS NO ME VTION OF THE RESPONSIBLE PARTIES WITH WHICH THE DEPARTMENT MUST ALSO DEAL: STATES, MUNICIPALITIES, CORPORATIONS, CCNTRACTORS, ETC.

I WOULD ALSO SJGGEST THAT IN THE: SECRETARY'S MEMO, THAT PARAGRAPH 5 THAT DISCUSSES RISK SHOULD EXPLICITLY POINT TO THE RISKS OF FAILURE OF THE DEPARTMENT TO MEET ITS OBLIGATIONS, (AND TO DO SO IN A TIIMELY MANNER), BY ADDING THE WORDS:

... consensus, including the risks to the riation and its people of failure of the Department carry out its obligations and meet its objectives. 
I BELIEVE THAT THE INTTENT OF BOTH THE POLICY STATEMENT AND MEMO IS EXCELLENT. AS YOU MAY RECALL, I FOUGHT HARD FOR PUBLIC INFORMATION AND INVOLVENENT DURING MY BRIEF TENURE AT DOE, AND DURING MY CAREER BEFORE AND SINCE.

PUBLIC PARTICIF'ATION IN DECISIONMIAKING HAS BECOME INSTITUTIONALIZED AS PART OF OUR DEMOCRATIC PROCESS. PROVIDING INFORMATION TO THE PUBLIC IS AN OBLIGATION OF GOVERNMENT, EECAUSE WITHOUT ACCURATE AND COMPLETE INFORMATION, PUBLIC INPUT IS NOT AS VALUABLE. PUBLIC INFORMATION IS ONE SUBJECT; PARTICIPATION AND INVOLVEMENT ANOTHER, AND THE TWO ARE CONFUSINGLY INTERTWINED IN BOTH THE DRAFT POLIOY STATEMENT AND THE MEMO.

THE DEPARTMENT IS RIGHT TO PROVIDE INFORMATION AND TO SEEK AND FACIL TATE PUBLIC INPUT. BUT IT IS IMPORTANT TO KEEP IN MIND TIAT EVEN THE CONGRESS NEVER CONFUSED THE RIGHT TO BE HEARD WITH THE OBLIGATION TO BE OBEYED. IT IS THE DEPARTMENT, NOT THE STAKEHOLDERS, THAT MUST MAKE DECISIONS AND SET POLICY.

HOWEVER, THESE DRAFTS, WITHOUT THE KIND OF AMENDMENTS NOTED ABOVE, S.HOW A SERIOUS LAC:K OF RECOGNITION OF RESPONSIBILITY ON THE PART OF DCE. THIS WILL BE OBVIOUS TO ALL THE PARTIES, BOTH WITHIN AND DUTSIDE OF GOVERNMENT, INCLUDING THE IMEDIA, WITH WHOM THE DEPARTMENT DEALS.

WITHOUT RECOGSIZING THAT THE TAXPAYERS OF THIS NATION EXPECT ITS CAB NET-LEVEL AGENCIES TO DO THEIR JOBS, THE POLICY STATEMENT AND THE MANAGEMENT MEMORANDUM WOULD SIMPLY SEEM TC BE HOLLOW.

SINCERELY,
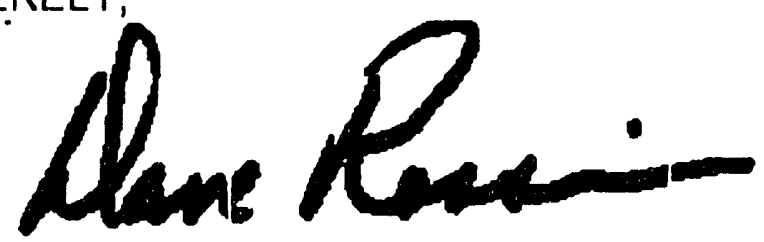

A. DAVID ROSSIN 


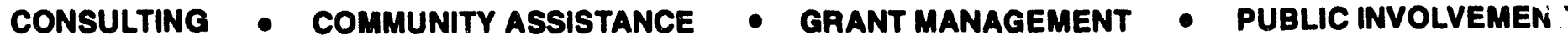

617 Terrace Street, Carson City, Nevada 89703 (702) 882-0296 FAX (702) 883-0226

January 10, 1994

Allen Benson

Director of Program Relations

Office of Civilian Radioactive Waste Management

U.S. Department of Energy

Washington, DC 20585

RE: Draft public involvement policy

Dear Mr. Benson:

I am a nuclear waste consultant with Eureka County, Nevada, specializing in public involvement. The following comments on the Department of Energy's (DOE) draft public involvement policy are submitted on behalf of the Eureka County Board of Commissioners.

We appreciate your granting us an extension on the deadline to comment on the policy. Four business days to comment on a draft policy is an inadequate amount of time, and is an unfortunate way to initiate public review of the DOE's public involvement policy. The draft did not address the issue of providing adequate scheduling and time for public involvement. In light of the problem with this deadline, we suggest that the draft policy include language requiring fully adequate opportunities and lengths of time for public review and participation.

Will these public involvement policies also apply to official public review processes such as environmental impact statements and environmental assessments? If so, this should be stated explicitly in the policy.

The draft policy is encouraging, as it indicates that the DOE is beginning to acknowledge the importance of public involvement or the need to appear to be more sensitive to the issue of public involvement. One area where the policy seems to be deficient is in implementation. While DOE managers are instructed to incorporate public involvement into their activities, the policy does not provide guidance or direction on doing more than listening and responding. If public involvement truly is "a means for Americans to influence their government", as defined in the policy, then the policy should provide some direction on how DOE managers can incorporate input from the public. Without such directions, DOE is at risk of being accused of going through the motions. 
We were unsure of the meaning of "risk-taking". It is not defined within the document, and should be, so that the public and DOE employees will be clear about when risk taking is rewarded and when it is not. For example, DOEscheduled briefings to coincide with a nuclear utility ad campaign in Nevada might be considered as positive risk-taking action by DOE while meeting with the families of contaminated workers might be received very differently by DOE.

In the memo from the Secretary to "Headquarters Elements Managers", it is stated that all levels of DOE will operate as an integrated team in planning public involvement activities. In the past it has been difficult for all DOE levels to work as a team. Is this a new directive? What special steps will be taken so that this effort is successful?

Further on it states that headquarters will develop clearance procedures for public information materials. What kind of clearance? How long will it take? Does this mean that field staff, who better understand local needs, could be hindered from releasing information to the public in a timely manner by headquarters procedures and personnel? While consistency is important, the policy should also permit discretion and flexibility at the local level.

Eureka County appreciates the opportunity to comment on the draft policy. For future mailings, please send correspondence to me at the above address and to the Eureka County Yucca Mountain Information Office, P. O. Box 714, Eureka, NV 89316.

Sincerely,

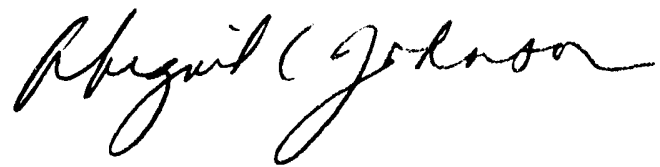

Abigail C. Johnson

Nuclear Waste Consultant to Eureka County 


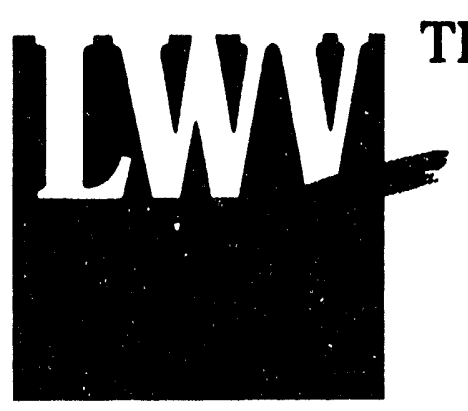

\section{THE LEAGUE OF WOMEN VOTERS OF NEVADA}

Post Office Box 779

Carson City, Nevada 89702

January 10, 1994

Allen Benson

Director of Program Relations Division

Office of Civilian Radioactive Waste Management

U.S. Department of Energy

Washington, DC 20585

Dear Mr. Bensen:

The League of Women Voters of Nevada is pleased to provide comments to the Department of Energy (DOE) on the DOE's draft public involvement policy. We appreciate the extension deadline to January 14 . The original comment deadline of January 4 was not practical; we did not receive the document until December 27 , which afforded us only four business days to comment.

Overall, the draft public involvement policy is going in the right direction. The League at all levels is a strong supporter of public involvement, and it is heartening that the DOE is recognizing the valuable role that citizens can play when they are informed and are afforded opportunities for involvement.

We have the following comments and questions.

1. Nowhere in the draft documents did we find mention of the need for allowing the public enough time to comment or participate. Since the draft policy itself was subject to that problem, and itself does not address the issue, we believe it is an inadequacy in the draft. The public involvement policy should include explicit language about giving the public adequate notice and sufficient time to participate.

2. The definition of public involvement in the draft is, "Public involvement provides a means for Americans to influence decisions made by their government."(underlining added for emphasis). While the implementation of the draft policy may lead to improved public participation, it does not address what DOE should do with the public's input other than respond. If Americans are to influence decisions, the policy 
should detail how this will occur - listening isn't enough. How will the information and ideas gleaned from pubic involvement be incorporated into the decisions and policies of the DOE? This draft policy does not tell us that, and without that information, the policy lacks substance.

3. The policy should also define what is meant by "risk-taking". Risk taking is encouraged and should be rewarded, but what is it? For example, is it releasing a draft document between Christmas and New Year's, allowing less than a week for the public to comment, or is an employee taking a risk by allowing enough time, even if schedules are not met, to allow real participation? What are the risks involved? Who's taking the risk? How will it be interpreted? One person's courageous risk is another's foolhardy gamble. Depending on your point of view, risky actions could be interpreted very differently. And what is the reward for risk-taking, and of what type?

4. Page 2 of the Secretary's draft memo states that all levels will operate as an integrated team in planning public involvement activities, combining resources, sharing information and coordinating schedules. This is a very optimistic goal which will need to be spelled out in extreme detail. As it is, these levels have a hard time coordinating - they will need some special incentives and guidelines in order to make this work.

We appreciate the opportunity to comment. Please continue to send us information on public involvement at the address shown above.

Sincerely,

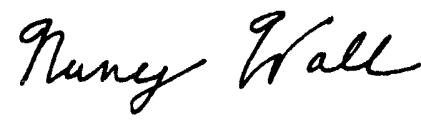

Nancy Wall, President 


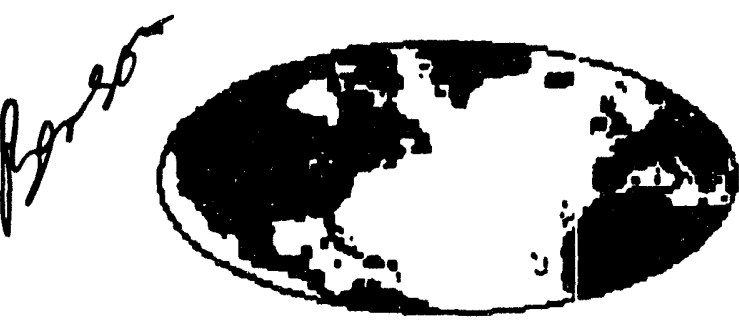

\begin{tabular}{|c|c|}
\hline 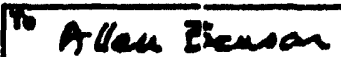 & room Solm Grakom \\
\hline$\omega_{0}$ & $\infty$. \\
\hline Doph. & thone \\
\hline Fax & $\tan 1$ \\
\hline
\end{tabular}

\section{Golden, CO 80401 USA}

Number of pages (including cover sheet):

Dear Mr. Benson,

Draft DOE Public Involviement Policy

1 have had a chance to review the draft of the Ixepartment of Energy's new public involvernent policy and take this opportunity of prcviding some comments prior to your review date of January 12, 1993.

1. The problem addressed is a long standing problem which has given the Department of Energy a reputation for arrogance and incompetsence from which it will he difficult to recover. This draft is an admirable start to correciing the problem.

2. The policy lacks specificiry in many respects -- it appears to depend on the "public" and stakeholders coming forward; it lacks any effort on behalf of the Department to approach stakeholders on anything other than a formul basis. For example, will the Department be encouraged to join locial Chambers of Commerce to seek input on programmatic directions before "pre-decisional access points" are reached? In many cases the Implementilig Actions appear to gather only stakeholder concurrence for programs already engaged.

3. The American Indian iribes are mentioned in passing in a couple of places as being an inclusive group within "the public". They are not. The Department of Energy's declared policy is to tritat the Indikn Tribes on a Government-to-Government basis and, therefore, consultancy is required on a Government-to-Government basis not merely in obtaining a stakeholder's interest and comments.

4. How will the Department of Energy's new policy affect program "conferences"? For example, the annual Environmental Conference (e.g. ER' 93 in Atlanta, GA) is not peer reviewed and is government controlled; the arnual Yucca Mountain show-cuase of government policies and programs admits to no objective peer review and is also

Please call (:303) $694-0700$ if you have ary problems with this transmission 
strictly controlled by the Department. Neither have the objectivity of being organized by a scientific society and the public have every right to believe that they are merely established to show-cise government programs and confirmutory analysis. This new draft policy has as onis of its core values -- scientific credibility. Are we thercfore to assume that these meitings will be abandoned or put into the hands of an objective organization which doss not accept DOE funding for the job?

5. The draft policy is a grod start but it is nowhere near to being ready to establish in final form. Implementation plans do not deal with infermation channels, publications, public reading rooms, speaking programs, school programs, etc. etc.

I would be very pleased to review and comment on the next draft in full. It is difficult to comment in detail on the present policy without reuriting many sections in more specific terms. Thank you for your time. 


\section{AGENCY FOR NUCLEAR PROJECTS \\ NUCLEAR WASTE PROJECT OFFICE \\ Capitol Complex \\ Carson City, Nevada $\mathbf{8 9 7 1 0}$ \\ Telephone: (702) 687.3744 \\ Fax: (702) 687-5277}

January 12, 1994

Mr. Allen Benson, Director

Program Relations Division

office of Civilian Radioactive Waste Management

U.S. Department of Energy

1000 Independence Avenue, S.W.

Washington, D.C. 20585

Dear Mr. Benson:

Enclosed are the State of Nevada's comments on the Department of Energy's draft Public Involvement Policy. It is encouraging that DOE is taking steps to institutionalize public involvement throughout the organization and in all of its activities. The draft policy is certainly a good beginning, although, as we have pointed out in the attached comments, this is not the first attempt to bring public sarticipation into the high-level radioactive waste program.

One formidable - perhaps insurmountable - problem DOE faces with respect to the Yucca Mountain program is the fact that a public involvement policy is being superimposed on a program where the major decisions have already been made, most of the time over the strenuous objections of the state of Nevada and its citizens. In this respect, DOE's Yucca Mountain effort differs from the Department's Environmental Restoration and Waste Management Program, where public input can still influence key decisions.

Secretary o'Leary has certainly set an encouraging tone with her new policy on openness with respect to the release of information about past AEC, ERDA and DOE environmental contamination and radiation experimentation. In the context of this new atmosphere, the draft Public Involvement policy holds promise for realizing the goal of transforming the Department into an agency that values public participation in its decision-making. It is to be hoped that the new spirit of openness and integrity will extend to the current Yucca Mountain program, and set the 
stage for a truly independent and comprehensive review of DOE's hlgh-level radloactive waste management activities and policy.

Thank you for the opportunity to comment on the draft Policy document. Should you have questions concerning any of the attached comments or need additional information, please do not hesitate to contact me.

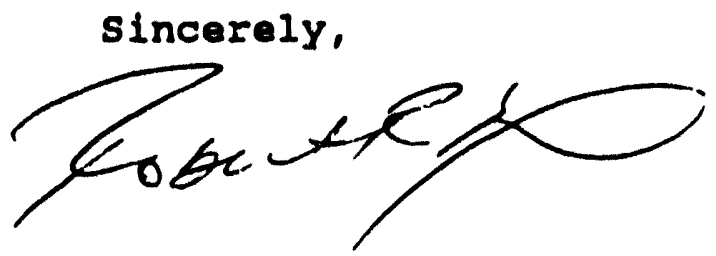

Robert R. Loux

Executive Director

RRL/Cs

Enclosure 


\section{STATE OF NEVADA COMMENTS ON THE U.S. DEPARTMENT OF ENERGY'S DRAFT PUBLIC INVOLVEMENT POLICY}

\section{A Brier comment on context and Bigtory}

In reviewing the Department of Energy's draft public involvement policy, it is instructive to put this initiative into some sort of historical context. The Nuclear waste Policy Act of 1982 (PL 97-425) attempted to create a repository site selection and development process wherein public participation played an important role. The Act contained language stipulating that:

"Congress finds that state and public participation in planning and development of a repository is essential in order to promote public confidence in the safety of disposal of such wastes and spent fuel."'

DOE's original Mission Plan for the Civilian Radioactive Waste Management program in 1985 contained specific commitments to public involvement and participation. In Chapter 4 (Institutional plans and Activities), DOE committed to "follow the letter and spirit of the law to assure a full and timely flow of information about the program to all affected parties and to provide frequent opportunities, both formal and informal, for the fullest possible participation in the program. The achievement of this goal depends on developing and maintaining information and interaction programs that meet the needs and address the concerns of states and affected Indian tribes, local governments, affected citizens, the general public, and other interested parties" (emphasis added).? The Mission Plan went on to specify that DOE would:

"1. Conduct activities in an open environment.

2. Listen to and understand the concerns of interested parties.

3. Actively involve affected parties in the program.

4. Execute faithfully the intent of Congress as expressed through the Act.

5. Provide equitable treatment for all parties affected by the implementation of the Act." 3

The goals and objectives for outreach and participation contained in the 1985 Mission plan speak to identifying and addressing the "concerns and interests of all affected parties" in a cooperative manner. The same section of the Mission plan called for the development of "facility-specific outreach-andparticipation programs based on input received from interested parties." In the Plan, DOE also committed to hold discussions with affected parties, respond to informational requests, hold briefings, meetings and workshops, carry out educational programs, establish community Information offices, hold formal hearings, and 
provide financial assistance to facilitate participation."

In the 1987 Mission Plan Amendment, DOE reiterated its commitment to extensive public participation. In responses to comments received on the draft Amendment, DOE stipulated that it "is developing the facility-specific outreach-and-participation plans specified in the Mission Plan. Moreover, DOE has been holding informal discussions with states, Indian Tribes, and local parties to gain an understanding of major program issues, information needs, and desired opportunities for input into program decisions." 5

Again in 1991, DOE incorporated extensive discussion of public involvement and participation in decision-making in 1 ts second Mission Plan Amendment. Stressing the need to improve trust and confidence in DOE and the waste program, the 191 draft Mission plan Amendment speaks to "initiating an institutional strategy aimed at expanding and improving our interaction and ... communication with affected governments, interested parties and the general public" with a focus on "effective, two-way communication." 6 Later in the same document reference is made to "substantive and early involvement in our decisionmaking process by affected governments, interested parties, and the public ..." before decisions are made.'

The 1991 Draft Amendment also called for the issuance of a five-year communications plan that would "detail the specific initiatives we will pursue to improve our communication products and processes and the criteria we will use to evaluate our progress towards earning public trust and confidence." 8

This somewhat lengthy discussion of past efforts by DOE to implement public involvement programs and processes serves to illustrate that the current secretarial initiative, while commendable, is not something new. Historically, well-meaning individuals and administrations have sought to promote change in the DOE "culture" and open decision-making to public input and influence. The notion that public participation could be internalized in a major federal program was, in fact, an important and innovative element in the legislation which created the office of Civilian Radioactive Waste Management.

It is important to recognize that the current draft public Involvement Policy arrives within the historical context of numerous disingenuous promises, programs and policies promising public participation and pre-decisional involvement in the highlevel radioactive waste management program. It will be difficult to convince a skeptical public that, this time, DOE really means it. 


\section{Comments specific to the Draft}

\section{public Involvement polloy Document}

1. The only new concept in the current draft policy is that public involvement "must be a routine component in program operations and planning activities" (emphasis added). The document lays out the process by which DOE hopes to implement the concept of "routine," which seems to be encapsulated in Goal II - "a clearly defined, coherent internal decisionmaking process with known access points for public involvement...". What seems to be missing from the "Responsibilities" section is how a decision-making process is defined and access points are established. This is the same shortcoming seen in the 1985, 1987, and 1991 Mission Plan documents. It could well prove to be the basic flaw in successfully implementing the current draft policy.

2. The "Definition" section of the draft Policy states that public involvement "requires routine, substantive two-way communication between the Department of Energy and other governmental entities, organized groups, individuals, and the general public interested in and/cr affected by the Department's decisions and activities." While two-way communication is an important and essential element in actualizing real public involvement, there is much more to the concept than is stated or implied by the draft Policy.

To be more than just an exercise, two-way communication must provide the opportunity for the public to actually influence decisions. All the two-way communication in the world will not enhance trust and credibility if decisions that are important to the public are not able to be informed and affected by the public's input. Meaningful public involvement processes must, of necessity, have an element of empowerment built in. This means that DOE will have to be willing to share decision-making power to some extent. One of the principal reasons why past DOE protestations about the desirability of public participation were never taken seriously is the fact that there was (and is) a disconnect between the public interaction process and the decision-making process. The current draft Policy does not appear to do anything to assure that the public will, in fact, be able to influence DOE decisions.

3. The draft Policy would be strengthened if it contained specific directives designed to break down the wall between public input and DOE decision-making. For example, the Policy might specify an administrative appeals process available to the public for recourse when decisions are seen as contrary to the public's interest or when they are not consistent with the public's input. 
4. The draft Policy may be inadequate to bring about the fundamental changes needed in the DOE bureaucracy. Without real teeth in the form of sanctions and systematic follow-up, there is nothing to keep the bureaucracy from turning the initiative into a public relations program by giving lip service to public involvement in decision-making while implementing activities that look good from a public relations standpoint.

In Nevada, past DOE public participation initiatives have vsually meant selling the repository project to the public, lobbying and attempting to influence legislators and public officials, and seeking out - or in some instances creating "friendly" groups/entities and attempting to increase their influence.

Real change, and real public involvement, will only come about as a result of a long-term, sustained effort which carefully scrutinizes public participation activities being implemented and has built in rewards and sanctions. Even then, the inertia of an entrenched bureaucracy is a difficult force to overcome.

5. Goal III of the draft Policy specifies that "[t]he public is informed about and empowered to participate in Departmental decision-making" (emphasis added). While a worthy goal, unless the term "participate" is defined in such a way as to afford real ability to influence decisions, this statement carries little real meaning. Nevadans have been "participating" intensively in DOE's high-level radioactive waste program for over 10 years, but no one would claim to have had any real participation in decision-making.

6. The "Responsibilities" section of the draft Policy places significant emphasis on "the Principal secretarial officer and Senior Department Managers" to ensure that "public involvement principles, values and processes are fully understood and practiced within their programs and that necessary training and resources ... are provided." The policy presumes a hierarchical structure of organization, where policy directives flow readily from one level to the next.

As noted above, in a bureaucracy implementation of policy is rarely as smooth as in the organizational chart. The Principai secretarial office and Senior Department Managers, as the actors at the top of the policy pyramid, will need not only the direction and authority to see the policy implemented at all levels, but they will also need training themselves on the fundamentais of public involvement. Real public participation is a messy affair: it is time consuming, difficult and frustrating. It constrains what managers and policy makers can or should do on their own. Having senior 
staff at the top of the policy hierarchy who are committed to public involvement and well versed in its practice will be essential for successful implementation at the bottom.

7. The "Responsibilities" section of the draft policy also specifies that DOE's Director of Public and Consumer Affairs will "establish a point of contact and mechanisms to coordinate public involvement activities Department-wide ...". While the specific role of Headquarters public and Consumer Affairs remains undefined, having DOE public relations staff coordinating public involvement activities raises the specter of the initiative devolving into a slick public relations campaign aims at selling DOE programs to uninformed consumers.

\section{A Comparison of the Draft Public Involvement Policy} and the Yucca Yountain Profect office Public participation Plan

Last October, DOE's Yucca Mountain Project office (YMP) issued a draft of a public participation plan for comment. 9 Examining the YMP plan in relation to the draft Department-wide public Involvement Policy allows certain insights into the differing perspectives amoung various entities within the Department.

The first draft of the YMP public participation plan, which is the only draft we have reviewed, is more restrictive in its view of public participation. The YMP draft states that "[p]ublic participation activities will predominantly focus on the affected couties (Nye, the situs jurisdiction, and the nine contiguous counties) and the state of Nevada."10 Likewise, the YMP plan would determine issues for public participation based on the level of perceived interest the public has in those issues. The draft YMP plan states, "If public interest is high, public involovement is probably appropriate; conversely, if interest is low or nonexistant, it is unlikely that public involvement is necessary." This narrower focus seems to conflict with the broad definition of public involvement contained in the draft Policy document.

\section{Public Involovement in the context of} the current Yucca Yountain Program

Realizing the goal of public involvement in an agency that is mission driven and burdened by over 40 years of culturally ingrained and reinforced proclivities for secrecy and heavy-handed decision making will not be an easy task. Compounding this, the very nature of the Yucca Mountain project, with its reliance on a forced siting approach and historical dependence on congressional mandates, makes any public participation effort suspect.

At a minimum, the DOE's public involvement policy should explicitly acknowledge the fact that public participation is being sought in a program where the key decisions (i.e. selection of Yucca Mountain as the only site, the size and configuration of the 
"exploratory" facility, and other such decisions) have already been made - over the strong objections of the state and its citizens.

If DOE is serious about involving the Nevada "public" in decision-making, a key goal of the plan should be to make DOE decision-makers more open to the need to abandon forced siting as the driving force behind the current repository program. Given the present state of affairs, it is difficult to envision a public participation program that can be much more than window dressing for an agency that has already made - or contributed to the making of - most important decisions.

\section{BOILDING TRUBT AND CONPIDENCE}

An important goal of the proposed public involvement policy is to enhance the trust and confidence people have in the Department of Energy and its programs. Certainly, simply establishing a department-wide public involvement policy is, itself, an important step in accomplishing this goal.

State of Nevada sponsored research into the dimensions of public trust and the role trust plays in risk perception may hold some insights for DOE in terms of what is needed, besides instituting a public involvement policy, to improve trust and confidence in the Department.

Attached is a summary of the state's research work on trust and the nuclear waste issue. It is instructive to note that state finding have consistently shown public trust with respect to the nuclear waste program to have several important dimensions, some of which can be addressed through improved public participation and shared decision-making and other which likely will not be.

The first dimension is the perceived capability of the agency (DOE) to competently manage the a program or facility in a safe manner. The second component of trust which is found to consistently and strongly predict risk perceptions is the perceived fairness in the process used by government in selecting the proposed site for the repository. While other components of trust, such as perceived honesty of the government, are important in understanding some citizen concerns and risk perceptions, fairness and management competence explain the greatest amount of variance across the dependent variables (opposition and risk perceptions).

Finally, there is a evidence that trust may be composed of such dimensions as competence, integrity, credibility, consistency, fairness, and openness. These different components may vary in their importance in determining how people view the trustworthiness of an institution, government or program. The importance of each of these trust dimensions in understanding risk perceptions may vary depending upon the nature of a proposed facility or program. Indeed, citizens' evaluations of the credibility of information or 
the efficacy of a public involvement effort may, in large-part, reflect the trust configurations for the source of the information. In other words, DOE may have to significantly increase it's trustworthiness (as perceived by people outside the organization) before a public participation program is likely to be effective or taken seriously. 


\section{REFERENCEB}

1. Public Law 97-425 (42 USC 10131), Sec 111.(a)(6).

2.U.S. Department of Energy, office of Civilian Radioactive Waste Management. Mission Plan for the civilian Radioactive Waste Yanagement Program, June, 1985 (Page 129).

3. Ibid.

4.Ibid. Pages 130-131.

5.U.S. Department of Energy, Office of Civilian Radioactive Waste Management. OCRWM Mission Plan Amendment With Comments on the Draft Amendment and Responses to the Comments, June, 1987 (Page 139).

6.U.S. Department of Energy, office of Civilian Radioactive Waste Management. Draft Mission Plan Amendment, September, 1991 (pages 21-22).

7.Ibid. Pages $124-125$.

8.Ibid. Pages $126-127.8$.

9.U.S. Department of Energy, Yucca Mountain Site Characterization Project office. Yucca Mountain Project Public Participation Program and Guidance (Draft), October 14, 1993.

10. Ibid. Page 2 .

11. Ibid. Page 5 . 


\section{TROBT NND THE REPOBITORY PROGRAY: TIMDIKG8 OI THE 8TATE OF NEVADA 8OCIOECONOMIC 8TODIB8}

The question of trust in the federal government's ability to manage a HLNW repository must be considered within a wider social context of low or declining confidence in government, business, science, and other important institutions.' In addition, findings by the state of Nevada socioeconomic research team documented a high correlation between trust ratings and public risk perceptions of the repository program. Those people who had low trust ratings for federal agencies tended to percelve high risks associated with the repository program and, if they were Nevada residents, to oppose the Yucca Mountain project. Because this relationship between trust and risk perceptions held true for respondents in the national and regional surveys as well as in Nevada, there is reason to think that trust also may be important in understanding stigma effects.

Lack of trust is found to be the best predictor of citizens' risk perceptions and opposition to the repository siting. For example, measures of federal agency trust are strongly associated with various risk perceptions associated with the repository program including: transportation risk, repository accidents, health and safety risks, and the ability to mitigate the impacts of these risks. State of Nevada studies consistently found that the lower the level of public trust in the federal government and its administrative agencies, the higher the perceptions of risk and opposition to the program among residents.

objectives

The studies of trust and confidence in government management of the repository program had the following objectives:

To measure public trust in the performance of governmental agencies and officials with respect to the repository program. These measures would include ratings of trust for federal, state, and local entities.

- To obtain ratings from different geographical areas and conditions within Nevada (e.g., rural and urban; by distance from Yucca Mountain or potential transportation routes, gender, etc.).

To obtain more information on the relationship between trust and risk perceptions, as well as trust and other variables (e.g., economic benefits and costs, positions on equity and

\footnotetext{
'Lipset, S., and $w$. Schneider. (1987). The Confidence Gap: Business, Labor, and Government in the Public Mind. rev. ed. Baltimore, Maryland: Johns Hopkins University Press.
} 
fairness issues, and opposition to or support for the repository program).

To examine the stability of trust perceptions and how wuch evaluations might be altered. A number of suggestions have been proposed to increase trust, such as providing more and better information to the public, allowing direct involvenent in program oversight by communities or states, and making structural changes in management agencies or their relationship with host areas.

To understand and describe the dimensions of trust-those factors, singly or in combination, that constitute a sense of trust. The research should explicate the importance of such factors as integrity, fairness, consistency, competence, and other elements constituting trust.

\section{Methods}

In addition to an extensive literature review, two major data collection methods were used. Focus groups addressed the dimensions of trust and their applicability to the repository program, and survey research, undertaken at various times, collected data on trust ratings and on variables relating to trust issues, information evaluation, and conditions that could result in change to public trust.

A team of researchers at Arizona state University also conducted a series of studies examining the relationships between public trust, citizen risk perceptions and support/opposition for the high-level nuclear waste repository within the urban Las Vegas area population. These studies utilized a combination of face-toface interviews and telephone surveys conducted in Nevada from 1987 to the present to explore the importance of public trust in governmental institutions and program in explaining the publics' risk perceptions concerning the repository siting.

\section{Annotated Bibliography of selected study Reports}

Mushkatel, A., D. Pijawka, and M. Dantico. (1990). Risk-Induced Social Impacts: Effects of the Proposed Nuclear Waste Repository on Residents of Las Vegas Metropolitan Area. MRDB: RP0107.

The report focuses on data from two surveys: the 1988 Urban Risk Survey and the clark County portion of the 1989 Nevada state Survey. An overview is presented for key findings related to public response and concerns about the repository program, including level of awareness, concern about harmful effects, benefits versus risks, and repository imagery. The report also addresses the role of 
political trust in repository risk perceptions. Political trust and perceptions of management capabilities were examined for the major repository risk clusters and for transportation risks specificaliy.

Mushkatel, A., and D. Pijawka. (1992). Institutional Trust, Information, and Risk Perceptions.

This draft report summarizes the results of a 1992 Las Vegas metropolitan area survey. A sample of 701 respondents was interviewed regarding repository risk perceptions, governmental trust, belief in information, and other attitudinal dimensions. Longitudinal data were used to compare this survey with the 1988 Urban Risk Survey on key variables.

Data collection was underway at the time that a major earthquake occurred in southern Nevada near the Yucca Mountain site (June 29, 1992). By increasing the sample size, it was possible to obtain statistically significant responses for both the pre- and post-earthquake conditions. The data show differences caused by the intervention of a seismic event.

Mushkatel, A., D. Pijawka, P. Jones, and N. Ibitayo. (1992). Governmental Trust and Risk Perceptions Related to the HighLevel Nuclear Waste Repository: Analysis of Survey Results and Focus Groups. MRDB: RP0135.

This report covers the basic literature on political trust and studies that address trust and the repository. The literature provides the backdrop for identifying issues dealt with in the findings from one survey and the focus groups. The report summarizes the trust findings from the 1988 Urban Risk survey, focusing on the relationship between trust and risk perceptions.

The report describes two focus groups undertaken in Las Vegas on trust perceptions. The purpose of the focus groups was to aid in the development of a survey instrument on trust perceptions. The focus groups also address questions related to the dimensions of trust-integrity, competence, consistency, fairness, and other elements. 


\section{Major rindings}

Among Nevada's citizens there is a high level of distrust for the federal governments's ability to manage the proposed high-level nuclear waste repository in a safe manner. The high level of distrust found has been consistent since the first survey in 1987 . Only about 15t-18\% of Nevada citizens in the urban Clark County area exhibit high trust in the key federal agencies' ability to protect their health and safety with respect to the repository. A 1992 survey found only $10 \%$ of these urban residents trusted the government to do what was right relative to the repository.

Analysis of 1992 survey data indicate that these low levels of trust can not be altered easily and are deeply rooted. Citizens were asked whether a variety of specific changes in the program, its management, or its institutional structure would result in altering their level of trust in the repository siting process. Results show that about 658 of the urban residents would not change their views of the program even if new risk information was provided by the Department of Energy. Three-fourths of the urban residents feel that DOE information consistently underestimates the risk of the repository. The publics' trust in the governmental institutions responsible for the program appears to have shaped by several factors; most importantly the negative perceptions of these agencies performance in the past, and the widespread perception that the Department of Energy has been dishonest with the public historically.

Multivariate analyses (regression and logit analysis) of the survey data confirms the importance of trust in explaining both risk perceptioris and opposition to the repository program. By using several different items and constructing scales which measure different dimensions of trust, the most important facets of trust in explaining risk perceptions of the repository can be isolated. These analyses identified two key dimensions of the trust construct as being critical to risk perceptions among Nevada's urban citizens.

The first dimension is the perceived capability of the agency to competently manage the facility in a safe manner. The second component of trust which is found to consistently strongly predict risk perceptions is the perceived fairness in the process used by government in selecting the proposed site for the repository. While other components of trust, such as perceived honesty of the government, are important in understanding some citizen concerns and risk perceptions, fairness and management competence explain the greatest amount of variance across the dependent variables (opposition and risk perceptions).

Finally, there is a strong likelihood that the construct of trust consists of several different dimensions. Trust may be composed of such dimensions as competence, integrity, credibility, 
consistency, fairness, and openness. These different components may vary in their importance in determining how people view the trustworthiness of an institution, government or program. The importance of each of these trust dimensions in understanding risk perceptions may vary depending upon the nature of a proposed facility or program. Indeed, citizens' evaluations of the credibility of information may, in large-part, reflect the trust configurations for the source of the information.

specific findings of the research to date include the following:

Public trust in the federal government to manage the repository program is highly correlated with risk perception. The relationship is inverse-those who perceive high risks show little trust in the government while those who perceive low risks demonstrate high trust. In turn, both trust and risk perceptions are highly correlated with support or opposition to the repository program. (See chapter 13, especially MRDB: RPo123, Flynn, et al., A structural Model Analysis of Public opposition to a High-Level Radioactive Waste Facility.)

Nevadans report the lowest levels of trust in federal agencies (DOE, NRC, and EPA) and in congress. Significantly higher trust ratings are given to state and local officials and public institutions. Trust in DOE has declined since 1989, while ratings for state and local entities have increased.

Las Vegas metropolitan area residents report little confidence in the ability of the federal government to design and operate an "acceptably safe" transportation program for HLNW, or to provide adequate response to accidents. There is a general lack of confidence in the efficiency of governmental response to nuclear accidents.

A majority of Nevada residents do not think that DOE will provide prompt and full disclosure on serious problems with the repository program.

A contributing factor to the lack of trust in the DOE repository program is the public's belief in Nevada that the decision process that resulted in the selection of Yucca Mountain was not fair or equitable.

The preliminary examination of information indicates that the most important dimensions of trust in the DOE repository program are integrity (history of trust), competence (the ability and application of correct knowledge and action), and credibility (confidence in the scientific process for decisions and unbiased information).

- The public appears to respond more quickly and strongly to 
Information about greater risk or stories encouraging distrust than to information about safety or improved risk-management plans. The case studies described in chapter 11 provide support for this finding from other locations and facilities.

Once trust is lost it is very difficult to regain. A distrusted entity encounters a suspicious examination of actions, statements, and motives especially in an adversarial process where evidence to support distrust is more 11kely to be accepted than evidence to regain trust. Substantial improvement in DOE's trust ratings might be possible if major changes were made in the structure of the agency and the procedures it uses, so as to provide greater access to program decisions and greater state, local, and public control.

If the source of information is mistrusted, the public response to its messages tends to be disbelief and further distrust.

\section{Implications for Future Work}

The findings described above are based on preliminary results from the focus groups, a review of the literature on trust, and the analysis of statistics from surveys.

The relationship between trust in the management of nuclear hazards and perceptions of risk deserves further examination. The causal direction from trust to risk perceptions (demonstrated with the 1989 Nevada state survey data) should be studied with alternative databases, especially with wita collected over time to examine the possible recursive nature of the relationship between these variables. The effect of policy changes on trust should also be addressed.

- Researchers should go forward with multivariate analyses to determine the strength of key trust relationships, especially the association between trust and risk perceptions and sociodemographic influences.

There is a need to assess the independent contribution of trust in hazards management, controlling for factors such as faith in nuclear technology.

Further research and analysis should be conducted on the role of the dimensions of trust and their variability.

- Continued work in trust research should concentrate on understanding the way in which events or mishaps amplify trust perceptions.

- Finally, much more work needs to be done on the potential for regaining institutional trust. Work on hypothetical scenarios and the explication of successful cases might be useful. 
Belected Publications of the Research Team relatibg to the rrust Insue

Flynn, J. (1992). Public trust and the future of nuclear power. Energy studies Review, 4, 268-277.

Flynn, J., Burns, w., Mertz, C. K. \&lovic, P. (1992, September). Trust as a determinant of opposition to a high-level radioactive waste repository: Analysis of a structural model. Risk Analysis, pp. 417-430.

Flynn, J., Burns, w., slovic, P., Mertz, C. K. (1991). Development of a structural model to analyze public opinion on a high-level radioactive waste facility. In High level radioactive waste management: Proceedings of the Second Annual International Conference (Vol. 1, pp. 773-779). New York: The American Society of Civil Engineers and the American Nuclear society, Inc.

Flynn, J., slovic, P. (In press). Nuclear wastes and public trust. Forum for Applied Research and Public Policy.

Kasperson, R. E., Golding, D., \& Tuler, S. (1992). Social distrust as a factor in siting hazardous facilities and communicating risks. Journal of Social Issues, 48(4), 16l-187.

Kunreuther, H., Desvousges, W. H. \& Slovic, P. (1988). Nevada's predicament: Public perceptions of risk from the proposed nuclear waste repository. Environment, $30(8), 16-20,30-33$.

Mushkatel, A. H., Dantico, M. K. (1991). Governors and nuclear waste: Show-down in the Rockies. In E. B. Herzik, B. Brown, et al. (Eds.), Gubernatorial leadership in state policy (pp. 173-189). Greenwood.

Mushkatel, A. H., Herzik, E. (1992). Intergovernmental complexity in nuclear waste disposal policy. Policy studies Review, $10(4), 139-151$.

Mushkatel, A. H., \& Herzik, E. (1993, forthcoming) . Nuclear waste policy. Greenwood.

Mushkatel, A. H., Nigg, J., \& Pijawka, D. (1988). Risk perception and intended behavior: The effects of the proposed high-level nuclear waste repository on Las Vegas residents. In Proceedings of the Conference on Nuclear Waste Management (pp. 103-109). Tucson, AZ: Society of Nuclear Engineers and U.S. Department of Energy.

Mushkatel, A. H., Nigg, J., Pijawka. (1990, April 8-12). Social impact assessment of siting the high-level nuclear waste repository in Nevala: The use of future risk scenarios in 
survey research. In Proceedings of the International HighLevel Nuclear Waste Management Conference. New York: American Soclety of Nuclear Engineers.

Mushkatel, A. H., Nigg, J., Pijawka, D. (In press). Nevada urban residents' perceptions of the nuclear waste repository. In $R$. E. Dunlap, M. E. Kraft, E. A. Rosa (Eds.), Public reactions to nuclear waste: citizens' views of repository siting. Durham, NC: Duke University.

Mushkatel, A. H., \& Pijawka, D. (1990, May). Public perceptions of transporting hazardous materials. In state and local concerns In transporting hazardous materials. Saint Louis, Mo: American Society of Civil Engineers.

Mushkatel, A. H., \& Pijawka, D. (1991, April 30). Political trust's role in explaining Nevada urban residents' perceptions of the proposed Yucca Mountain repository. In Proceedings of the High-Level Nuclear Waste conference. Washington, DC: U.S. Department of Energy.

Mushkatel, A. H., \& Pijawka, D. (1992, winter). Public opposition to the siting of the high-level nuclear waste repository: The importance of trust. Policy studies Review, pp. 180-194.

Mushkatel, A. H. \& Pijawka, D. (1992, February) . [Review of Gerald Jacob's site unseen: The politics of siting a nuclear waste repository.] Land Economics, pp. 123-126.

Mushkatel, A. H., Pijawka, D., \& Gickman, T. (In press). The perceived risks of transporting hazardous materials and nuclear waste: $A$ case study. In Proceedings of the International Consensus Conference on the Transportation of Hazardous Materials. Waterloo, Ontario: University of Waterloo.

Mushkatel, A. H., Pijawka, D. \& Nigg, J. (1988). Measuring environmental, developmental and property value: Impacts of solid waste facilities. In The forum 1988.

Pijawka, D., \& Mushkatel, A. H. (1992, winter). Editors introduction. Po?icy studies Review on Nuclear Waste Policy, pp. 88-90.

Pijawka, D., \& Mushkatel, A. H. (1992). Nuclear waste policy and siting the nation's repository. Policy studies Review, 10(4)

Pijawka, D., Mushkatel, A. H., \&lickman, T. (1993). The perceived risks of transporting hazardous material and nuclear waste. In Proceedings of the International Consensus Conference on the Risks of Tranporting Dangerous Goods. Waterloo, Ontario: University of Waterloo. 
slovic, P., Flynn, J., Layman, M. (1991). Perceived risk, trust,. and the politics of nuclear waste. Sclence, 254, 1603-1607.

Slovic, P., Layman, M., Flynn, J. (1991, Apri1). Risk perception, trust, and nuclear waste: Iessons from Yucca Mountain. Environment, pp. 6-11, 28-30.

Slovic, P., Layman, M., Flynn, J. (In press). Risk perception, trust, and nuclear waste: Lessons from Yucca Mountain. In $R$. E. Dunlap, M. E. Kraft, E. A. Rosa (Eds.), Public reactions to nuclear waste: Citizens' views of repository siting. Durhain, NC: Duke University. 


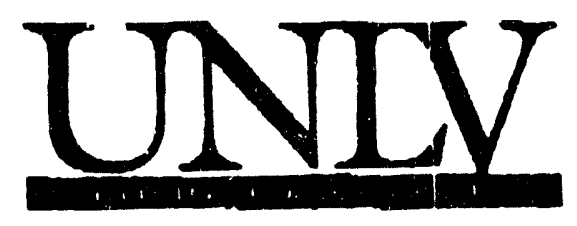

Jankiary 18, 1994

Mr. Allen Benson

Director of Program Relations Division

Office of Civilian Redionctivs Waste Management

US Department of Energy

1000 Independence Ave SW

Washington, DC 20585

Dear Allen,

Thank you for the oppurtunity to provide comments on the draft DOE public involvement policy. I realize that the dezdline is past, but I felt that this issue is important and will be around long enough that comments would be useful fo; your future activitles.

My reaction to the draft pollcy is that it is in important first step toward a more challenging goal of "Total Crediblilty Management" (T.CM). The concept of TCM would go far beyond passive stakeholder' participacion afforded by "listening" and "access points" outlined in the cument draft policy to al fundamental restructurting of how department activities that lead up to a decision making process are conducted. Irevelopment of a TCM policy would acknowledge that by whom and how work is done is as important as what is done when the objective is "buliding mutual isust".

Public health and safety evaluations of potential actions are an example of an activity that could benefit from direct involvement of lochnicaliy qualified stakeholders under a TCM pollcy. The drat public participation policy, by its' silence on the matter, endorses a continuation of contractors doing the work, public comment and response. This approach taken in combination with peer reviews being "encouraged" sather than required leaves me with littlo confidence that the "core valides" of sciendfic credibility, openness and peer review will be achieved.

I would be interested in commenting on future documenti on this subject. Please contact me if you would like to discuss this matter furtiner.

Sincerely

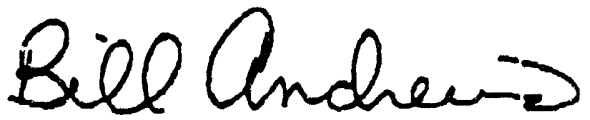

W. B. Andrews, PE

Deputy Director

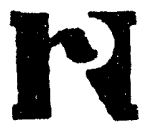

Hern, Reid Conter for Environmer tal Studies

4506 Maryland Par iwey - Box 454000 - Las Vojes, Nevada $89154-4008$

(702) 895-3382 • To1ex 62048184 UNLV/MSN • FAX 17021 895-3094 
555 North Kensington Avenue, Lo Grange Park, Illinois 60525 USA

Telephone: (708) 352-6611 • Telecopier: (708) 352.0499 - Telex: 4972673

January 21, 1994

monim

20. Fum

1940 sampereunnywab nowe

sun ox

san Jeen. ca csico use

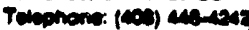

Mr. Jerome Saltzman, Director

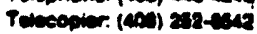

Office of External Relations

US Department of Energy

Washington, DC: 20585

\section{Dear Mr. Salizmian:}

The undersigned, as officers of the Arrerican Nuclear Society (ANS), have reviewed your December 17 memorandum and draft policy statement on public involvement, we respectfully pravide the following comments, which have been approved by the officers under the procedure specified in the ANS Bylaws, and are therefore submilted as a statement of the President on behalf of the Society.

1. The statement of purpose could be strengthened by noting the commitment of DOE to fulfill its cbligations to the nation and its people. It could be amended to read:

-..trust tetween the Department and the public it serves in order that it may more effective y carny out its responsibilitios to the nation and its people."

2. In the background section, it would add perspective to mention that notable exceptions to the poor $h$ story of public involvement include the Civilian Waste Management program and the Low-Level Waste Managernent program.

3. Under desfinitions, it would be he pful to include the responsible parties with which DOE must also deal: states, municipalities, corporations, contractors, etc.

4. In the Seicretary's memo, paragraph 5 (which discusses risk) could be made complete by mentioning that there are risks associated with DOE being unable to meet its obiligations to the nation. It could be amenders to read:

“. consenisus, including the risks to the nation and its people if the Department fails te carve out its obligations and meet its objectives in a timely fashion."

We have several general observations after reviewing this material. The overall intent of the policy statement and the letter is highly appropriate, but certain areas a:e left philosophically unclear.

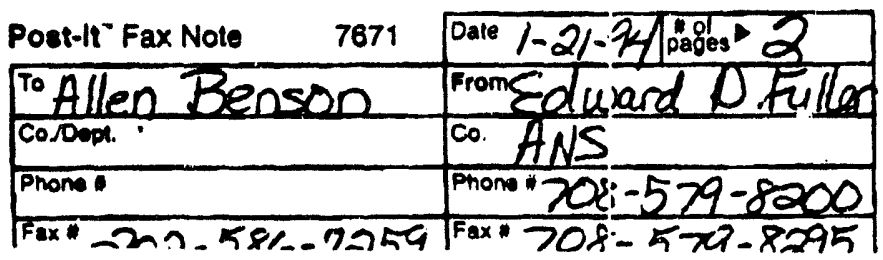


Publlc participation in decision making has become institutionalized as part of our democratic process. However, without accurate and complete information, public input would not be weill founded and could in principle be manipulated. These two important public rights under our government (information and participation) are interdependent, but nevertheless conceptually and practically distinct. The memorandum and policy statement could bo improved by recognizing this distinction.

On a different facet of the same general subject, the memorandum and policy statement could be significantly strengthened by explicitly acknowledging that DOE is prepared to do the complete job that US citizens expect their cabinet-level agencies to do. Part of that job is providing information and facilitating public inp st, which the policy appropriately supports. But ar other part is making desisions and providing accountability. With its focus on public involvement, the policy has lett this responsibility somewhat vague.

It is very important to clarify that DOE, not stakeholders, will ultimately make decisions and set policy. More broadly, $t$ is our government, not any special interest (even ourselves), that is ultimately accountable to the American people for such actions. Even Congress never contuses the right to be heard with the obligation to be obeyed

If you would like clarification on any of thiese items, please contact any of us directly. We appreciate the opportunity 10 be of service to DOE.

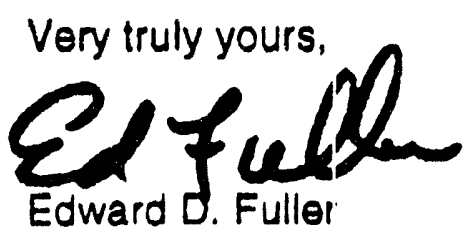

$x C$ ANS Board of Directors ANS Execiutive Committee PWMurphy 
December 31, 1993

Mr. Allen Benson

Program Relations Division

office of Civilian Radioactive

Waste Management

Department of Energy

Washington, D.C. 20585

RE: Comments to Draft Policy on Public Involvement/In Consultation With Esmeralda, Iincoln, and White Plne Counties.

Dear Mr. Benson:

Pursuant to the request contained within Mr. Jerome Saltzman's letter of December 17, 1993, the following comments to the Department of Energy draft policy on public involvement are providea. Because many facets of the nations' HLW program which may ultimately impact upon Nevada occur outside the state and beyond the programmatic lines which define DOE's Yucca Mountain project office, it is imperative that OCRWM at the headquarters level have in place an effective public involvement process. In this regard, DOE is to be commended for striving to put in place a pollcy which addresses local needs for public involvement at the national level.

Based upon a review of the draft policy on public involvement, the following comments are offered:

Policy: The concept that DOE public involvement needs to be routine suggests that it may be unimaginative, unable to accommodate evolving stakeholder needs, untimely, and potentially ineffective. Rather, than programmatic routine, DOE should strive to create and operate a civilian radioactive waste management program which is entirely transparent and fully open to affected and other interested party scrutiny and input. An effective public involvement process will permit public participation when and to what degree various publics determine appropriate to their needs.

Purpose: The statement of purpose aptly recognlzes the value that early public involvement can add to deriving optimal decisions. The purpose statement might note that the policy is intended to ensure that effective public involvement occurs and that DOE decisions ore not made without the benefit of important public perspectlves. As this paragraph now stands, the purpose of public involvement is articulated, yet the purpose of the policy on public involvement is not described. In order for the pollicy to be adopted and subscribed to, it would seem important to indicate its purpose. 
Page 2

Mr. Allen Benson

December 31, 1993

Backeround: The background statement effectively conveys the legacy from which DOE must regain pubiic trust and cunfidence. Perhaps missing though, is the important recognition that historically, because of its primarily defense oriented mission, DOE staff have assumed an "us and them" approach to dealing with the public. This mentality can be readily observed today in puhlic meetings between OCRWM headquarters and project office staff and various affected and otherwise interested parties. The effective management of radioactive wastc is a problem shared by all Americans and DOE staff are the public servants vested with responsibility for managing its management. DOE culture must emerge from it's defensive sbell to one of cooperation in the spirit of "we" as waste management is all our responsibility.

Definitioni Again, the concept of demand driven public involvement rather than instintion of routine may be more appropriate. Rather than simply than providing a means for Americans to influence DOE decisions, an effective public involvement initiative should be the means through which DOE decisions are reached. This definition might also he restated to reflect less emphasis upon inducing greater public involvement and greater focus at improving ways in which DOE can enhance and better use input the public has demonstrated a propensity to be willing to offer.

Goals I: Perhaps the fact that public involverment has, to a certain extent, already been routinized, is in part to blame for the low levels of public trust and confidence placed in the Department. While this is supposed to be a goal, one senses that DOE may consider that it has already achieved this. One wonders to what extent if at all, DOE employees would regularly cousider thernselves responsible for practicing and improving publlc involvement. More than likely, most employees consider the vast majority of their daily routines to be of non-interest or irrelevant to the public. There may in fact be countless actions taken every day by DOE and cnntractnr employees which individually and/or collectively would be and are of significance to the public. Unfortunately, the public is largely unaware of these actions. IIence the need for Departuental transparency (ie. Why is it that program budget meetings which follow open Technical Project Officer meetings at the YMP need to be closed? Are not the DOE and its contractors spending public monies on a non-classified program in which all Americans have a responsihility?)

Goal I needs to be restated to incorporate contractor staff as having an equal responsibility to effect public involvement.

Goals II: Internal decision-making should be reserved for those actions for which the Department has little or no discretion. In areas where much latitude has been given to DOE in implementing the Nucloar Wasto Policy $\Lambda$ ct, as amended, an open decision-making process should be devised. In all likelihood, the vast majority of DOE programmatic 
Page 3

Mr. Allen Benson

December 31, 1993

decisions are purely discretionary and could support external participation.

Goals III. This goal might be restated as, The public is informed in a timely manner about and empowered to participate in all Departmental decision-making activities of a discretionary nature."

Core Yalucs: Other guiding principles might include: transparency, early involvement, health risk-minimization, benefit-maximization, procedural equity, and distributional equity.

Responsibilities: If public involvement in to he a discrete performance element, how will performance be measured? Who will decide to what extent the stated goals of the policy have been met? Should not the public be responsible for eva'uating the perfurmance of senior departmental and program managers with respect to fulfiliment of public involvement goals?

The desire for consistency noted in the second paragraph of this section may be insensitive to differences botw'een DOE programs which are by nature adversarial (ie. facility siting) and those which may be much more cooperative (ie. energy conservation). Each programmatic office (ie. fossil fuels, solar, conservation, civilian radiogetive waste management) should be encovraged to develop unique public involvement initiatives which are responsive to the particular needs of affected and other interested parties. The difference between Program and Staff Offices is not clear. Are there offices within DOE which have staff but no programmatic responsibility? What does the terms coordinate imply? Will Orrice of Public and Consumer Affairs approval be required by field offices to respond to local stakeholder needs? Will this layering of administration in the name of consistency and efficiency perhaps result in bureaucratic paralysis? The function of the Office of Public and Consumer Affairs (Consumer Affairs? What is it that the Department of Enerzy sells? Are not members of the public also consumers? Are there consumers who are not members of the public?) is unciear and nut justifled with regard to effective publlc involvement.

Perhaps the Office of Public and Consumers Affairs should act more like an ombudsman to whom the public can go if they feel local public involvement is inadequate and program managers are being non-respmnsive.

Given the various levels of DOC staff with public involvement respolisibility, it would be helpful to provide an orgarizational chart as well as an indication of those astions for which each position has authority and those for which approval from a higher authority would be required. 
Page 4

Mr. Allen Benson

December 31, 1993

COMMENTS TO GUIDANCE ON IMPLEMENTATIONS OF THE DEPARTMENTS PUBLIC INVOLVEMENT POLICY

1st Paragraph, 1st sentence - Again, DOE is encouraged to reconsider the routine nature of its public involvement policy. Perhaps the term integral might be more appropriate.

1st Paragraph, 3rd sentence - Does the phrase "open to the full view and input" mean that if the public becomes aware of a DOE meeting that the public will be entitled to participate therein? Are al. DOE meetings to become "open" meetings (ie. the aforementioned budgeting meetings held by YMPO following TPO meetings)? Does this imply there will no longer be internal meetings? The terms "open", "full view", and "Input" need to be defined so as to make explicit the secretary's intent.

\section{Critical Policy Elements}

\section{$\# 1$.}

Implementing actions:

Affected and other interested parties should be vested with the responsibility to regularly review and report to the secretary departmental performance in meeting agency involvement goals.

\#3 - The integrated team must include affected and other interested parties in all public involvement planning activities, The third bullet item, refers to public information materials. It is important that DOE not confuse public involvement and public information/education initiatives. The former is driven largely by demands of affected and other interested parties. The latter can be driven by stated needs of such parties may also be motivated by Department needs to inform the public, despite the publics' having not requested such information.

White Pine, Esmeralda, and Iincoln Counties hope that these comments on public involvement will be reviewed.

\section{sincerely,}
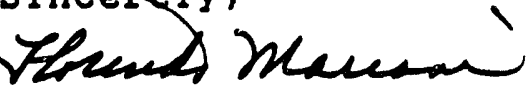

Florindo Mariani

White Pine County

Nuclear Waste Project

Coordinator 
D. Bums

Sr. Communications Specialist

(702) $794-1926$

Comments 12/1/93 Draft of Department of Energy Public Involvement Policy

Policy on Public Involvement

Generally, the Draft Policy on Public Involvement is an admirable and attainable effort to promote open government. While many of the concepts and directives outlined in the Draft are new to the Department of Energy, these same concepts and directives are not unlike the typical Mission Statement or Mission Plan from any serviceoriented business in the private sector.

Particularly salient are certain recommendations suggesting greater jurisdictional leeway for local DOE Offices in dealings with issues, concerns, and involvement of local citizens.

\section{COMMENTS:}

\section{Polley on Public Involvement}

Page 1, Paragraph 5, Definition Section: (COMMENT) Public Involvement should also include "substantive two-way communication" with employees (internal audience). The value of the interpersonal communications employees have in any given community is sizeable, often overlooked, and integral to communication on a local level

Page 1, Paragraph 5, Definition Section: (COMMENT) in the interest of clarity, examination of the use of the terms "public" and "stakeholder" might be helpful. Some consider stakeholders as part of the public, but do not consider the public (ie. mainstream citizer.3) as stakeholders.

\section{Goals}

Page 1, Paragraphs 7 and 8, Goals Section, Parts II \& III (COMMENT) Additional language could be added to clarify whether public involvement will be sought on all Department decisions. Also, language could be added to clarify as a goal of the Department to communicate the decision-making access points and accessibility of the Department's decision-making processes to the public. 


\section{Core Values}

Page 2, Top of Page, (COMMENT) "Accessibllity" should be added to the list of 11 Core Values. A Core Value should state the Department's commitment to be accessible to the public. A core value of accessibllity is necessary and appropriate with the other values of epennese, elncerity and honesty.

\section{Responsibilities}

Page 2, Paragraph 4, Program Managers Section(COMMENT) Effective public communication/involvement training for Department personnel is crucial to improving the Department's effectiveness. credibility, and public accessibility. The responslbility of communication/involvement training is listed as a responsibility of Program Managers but is later listed as an Implementing Action for the Director of Public and Consumer Affairs. The Director of Public and Consumer Affairs may be better sulted for decisions regarding communication/involvement issues because that position likely has more frequent public interactions.

Page 2, Paragraph 5, The Director of Public and Consumer Affairs Section: (COMMENT) As mentioned in an earlier comment, the development and implementation of communications/public involvement strategies for employees (internal audience) is very important.

Page 2, Paragraph 6, Managers of Field Organizations Section: (COMMENT) The action of "assuring that public involvement activities at their respective facilities and sites meet local needs" could prove a difficult task without an innovative (and allowable) method of accurately assessing the local needs. This assessment must be from the perspective of the local citizenry, rather than the Department's perception of the needs of local citizens. Effective assessment of public needs may include various types of public opinion research (polls, focus groups, etc.). 


\section{DRAFT MEMORANDUM}

\section{Critical Polley Elemente}

Page 2, Item 3. "Site managers and local program officlals will routinely advise headquarters on local stakeholder needs/concerns and on the appropriateness/adequacy of public information/involvement efforts in their areas." (COMMENI) To promote more accurate reporting of public perceptions/needs/concerns and to accurately report the effectiveness of public information/involvement efforts, a system of community research to gauge public response to Department efforts might be effective and appropriate. Reliance on the creation of "public response" reports with input from "officlal stakeholder groups" may not provide an accurate representation of "public perception."

Page 3, Item 5. "The Department will work to establish, announce, and manage a data base of real-time information avallable to the public through telephone and computer access points." (COMMENT) This implementing action is meant to "foster candid information exchanges directed at reaching a common understanding of options and risks and developing consensus." Further implementing actions should be examined that would transmit accurate and timely information to large segments of the public. Development of communication programs using mediums the public is already using (Television and radio announcements) migh. be effective to reach this goal. This, together with a program of appropriate means for public response would create the foundation for a Department/Public dialogue that would require little of the public's time or effort to be effectively involved in. 
P.E. Seidler

Comments 12/1/93 Dratt of Department of Energy Public Involvement Policy

- Like the 10/12/93 Drat Policy the 12/1/93 revised Policy is excellent. The participatory philosophy defined by the Department is both pragmatic and progressive.

- The Office of Public and Consumer Aftairs was very responsive to YMP comments on the 10/12/93 Draft Policy.

- The Policy document lacks a numbering system. Numbering is necessary to aide stakeholders who will review and comment on the document. At the very least the pages should be numbered.

- While the Policy correctly leaves implementation as the responsibility of each program office it has a potentially burdensome and counterproductive coordination requirement (page 2, paragraph 2). The requirement to "assure a consistent approach throughout the agency and with its contractors and to avoid unreasonable demands on site personnel or the public's time, Program and Staff Offices will coordinate their public involvement activities through the Office of Public and Consumer Affairs... This coordination role in no way limits or dilutes program manager's responsibility...". This Policy requirement has a number of shoncomings:

- A consistent "approach" to public involvement is neither feasible nor desirable. The approach of each site will be determined by the political environment of that locality and the issues being addressed.

- A more appropriate objective is a consistent "understanding" of the Department's public involvement "philosophy" and a commitment to implement it. This does not require an on-going coordination function. Cultural change will not come through coordination. Good leadership and an effective incentive structure will produce the desired cultural change.

- Unfortunately the historical reality in the Depanment has been that "coordination" is usually synonymous with control, bureaucratic bumbling, resource waste and delay. Without substantial improvements to the broader management and decision making culture of the Department "coordination" could, sadly, be counterproductive. 


\section{Department of Energy \\ Washington, DC 20585}

January 21, 1994

NOTE TO: Betty Nolan

SUBJECT: Comments on Draft Public Involvement Policy

Please find attached comments from members of the Environmental Management Advisory Committee regarding the Department's Draft Public Involvement Policy.

Comments received via phone conversations were recorded and are attached as well as written comments received.

If you have any questions or if I can be of any further assistance with respect to the plan, please give me a call at (202) 586-4400.

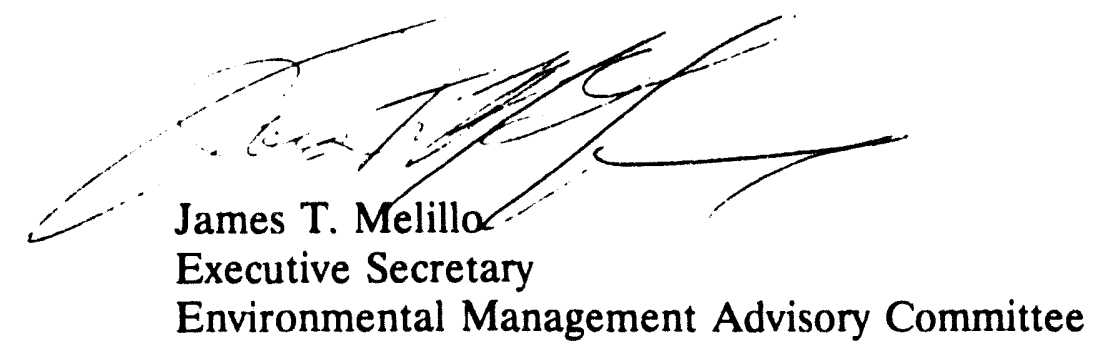

\section{Attachments}

1. List of phone comments

2. Vicky Dastillung Comments

3. Shira Flax Comments

4. Russell Jim Comments

5. Tom Winston Comments 


\section{Comments Received Via Phone Conversation}

1. Mr. Al Alm

Science Applications International Corporation

1710 Goodridge Drive

McLean, VA 22102

(703) $821-4530$

Comments: A good plan.

2. Jerry Christean

Mid-Atlantic Public Service

District Council of Laborers

10521-C Braddock Road

Fairfax, VA 22032

703-425-3643

Comments: A good plan.

3. Mr. Tad McCall

BDM Federal

1501 BDM Way

McLean, VA 22102

703-848-6274

Comments: Very good plan. Maybe we can send it over to DOD and EPA! What is the purpose of the core values section? It seems to "just sit there."

4. Mr. Ron Ross

Western Governors' Association

60017 th Street, Suite 1705

Denver, CO 80202

(303) 623-9378

Comments: A very good plan. 


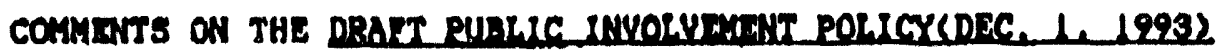

\section{Submitted by}

Vicky Dast lllung

(613) $738-6538$

The Publle Involvewent Polloy and lta Guldance on Implementation pute in print what the publle has been agking tor tor many yeara. If DOs can turn thla pollay Into reallty. It wlll be a blg atep forward for all of uo.

There are a couple of areas that ol cht be atumbling blocks to full and efflelent implementatlon of this polley?

Having traveled to varloue BM facllitles with EMAC. there are often questlone that the publle has or Intormatlon that people would like to access. However, they have often been truatraced in thelr efforts to learn more. It would be ueeful if DOS would clarlfy who la in charge of what publle involvement activitleo at each alte or at up one poreon who could then refer the public to the proper person and procedure(lif there Io one) in order to have their neode addresecd. Wl th changlng Job titlos and the rapld changes in perronnel fllling those Jobe. It Is hard for the publle to know where to go to aok the questlons. Aleo, how wlll thio polloy Impact the contractora that run many of the altog. WIII they also be requlred to adopt thle? otten the publlo does not diatingulah batween DOE people and contractor people. In the yes of the publla they are all Juat "people trom the alte". If the publle has a oood or bad experlence with the DOE or 1 te contractors, It le often vlewed as a good or bad experlence "with people at the olte" ragardloge of who they actually work for. Thle factor needs to be consldered as DOZ works to Implement this polley.

Inevitably, there will cane time when someone in the publlo wlll teel that DOB is not IIving up to Its publle Involventent polley. Who would thay go to with any complalnta? WIIl DOE make thlo person (and phone and addreas) clear to the publlo, so they wlll know the proper place to get such concerne rosolved?

How wlll DOE evaluate how well thla polloy fo actually being Implemented? 8ele-evaluation lo eseential, but it ghould not be the only method of evaluation. The publls should be Included somohow too. 


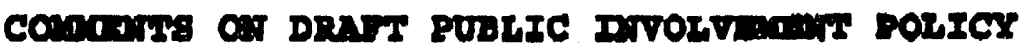

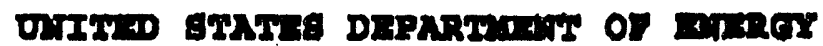

I want to thank the taff from DOB' Advisory Commlttee to the Aselstant secretary for Bavironmental Restoration and Waste Management (BMAC) with making it possible for BMAC membere to coument on the araft public involvement policy.

I found the pollcy to the polnt, well written and weld thought out. I have simply a few questions:

Why does the chain of responsibility stop with the fleld Public Affalra/Bxternal Relatione Directors. Have they been the traditional contact polnte with the commulty?

I aspoclate Public Affaira/Bxternal Relat1ong gtafe with prese relations, briefling tasks.

Does the Department of Bnergy Intent to draw upon the taleate of otaff that have the skilis of managing a program that allows the public to 'Ineluence dectolono made by thelr govermment.' Doee DOR have otaff avallable that can tdentify the training and support their colleagues need to begin 'routine eubstantive two-way communication...

- How axe the 'Critlcal Policy alemente' Integrated in performance evaluations (one tool that could ensure that the implementing actions are, in fact, implemented).

- Complemento to the policy author for including 'ataef Involvement' an part of commintty involvement: and focusaing on 'appropriate pre-declelonal accese polntg...'

I hope the above comments are helpeul. And thanks for the opportunity to comment.

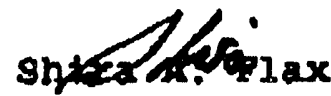




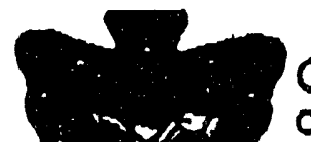

Confederated Tribes and Bands

Established by the of the Yakima Indian Nation

January 4, 1994

James T. Mel1110

Executive secretary

Environmental Management Advisory Committee

U.S. Departmant of Energy

1000 Independence Ave. SW

Washington, D.C. 20585

c/o Kelly Rippeto

Fax: 202-586-0590

Daar James:

Here are some coments on the Draft Public Involvement Pollcy;

I hope thero will be training for managers on implications of

Treaty rights of Indigenous people. It usually emerges as an

I would recommend the policy discuss notlae, what 1sgues, who gets it and whon. For inetance, the Yakima vation considors its general public notices, and does not with to be lumped in with 'rribal governments feel the same.

If you have any giestions please call me at (509) 452-2502.

sincerely,

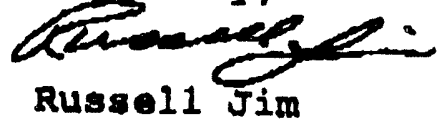

Post Office Box 151, Port Road, Toppenth, WA Doses (509) 865-5181 
Soutrumed Dlstritot Offles

40 South Maln 8troet

Daylen, Chis $46402-2080$

(510) 22669857

FAX (513) 285-6104

Ceorge V. Volnovich Governor

January 7, 1994

catherine Volk.

ax-14

Fors-1H-031

Department of Energy

Washlington, D.C. 20585

Dear Ms. Volk,

Several of us at Ohlo EPA have reviewed tho draft DOE polloy on Publia Involvement. I shared it with all of our site coordinators for the DOE sites as well as Jennifer Tiell, our Deputy Director Ior Programs.

Basically, we feel that the policy represente a good eftort to further "open up" the Department of Energy. Specific comments on this policy are listed below.

1. General Comment: To develop a successful public Involvement program at each site, reguires a long term committment from top management ifDOE site managor and president of the main operating contractor ox ERMC). It is extremely important that the public have a chance to interact at this level. It 18 also just as important for top Don taf and contractors to understand that this is a critical factor in selecting contractors and key staff.

2. Page 2, under responsibilities: It is important to note that training employees is not enough. DOE needs to evaluate efrectiveness; devise 1mprovements; create incentives; and discourage onetions for tnept, 121-adviged, but well Intentioned communication.

3. Page 5, 4: Education of the public is as essential as that of DOF staff if "common understanding" is the goal. The publio can help you ldentify education needs and design programs to meet those needs.

As you know, I have stated on numerous occasions that DOE must work very aggressively to "aven" tha, quality of public involvement across the complex. There are definite success storles, but there axe lso sites who lag behind. Clear expectations from top DOE management will halp to bring about improvement from in those lagging areas. 
Catherine Folk

January 10,1994

Page 2

Thanks for the opportunity to comment. Please let me know if you have any questions:

sincerely,

Them en Anime

Sis

Thomas A. Winston, P.E./

Chief, Southwest District office

cc: Jennifer Tied 1, Deputy Director Graham Mitchell, swDO 
January 24, 1994

To: Betty Nolan

DOE-HQ

Yrom:

Connie Nash, DOE-ID

Public Participation Coordinator

DOE-ID Communications Division

8ubject: Comments on HQ Public Participation Policy

Attached are the comments from the Idaho operations office, from both internal reviewers and external stakeholders. The greatest response came from external parties, while most internal managers chose to not respond or respond with "no comment.

My impressions, from both these written transmissions and informal conversations, are that the policy was well-received. This time of transition in DOE's level of disclosure can be somewhat difficult to manage, and the resultant discomfort is understandable. I hope that as greater information is dispersed, both externally as to the nature of DOE operations and internally as to the nature of DOE expectations in the way of public involvement, this discomfort will subside. We have directed the Department toward a better way of dolng business; the fact that some individuals may fear the path should not deter us from the destination.

I hope these comments are well-received and may be incorporated into the final policy statement. If there is anything else you need from me, please don't hesitate to call.

Attachment: ID Comments

Post-1t'm brand fax transmittal memo 767

of pages 5

\begin{tabular}{|c|c|}
\hline "Betay Nelax & $\operatorname{lesh}$ \\
\hline C. IDOE- $1+Q$ & C. $D D C=$ \\
\hline Dept. & Phoné 209$) \approx 6-5920$ \\
\hline 2). $586=$ & Fat: \\
\hline
\end{tabular}


Comments on the DOE Public participation Pollcy

from the DOE-Idaho Operations Office

and Representative stakeholders

\section{overview}

In general, the policy was very well recelved and people greatly appreciated the opportunity to comment prior to finalization. stakeholders who received the document viewed the attempt to include their input as a reflection of the Department's efforts to increase stakeholder awareness and involvement in tandem with greater openness on the part of DOE. We have divided our comments into five categories:
the tone and language of the policy;
the format and structure of the document;
implementation of the policy;
relationship of this document to other public
partlcipation efforts and guidance; and
other comments.

In an effort to minimize "filtration," we have provided the input in the commentor's own words wherever possible. Each comment is provided with its source, to aid in understanding that person's perspective.

\section{Tone and Ianguage of the Pollcy}

After reviewing the memorandum regarding guidance on implementation of the Department's Public Involvement Policy from the secretary. I strongly agree that the process must be tailored to specific stakeholder's needs and that the policy only be used as a guide based upon the diversity of stakeholders. - Brett Hayball, Shoshone-Bannock Tribal/DOE Coordinator and Project Director

I've read through the proposed public participation policy document and find it to be well stated, though perhaps too nonspecific in the area of identifying stakeholders. I hope that the Department's commitment to two-way communication with "other governmental entities [w1Il] include local (city and county) as well as state and tribal officials. - Iinda Milam, Mayor of Idaho Falls

The document is well thought out and written. If embraced by Department managers, it will produce positive results. - Candis $J$ Webb, DOE-ID

overall, the draft is very good. The key truly is establishing public involvement as an institutional way of life, rather than a goal to give lipservice to. To that end, holding officials accountable and rewarding risk-taking is a step in the right direction. - Terry Smith, Public Information officer, state INEL Oversight Program 
I have reviewed the draft statement on public involvement and find it consistent with other statements of this type. It is very wordy and to me states the obvious. I expect truthful answers. I expect to be able to express concerns about public matters. - Ellie Hamilton, Private Citizen/Retired $R$. $N$.

I would summarize the policy as follows:

Be honest in all answers;

Encourage questions within the Department and from the

Public; and

Share the concerns of everyone at all levels.

- Ellie Hamilton, Private

Citizen/Retired R. N.

\section{Format and structure of the Document}

The secretary may want to conslder issuing separate short letter to all Departmental employees to emphasize culture shift and positive aspects of goals. - Candis $J$ Webb, $D O E-I D$

I assume this policy is related to the DOE mission statement and 1s a part of core value 1, "We are customer-oriented. A copy of that mission statement along with the draft on public involvement would have been helpful to put the draft statement in proper perspective. - Ellie Hamilton, Private Citizen/Retired $R . N$.

In you section on "Program managers and staff communication training: Use resources already available. Emphasize the need for basic communication skills; reading, writing, and speaking to the public and private education at all levels. These skills begin at the elementary level. Critical thinking is necessary in all areas of 11fe. Work may be necessary in the short-run but dont make it a permanent part of the DOE program. - Ellie Hamilton, Private Citizen/Retired $R$. N.

In your Core Values section: Include "accuracy. A statement may be consistent with previous statements. It may be credible. It may be an honest expression of your beliefs but is it accurate? - Ellie Hamilton, Private Citizen/Retired R. N.

\section{Implementation of the policy}

These policies can be effective for the Tribes only if federal and state officials deliberately recognize our governmental sovereignty and that a trust responsibility derives irom the historical relationship between the Federal government and Native American Tribes, as expressed in certain treaties and Federal Indian law. When undergoing any negotiations with states that may affect the Tribes, the Department of Energy must assure that Tribal rights and concerns are represented and considered before taking action, making decisions, or implementing programs, as this is the Tribes unigue government-to-government relationship 
with the United States of America. - Brett Hayball, ShoshoneBannock Tribal/DOE Coordinator and Project Director

The policy should be implemented through the DOE order system, rather than just issued as a policy letter. - Candis $J$ Webb, DOE-ID

There will be some resource impacts at the Field office level. over the past several years, many public Affairs offices have experienced reduced staffing. While the line organizations may absorb much of the support activity, there will be a correlative increase in PA workload. The requirements need to be analyzed and defined. - Candis $J$ Webb, DOE-ID

Regarding the second implementing action under section 2: "Site managers ... will advise on appropriate pre-decislonal access points for public input and facllitate accommodation between local and national interests." That concept could and should be incorporated into each site's citizens advisory board responsibilities, or some other appropriate citizen group. Let the citizens advise the site manager first on which access points are most appropriate. - Terry Smith, Public Information

officer, state INEL Oversight Program

The final implementing action (section 5) providing for the establishment of a data base of real-time information is wonderful in theory, but is it workable or feasible cost-wise? Is the information highway ever to be paved? - Terry Smith, Public Information officer. State INEL Oversight Program

\section{Relationship of Policy to other afforts and Guidance}

The Shoshone-Bannock Tribes and the Department of Energy Idaho Operations office are currently operating under a Native American Policy which is a speciallzed living document that pertains specifically to some of our needs. That policy, in concert with our "Working Agreement" between the Shoshone-Bannock Tribes and the Department of Energy idaho Operations office, both of which can be updated as the need arises, create the premise on which we interface our public involvement with the Department. - Brett Hayball, Shoshone-Bannock Tribal/DOE Coordinator and Project Director

It is DOE's hope and the expressed desire of many [stakeholders] that the INEL Citizens Advisory Board would provide a level of public examination beyond the Environmental Restoration \& Waste Management program. However, it was agreed that the relationship of the Citizens' Advisory Board with other existing mechanisms, including those defined in the [legally mandated] Community Relations Plan, needed to recelve attention and resolution. Brett Hayball, Shoshone-Bannock Tribal/DOE Coordinator and Project Director 


\section{Other comments}

I would like to extend my appreciation to have the opportunity to offer my comments regarding the DOE Publis Involvement Policy. as it does represent the Department's openness initiative towardo sakeholder involvement. - Brett Hayball, Shoshone-Bannock Tribal/DOE Coordinator and Project Director

The Shoshone-Bannock Tribes will recognize the existing Native American Policy and the Working agreement before any other stakeholder policy, [unt1] such a time that the INEL Citizans Advisory Board is in place and able to review such policy from a wider perspective]. - Brett Hayball, Shoshone-Bannock

Tribal/DOE Coordinator and Project Director

I am certainly pleased to represent the city of Idaho Falls on the INEL Economic Development Working Group Team, and hope other opportunities will be identified. - Linda Milam, Mayor of Idaho Falls 
MEMORANDUM TO: Betty Nolan, PA-2

\section{SUBJECT: Comments on Draft Public Involvement Policy Statement}

The Office of Nuclear Energy, including the Office of Naval Reactors, has reviewed the draft DOE Public Involvement Policy Statement, as requested by Mike Gauldin in his memorandum of December 1, 1993. We have the following general comments, plus suggestions for modifying specific passages.

We believe that increased public involvement in DOE program activities is a worthwhile objective, and we support the Secretary's efforts to move the Department in this direction. However, the draft policy statement conveys the impression that the public can have daily and unrestricted access to the policy-making process and staff in all DOE program offices. This is not feasible, especially in the case of DOE program offices which have a national security mission.

Also, in its decision and policy-making, the Department often uses certain information from private industry and other Government agencies that must remain classified, proprietary, or privileged. Any. release of this information needs to be carefully coordinated and cleared with the groups that have given it to us. Language to that effect should be included in appropriate sections of the policy statement.

With this in mind, we have marked suggested wording changes and other comments directly on the draft document, which is attached. For certajn changes, we have placed a number in the right-hand margin indicating our rationale for suggesting the change, as follows:

1. Inappropriate for a policy statement, since the statement could be around for years and would then refer to events in the distant past. Also, it puts the initiative in a negative context which is potentially counterproductive in its impact on those in the Department who may not agree with all the characterizations of past policy.

2. Intended as a clarification. The public cannot, practically be involved in daily "program operations".

3. The public provides input to the Department, which we use in making decisions. As written, this section implies that the public actually participates in the decisions themselves. 
4. Need to clarify or delete. Certain matters should be cleared with PA, but it appears impractical to both increase the involvement of the public as described in the policy and clear everything with PA. This will tend to delay response to the public and convey the wrong impression re openness.

We look forward to the opportunity to review and commient upon further revisions of the draft Public Involvement Policy statement.

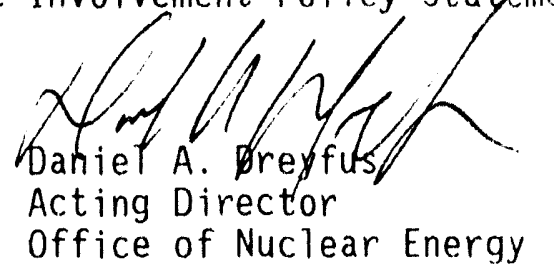


POLICY: The policy of the Department of Energy (DOE) is that public involvement activities, at headquarters and in the field.

PURPOSE.

Public involvement brings a full range of diverse staketolder viewpoints and values early into the Department's decision-making process, enabling the Department to make decisions and

The Energy Department is reldively new at encouraging public involvement in ing affairs. The Department grew largely out of the highly regimentad Cold War culfure of two of its predecessor agenjies, the Atomic Eergy Commissten and the Energy Research and Developent Administratton. The focul was on national defense through nyclear deterrence the priority on design and production of nuclear apons; and the exphasis on chassified information and legally-requiled secrecy.

Changing this 50 yoar old culture flem a closed. command-oriented hierarchy into an open, participatory culture that values diversity and innovation requires specin attention and leadership from the top down. Such headership and donge are essential if the Department is to succeed in meeting tha economic and environmental challenges of the next century.

DEFINITION: Public involvement provides a means for Americans to influence decisions made by their government. It requires routine, substantive two-way communication between the Department of Energy and other governmental entities, organized groups, individuals, and the general public interested in and/or affected by the Department's decisions and activities. This communication will vary widely in nature and scope, from informal cunversations between individuals to scheduled meetings and workshops, to legally-required public meetings and hearings and federal-statelocal-Tribal agreements. The Department will actively seek, incorporate, or otherwise respond to the views of its stakeholders.

GOALS: I. Credible, effective public involvement processes are routinely incorporated into the Department's d activities, at headquarters and in our laboratories, facilities, and field offices

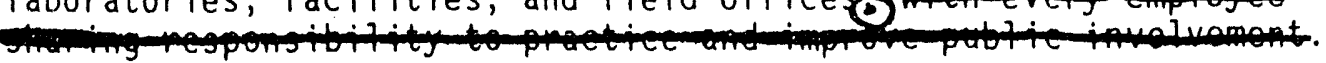

II. A clearly defined, coherent internal decisionmaking process with known access points for public involvement is routinely followed.

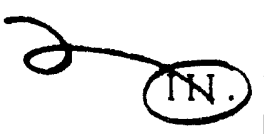

The public is informed about and Departmental decision-making.

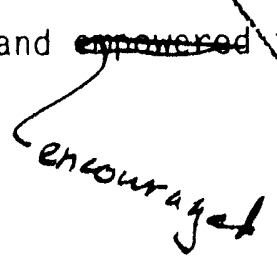

to participate in

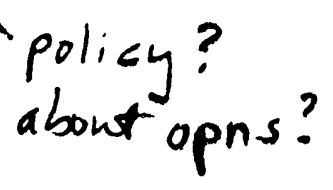




\section{DRAFT}

CORE VALUES

\author{
Accountability \\ Fairness \\ Openness \\ Respect \\ Risk-taking \\ Sincerity
}

\author{
Consistency \\ Honesty \\ Peer Review \\ Responsiveness \\ Scientific Credibility
}

\section{RESPONSIBILITIES: $0 \uparrow$}

Under this poltay, public involvement will be a discrete performance element for Enior departmental and program managers directly responsible for its effective implementation.

To assure a consistent approach throughout the agency and with its contractors and to avoid unreasonable demands on sitle personnel or the public's time, Program and Staff offices will coordinate the ir public involvement activities through the office of pubic and consumer Affairs, at headquarters and in the field. This coordination role in no way Timits or dilutes program managers' responsibility to plan, fund, and support appropriate levels of public involvement in their programs.

The Principal Secretarial Officer and Senior Departmental Mahagers will ensure that public involvement principles, values, and processes are fully understood and practiced within their programs and that necessary training and resources (human, information, systems, and financial) are provided.

Program Managers are responsible for identifying, planning, badgeting, and implementing the appropriate hevel and scope of public involvement activities in their programs, and coordinating activities through the Office of Public and Consumer Affairs. Program managers will assure that their staff receive basic communication training and, where appropriate, advanced public involvement training.

The Director of Public and Consumer Affairs, headquarters, will e.iablish a point of contact and mechanisms to coordinate public involvement activities Department-wideg

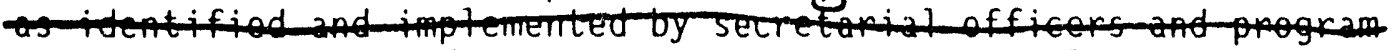

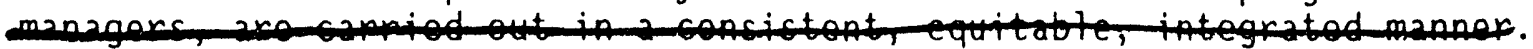
Public and Consumer Affairs will provide advice and support to program offices in developing and implementing effective communications/public involvement strategies and information materials for local communities, stakeholders, employees, and the media.

Managers of Field Organizations are responsible for assuring that public involvement activities at their respective facilities and sites meet local needs, are appropriately coordinated, and reflect Departmental principles and values. Field managers will regularly advise headquarters on public involvement issues/needs of regional or national importance and recommend appropriate courses of action. 
(i)

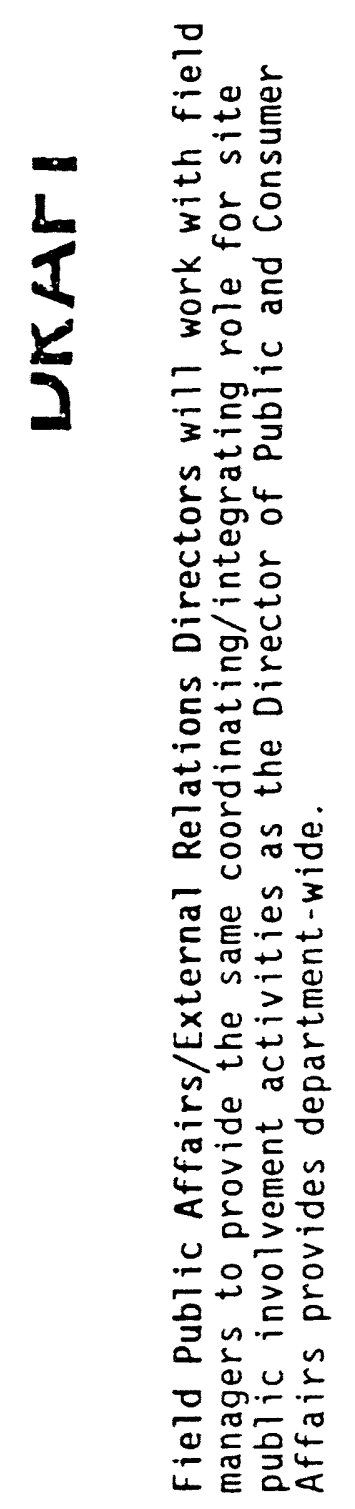


DATE

MEMORANDUM FOR: HEADS OF HEADQUARTERS ELEMENTS MANAGERS, DOE OPERATIONS OFFICES

FROM:

THE SECRETARY

SUBJECT:

GUIDANCE ON IMPLEMENTATION OF THE DEPARTMENT'S PUBCIC INVOLVEMENT POLICY

It is the policy of (he Department of Energy (DOE) that public involvement be a routine component program activities at headquarters and in the field. This policy marks a clear break with past practice by challenging the Department and its contractors to embrace a new culture of openness Henceforth, the business of the pepartment will be open to the full view and input of those whom it serves,

While public involvement processes must be tailored to specific site and program needs, the following broad guidance is provided to assist headquarters and field managers in implementing this policy department-wide. Several critical policy elements and implementing actions are identified below. These should be viewed as a beginning point. They illustrate the comprehensive nature of public involvement as envisioned in this policy and the innovative leadership required to implement it. Using the following elements as a guide, you should consult with your stakeholders to develop public involvement plans and activities.

\section{CRITICAL POLICY ELEMENTS}

1. The Department recognizes that honesty, forthrightness in dealing with external parties, and consistent, credible, quality performance are the bases on which to build public understanding and trust.

Implementing actions:

- Officials representing the Department will be empowered and accountable for the honesty and accuracy of their public statements and for assuring diligent follow-up and timely results from the commitments they make.

7 Departmental officials will routinely and consistently listen and respond to public input.

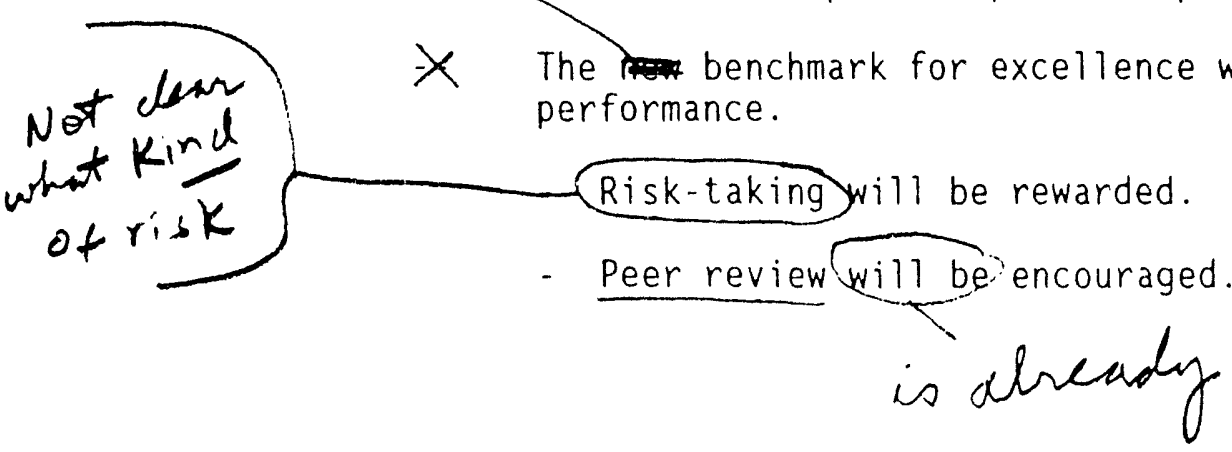


2. Departmental program development, planning, and decision processes must be clearly defined, with regular, well-known access points for public input.

\section{Implementing actions:}

- Principal Secretarial officer and other senior departmental managers will ensure that other affected program officiais, site managers, and stakeholders are appropriately integrated into their planning and decision-making processes.

- Site managers, as those closest to affected communities and interested parties, will advise on appropriate predecisional access points for public input and facilitate accommodation between local and national interests.

3. Headouarters, Jaboratories facilities, and field offices will operate as an integrated team in planning public involvement activities, combining resources, sharing information, and coordinating schedules.

- Cooperation will be rewarded.

Site managers and local program officials will routinely advise headquarters on local stakeholder needs/concerns and on the appropriateness/adequacy of public information/ involvement efforts in their areas.

The Director of Public and Consumer Affairs, working with the Programmatic Assistant Secretaries, will develop consistent formats and clearance procedures for public information materials, LWon't work of evengthing goves through $P A$

4. The Department must establish/and support training/education programs to meet evolving pyblic involvement needs, both internal and external.

Implementing actions:

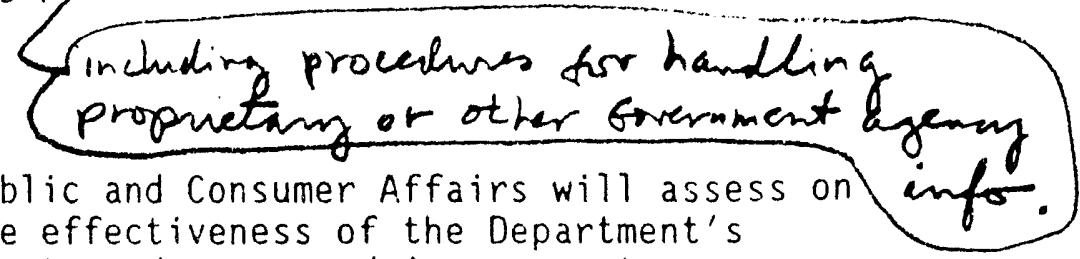

The Director of Public and Consumer Affairs will assess
an annual basis the effectiveness of the Department's communications efforts and recommend improvements.

The Director of Public and Consumer Affairs and the Assistant Secretary for Human Resources and Administration, working with the Programmatic Assistant Secretaries, will identify and coordinate communication/public involvement training on a priority basis until all appropriate headquarters and site personnel are trained. 
DRAFT $\odot$

5. The Department must foster candid information exchanges directed at reaching a common understanding of options and risks and developing. consensus.

Implementing actions:

-- Whether formal or informal, all public involvement activities will be conducted in a spirit of openness, respect for different perspectives, and a genuine quest for information and ideas.

? -. The Department will work to establish, announce, and manage a data base of real-time information available to the public through telephone and computer access points.

Need to clingy 
$217-782-6761$

January 18,1994

Ms. Betty Nolan

Ofice of Public Affairs

$8 \mathrm{H}-0.73$

U.S. Department of Energy

1000 Independence Avenue, S.E.

Washington, D.C. 20585

RE: Comments on DOE Public Involvement Policy

Dear Ms. Nolan:

Attached you will find comments on the DOE "Draft Public Involvement Policy" dated December 1, 1993. It has been a pleasure reviewing and commenting on this document and I trust the IEPA comments will be of use to you. Please note the following:

\section{GENERAL COMMENTS:}

For the most part the draft policy is a fair attempt at establishing a protocol for involving the public in DOE decision making. It should be noted however that DOE should not stop at just drafting this policy. In order for DOE to be effective at community involvement, a guidance document or handbook must first be drafted to expand on the newly generated policy. A document that may be useful for DOE to review prior to drafting a guidance document would be USEPA document "Community Relations in Superfund: A Handbook" EPA/540/R-92/009 January 1992.

It would also be userul for DOE to investigate the community involvement requirements of the specific program or law that it intends to comply with when conducting environmental remediation (ie. RCRA or CERCLA). Many environmental regulatory programs presently have very defined community relations guidelines in place that should be followed when these laws are determined to be applicable, relevant or appropriate to the planned remedial activity.

The purpose, core values, and goals, as outlined in this draft policy, contain many elements that are proven to be essential for an effective public involvement program. This draft policy would appear to provide the design for a good foundation for DOE's public involvement program. The effectiveness of this public involvement progiam, as like similar programs, will in large part hinge upon 
two other key components-- the quality of staff interpersonal skills, and the level of support from upper management.

\section{SPECIFIC COMMENTS}

\section{Definition:}

A. The definition calls for two-way communication between DOE and those "interested in an/or affected by the Department's decisions and activities." This definition should include two other groups: 1) those living or working in the immediate vicinity of a DOE facility who are potentially affected, and 2) those who are not affected by perceive that they are affected. These two groups have been able to delay projects at various sites throughout the Nation when not included in a public involvement program.

B. The term "stakeholders" should be changed to reflect something a bit more personal or relative to the public.

\section{Responsibilities:}

A. "Public involvement will be a discrete performance element for senior departmental an program managers..."Does this statement mean that these managers will be responsible for public involvement activities, that this responsibility will be measured on their annual performance evaluation, both or something else?

B. Who will be responsible for responding to news media inquires?

C. Who should the IEPA and other government officials contact at DOE about news media inquiries? Issuance of news releases? Approval of quotes from upper management on joint news releases?

D. Will IEPA and other government agencies have the opportunity to review and comment on news releases affecting their particular state? Public involvement plans?

E. Why are senior level departmental and program managers only responsible for the policy's effective implementation? should this concept be carried out through the DOE ranks to be implemented? 
3. Goals:

A. How is the public informed about and empowered to participate in Departmental decision-making?

Again, thank you for the opportunity to review and comment on this draft policy. If you have any questions or comments concerning any of the above mentioned comments, please do not hesitate to contact me.

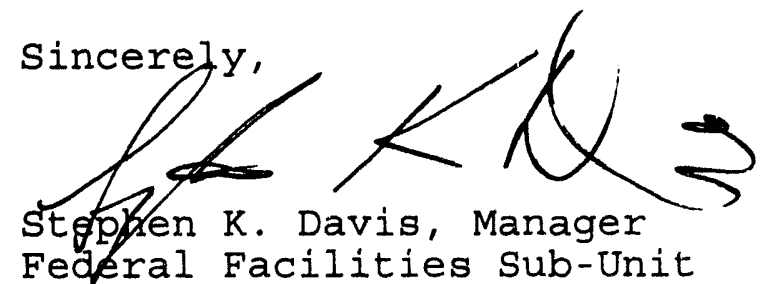

Remedial Projects Management section Bureau of Land 


\author{
DATE: JAN 211994 \\ REPLY TO \\ ATTN OF: \\ Department of Energy Oakland Operations Office, Office of Public Affairs \\ subject: $\quad$ Public Involvement Policy Comments \\ To: Betty Nolan, Director \\ Consumer and Public Liason Division
}

We are providing the following comments from the Oakland Operations Office and its Laboratories on the Draft Public Involvement Policy. We are summarizing the comments and providing a multi-page full response.

1. The policy should stress proactive public involvement activities by DOE rather than reactive actions.

2. Public involvement should be balanced against delays in activities caused by time needed for consultation. In some cases, it may be better for DOE to cnnsider stakeholders' opinions without going through a formal process.

3. POLICY:

- Definition: (fourth and fifth lines) "individuals" and "general public" are redundant.

- Responsibilities: Commitment of resources should be made explicit.

- Goals I: (fourth line) change "field" to "operations."

- Goal II: delete "intemal," change "known" to "pre-specified" or "established."

- Goals III: Items such as personnel records and classified data that will not be made public should be listed.

- Purpose: Replace "better" decisions with "more-informed" or a similar phrase.

4. GUDDANCE: Critical elements - (Implementing actions)
- "The new benchmark for excellence will be leadership/performance" Excellence of what?" (e.g. Public Affairs).
- Risk taking should be better defined.
- "Peer review" Of what? 
5. There should be more direct connection between the policy goals and implementing actions to achieve those goals.

6. The commitment to provide training and resources to achieve goals should be made explicit. The only non-staff resource mentioned in the draft guidance is a data base.

7. "Risk-taking" should be clearly defined.

8. "Public participation" is favored over "public involvement" as more descriptive and accurate.

9. The issue of assuring a "balanced" or "representative" public is not addressed. The term "public" is used too often and too broadly without additional definition.

10. The role of public participaticia seems to vary between the draft policy and guidance. The policy says the the public is "empowered to participate in Departmental decision making." The second says the policy is for the public to be involved with the Department in "developing concensus."

11. The policy and guidance should be flexible to meet the different needs of different communities and not place unreasonable demands on site personnel or the public.

12. The policy is too broad. It is hard to determine which activities should be coordinated with the public. It also should address who should determine which activities the public should be involved in.

13. Public involvement policy should be coordinated with customer advocate policies and activities to assure consistency.

14. The policy should tell the Operations Offices "what" rather than "how" (through the Office of Public and Consumer Affairs at headquarters and in the field) as it does on Page 2.

15. Reference is made to empowering the public to participate in Departmental decision making. Both the Department and the public need to have a clearly defined understanding of what role public participation will play in Department decision making.

16. Will public input be taken under consideration or will it substantially influence decisions, and if so, to what extent. How much weight will public opinion really carry in a decision, particularly if it is contrary to the prevailing Departmental position?

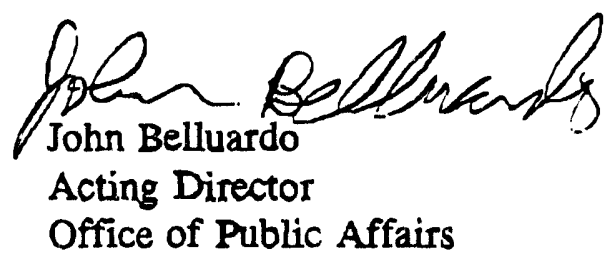


January 7, 1994

Mr. Paul Thrash

Department of Energy

1301 Clay Street

Oakland, Ca, 94612

RE: Review of Draft Public Involvement Policy

Dear Mr. Thrash:

Thank you for the opportunity to review and comment on DOE's Draft Public Involvement Policy.

The goals of this draft policy are praiseworthy and laudable; I support openness and truthfulness in dealing with stakeholders and I encourage DOE's efforts to change the culture within the DOE complex. For DOE to build understanding and trust with its stakeholders and to openly and honestly respond to stakeholder questions and concerns is fully appropriate. However, I am concerned about the degree and extent to which this policy will be implemented and I question the usefulness of actively seeking stakeholder involvement in all aspects of the Laboratory's business. This policy could potentially provide an open door to extremist or environmental groups to "shut down the Laboratory." "The process of inviting full public involvement in all Laboratory activities will seriously hinder the rapid accomplishment of the Laboratory's missions because of the increased number of people who will have to be consulted in the decision-making process. Implementation of this Public Involvement Policy will run counter to DOE's attempt to be more responsive to the competitive needs of U.S. industry.

The recent history of the LLNL Environmental Restoration Division's interactions with stakeholders on LLNL's two Superfund sites clearly demonstrates the delays that result from such interactions with questionably improved decisions being made. After being named to EPA's Superfund list, progress on environmental cleanup at both sites was set back by at least two years as a result of having to consult and work with regulatory agencies, environmental groups, and local citizens, all key members of the stakeholders. Progress since then has been slower than it otherwise would have been without stakeholder involvement. 
TO: Paul Thrash

FROM: Harry Galles

January 7, 1994

Page 2

Should this pollcy be implemented as presented here, all Laboratory schedules will have to be revised and costs will rise accordingly. Does DOE really intend for all its Programs to interact daily with the stakeholders, as suggested in the second line of Goal I? ERD interacts with environmental stakeholders by conducting monthly or more frequent face to face technical meetings; having numerous telephone conversations each week; writing monthly, annual, and topical reports; having stakeholders review and comment on those reports; and conducting formal public meetings. This is a tremendous drain on the resources of the Laboratory. Because of the highly technical nature of the work conducted at the Laboratory, I see little added value to be gained by conducting such an intensive participatory process with stakeholders.

I prefer an approach in which DOE and the Laboratory are fully responsive to and take full consideration of questions, comments, concerns and opinions volunteered by stakeholders, without instituting a formal process to solicit that input. This would still allow those individual stakeholders with strong opinions to "be heard," without diluting the efforts of the entire laboratory in a formal process that would have little technical value.

A specific issue not addressed in this draft is how this policy would apply to classified work performed at the Laboratory. Certainly the Weapons Program will not submit its documents to a group of interested community members for review, as ERD now does under Superfund.

In short, this policy would seriously delay progress in accomplishing DOE's missions and increase costs for marginal benefit.

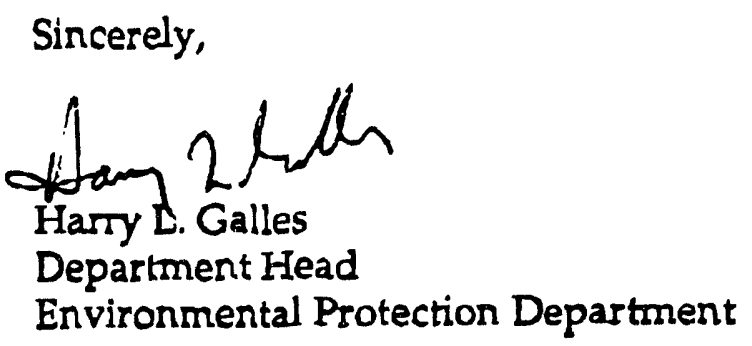

HLG:ALL:jco

CC:

A. Copeland

D. Fisher

A. Lamarse

W. McConachie 


\section{STANFORD UNIVERSITY}

STANFORD LINEAR ACCELERATOR CENTER

Mail Address

Bin 77

SLAC, P.O. Box 4349

Stanford, California 94309

(415) $926-3801$

FAX (415) $926-3175$

January 4, 1994

Paul Thrash

ERWM Division

U.S. Department of Energy

1301 Clay Street

Oakland, CA 94612

Subject: Review Comments on (1) Draft Policy on Public Involvement and (2) Draft Guidance on Implementation of the Department's Public Involvement Policy

Dear Mr. Thrash:

The following are my comments on the subject documents, in response to the December 17, 1993 memo of Henry M. DeGraca requesting comments by January 5, 1994.

As a general comment, there should be more direct correspondence between the goals of the policy and the implementing actions to achieve those goals. In particular, since both training and resources are to be provided, commitment of specific resources at the appropriate level needs to be addressed more explicitly along with training actions. The only non-staff resource mentioned in the draft guidance is a data base, listed in the last implementing action.

Some of the terminology used should be explained or placed in context, as noted below. In particular, however, "risk-taking" (cited in both documents) should be clearly defined, Although its apparent intent here is to describe proactive, resourceful, and responsive actions, it could be misinterpreted by members of the public as (e.g.) jeopardizing health and safety to meet a given objective.

The remaining comments are listed by document and in order of decreasing priority, as requested:

Draft Policy en Public Involvement

RESPONSIBILITIES: Providing training and resources is pivotal to the succes of such a program. In particular, commitment of resources should be addressed more explicitly.

GOAL II: Delete "internal", which should be implicil, and change "known" to "pre-specified" or "established". The wording in the draft implies lingering air of secrecy.

PURPOSE: The term "better decisions" is unnecessarily vague. "Better" should be replaced with "more informed", "more conscientious", "more thoughtful", or the like. 
DEFINITIONS: The term "Americans" should be replaced by "United States citizens" or "United States residents", as it may be considered by some to ignore the peoples of North, Central and South America who live outside the United States. Political correctness aside, a public involvement policy in particular should strive 10 avold any unnecessary slights or confusing terms.

RESPONSIBILITIES: For planning and scheduling purposes, it will be important to know what type of document review process will be involved in coordination of activities at the various levels.

Throughout this document, "assure" and "assuring" should be replaced by "ensure" and "ensuring". The latter term is used only once under RESPONSIBILITIES.

Draft Guidance on Implementation of the Department's Public Involvemest Policy

\section{CRITICAL POLICY ELEMENTS:}

\#5 - A "real-time" data base is inappropriate for public use, since it raises major concerns regarding quality assurance/quality control, and conflicts with the "clearance procedures for public information materials" listed in Item 3. Replace "real-time" with "timely" or define the intended application in more detail.

\#4 - Address commitment of resources, cither combined with training or as a separate item.

\#2 - "Well-known" seems vague here; replace with "well-defined" or "well-established".

If you have any questions regarding these comments or require further information, please contact me at (415) 926-3801.

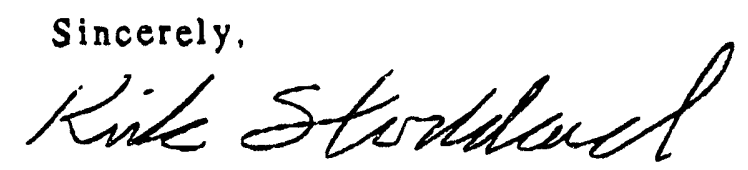

Kirk Stoddard

Environmental Scientist

Environmental Protection and

Waste Management Department

$\mathrm{KMS} / \mathrm{kms}$

cc: John Muhlestein, SLAC Site Office

Lois Marik, DOE/SF 
dato: January 21, 1994

to: Betty Nolan DOE/PA-2

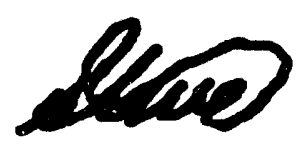

from: Steve Baca, 12650
Abuquerqu, Now Maxico 871 assec0 Uvemore, Caliomia sassi-ooso

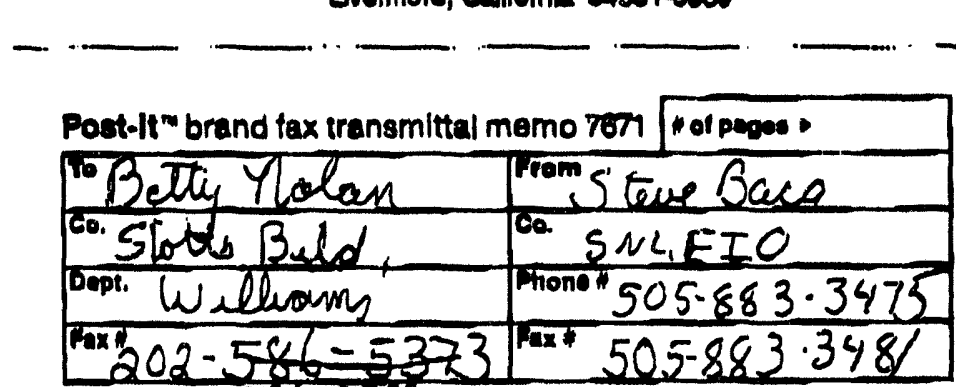

586.0534

subject: Comments on Draft Public Involvement Policy

On behalf of Sandia National laboratories, I want to thank you for the opportunity to comment on DOE's draft public involvement policy.

As part of our Environmental Restoration Program at Sandia National Laboratories we have been doing public involvement to establish genuine and lasting relationships with customers and stakeholders based on mutual trust and respect. We are committed to the Public Involvement Process and believe in the value of the decisions that result. Public Involvement will be a new way of doing business for the rest of our program operations and planning activities. As stated in the draft policy such an enormous cultural change "requires special attention and leadership from the top down."

With that background the following is offered for your consideration.

We have learned that public involvement is a labor intensive activity. It requires significant resources and the efforts of dedicated people to build and maintain the trust and respect necessary to realize the critical policy elements described in the draft implementation guidance. On the other hand, the price of not improving how we are perceived by the public is an environment of mistrust that results in constantly reacting to public challenges and questions. Therefore, the cost of public involvement should be an integral part of each programmatic effort. To achieve different results requires different processes than we have used in the past. Therefore, I recommend that each program manager commit that program's public involvement dollars in the field and at the laboratories, in a way that is both effective and accountable. Unlike the past, Public Affairs and External Affairs Offices should, per this implementation guidance, receive funding directly from the program managers and should be accountable to the program managers. As we are experiencing at Sandia, through our involvement in a cross-cutting Community Relations (CoRe) Team, this is a coordinated approach that produces the desired results. 
Further, one could infer from the draft policy that "public involvement must be a routine component" in everything that we do. If that is the intent it should be so stated in a section on Scope. The implications for implementing such a policy will obviously be far greater than a policy of more restricted scope, such as soliciting and receiving advice on new programs. I believe that some individuals will interpret this draft as meaning that they will actually help make the decisions as opposed to others who will read it as providing advise.

There is no mention of balance in the public involvement. One of our biggest problems is assuring that our public involvement is balanced and includes the full range of community views and opinions.

A critical component of public involvement is that it be productive. The process must always move forward and should be based on consensus. Since there is no one public but rather many publics, consider the addition of "Commitment to progress in solving each problem through consensus" as an addition to the CORE VALUES.

An overall comment made by several individuals reading the draft is that it is vague and as such could result in a variety of interpretations. What will he the process for continuously improving the policy and implementation guidance as well as measuring their effectiveness?

One minor item is the omission of the phrase "Implementation actions:" in the third CRITICAL POLICY ELEMENT of the Implementation Guidance.

Finally, I am personally encouraged that the Department is taking the approach of developing a cross-cutting policy. Those of us involved in this work see it as an opportunity to present to our stakeholders (and some would say employers) a consistent and strategic approach based on quality principles.

As always it's a pleasure working with you. I look forward to working with you to define this policy, its implementation guidance, and through them taking action to realize an improved relationship with the public, based on the quality of our future decisions. Thank you.

I can be reached at (505)-883-3475.

Copy to:

Kathy Carlson DOE/KAO

0001 Yolanda Moreno

7000 Lynn Jones

7200 Jim Baremore

7500 Tom Blejwas

11110 Harold Folley

12120 Shanna Lindeman

12600 Jerry Langheim
12650 Mike DeWitte

12650 Steve Baca

Members of the Community Relatic

Team

Members of Sandia's Line-

Implementation Working Group

(LIWG) 

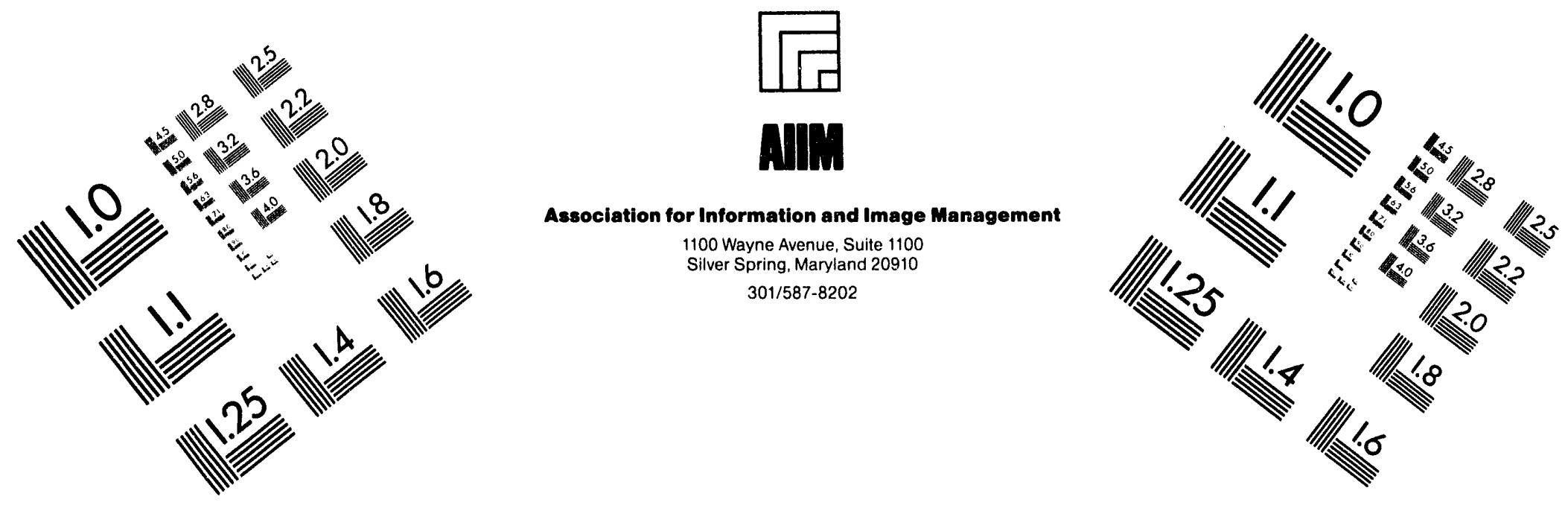

\section{Centimeter}

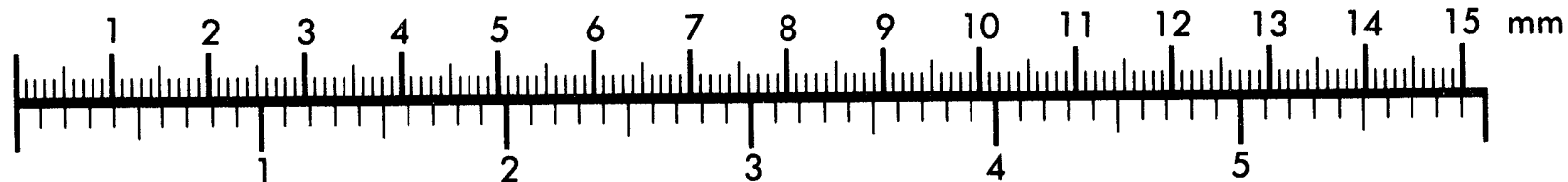
Inches
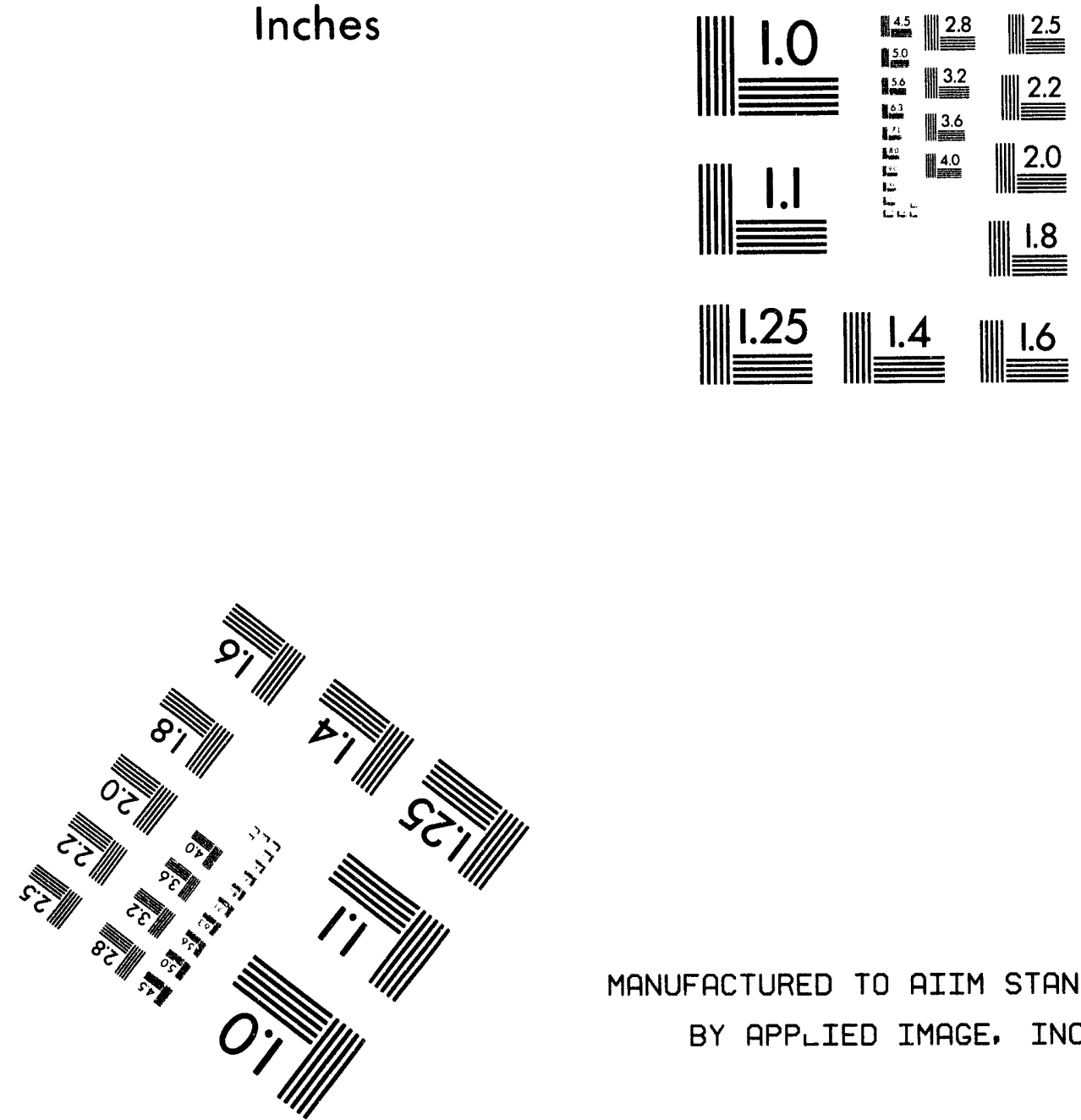

MANUFACTURED TO AIIM STANDARDS

BY APPLIED IMAGE, INC.

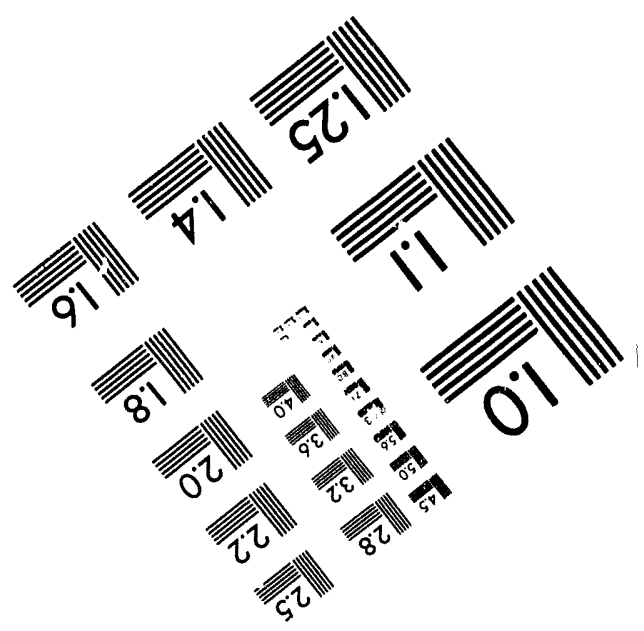



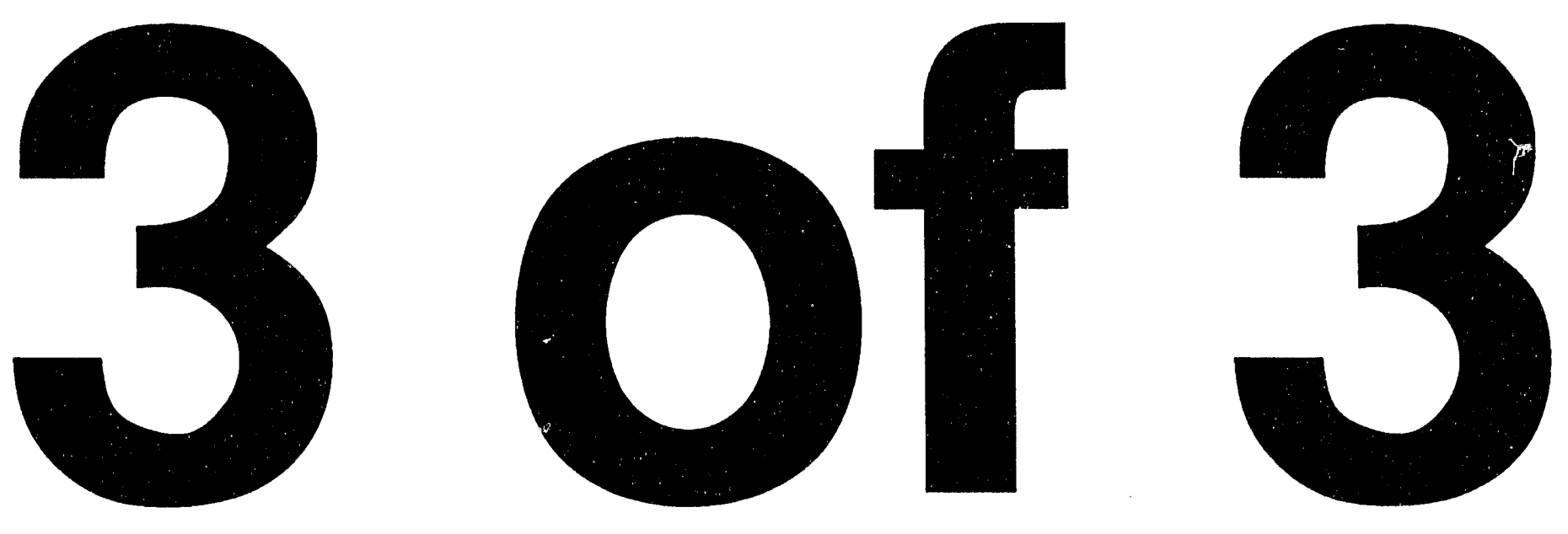


\section{Department of Energy \\ Chicago Operations Office \\ 9800 South Cass Avenue \\ Argonne, Illinois 60439}

January 21, 1994

Betty Nolan
Office of Public and Consumer Affairs

SUBJECT: COMMENTS ON THE DRAFT DOE PUBLIC INVOLVEMENT POLICY

As requested by Mike Gauldin in his December 1, 1.993, memorandum, the Chicago Operations Office has reviewed the Draft Public Involvement Policy and shared it with our internal and external stakeholders. External stakeholders were asked to reply to you directly. Following are $\mathrm{CH}$ comments on the draft policy:

1.) The phrase "...risk-taking will be rewarded..." needs clarification. This could $L \geq$ perceived by some readers as referring to "technical risk" that puts program accomplishment ahead of public, worker or environmental safety.

2.) The policy needs to provide more guidance on how it will be implemented and coordinated with other departmental initiatives, such as on-going EM public involvement activities and the Communications and Trust Strategic Plan. The document should also be codified as a DOE Directive to establish the policy in formal way.

3.) References to DOE and contractor-operated organizations needs to be clarified and made more consistent. Operations, Site, Area, Project and Field offices should be referred to as "DOE." Laboratories, production plants and other facilities should be identified as "contractor-operated."

4.) Regarding Critical Policy Element 4, which calls for an annual assessment by the Director of Public and Consumer Affairs of the Department's communications efforts, the development of performance measures will be critical to the success of this assessment process. The Director of Public and Consumer Affairs should participate in all departmental planning for these activities and the identification of suitable performance measures. 
5.) Section 3, Critical Policy Elements, last paragraph: add the word "prompt" before the phrase "clearance procedures for public information materials." Timeliness in such reviews is critical.

We hope you find these comments helpful.

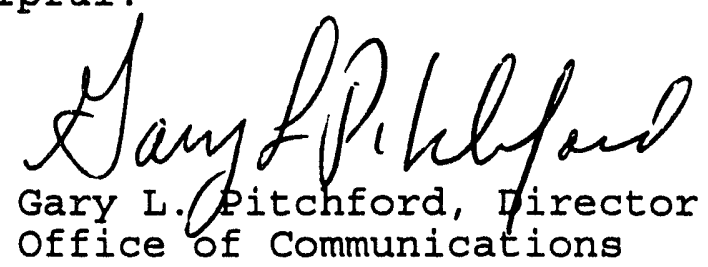




\section{Department of Energy}

Washington, DC 20585

January 11,1994

MEMORANDUM TO MICHAEL GAULDIN

DIRECTOR, PUBLIC AND CONSUMER AFFAIRS

FROM:

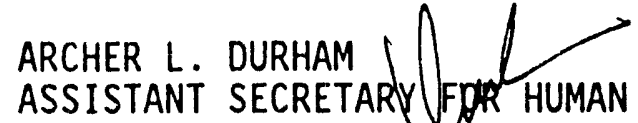

RESOURCES AND ADMYNISTRATION

SUBJECT :

DRAFT PUBLIC INVOLVEMENT POLICY

In response to your December 1, 1993, request to review the draft public involvement policy, Human Resources and Administration offers the following comments:

- The broad manner in which the draft policy is written makes it very adaptable to local situations, but also leaves it open to inconsistent interpretations. For example, it is not clear if any internal administrative processes and decisions are subject to the policy or if these would never be considered "program operations and planning activities." A general statement of what is excluded from coverage would be helpful.

- Along the same lines, we do not interpret the program managers' responsibilities to include coordinating procurement rulemakings with your office, as we are interested in streamlining the rulemaking process.

- Another area of concern is the requirement that "...public involvement will be a discrete performance element for senior departmental and program managers directly responsible for its effective implementation." This definition is not clear as to what levels are considered "senior" or what constitutes direct responsibility. 
- Our final comment deals with the portion of the draft policy which states that "...public involvement will be a routine component of the organization..." and "...managers will provide the necessary training and resources required...." Our concern is that organizations will request additional resources (FTEs and funding) to meet this requirement. Our recommendation is that a statement needs to be included either within the actual policy or the Secretary's cover memorandum which states that the incorporation of this responsibility will be accomplished with existing resources.

If you have any questions about our comments, please contact Greg Bettwy on 586-8024. We thank you for the opportunity to comment on this draft policy.

CC:

T. Dirks

H. Raiken

G. Allen 


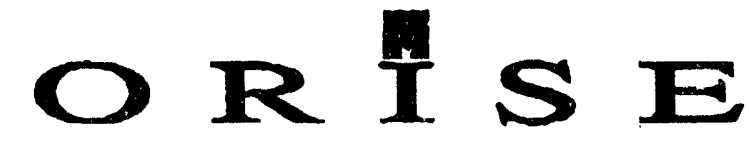

OAK RIDOE INSTITUTE FOR SCIENCE ANO EDUCAMON

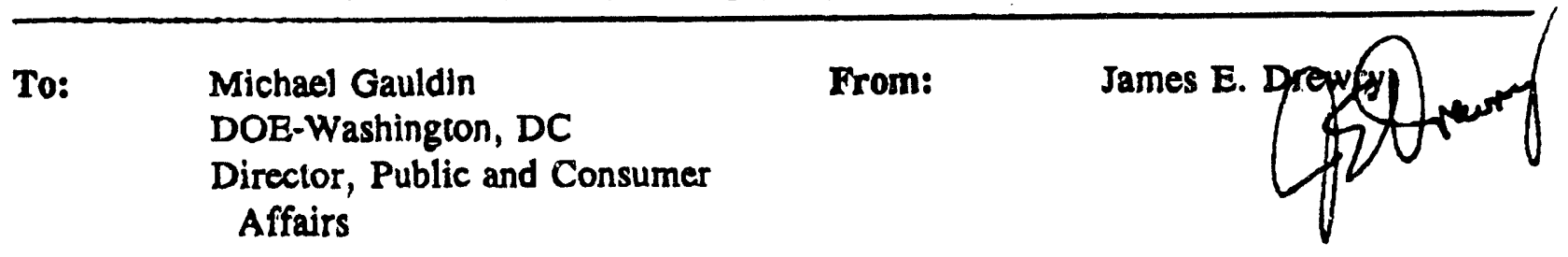

Date: January 7,1994

Copies To: Don Hagengruber

File

\section{Subject: DRAFT PUBLIC INVOLVEMENT POLICY}

After sharing the above referenced draft policy with the ORISE internal management team, the following is the only comment we wish to submit.

This draft public involvenent policy needs to address the one item that is only briefly noted in your cover memo, i.e., that public involvement activities may impact upon legal requirements and duties set forth in the Administrative Procedures Act in Title 5 of the U.S. Code. An example would include whether or not notice in the FEDERAL REGISTER would be required if public involvement were sought on a Departmental initiative.

JED:dlh

MARMostenMizmoz.Jn 


\section{Department of Energy}

Washington, DC 20585

December 1, 1993

MEMORANDUM TO MANAGERS: DOE OPERATIONS OFFICES

DOE LABORATORIES

FROM: $\begin{aligned} & \text { Michael Gauldin } \\ & \text { Director, Public and Consumer Affairs }\end{aligned}$

Subject: Draft Public Involvement Policy

Attached is a draft policy requiring that public involvement be a routine component in program operations and planning activities. The draft was developed and revised over several months by a crosscutting management team which included field representatives.

You are asked to share this draft policy with your internal management team and external stakeholders and return comments to us by Friday, January 7 , 1994. If you can consolidate and prioritize your comments, it would be helpful. Comments and any questions you have concerning the draft should be directed to Betty Nolan at 202/586-5373 (fax: 202/586-0539).

Also, General Counsel has asked us to remind you that, as you pursue specific public involvement activities, you may trigger legal requirements. If you have any questions or concerns, you should seek advice of counsel, either onsite or at headquarters. Additionally, the whole issue of advisory committee requirenients is under review here at headquarters, and summary information is available.

\section{Attachment}

cc: Heads of Headquarters Elements

Chief of Staff

Deputy Chief of Staff

Executive Assistant to the Deputy Secretary 
POLICY ON PUBLIC INVOLVEMENT

\begin{abstract}
POLICY: The policy of the Department of Energy (DOE) is that public involvement must be a routine component in program operations and planning activities, at headquarters and in the field.
\end{abstract}

PURPOSE: Public involvement brings a full range of diverse stakeholder viewpoints and values early into the Department's decision-making process, enabiling the Department to make better decisions and building mutual understanding and trust between the Department and the pubic it serves.

BACKGROUND: The Energy Department is relatively new at encouraging public involvement in its affairs. The Department grew largely out of the highly regimented Cold War culture of two of its predecessor agencies, the Atomic Energy Commission and the Energy Research ano Development Administration. The focus was on national defense through nuclear deterrence; the priority, on design and production of nuclear weapons; and the emphasis on classified information and legally-required secrecy.

Changing this 50 year old culture from a closed, command-oriented hierarchy into an open, participatory culture that values diversity and innovation requires special attention and leadership from the top down. Such leadership and change are essential if the Department is to succeed in meeting the economic and environmental challenges of the next century.

DEFINITION: Public involvement provides a means for Americans to influence decisions made by their government. It requires routine, substantive two-way communication between the Department of Energy and other governmental entities, organized groups, individuals, and the general public interested in and/or affected by the Department's decisions and activities. This communication will vary widely in nature and scope, from informal conversations between individuals to scheduled meetings and workshops, to legally-required public meetings and hearings and federal-statelocal-Tribal agreements. The Department will actively seek, incorporate, or otherwise respond to the views of its stakeholders.

GOALS: I. Credible, effective public involvement processes are routinely incorporated into the Department's daily program operations and long-term planning activities, at headquarters and in our laboratories, facilities, and field offices, with every employee sharing responsibility to practice and improve public involvement.

II. A clearly defined, coherent internal decision-making process with known access points for public involvement is routinely followed.

III. The public is informed about and empowered to participate in Departmental decision-making. 
CORE VALUES

Accountability
Fairness
Openness
Respect
Risk-taking
Sincerity

\section{DRAFT}

Consistency

Honesty

Peer Review

Responsiveness

Scientific Credibility

\section{RESPONSIBILITIES:}

Under this policy, public involvement will be a discrete performance element for senior departmental and program managers directly responsible for its effective implementation.

To assure a consistent approach throughout the agency and with its contractors and to avoid unreasonable demands on site personnel or the public's time, Program and Staff offices will coordinate their public involvement activities through the Office of Public and Consumer Affairs, at headquarters and in the field. This coordination role in no way limits or dilutes program managers' responsibility to plan, fund, and support appropriate levels of public involvement in their programs.

The Principal Secretarial Officer and Senior Departmental Managers will ensure that public involvement principles, values, and processes are fully understood and practiced within their programs and that necessary training and resources (human, information, systems, and financial) are provided.

Program Managers are responsible for identifying, planning, budgeting, and implementing the appropriate level and scope of public involvement activities in their programs, and routinely coordinating activities through the Office of Public and Consumer Affairs. Program managers will assure that their staff receive basic communication training and, where appropriate, advanced public involvement training.

The Director of Public and Consumer Affairs, headquarters, will establish a point of contact and mechanisms to coordinate public involvement activities Department-wide, and to assure that initiatives, as identified and implemented by secretarial officers and program managers, are carried out in a consistent, equitable, integrated manner. Public and Consumer Affairs will provide advice and support to program offices in developing and implementing effective communications/public involvement strategies and information materials for local communities, stakeholders, employees, and the media.

Managers of Field Organizations are responsible for assuring that public involvement activities at their respective facilities and sites meet local needs, are appropriately coordinated, and reflect Departmental principles and values. Field managers will regularly advise headquarters on public involvement issues/needs of regional or national importance and recommend appropriate courses of action. 


\section{DRAFT}

Field Public Affairs/External Relations Directors will work with field managers to provide the same coordinating/integrating role for site public involvement activities as the Director of Public and Consumer Affairs provides department-wide. 
MEMORANDUM FOR: HEADS OF HEADQUARTERS ELEMENTS

MANAGERS, DOE OPERATIONS OFFICES

FROM:

THE SECRETARY

SUBJECT:

GUIDANCE ON IMPLEMENTATION OF THE DEPARTMENT'S PUBLIC INVOLVEMENT POLICY

It is the policy of the Department of Energy (DOE) that public involvement be a routine component in program operations and planning activities, at headquarters and in the field. This policy marks a clear break with past practice by challenging the Department and its contractors to embrace a new culture of openness and service. Henceforth, the business of the Department will be open to the full view and input of those whom it serves.

While public involvement processes must be tailored to specific site and
program needs, the following broad guidance is provided to assist headquarters
and field managers in implementing this policy department-wide. Several
critical policy elements and implementing actions are identified below. These
sheuld be viewed as a beginning point. They illustrate the comprehensive
nature of public involvement as envisioned in this policy and the innovative
you should consult with your stakeholders to develop public involvement plans

\section{CRITICAL POLICY ELEMENTS}

1. The Department recognizes that honesty, forthrightness in dealing with external parties, and consistent, credible, quality performance are the bases on which to build public understanding and trust.

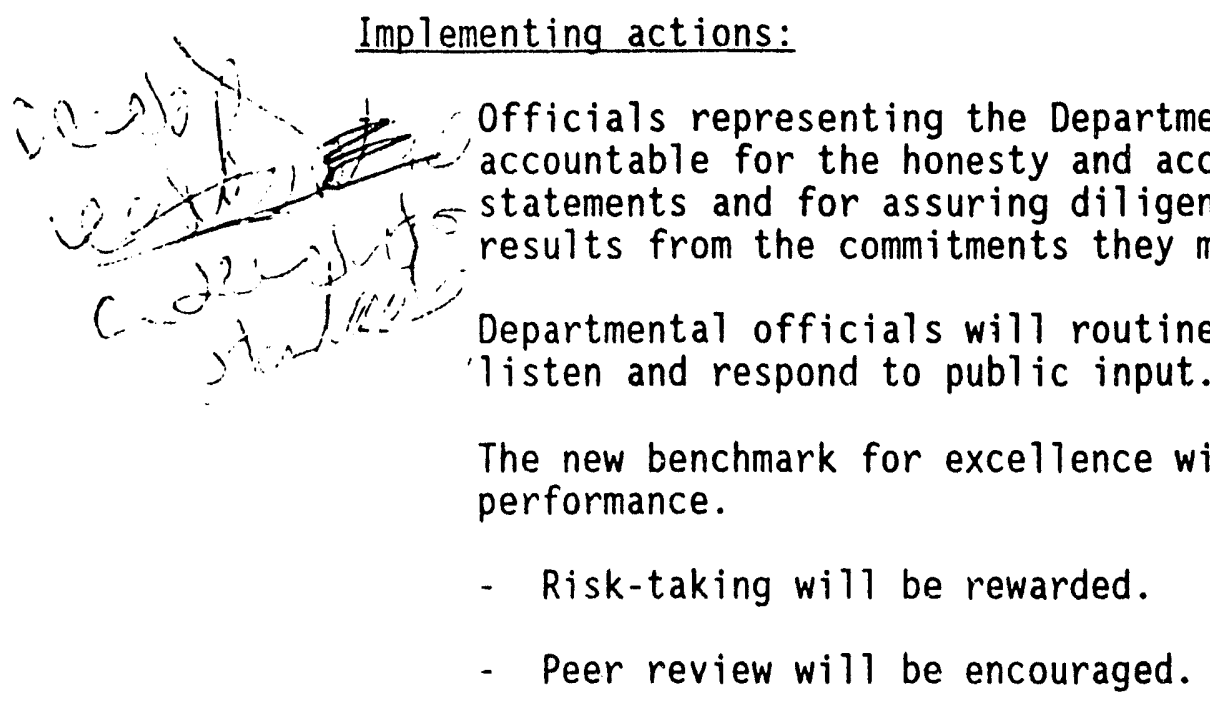


2. Departmental program development, planning, and decision processes must be clearly defined, with regular, well-known access points for public input.

Implementing actions:

-- Principal Secretarial Officer and other senior departmental managers will ensure that other affected program officials, site managers, and stakeholders are appropriately integrated into their planning and decision-making processes.

-- Site managers, as those closest to affected communities and interested parties, will advise on appropriate predecisional access points for public input and facilitate accommodation between local and national interests.

3. Headquarters, laboratories, facilities, and field offices will operate as an integrated team in planning public involvement activities, combining resources, sharing information, and coordinating schedules.

- Cosperation will be rewarded.

- Site managers and local program officials will routinely advise headquarters on local stakeholder needs/concerns and on the appropriateness/adequacy of public information/ involvement efforts in their areas.

- The Director of Public and Consumer Affairs, working with the Programmatic Assistant Secretaries, will develop consistent formats and clearance procedures for public information materials.

4. The Department must establish and support training/education programs to meet evolving public involvement needs, both internal and external.

$\because$ Implementing actions:

- The Director of Public and Consumer Affairs will assess on an annual basis the effectiveness of the Department's communications efforts and recommend improvements.

The Director of Public and Consumer Affairs and the Assistant Secretary for Human Resources and Administration, working with the Programmatic Assistant Secretaries, will identify and coordinate communication/public involvement training on a priority basis until all appropriate headquarters and site personnel are trained. 
5. The Departinent must foster candid information exchanges directed at reaching a common understanding of options and risks and developing consensus.

Implementing actions:

-. Whether formal or informal, all public involvement activities will be conducted in a spirit of openness, respect for different perspectives, and a genuine quest for information and ideas.

- The Department will work to establish, announce, and manage a data base of real-time information available to the public through telephone and computer access points. 
Ms. Betty Nolan

Washington, DC 20585

Re: Draft Public Involvement Policy and Implementation Guidance

Dear Mis. Nolan,

We appreciate the opportunity to comment on the Department of Energy's (DOE) draft public involvement policy and implementation guidance. The drafts are refreshing statements of principles. They accurately identify the problem (see "Background", p. 1) and, at least in broad terms, commit DOE management to seeking solutions.

We have only a few comments. First, there is little mention of any system by which DOE can determine whether the goals are being accomplished. As well intentioned as the goals and expressed commitments are, DOE should add a pledge to measuring its accessibility and responsiveness to meaningful public involvement. The implementation guidance gives the Director of Public and Consumer Affairs responsibility for annually assessing the effectiveness of DOE's communication efforts. Perhaps this person would also be the appropriate one to evaluate the effectiveness of the overall public involvement policy.

Second, the draft policy and implementation guidance beg the question of what citizens should do. when they have grievances about the effectiveness or resporsiveness of DOE's public involvement policy. There is, for example, no mention of identifying an ombudsman as a visible and central point of contact for such grievances (though establishing an Office of Ombudsman has been recommended to DOE in the past).

Third, DOE is in the process of establishing nearly a dozen site-specific advisory boards. These boards may quickly become a central element in many of the Department's public involvement activities. Perhaps the policy and implementation guidance should indicate how these boards will mesh with other elements of DOE's public involvement program. Also, the policy might 
indicate points of contact for these boards.

Finally, the policy and guidance should contain more details on how officials who are progressive and successful in implementing meaningful public participation will be rewarded. For example, the guidance might direct that performance on public participation issues be considered in personnel performance evaluations.

We hope these comments are helpful and look forward to receiving copies of the completed documents. If you have any questions about our comments, please contact me at 509/838-4580. Thank you.

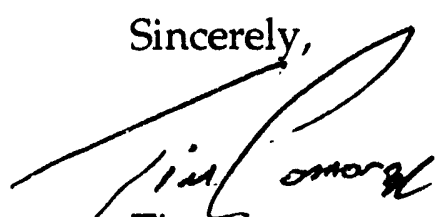

Tim Connor

Associate Director 


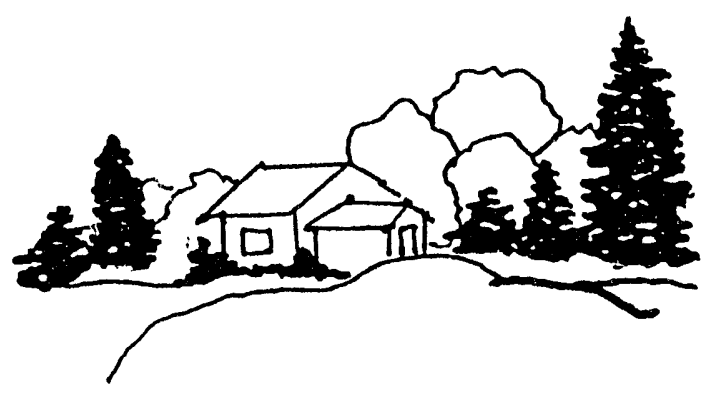

Michael Gauldin

Director, Public and Consumer Affairs

U. S. Department of Energy

1000 Independence Avenue, SW

Washington, D.C. 20585

Dear Mr. Gauldin:

This letter is a stakeholder response to the "Draft Public Involvement Policy"of December 1, 1993.

I am pleased to read that sincere efforts are underway to advance from a secretive operations culture of the past to an open participatory culture which includes stakeholders being able to influence decisions and activities.

My one question about the "Draft" concerns the paxameters of public involvement -- are public involvement plans being designed solely for clean-up and health study activities at Department of Energy weapons sites, or do plans include the programs which concern future energy needs as well?

As a stakeholder, I should like to be able to participate in the structuring of agendas for public meetings and the educational activities of these meetings. In all past meeting which I have attended, the agendas have been imposed, and any questions I have asked, have been briefly or incompletely answered.

The "Draft Policy" appears to be a genuine approach for change from past practices. I heartily encourage this public involvement policy change.

Sincerely,

Velma Mn.

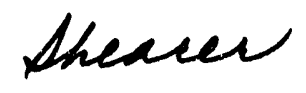

Rev. Dr. Velma M. Shearer

Staff Minister
NEIGHBORS IN NEED

Englewood, OH 45322

January 5, 1994 


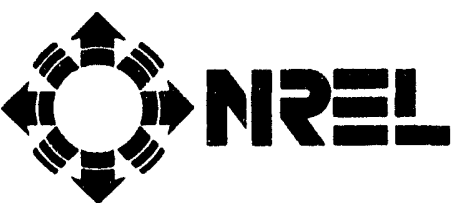

January 7,1994

Mr. Michael Gauldin

Director, Pubiic and Consumer Affairs

U.S. Department of Energy

1000 Independence Ave., S.W.

Washington, DC 20585

Dear Mr. Gauldin:

\section{SUBJECT: DRAFT PUBLIC INVOLVEMENT POLICY}

Overall, we think the goal of changing the culture at DOE to one that is open and participatory rather than one that is "command and control" drive, due primarily to national security concerns, is highly commendable. This is a philosophy that we at NREL have fostered for some time, mainly because our unique, single-purpose and non-defense mission in support of DOE.

The following are recommended changes, additions, and clarifications that can help improve the document and its usefulness. Most of our comments are directed to the implementation guidance rather than the policy itself. We do not address editorial concerns.

\section{Draft Policy Section}

- In the "definition" paragraph, there should be a majur focus or emphasis on interactions with the public and less emphasis on interactions with other government agencies. Interaction with other government agencies is also needed, but these interactions are much less central to the need being addressed by the policy.

- Goal one states that "every employee shares the responsibility to practice public involvement." This should be addressed in the "guidance" section (it currently is not), and some broad guidelines on employee responsibilities should be provided.

- The core values as presented in the draft statement are different from those published by DOE (e.g., Sue Tierney's presentation in December of 1993). Also, some consolidation in the list that is provided appears to be possible (e.g., integrity is one value that encompasses honesty, fairness, openness, sincerity, etc.). 


\section{Guidance on Implementation}

- The term "triggering legal requirements" is ambiguous and may result in multiple (and probably inconsistent) interpretations by various DOE organizational units and supporting laboratories. More information on "triggering legal requirements" (cited in the cover memorandum) should be provided by the policy-setting body before providing implementation guidance, since the guidance itself must conform to legal requirements. See the next bullet for an example of a legal requirement.

- Though this is probably implicit, we suggest that an explicit statement be provided noting the need for protection of business-sensitive information, such as CRADA-protected information, proprietary data, and trade secrets. Protection of such data is required by law and is absolutely essential as we work more closely with industry and the public.

- In several places, statements such as "risk taking will be rewarded" are made. This is a very important concept in an "open" process, and a better description of what is really meant by "risk taking" and its boundaries should be included (e.g., what kind of risks are people to take, how will people be encouraged to do so, how will DOE assure that this will actually be carried out throughout DOE?).

- A definition of "program operations" and "planning activities" is needed, as well as guidance regarding the level at which we involve the public in our planning activities.

- Guidance outlining how public input will be used by the Department is lacking and should be provided.

- In Critical Policy Element 3 of the memorandum from the Secretary, it is stated "the Director of Public Consumer Affairs . . . will develop . . . clearance procedures for public information materials." This requirement has the potential to become quite onerous. We encourage simple, streamlined clearance procedures that do not overly inhibit the central goal of openness.

- In Critical Policy Element 4, the word "external" should not apply to training the public since DOE has a responsibility to help educate but not necessarily train the public.

- Regarding Critical Policy Element 5, an Internet connection to DOE may be useful for obtaining public input.

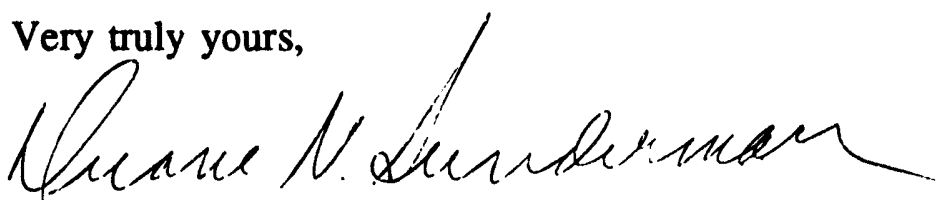

Duane N. Sunderman

Director

cc 
January 6, 1994

\section{Battelle}

Pacific Northwest Laboratories Battelle Boulevard

P.O. Box 999

Richland, Washington 99352

Telephone (509) 375-3441

Mr. Michael Gauldin

Director

Public and Consumer Affairs

U.S. Department of Energy

Washington, DC 20585

Dear Mr. Gauldin:

DRAFT PUBLIC INVOLVEMENT POLICY

Ref: Your letter to the Director, PNL, dated December 1, 1:93, subject as above.

The Department of Energy's draft policy on public involvement represents an important first step in institutionalizing an open and participatory culture and the Pacific Northwest Laboratory (PNL) is fully supportive of its intent. The policy, when implemented, should lead to greater public involvement coordination and integration across the Department and its field organizations and more effective public involvement efforts overall.

Specific comments on the draft "POLICY ON PUBLIC INVOLVEMENT" are as follows:

1. "GOALS" Section

- A fourth goal should be considered which would read; "The public is informed about how their input influenced Departmental decision-making."

This would spotlight the importance of accountability to the public involvement process which, in large measure, will determine both the credibility and effectiveness of the process.

2. "RESPONSIBILITIES" Section

- Paragraphs Two and Four - Departmental program managers' responsibilities also should include "participating" in appropriate levels of public involvement in their programs. These paragraphs should explicitly state this expectation in addition to the identifying, planning, budgeting and implementing responsibilities al ready mentioned. 
Mr. Michael Gauldin

January 6, 1994

Page 2

- Paragraph Four - Program managers need to receive "basic public involvement training", in addition to basic communication training. The basic public involvement training EM has offered over the past year, for example, emphasizes the responsibility of the manager to integrate public involvement in overall program planning. Early identification of public involvement needs in initial program planning helps to make such efforts more effective. All managers need to understand when and how to factor public involvement into their program decision-making processes.

- Managers of Field Operations, similar to their Departmental counterparts, also need to be held responsible for "assuring that their staff receive necessary training and participate in appropriate levels of public involvement." These additional expectations should be explicitly stated.

3. Specific comments on the draft "GUIDANCE FOR IMPLEMENTATION" are as follows:

- Policy Element \# 3 - Cooperation "and teamwork" should be rewarded. Teamwork with internal and external stakeholders forms the basis for credible and effective public involvement processes and should be recognized.

- Policy Element \# 4 - The Department's communication "and public involvement" efforts should be assessed for effectiveness annually. Criteria for public involvement effectiveness wi?l need to be developed and, to assure that they are meaningful to the public, the criteria should be reviewed by external stakeholders.

PNL commends the Department of Energy for taking the initiative to develop an agency-wide policy on public involvement. We strongly endorse the Department's commitment to build public understanding and trust by involving the public in its decision-making processes and look forward to supporting the Department with the implementation of its policy.

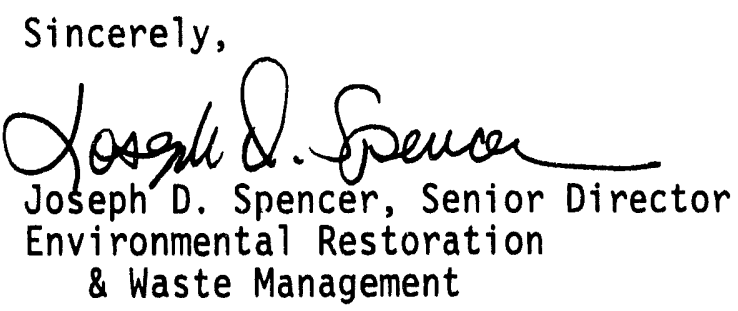

WRW: ds

In triplicate

cc: GM McClure, RL 
Ms. Betty Nolan

U. S. Department of Energy

Office of Public and Consumer Affairs

Washington, D.C. 20585

Dear Ms. Nolan:

Thank you for the opportunity to comment on the Draft Public Involvement Pulicy (subject of Mr. Michael Gauldin's memorandum of December 1, 1993). Our comments follow:

- Much of the technology and science sponsored by DOE engenders fear in the lay public. If the public is to be included in planning, and if its participation is to be constructive, then the public needs to have a good understanding of risk concepts. Any focused effort by DOE to use public involvement in project conception, mission, and siting should be accompanied by useful, relevant explanation of potential hazards in terms that relate to common life experiences. (Good examples of risk communication can be found in the work of Peter Sandman, Professor of Environmental Journalism at Rutgers University.) This kind of approach should be used as a starting point for DOE public involvement initiatives.

- While the creation of an effective public involvement policy is critical to the foundation of DOE's new culture of participatory decision making, the actual implementation of this policy should be cautious of superseding sound business management decisions with more visible and favorable political choices. This delicate balancing of two strong forces can be achieved only in an environment that cultivates and encourages "win-win" decisions and allows responsible informed stakeholders to be effective team players.

We also request the summary information on the issue of advisory committee requirements referenced in your memorandum (last paragraph).

Again, my thanks for the opportunity to participate.

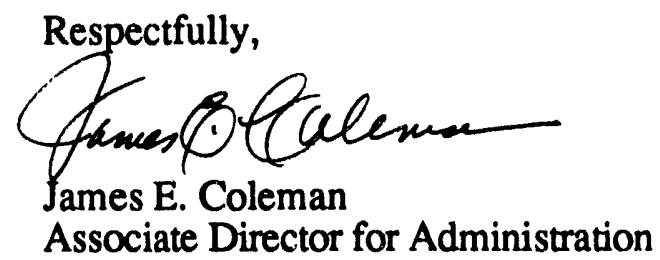

cc: Hermann A. Grunder w/encl.

Dennis W. Barnes w/encl. 
Department of Energy

Albuquerque Field Office

Amarillo Area Otfice

P. O. Box 30030

Amarillo. Texas 79120

January 12,1994

MPMO TO: Ms. Betty Nolan, PA

FROM: TOm WIIIIams, AAO

SUBJECT: Draft Public Involvement Policy

As a follow-up to my memo to you of Friday, January 7, 1994, I am forwarding to you additional comments provided to us by the Metal Trades Council of Amarillo (MTC), on the draft policy document on "Public Involvement." The MTC represents the "Trades" employees at the plant and we hope you give duo consideration to their views.

If we can provide you with additional information, I can be reached at (806) 477-3121. MY FAX number is (806) 477-5895.

Enclosures

cc: Leroy Apodaca

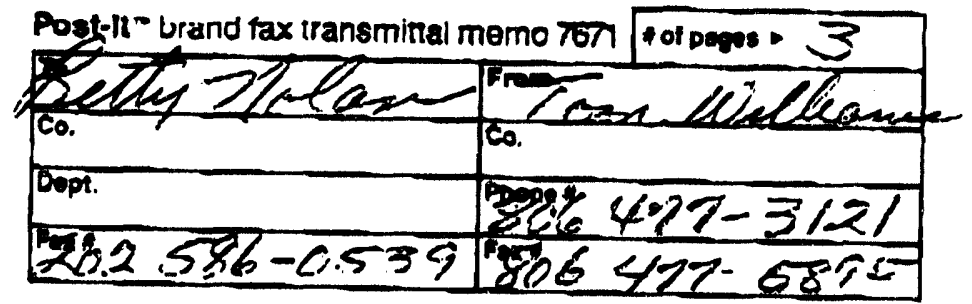


Ms. Betty Nolan

Office of Public and Consumer Affairs

U. S. Department of Energy

Washington, D. C. 20585

Subject: Policy on Public Involvement (DRAFT ISSUE)

Dear Ms. Nolan:

After reviewing the above referenced document, the Metal Trades council has a few concerns and ideas we would like to share.

Policy: We have no problem with the public being involved in giving their views on certain issues, but when an overwhelming majority of the public express a viewpoint and a very small minority is allowed to hold up a process, this is a concern to us and we feel the DOE should look at this type situation more closely.

Definition: we fael no one is more affected by the Department's decisions and activities than the employees of the plant. An as far as involvement in decision making goes, the most logical group to be involved is the plant employees an we know more about every operation at Pantex than any outside group or individual.

Cosin: Our only oonoorn haro io number III. Our concern is the word "empowered". How would the public be empowered and to what extent? It has been suggested by some of the outside "stakeholder groupe" that thoy bo involvod in decisione that directly relate to how we do our jobs, mainly dismantlement and production operations. We certainly hope they never receive the power to get involved to that dogrea. 
In closing I would reference the Openness Press Conference Fact Sheets, Decomber 7, 1993. This document refers to the declaseiflcation of Plutonium Inventory at a number of sites within the complex. At the and of each section the question 1 s asked nkho are the key stakeholders?" The answers given are:

1. The general public

2. Enviromentalists

3. Freedom of Information Act requestors

4. Health Researchers

5. Regulators

6. Environmental, safety and Health interests

It is our opinion that the employees at the Dof sites are being left out of a very important loop by not being recognized as a separate stakeholder group when it comes to decision making input.

Thank you for your cooperation and attention to these concerne and ideas.

sincerely,

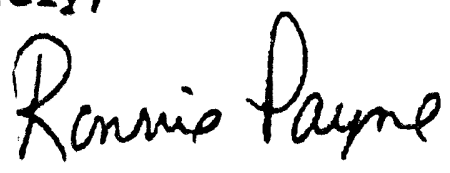

Ronnie Payne, President Chief/Steward

Metal Trades Council of Amarillo, Texas

and Vicinity, AFL-CIO

2915 S. Birmingham

Amari110, Texas 79103

cc: TOM Williams, DOE/AAO

MTC File 
January 5, 1994

Betty Nolan

U.S. Department of Energy

1000 Independence Avenue

Office of Public and Consumer Affairs

Washington, DC 20585

Dear Ms. Nolan:

We have reviewed the Draft Public Involvement Policy and find the policy to be satisfactory. We have no comments.

Sincerely,

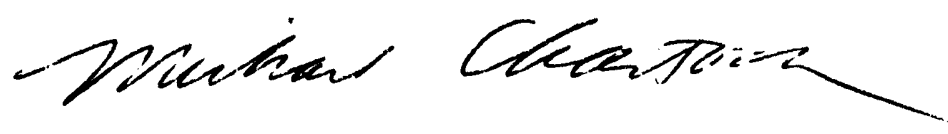

Michael Chartock

Acting Head

cc: P. Oddone

R. Edwards

S. Fennessey 


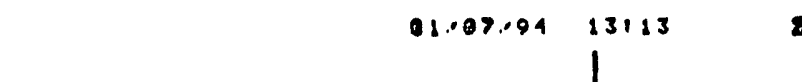

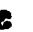

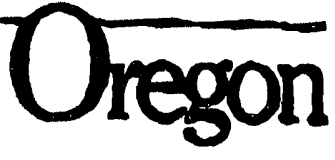

DTEPARTMENT OI

FNRTRC:Y

Dare: Innuary 7,1901

state and gribal dovernment Working group (erGwo), aoked mo 20

roviow UBDor' Drdet public Informatlon polloy, whioh was ant to

BRGHO nombers ror reviow.

I belfeve the draft pollcy, if adopted and lollowed, w12l reoult In roaningful luvolvomene for those who have a leglt inate stake in DOE programo.

There are, howevar, a fow key elemente which I belleve would etrongthen thio document:

Refoxence chould to made to the Adminietration's oommitiont to - tranine and oinpliey the Preodor of Information Act provers.

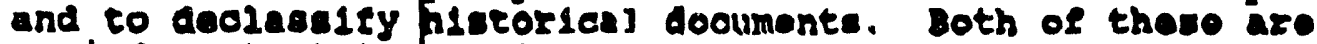
remindere that the Adminiotication oupports an open prooess and that DOE chould acsiat in both of these arcas.

Thle document may hot be the approprlate place to discusa radueing the numbef of doouments that are oleselfied, but it is worth mantioning. Although there may bo sueh an olsort undorway, I as not avare of any concerted efrort to reduce the numbar of. documente that bospmo olaceleled ac/aftar thoy are creatad. This will oniy result if having to declassily those dooumente at some future date, wisen porhaps tnere In no oompeling rpasen to olaceley ther in the elrst plaoe.

If you have any qupetlone about these commente, thiplonina Kloberin pleace call to as $303-378-4906$. 


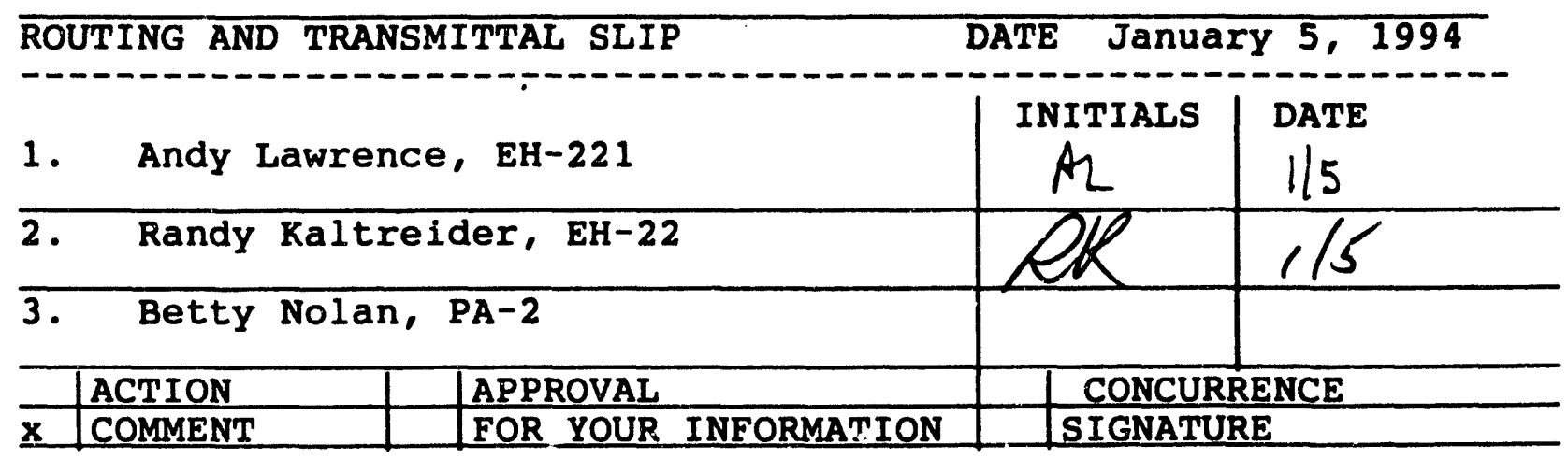

SUBJECT: DRAFT PUBLIC INVOLVEMENT POLICY

EH-22 has reviewed the subject document.

The draft policy appears to be comprehensive and inclusive addressing the secretary's new culture of openness.

Upon finalization of the draft, a graphic depiction of the lines of internal DOE coordination would be a useful adjunct to understanding the various responsibilities and lines of authority for the DOE levels described.

FROM: Lea A. Ekman, EH-221 LffC
ROOM - BLDG. 3G-089, Forrestal PHONE 
[540] From: Dev1d Parote1 12/22/93 1:27P4 (1014 bytes: 17 In)

To: Bobble smith

Subject: Publie Involvamant policy

\section{Bobbie:}

Ex-42 did not ralee any iscues with the specisie Public Involvoment Policy implamentation guidelines or responsibilities. Mr-42 does,

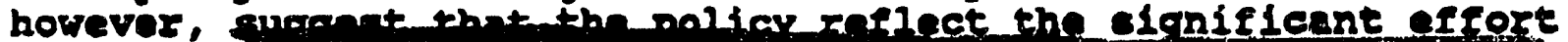

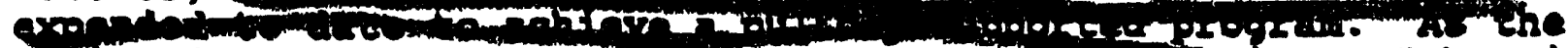
polley is presently witeen, It places undur juples is on "changing the old culture."

- Dof, under both Watkine and now O'Leary, has made signifleant strides in Initiating and encoureging pubile involvient.

- The polley chould acknowledge this and provide the besis for improving the ongoing incoroprotation of stakcholder concerns.

Dave 
INFORRAL MOTE

December 22, 1993

To: M. Lathrop, EM-40

From: Bobbie Sintth, EM-433 ff

Subject: Comments on Draft Public Involvement Policy

As requested, the Office of Program Support (EM-43) has roviewed the Draft Publite Involvement Poltcy developed by the Department of Energy's (DOE) Office of Public and Consumer Affairs. In general, we believe this polley is not inconsistent with the office of Environmental Restoration and Waste Management's (EM) public participation policy, the Office of Environmental Safaty and Health's (EH) public participation guidance, and the public participation requiraments embodied in the Comprahensive Environmental Response, Compensation and Liability ACt (CERCLA) and the National Contingency Plan (NCP).

However, the policy is simpilstic and provides few detalls on how these objectives will be met and tho roles and responsibilitios for ensuring public participation is embraced by all DOE program participants as in integral component of thair jobs. Moreover, this policy is filled with "feel-good" jargon that may not be well-received by the varlous stakeholder communitios.

More specifically:

- The terms "public involvement, "public participation," and "public outreach" seem to be used interchangeably within the Department. Unfortunazely, these three terms have difforent connotations in the stakeholder community. In addition, there difference between involving and communicating. It may bo more palatable to DOE's stakoholders to use the term "public participation" consistentiy in all DOE documentation. "Participation" implies a more active, two-way approach.

- Under Core Values, it may be nore helpful to provide value statoments rather than a list of words. The words are filled with good intentions, but do not mean much out of the context of real milestones and activities. How is Headquarters and the Field supposed to apply these core values?

- DOE should not continue to punish itself for the secrecy of the past. It may be too negative to use terns such as "clear break with the past" and "a naw culture of openness and service." DOE, and the EM program

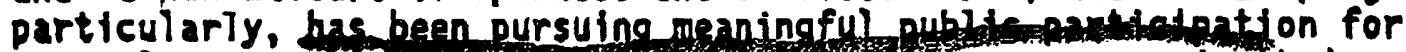
several years. In fact, aring surpasseg epts programs in their proactive approach to stakeholder involvement. 
- The policy is filled with buzz words that are trandy and show that the Department can talk the talk (e.g., aceess points, benchark for excellence, ampowerment). As a strictly internal document this approach may be appropriate. However, to outside stakeholder groups these terms lack substance and may appear to be too boflerplate or cookbook.

ec:

H. Hisenbaker, EH-43

G. Turt, EH-43

S. Moador, EM-433 


\section{STATE OF MISSOURI \\ DEPARTMENT OF NATURAL RESOURCES}

- DIVISION OF ENVIRONMENTAL QUALITY

P.O. Box 176 Jefferson City, MO 65102-0176

December 28, 1993

Betty Nolan, EM-14

Department of Energy

FORS-1H-D31

Washington, DC 20585

SUBJECT: Draft Public Involvment Policy

Dear Ms. Nolan:

With reference to the FAX copy of the subject draft, this office fully supports the goals and apparent intent of the proposed policy. As the final document is developed and specific refinements are established, we welcome the opportunity to review and participate in addressing the issues.

We recognize that your office has not had enough time to develop lists of other stakeholders that may want to provide input. For future documents, we would like to suggest several individuals and organized groups here in Missouri that have provided comments and shown interest in various governmental activities, specifically in the area of environmental management.

If you need additional information or have questions, please feel free to contact me at (314) 751-3176.

Sincerely,

HAZARDOUS WASTE PROGRAM

Robert Yelle

Robert Geller, Chief

Federal Facilities Section

RG : lea 


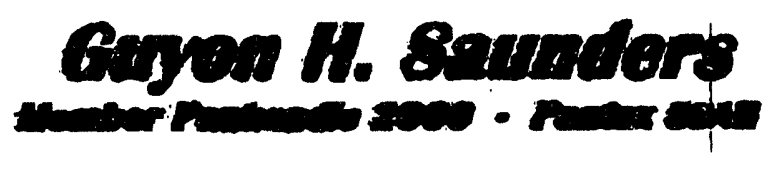

Decomb 29, 1993

Nir. Cuns Johpon

$F \times 477-5895$

Amanto Aren Ouve

U.S. Depertwence Esure.

P.O. Box 30030

Amerillo, Terex 79120

Dear Gerry,

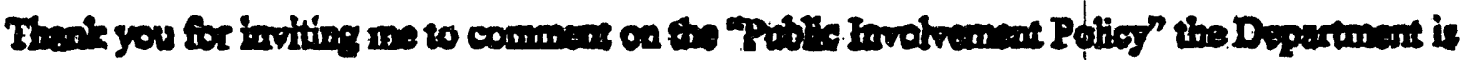

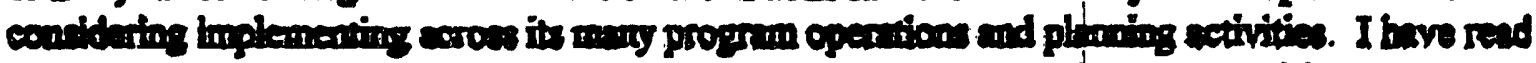

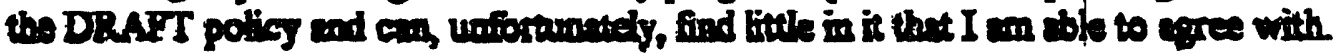

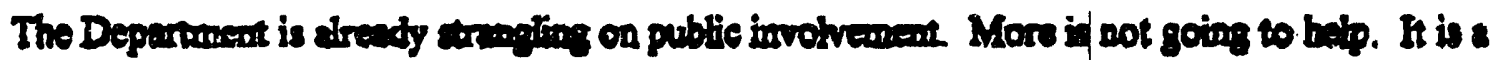

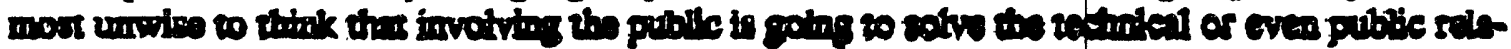

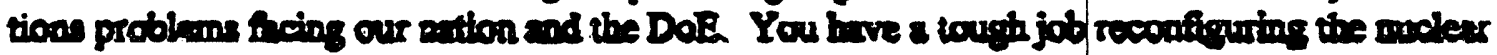

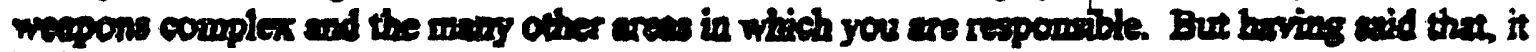
in time to gen on with the proconal

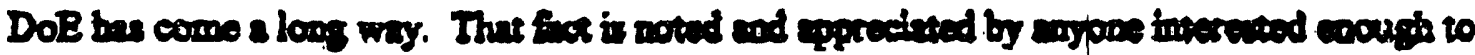

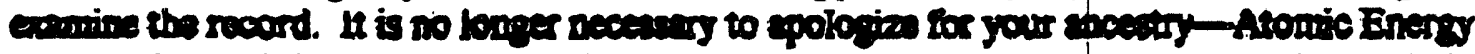

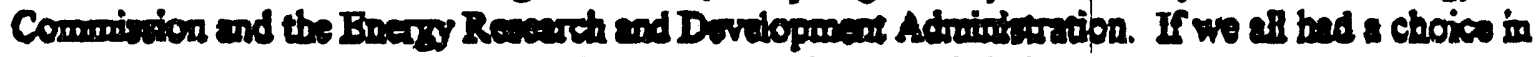
not doine the hat wor, you cen bee the vote would bo overwbelaing

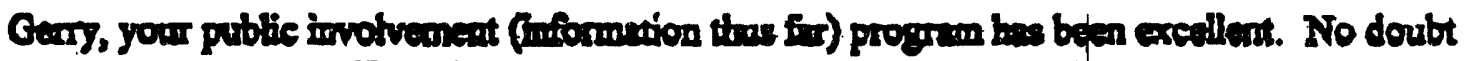

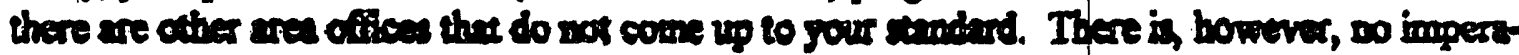

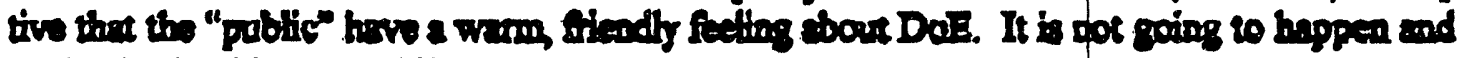

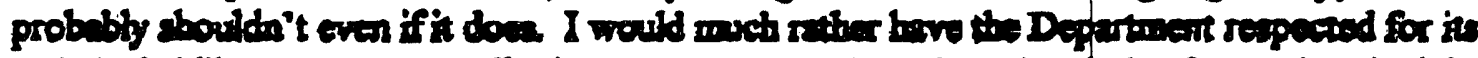

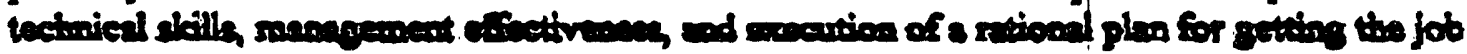
desos.

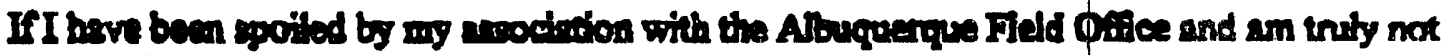

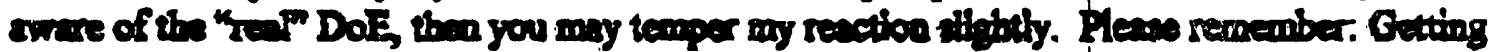
the job done riptr is a whole lot wore importent than trying to mike ifl of we fed good about how

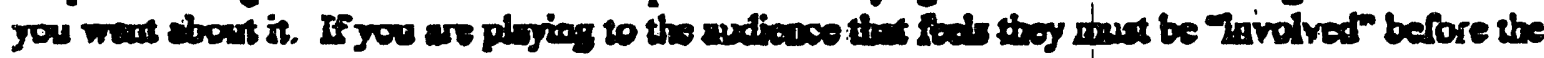

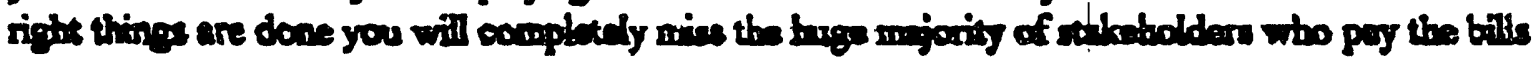
and knop this courntry gaine.

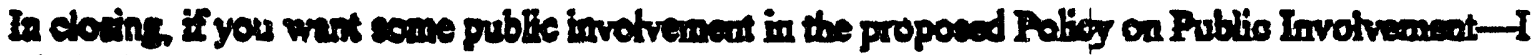
wit be happy to become involved.

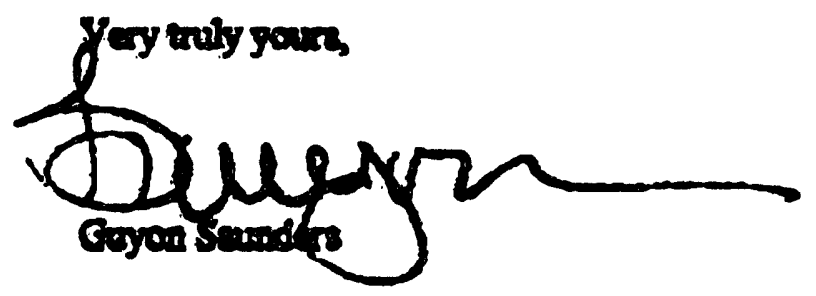


Tom Williams

Program Manager

Department of Energy

Amarillo Area Office

P.O. 30030

Amarillo, Texas 79120

Dear Tom,

Thank you for the opportunity to comment on the "Public Involvement Policy." I apologize for not having time to do this more formally, but l'm enclosing some informal thoughts, both on the draft policy and on the memorandum on guidance on implementation. I will fax a copy directly to Ms. Nolan, at the number indicated in your letter.

\section{DRAFT: Policy on Public Involvement}

In the paragraph on definition, I suggest changing the word "Americans" to U.S. citizens/residents.

In the section on core values, I'm unable to come up with a single word, but I think there should be some commitment to providing context for decision.s. Because of the DOE's history of secrecy and classification, I believe this is more important for DOE than it might be for some other government agencies.

In addition to site-based public involvement, the policy should include the same broad-based review of DOE materials designed for use in schools and other educational programs or institutions.

\section{DRAFT: Guidance for implementation}

2. -- Because site managers are seen by those in the affected communities as being their most direct access to DOE, headquarters and field offices will be responsible for seeing that plant managers are fully included in communications, and have at the earliest moment the information they need to respond to inquiries or initiate public comment. When site managers are put in the position of appearing "outside the loop," of having no information or misinformation, the credibility of DOE as a whole is damaged.

5. -- Although documents are available in public reading rooms, photocopy costs are high and hours of availability limited. The DOE should consider making technical and other appropriate 
page 2--comments on "Policy on Public Involvement"

documents available on a loan basis. As documents become available on computer disks, these should also be available in the public reading rooms, with capability for printout whenever possible, if printout costs are lower than photocopy costs.

-- All regulatory permits or permit amendments should be available in the public reading rooms at the same time they are submitted to the state and/or federal regulators.

Again, thank you for the opportunity to review these drafts.

Sincerely,

Mavis Belize

Mavis Belisle

Director 
December 29, 1993

TO: Thomas F. Williams and Ms. Betty Nolan

SUBJECT: Public involvement policy

We all welcome a policy that seeks to booster relations between DOE and the public. I believe it is important to differentiate between public relations and effective communications. It is my feeling that the success of your public involvement policy will not rest with this policy, but will depend on good sound overall public policy in DOE on the issues the public is interested in tracking.

I have noticed that often weak policy decisions are accompanied with strong public relations efforts. Some recent examples are:

- The flawed decision to do an EA instead of the EIS required under NEPA on the storage of pits at Pantex. This was followed with a full scale public relations campaign to garner public support. True public support would be earned if the Department explained their problem to the public, told them why they were needing to continue dismantlement, and then sought a legal means for accomplishing this objective.

- The PEIS will decide the reconfiguration of the weapons plants. It will be impossible to make a sound decision until broader public policy issues have been decided, such as the determination as to whether excess plutonium is waste or a resource. A public relations effort will not overcome this fact.

- High risks operations should be identified as such. Efforts to persuade the public that certain operations are not high risk should be avoided.

Operations should be grouped into different categories according to the level of risk so full disclosure will allow all parties full knowledge of their exposure.

Communications are a two way street. Input can only have a meaningful 
W.H. O'Brien

Pago 2

December 29. 1993

impact with output. We would welcome honest appraisals from DOE of where you are and where you want to go with these various projects. Subjecting your operations to outside regulators would be a positive step. We will look forward to working with DOE in a new trusting relationship.

Yours truly,

W.H. O'Brien 
Department of Energy

Washingron, DC 20585

$$
\begin{aligned}
& \because \because 66= \\
& \therefore \text { ¿11-0 } \\
& \text { " C clllariesu } \\
& \text { is ivir..pere, }
\end{aligned}
$$$$
\therefore 4, \because i 4
$$

December 1, 1993

MEMORANOUM TO MANAGERS: DOE OPERATIONS OFFICES

DOE LABORATORIES

FROM: Michael Gauldin $6(4)$

Director, Public and Consumer Affairs

Subject: Draft Public Involvement Policy

Attached is a draft policy requiring that public involvement be a routine component in program operations and planning activities. The draft was developed and revised over several months by a crosscutting management team which included field representatives.

You are asked to share this draft policy with your internal management team and external stakeholders and return comments to us by Friday, January 7 , 1994. If you can consolidate and prioritize your comments, it would be helpful. Comments and any questions you have concerning the draft should be directed to Betty. Nolan at 202/586-5373 (fax: 202/586-0539).

A1so, General Counsel has asked us to remind you that, as you pursue specific public involvement activities, you may trigger legal requirements. If you have any questions or concerns, you should seek advice of counsel, either onsite or at headquarters. Additionally, the whole issue of advisory committee requirenients is under review here at headquarters, and summary information is available.

\section{Attachment}

cc: Heads of Headquarters Elements Chief of Staff

Deputy Chief of Staff

Executive Assistant to the Deputy Secretary

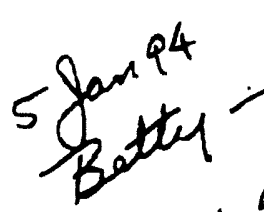




\section{Military Production Network}

A national alliance of organizations working to address

issues of nuclear weapons production and waste clean-up

FROM: Stephen schwartz, Washington, D.C. Representative

TO: Betty Nolan

FAX : $\quad 586-0539$

DATE: $\quad$ January 5

Number of pages, including this sheet: 1

MESSAGE:

Thank you for allowing us the opportunity to review the draft policy on public involvement.

While we applaud the secretary's recent and continuing openness initiatives, we continue to have concerns over the focus of these efforts--principally on the problems of the past. We are hopeful, however, that with the implementation of the public involvement policy the focus can begin to shift to the more important arena of current and future DOE programs and decisions.

The draft policy itself is a fine document which clearly and succinctly lays out the need for a new way of doing business. Indeed, much of the rhetoric closely matches what we have been saying for years.

At this point we have three basic concerns:

1) Who -- How will officlals, espectally regional officials and contractor employees, be held accountable for implementing the new policy. And what measures will be taken if employees do not follow the policy? Rewarding "cooperation" and "rlsk-taking" is a good and necessary step, but how will a lack of cooperation be dealt with and to whom can a stakeholder turn when the inevitable personnel or procedural roadblocks are encountered?

2) HON -- How does DOE plan to measure progress in implementing this pollcy? What factors will you be assessing and how will we know when "success"--on your terms--has been achleved? In TQM lingo, what are your metrics?

3) WheN -- What funding mechanisms are envisloned for FY95 and beyond to help implement this proposal? In particular, what additional resources will be allocated to FoI officers, both at HQ and the reglons, to ease the enormous case backlog? And when can we expect to be able to access a DOE database to obtain draft orders, budget documents, reports, speeches, etc...?

Answers to these questions will assist us in helping the DOE to become more trustworthy and accountable federal agency. 


\section{FAX}

\section{U.S. DEPARTMENT OF ENERGY WASHINGTON, D.C. OFFICE OF DEFENSE PROGRAMS}

This FAX consists of the following 1 page(s), plus cover.

TO: BEIYY MOLAN

FROM: $\quad$ Greg Rudy, DP-3

DATE: $\quad$ DECTEMBER 14, 1993

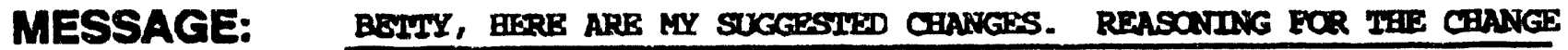
IS PROVIDED IN THE MARGDNS. YOUR CALL. LET IE NWW IF YOU

NEED TO DISCUSS. GRE

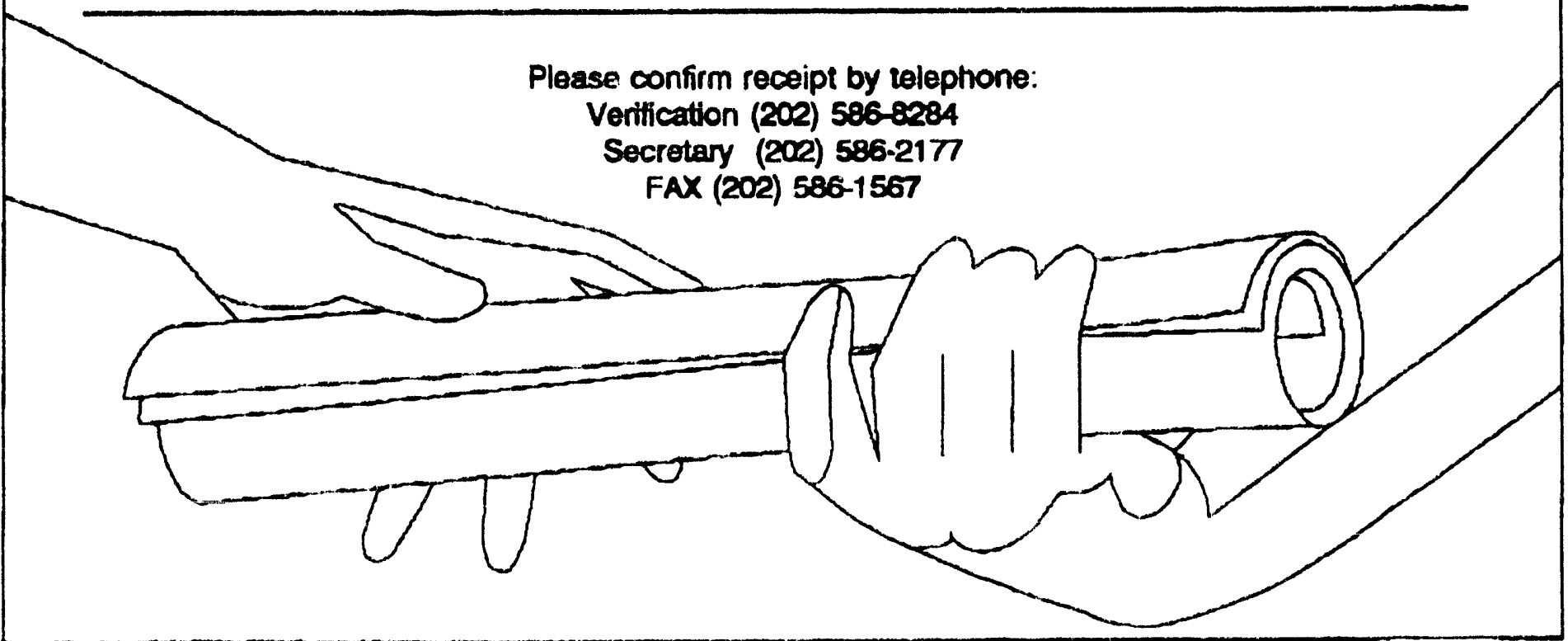




\section{Department of Energy}

Washington, DC 20585

December 1, 1993

MEMORANDUM TO MANAGERS: DOE OPERATIONS OFFICES

DOE LABORATORIES

FROM: $\begin{aligned} & \text { Michael Gauldin } \\ & \text { Director, Public and Consumer Affairs }\end{aligned}$

Subject: Oraft Public Involvement Policy

Attached is a draft policy requiring that public involvement be a routine component in program operations and planning activities. The draft was developed and revised over several months by a crosscutting management team which included field representatives.

You are asked to share this draft policy with your internal management team and external stakehoiders and return comments to us by Friday, January 7 , 1994. If you can consolidate and prioritize your comments, it would be helpful. Comments and any questions you have concerning the draft should be directed to Betty Nolan at 202/586-5373 (fax: 202/585-0539).

Also, General Counsel has asked us to remind you that, as you pursue specific public involvement activities, you may trigger legal requirements. If you have any questions or concerns, you should seek advice of counsel, either onsite or at headquarters. Additionally, the whole issue of advisory committee requirements is under review here at headquarters, and summary information is available.

\section{Attachment}

cc: Heads of Headquarters Elements

Chief of Staff

Deputy Chief of Staff

Executive Assistant to the Deputy Secretary 


\section{DATE}

\section{DRAFT}

POLICY ON: PURLIC INYOLVEMENT

POLICY: The polTcy of the Department of Energy (DOE) is that public invoivement must be a routine component in program operations and planning activities, at headquarters and in the field.

PÚRPOSE: Public involvement brings a full range of diverse stakeholder viewpoints and values early into the Department's decision-making process, enabling the Department to make better decisions and buildifinutual understanding and trust between the Department and the public it serves.

BACKGROUND: The Energy Department is relatively new at encouraging public involvement in its affairs. The Department grew largely out of the highly regimented cold War culture of two of its predecessor agencies, the Atomic Energy Commission and the Energy Research and Development Administration. The focus was on national defense through nuclear deterrence; the priority, on design and production of nuclear weapons; and the emphasis on classified information and legally-required secrecy.

Changing this 50 year old culture from a closed, command-oriented hierarchy into an open, participatory culture that values diversity and innovation requires special attention and leadership from the top down. Such leadership and change are essential if the Department is to succeed in meeting the economic and environmental challenges of the next century.

AmorG

DEFINITION: Public involvement provides a means fop Americans to influence decisions made by their government. It requires routine, substantive two-way communication the Department of Energy and other governmental entities, organized groups, individuals, and the general publis interested in and/or affected by the Department's decisions and activities. This communication will vary widely in nature and scope, from informal conversations between individuals to scheduled meetings and workshops, to legally-required public meetings and hearings and federal-statelocal-Tribal agreements. The Department will atively seek, Codriden incosorespond to the views of its stakeholders. 'and

GOALS: 1. Credible, effective public involvement processes are routinely incorporated into the Department's daily program operations and long-term planning activities, at headquarters and in our laboratories, facilities, and field offices, with every employee sharing responsibility to practice and improve public involvement.

I1. A clearly defined, coherent internal decision-making process with known access points for public involvement is routinely followed.

III. The public is informed about and participatefin Departmental decision-making. 
CORE VALUES

\section{DRAFT}

Accountability

Fairness

Openness

Respect

Risk-taking

Sincerity
Consistency

Honesty.

Peer Review

Responsiveness

Scientific Credibility

RESPONSIBILITIES:

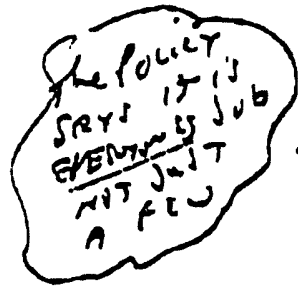

Under this policy, public involvement will be a discrete performance element for senior departmental and program managers-dity fesponsible for its offective-implementation.

To assure a consistent approach throughout the agency and with its contractors and to avoid unreasonable demands on site personnel or the public's time, Program and Staff Offices will coordinate theirupublic involvement activities through the Office of Public and Consumer Affairs, at headquarters and in the field. This coordination role in no way limits or dilutes program managers' responsibility to plan, fund, and support appropriate levels of public involvement in their programs.

The Principal Secretarial Officer and Senior Departmental Managers will ensure that public involvement principles, values, and processes are fully understood and practiced within their programs and that necessary training and resources (human, information, systems, and financial) provided.

Program Managers are responsible for identifying, plinning/budgeting

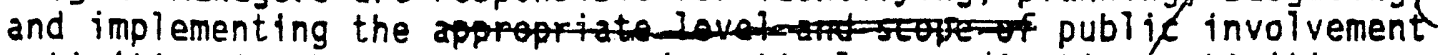
activities in their programs, and routinely coordinatinglactivities through the Office of Public and Consumer Affairs. Program managers will assure that their staff receive communication and, public involvernent training.

ApProlatite

The Director of Public and Consumer Affairs; headquarters, wi 71 establish a point of contact and mechanisms to coordinate public involvement activities Department-wide, and to assure that initiatives, as identified and implemented by secretarial officers and program managers, are carried out in a consistent, equitable, integrated manner. Public and Consumer Affairs will provide advice and support to program offices in developing and implementing effective communications/public involvement strategies and information materials for local communities, stakeholders, employees, and the media.

Managers of Field Organizations are responsible for assuring that public involvement activities at their respective facilities and sites meet local needs, are appropriately coordinated, and reflect Departmental principles and values. Field managers will regularly advise the Dinect of prouters on public involvement issues/needs of regional or national importance and recommend appropriate courses of action.

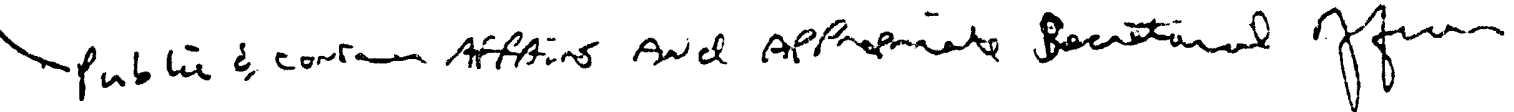


Field Public Affairs/External Relations Directors will work with field managers to provide the same coordinating/integrating role for site public involvement activities as the Director of Public and Consumer Affairs provides department-wide. 
MEMORANOUM FOR: HEADS OF HEADQUARTERS ELEMENTS

MANAGERS, DOE OPERATIONS OFFICES

FROM:

THE SECRETARY

SUBJECT: GUIDANCE ON IMPLEMENTATION OF THE DEPARTMENT'S PUBLIC INVOLVEMENT POLICY

It is the policy of the Department of Energy (DOE) that public involvement be a routine component in program operations and planning activities, at headquarters and in the field. This policy marks a clear break with past practice by challenging the Department and its contractors to embrace a new culture of openness and service the business of the Department will be open to the full view and input of those whom it serves.

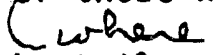

While public involvement processes must be tailored to specific site, program needs the following broad guidance is provided to assist headquarters and field manaers in implementing this policy department-wide. Several critical-policy elements and implementing actions are identified below. These should be viewed as a beginning point. They illustrate the comprehensive riature of public involvement as envisioned in this policy and the innovative leadership required to implement it. Using the following elements as a guide, you should with your stakeholders to develop public involvement plans and activities appopriate to their needs.

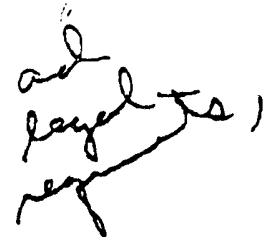
woute

\section{CRITICAL POLICY ELEMENTS}

1. The Department recognizes that honesty, forthrightness in dealing with external parties, and consistent, credible, quality performance are the bases on which to build pubijic understanding and trust.

\section{Imolementing actions:}

- - Officials representing the Department will be empowered and accountable for.the honesty and accuracy of their public statements and for assuring diligent follow-up and timely. results from the commitments they make.

- Departmental officials will routinely and consistentiy listen and respond to public input.

-. The new benchmark for excellence will be leadership/ performance.

- Risk-taking will be rewarded.

- Peer review will be encouraged. 
2. Departmental program development, planning, and decision processes must be clearly defined, with regular, well-known access points for public input.

\section{Implementing actions:}

- Principal Secretarial Officer and other senior departmental managers will ensure that other affected program officials,

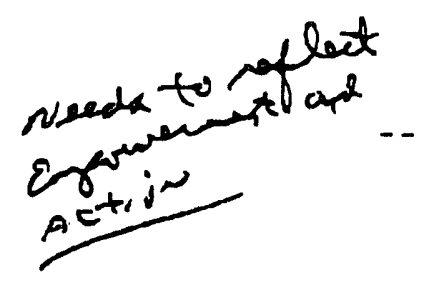
site managers, and stakeholders are appropriately integrated into their planning and decision-making processes.

Site managers, as those clogest to affected communities and interested parties, will appropriate predecisional access points for public input and facilitate accommodation between local and national interests.

3. Headquarters, laboratories, facilities, and field offices will operate as an integrated team in planning public involvement activities, combining resources, sharing information, and coordinating schedules.

- Cooperation will be rewarded.

-- Site managers and local program officials will routinely advise headquarters on local stakeholder needs/concerns and on the appropriateness/adequacy of public information/

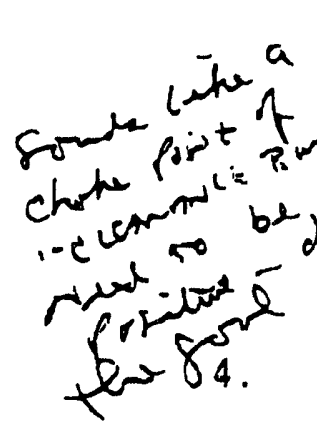
involvement efforts in their areas.

The Director of Public and Consumer Affairs, working with the Programmatic Assistant Secretaries, will develop consistent formats and procedures for public acen to information aterials

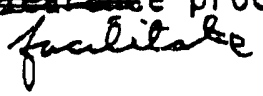

The Department must establish and support training/education programs to meet evolving public involvement needs, both internal and external.

\section{Implementing actions:}

- The Director of Public and Consumer Affairs will assess on an annual basis the effectiveness of the Department's communications efforts and recommend improvements.

- The Director of Public and Consumer Affairs and the Assistant Secretary for Human Resources and Administration, working with the Programmatic Assistant Secretaries, will identify and coordinate communication/public involvement training on a priority basis until all appropriate headquarters and site personnel are trained. 
5. The Department must foster candid information exchanges directed at reaching a common understanding of options and risks and developing consensus.

Implementing actions:

-. Whether formal or informal, all public involvement activities will be conducted in a spirit of openness, respect for different perspectives, and a genuine quest for information and ideas.

-- The Department w111 work to establish, announce, and manage a data base of real-time information avaflable to the public through telephone and computer access points. 
Deputy Chief of Staff and Counselor

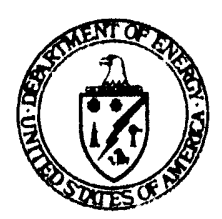

To: Mike Gauldin

November 9, 1993

From: Dan Reicher.

This is well done.

(8) Printad with soy rikik on recycled paper 
MEMORANDUM TO MANAGERS: DOE OPERATIONS OFFICES

DOE LABORATORIES

FROM: $\quad \begin{aligned} & \text { Michael Gauldin } \\ & \text { Director, Public and Consumer Affairs }\end{aligned}$

$\left.M_{1}^{-}\right) e^{\circ}$

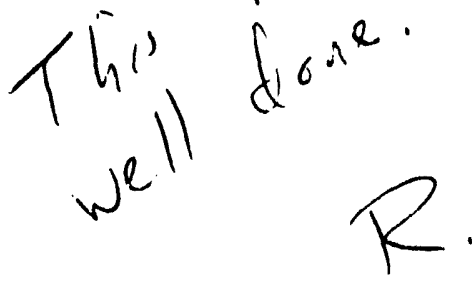

Yar

Subject: Draft Public Involvement Policy

Attached is a draft policy requiring that public involvement be a routine component in program operations and planning activities. The draft was developed and revised over several months by a crosscutting management team which included field representatives.

You are asked to share this draft policy with your internal management team and external stakeholders and return comments to us by Friday, January 7 , 1994. If you can consolidate and prioritize your comments, it would be helpful. Comments and any questions you have concerning the draft should be directed to Betty Nolan at 202/586-5373 (fax: 202/586-0539).

Also, General Counsel has asked us to remind you that, as you pursue specific public involvement activities, you may trigger legal requirements. If you have any questions or concerns, you should seek advice of counsel, either onsite or at headquarters. Additionally, the whole issue of advisory committee requirenients is under review here at headquarters, and summary information is available.

At tachment

cc: Heads of Headquarters Elements

Chief of Staff

Deputy Chief of Staff

Executive Assistant to the Deputy Secretary 


\section{CITY OF \\ OAK RIDGE

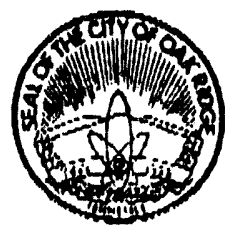 \\ EDMUND A. NEPHEW \\ MAYOR}

POST OFFICE BOX 1 - OAK RIDGE. TENNESSEE 37831-0001

February 9,1994

Mr. Frank Juan

Public Information office

U.S. Department of Energy

Oak Ridge Field Office

P. O. Box 2001

Oak Ridge, TN 37831-8502

Dear Mr. Juan:

Thank you for the opportunity to comment on the draft Public Involvement Policy issued by DOE headquarters. The fact that DOE recognizes the need to improve its public involvement program is a positive step toward developing public trust and confidence in decisions made by the agency. I do, however, have several comments to make about the draft.

Understanding that this document represents a broad policy rather than a detailed plan, I get the impression that state and local governments are considered to be merely two of the many "stakeholders" with which the DOE must deal. The Tennessee Oversight and Federal Facilities Agreements established a relationship between the Tennessee Department of Environment and Conservation, the Local Oversight Committee, and the DOE that is more formal than just a "policy" between the DOE and the general public. A more explicit statement that distinguishes public input from intergovernmental contractual agreements is approprlate. In fact, because of the confusion among the public (and DOE employees as well), as to what constitutes a "stakeholder," it may be best to simply avold the use of the term in your national policy document.

Second, because elected and appointed officials are legal representatives of the public, it is more accurate to state, "Public involvement provides a means for Americans to more directly influence decisions made by thelr goverriment." Citizens have, and continue to have, the means to influence government decisions by exercising their right to vote. If I were a DOE employee, I would not understand what you meant by your definition of "public involvement."

Finally, the DOE should receive training on public involvement from experts in that fleld, rather than relying on public relations contractors. Since the DOE Is "relatively new at encouraging public involvement in its affairs, " moving forward at full speed without adequate training for management and staff could actually worsen the agency's Image with the public. Many DOE and contractor personnel have little or no experience in dealing with the general public. 
-2-

Again, thank you for contacting me, and I look forward to seeing the final document.

Sincerely,

Edunend A. Nephew

Edmund A. Nephew

Mayor

$\mathrm{jb}$ 
DATE: February 7, 1994

REPLY TO

ATTN OF: EM-5

subject: Draft Public Involvement Policy

TO:

B. Nolan, PA-2

Attached are the Office of Waste Management's comments on the draft policy requiring that public involvement be a routine component in program operations and planning. The comments focus on the policy's consistency with the office of Environmental Management's public participation guidance and implementation plans.

If you have any questions, please call Denise Lenz, EM-5, at 6-5689.

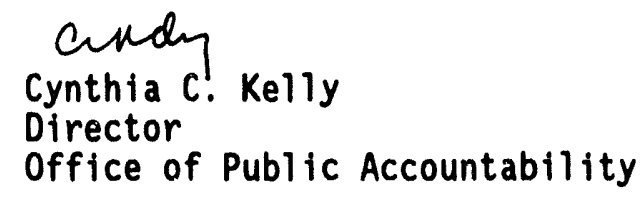

Attachment

CC: D. Blaney, EM-33

K. Donovan, EM-333 


\author{
OFFICE OF WASTE MANAGEMENT \\ COMMENTS ON $12 / 1 / 93$ DRAFT \\ DOE POLICY ON PUBLIC INVOLVEMENT
}

\title{
General Comments:
}

The format of the policy is very bureaucratic; suggest that the headers be less abrupt (i.e., Policy Statement, Purpose of the Policy, Definition of Public Involvement, etc.)

An editorial review would improve the consistency of both the policy and the implementing guidance, as they currently reflect many different viriting styles and sentence structures.

\section{Purpose Section:}

The primary purpose of public involvement is working with the public to reach consensus on how to solve problems in a more publicly acceptable way. This idea, which goes beyond "building mutual understanding and trust. should be incorporated into the statement of why we are pursuing public involvement.

\section{Background Section:}

The second sentence should be deleted. The third sentence should be changed to read "The focus of DOE's efforts during the Cold War was on national defense through nuclear deterrence; the priority, on design ... "Insert this after the sentence "This focus resulted in an operating culture that allowed for limited public interaction only."

The second paragraph could be improved by deleting "from a closed, command-oriented hierarchy".

In addition, in the last sentence delete "such leadership and change are essential: and insert "This new culture is essential if ...". Although leadership and change are essential, the change in culture is what can help the Department succeed in meetirig its challenges.

\section{Definition Section:}

Suggest rewording the lead. in sentence to "Public involvement is participation by interested members of the public in the activities and decision processes of the Department, and provides a means for members of the public to influence these decisions."

The last sentence should be reworded as follows: "The Department will actively seek and consider public input, and will incorporate or otherwise respond to the views of its stakeholders in making its decisions." It would also be helpful to add a sentence regarding the need to build 
ielationships with the stakeholders and to strive to reach consensus regarding DOE decisions. This provides a better feeling of ongoing relationships and partnerships rather than the input-output feeling of the "seek and respond" phrase.

Goals:

Need to add a lead in sentence and reword the goals to clarify the meaning:

The goals of the Department's public involvement policy are:

a) To assure that credible and effective public involvement processes are a part of the Department's daily operations and long-term planning activities;

b) To assure DOE has a clearly defined and coherent internal decision-making process with access points for public involvement; and

c) To assure that the public is informed about Departmental issues and decision-making processes and is thus empowered to participate at formative stages of specific projects.

\section{Core Values Section:}

Add the following sentence to open the section: "In order to develop a successful public involvement program for its activities and programs, the Department should consider and incorporate the following values:". Also need to add a short statement to each core value to clarify the meaning and intent of each value. Examples would also be very useful, especially in regard to Risk-taking, a phrase that could be interpreted to mean taking risks with health and safety.

\section{Responsibilities Section:}

It would be helpful to clarify what is meant by each of the responsible groups. For example, who are the Principal Secretarial Officers and Senior Departmental Officers? Does this include what the Office of Waste Management refers to as Office Directors?

In the second paragraph, it is stated that "...Program and Staff offices will coordinate their public involvement activities through the office of Public and Consumer Aftairs, at headquarters and in the field. "What does this coordination consist of? It would be helpful if this could be further defined to let the Program and Staff offices know what they are expected to do. Is this advisory only or will the office of Public and Consumer Affairs be actively involved? This must be an efficient and streamlined process, as many public involvement activities must be undertaken promptly in order to be responsive to an issue or concern. Perhaps this could be clarified in the guidance. 
It seems that we may need to add another responsibilities section regarding the responsibilities of Deputy Assistant Secretaries and Office Directors to oversee their program managers and ensure that they are including public involvement in their projects as early as possible. These managers are also responsible for providing resources to support public involvement activities. It would be highiy unusual for Principal Secretarial Officers and Senior Departmental Managers to have direct interaction with Program Managers; the managers in between these two levels also have responsibilities.

Within the Director of Public and Consumer Affairs, delete "to" immediately prior to "...assure that initiatives, as identified...".

\section{IMPLEMENTATION MEMORANDUM}

Paragraph 1, suggest rewording to: "It is the policy of the Department of Energy (DOE) that public involvement should be a routine component in program operations and planning activities, both at Headquarters and in the field. The business of the Department is to be open to the full view and input of those whom it serves, consistent with other laws. This policy marks a departure with past practices; in doing so, it challenges the Department and its contractors to perform to a new standard of service and openness."

The last sentence in the second paragraph should be revised to reflect that public involvement plans and activities should be appropriate to the needs of both the program and the stakeholders. It is not appropriate to involve the stakeholders in everything, nor are they interested in being involved in everything. DOE must be very clear in defining what it needs from the public involvement process in terms of recommendations, alternatives and priorities, etc.; the process must serve DOE as well as the public.

The introduction to the Implementation memorandum should contain a paragraph that discusses very directly the different Departmental elements (Waste Management, Defense Programs, Nuclear Energy, etc.) and reinforces the need for these elements to work cooperatively in public involvement efforts both at the sites and at headquarters. The memorandum now states the coordinating role of Public and Consumer Affairs, but does not clearly state that the reason for coordination is the need to be consistent and accurate in public involvement efforts, and to afford the public an opportunity to focus their involvement efforts as they see appropriate.

\section{Critical Policy Element \#1}

Suggest rewording first bullet under Implementing Actions to clarify what officiais will be empowered to do. Possible rewrite could be: "Officials representing the Department will be open, honest, and accurate in their public statements, and will assure diligent follow-up and timely results from the commitments they make." 
Second bullet: Change to read "...routinely solicit public input, consider it in making their decisions, and provide timely responses to the public. Responsiveness to public input is critical in building credibility."

Third bullet: This is not an action, either delete or incorporate into the introductory paragraphs.

\section{Critical Policy Element \#2}

Replace "well known access points" with "clearly identified access points".

Second bullet under Implementing Actions: insert "...will consult with Project Managers to identify appropriate pre-decisional...". Also, need to clarify what is intended by "facilitate accommodation between local and national interest:".

\section{Critical Policy Element $\# 3$}

First bullet begs for some clarification or expansion-cooperation should be given in any organization and should not necessarily be "rewarded". If these bullets are to be Implementing Actions (header is missing), it may be better to state this as an action "A system will be developed to evaluate and recognize examples of innovative, efficient or cooperative team efforts in public involvement activities." Specific guidance will be necessary to make this work.

\section{Critical Policy Element \#4}

It would be more logical to switch the sequence of the Implementing Action bullets to first list training, then evaluation.

\section{Critical Policy Element \#5}

This is the first time developing consensus has been mentioned in the policy or the implementation memorandum. This should be a greater emphasis in the policy. Effective public involvement activities will seek to build consensus and understand public values, not just exchange information.

Second bullet: Will this be one database? Suggest changing to "...manage appropriate (or topical) databases of reai-time information..." 


\section{STANFORD UNIVERSITY}

Stanford Linear Accelerator Center Business Services Division, MS 80
2575 Sand Hill Road Menlo Park, CA 94025

(415) $926-2601$ (phone)

(415) $926-4550$ (fax)

January 3,1994

Mr. Michael G, Gauldin, Director \& Press Secretary

Public \& Consumer Affairs 7A-145

U.S. Department of Energy

Forrestal Building

1000 Independence Avenue S.W.

Washington, D.C. 20585

Subject: Draft Public Involvement Policy

Dear Michael:

Thank you very much for the opportunity to review and comment on the draft of the proposed DOE Public Involvement Policy. We, at the Stanford Linear Accelerator Center, (SLAC) see a great deal of value in public involvement as a routine component in major program operations and planning activities and feel that the Department's move from "a closed, command-oriented hierarchy into an open, participatory culture" will, in the long-term, have many beneficial effects. SLAC is a research center performing only non-classified research and has routinely sought public involvement on major projects and ES\&H activities. This has been extremely valuable in maintaining community awareness and support for the programs carried out at the Laboratory.

In developing department-wide programs which will assure a consistent approach throughout the agency, it is important to keep in mind that each laboratory and community is different and that local needs may vary widely from site to site. Those closest to the community should have as much flexibility as necessary in order to meet the local needs. In addition, as noted in the draft policy, in implementing this policy it is important to avoid unreasonable demands on site personnel or the public's time. Keeping this principle in mind, we would hope that the implementation of the policy will not result in a requirement to hold a public meeting or seek public comment for every planned minor Accelerator Improvement or General Plant Project or for every NEPA document issued by the Labozatory. In our opinion, an appropriate level of public involvement is one in which the publics' viewpoints are sought on all major projects and periodically on the Laboratory's directions and programs. This periodic input could be obtained at an annual "town hall" meeting held to discuss the Laboratory's upcoming programs and future directions. 
U.S. Department of Energy

In summary, we think public involvement is a necessary and helpful element of the Department's decision-making process and look forward to doing our part to further the Department's goals in this area.

Sincerely,

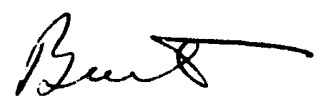

Burton Richter

Director

BR:laj 
DATE: AN: I: $: 996$

OIEA

$i c$.

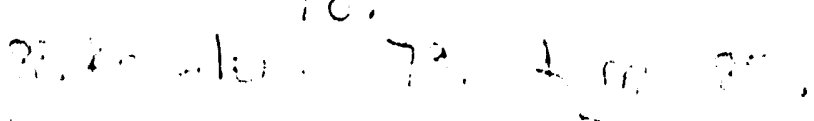

REPLYTO

ATTN OF:

SUBJECT:

Comments on Draft Public Involvement Policy

Tо: Michael Gauldin, Director, office of Public and Consumer Affairs, $P A-1$, HQ

Attached are comments received from the Department of Energy (DOE) Albuquerque operations office (AL) organizations and stakeholders.

Following is a summary of the comments:

- In general, most who commented felt that this was a major step in the right direction, but that the policy could be more comprehensive.

- There were some negative reactions on the short amount of time allowed for review and comment.

- Comments ranged from none to extensive.

- The largest number of comments came from activist groups in northern New Mexico.

- One major comment was the limitation of citizen involvement caused by the refusal of DOE to release classified information, even under the openness policy.

- "Values" were listed as a major point of controversy that needs to be addressed.

It is clear that this policy is perceived by DOE, contractor and public stakeholders as important, if properly implemented.

Please call David G. Jackson of the AL Office of Intergovernmental and External Affairs at (505) 845-5699 if you have any questions concerning this submission.

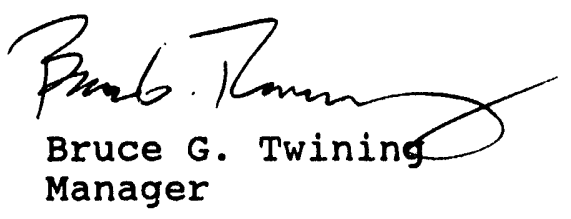

Attachment 
T0: Patricia Trujullo-Orieds 1-665-4411

78

From: Mary Riseley

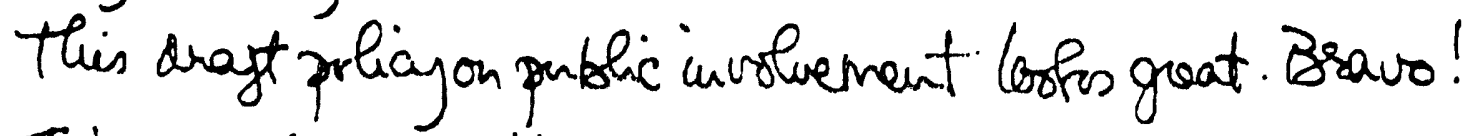

I have a fen questions:

(1) under DEFINition - are you orly going to Conduct "Wally. regained "meetings? I suggest omitting the mockers an hurtfully you will hold other pun ic meetings

(2) Under RESPONSIBiLITIES - the second paragraph. This is unclear and sounds cumber some. $a_{n}$ expectston of consistency and training and asot-checking,

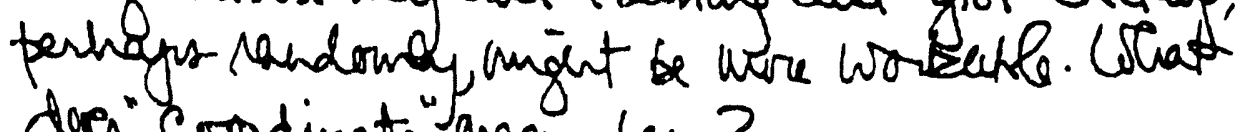
dee: Coordinate. Mean here?

(3) under GUIDANCE ON IMP LEMENTATTON- last sentence, just paragraph. This state rent is patently overstated. "Te business of D OF includes many matters that incl never to gen to full view schedves of Pu ship kente, plans for bract rations s amounts of weapons Coryponants storage, for ex ample. I would hare for a lure honest state pent with qualifying grosses. of course it is my fervent hope that soon there biel te no weapons programs to protect with sececy-trut even in an bra 8 stewardship there tref be "dangereres know. lodge "- this " one thing fund mentally wrong with all things nuclear - the price in loss of civil ubieties and gauress is Gif worth it, too high

Cartes, Pat'

B mary. 


\section{Comments on DOE Draft Policy on Public Involvement}

I believe this new DOE policy on public involvement is so sweeping in its changes, so radical in its approach, that it amounts to nothing less than a fundamental paradigm shift for our society. Furthermore, if it can be implemented, I believe this policy shift will affect the policies of all other governmental agencies.

It is long overdue.

In my view this paradigm shift is a shift of fundamental attitudes. It is a shift from the fundamental attitude of domination to an attitude of partnering. It is an attitude shift that will affect our entire way of behaving. Shifting to an attitude of partnering will not be an easy shift. Nevertheless, I, as one citizen, applaud DOE leadership's courage in putting forth such a bold, clear, policy intent. Attitude changes always precede changes in behavior.

A word of caution. It may be too early to predict how resistance to this shift will manifest, but manifest it will. Because this attitude shift is so radical, our citizens will likely become aware of its full implications only gradually. In addition to resistance from what is typical for anything new, resistance to this paradigm shift will come from individual citizens and citizen groups who are unconsciously committed to attitudes of domination, be they religious, technical, social, whatever. Such people often need secrecy or to have an enemy. We should allow for the discomfort that inevitably accompanies any radical change. I hope that we as citizens, in and out of leadership positions, can prepare for compassionate encounters of those whose entire ways of thinking or feeling will feel threatened by this shift. We need schooling on being introspective. We need to take personal responsibility for what needs transforming within ourselves first before seeing it in others. In so doing, let us educate ourselves to look for the best in ourselves and each other, rather than focusing on what is worst.

This is not to ignore what is wrong. There is much obvious and not so obvious wrong that needs attention and transformation. That is a given. This awareness seems clearly behind the new policy. There will doubtless be significant programmatic pain in implementing this policy. Let us, however, he creative about implementing it and not succumb to recriminations, finger pointing, scapegoating. Let us give this new policy an honest chance. Perhaps, as one of my colleagues has suggested, we could declare a national day of mourning for past misdeeds as a way of getting through the paralysis of guilt. This could be followed by a national resolve to be creative.

Those with hierarchical attitudes will likely be among the first to feel the press of this shift and feel threatened. Also, those who value rational processes over feeling processes as the best, if not only, way to make decisions will also feel threatened by this shift. Reverse domination of emotion over reason is always a threat. It should not be either/or, but both. That is, reason balanced by appropriate emotionality.

And so, it is a time for poets. Poet industrialists. Industrial poets. Poet scientists. Scientist poets. Poets from all walks of life, professions, trades, and ways of being. Maya Angelou said it best. She set the tone for this change in her prophetic inaugural poem, $A$ rock, a river, and a tree. May we citizens review it often. The government (read DOE) is now listening. After all, as another colleague said, newly inspired, "We don't have to fight City Hall any more!"

Eugene Kovalenko

January 13, 1994 
80

Dear Dot \& Chrrs-3े What is this? a gan 6 postmark

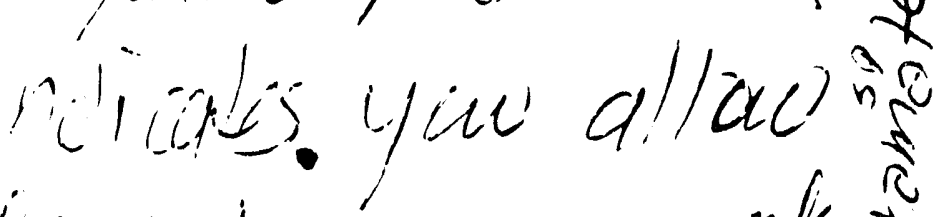
list than ono week \& to travel, read \& respond to this request? ¿ Surely y au must be

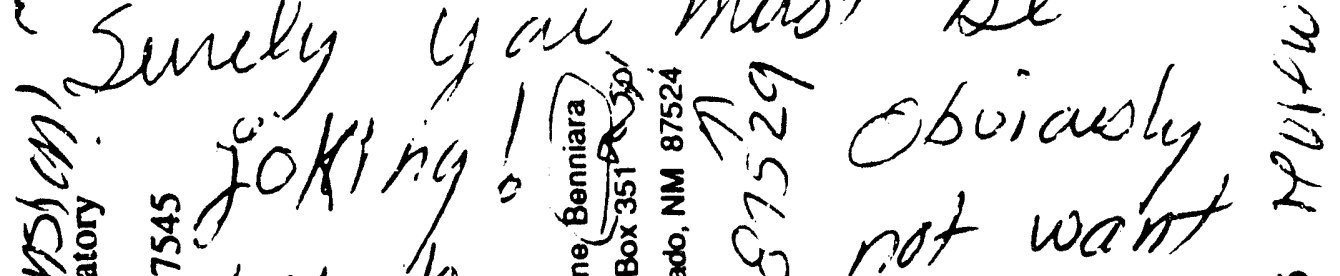

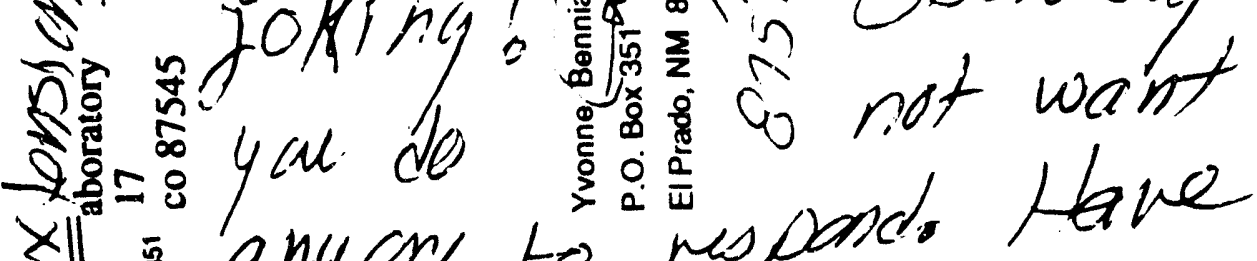

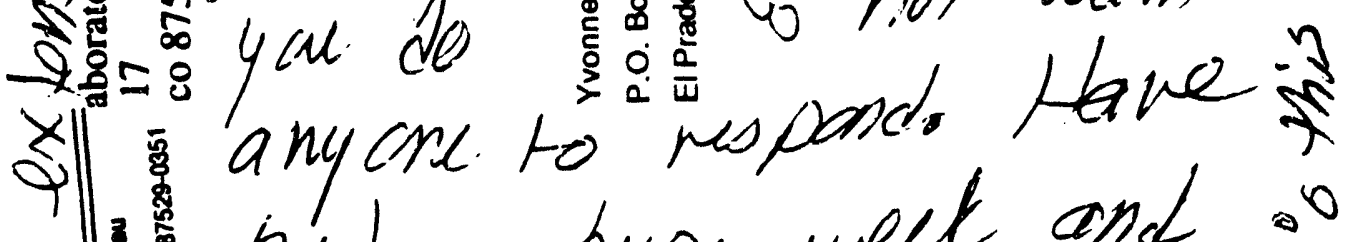
In had a busy week and: \$18.blliele 30-60-ar 90 Silt days notice is more in line with nIPA \& legitimate review processes y ans (Rommel 1) vane tonneau 


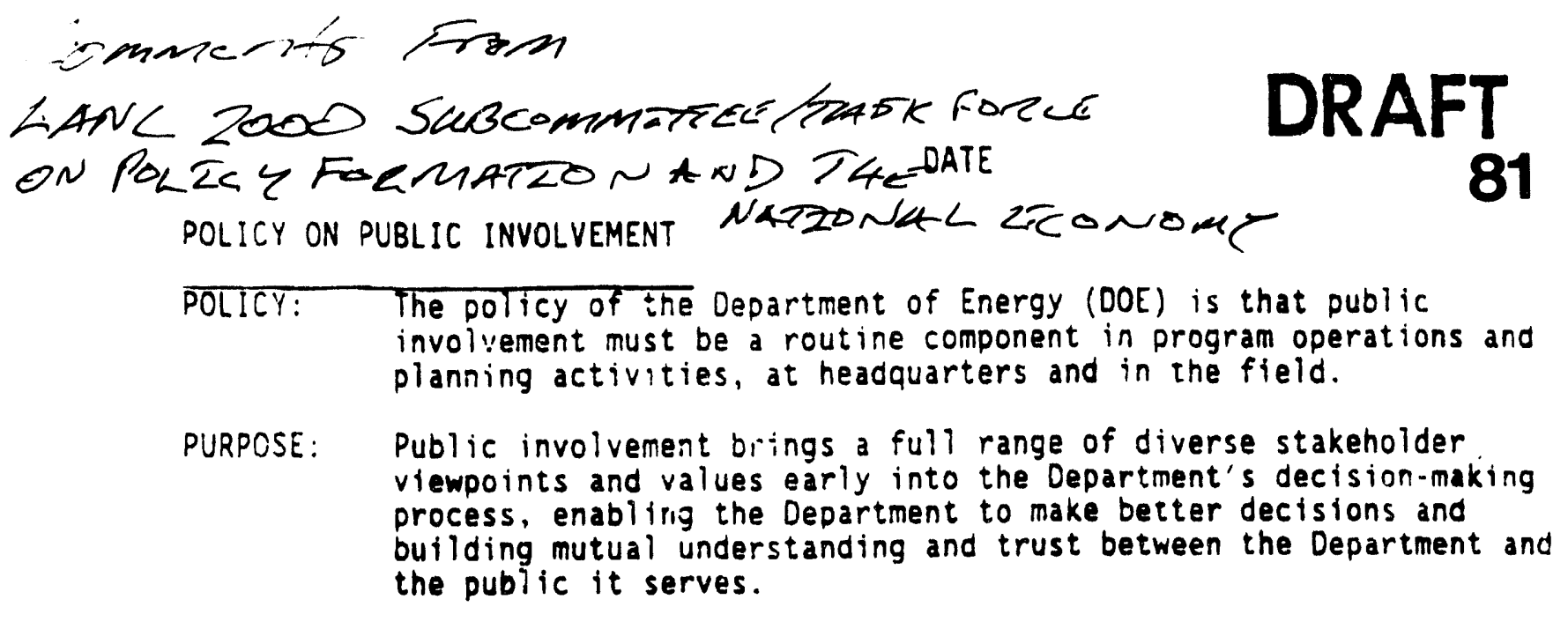

BACKGROUND: The Energy Department is relatively new at encouraging public involvement in its affairs. The Department grew largely out of the highly regimeited Cold War culture of two of its predecessor agencies, the Atomic Energy Commission and the Energy Research and Development Administration. The focus was on national defense through nuclear ceterrence; the priority, on design and production of nuclear weapons; and the emphasis on classified information and

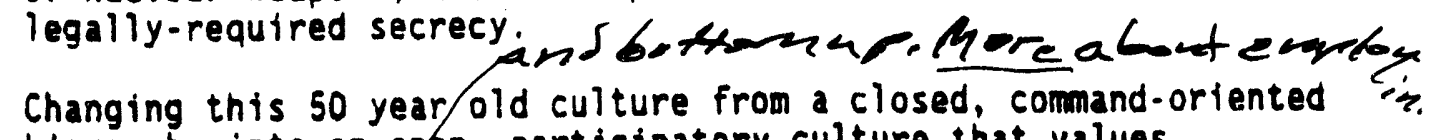
hierarchy into an open, participatory culture that values diversity and innovation requires special attention and leadership from the top dowrt. Such leadership and change are essential if the Department is to succeed in meeting the economic and environmental challenges of the next century.

OEFINITION: Public involvement provides a means for Americans to influence decisions made by their government. It requires routine, substantive two-way communication between the Department of Energy and other governmental entities, organized groups, individuals, and the general public interested in and/or affected by the Department's decisions and activities. This communication will

Connowert to exmeneats and we reverheir back we a remponse. so ad soactifitits: I. prout tidiely comprents vary widely in nature and scope, from informal conversations between individuals to scheduled meetings and workshops, to legally-required public meetings and hearings and federal-statelocal-Tribal agreements. The Department will actively seek, incorporate, or otherwise respond to the views of its stakeholders.

Credible, effective public involvement processes are routinely incorporated into the Department's dally program operations and long-term planning activities, at headquarters and in our laboratories, facilities, and field offices, with every employee sharing responsibility to practice and improve public involvement.

involumblic 11 . restriter to

111. The public is infirmed about and empowered to participate in A clearly defined, conerent internal decision-making process with
known access points for public involvement is routinely followed

$$
\text { non }(\text { द soife) materis? ? }
$$

will the pablic have aceso

to neclear information so 


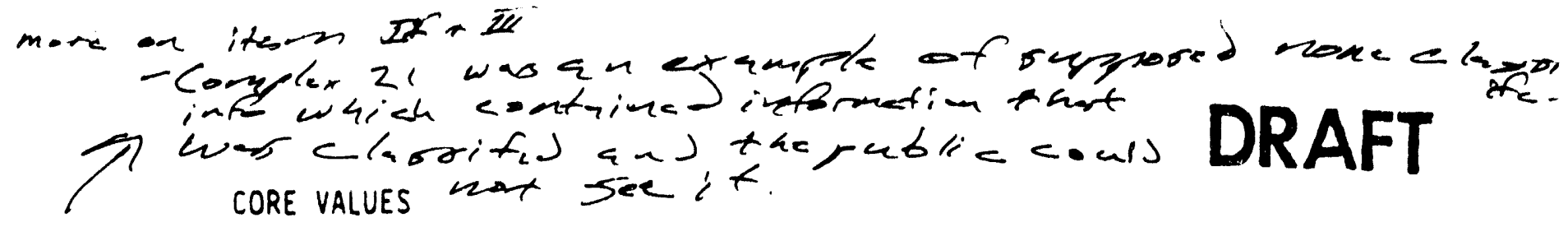

$$
\begin{aligned}
& \text { aloo will } \\
& \text { SSAB inenber Lave Fairness } \\
& z<a=00 \text { to ar Openness } \\
& \begin{array}{l}
\text { Clapoifal -nferats Respect } \\
\text { or will tee? Risk-taking }
\end{array} \\
& \text { have to extain } \\
& \text { a } 2 \text { ? RESPONSIBILITIES: }
\end{aligned}
$$

The Principal Secretarial officer and Senior Departmental Managers will ensure that public involvement principles, values, and processes are fully understood and practiced within their programs and that necessary training and resources (human, information, systems, and financial) are provided.

Progran Managers are responsible for identifying, planning, budgeting, and implementing the appropriate level and scope of public involvement activities in their programs, and routinely coordinating activities through the office of Public and Consumer Affairs. Program managers will assure that their staff receive basic communication training and, where appropriate, advanced public involventent training.

The Director of Public and Consumar Affairs, headquarters, will establish a point of contact and mechanisms to coordinate public involvement activities Department-wide, and to assure that Initiatives, as identffied and implemented by secretarial officers and program managers, are carried out in a consistent, equitable, Integrated manner. Public and Consumer Affairs will provide dvice and suppert to program offices in developing and implementing effective comunications/public involvement strategies and information materials for local communitles, stakeholders, employees, and the media.

Managers of field Organizations are responsible for assuring that public involvement activities at their respective facilities and sites meet local needs, are appropriately coordinated, and reflect Departmental principles and values. Field managers will regularly advise headquarters on public involvement issues/needs of regional or national importance and recommend appropriate courses of action. 



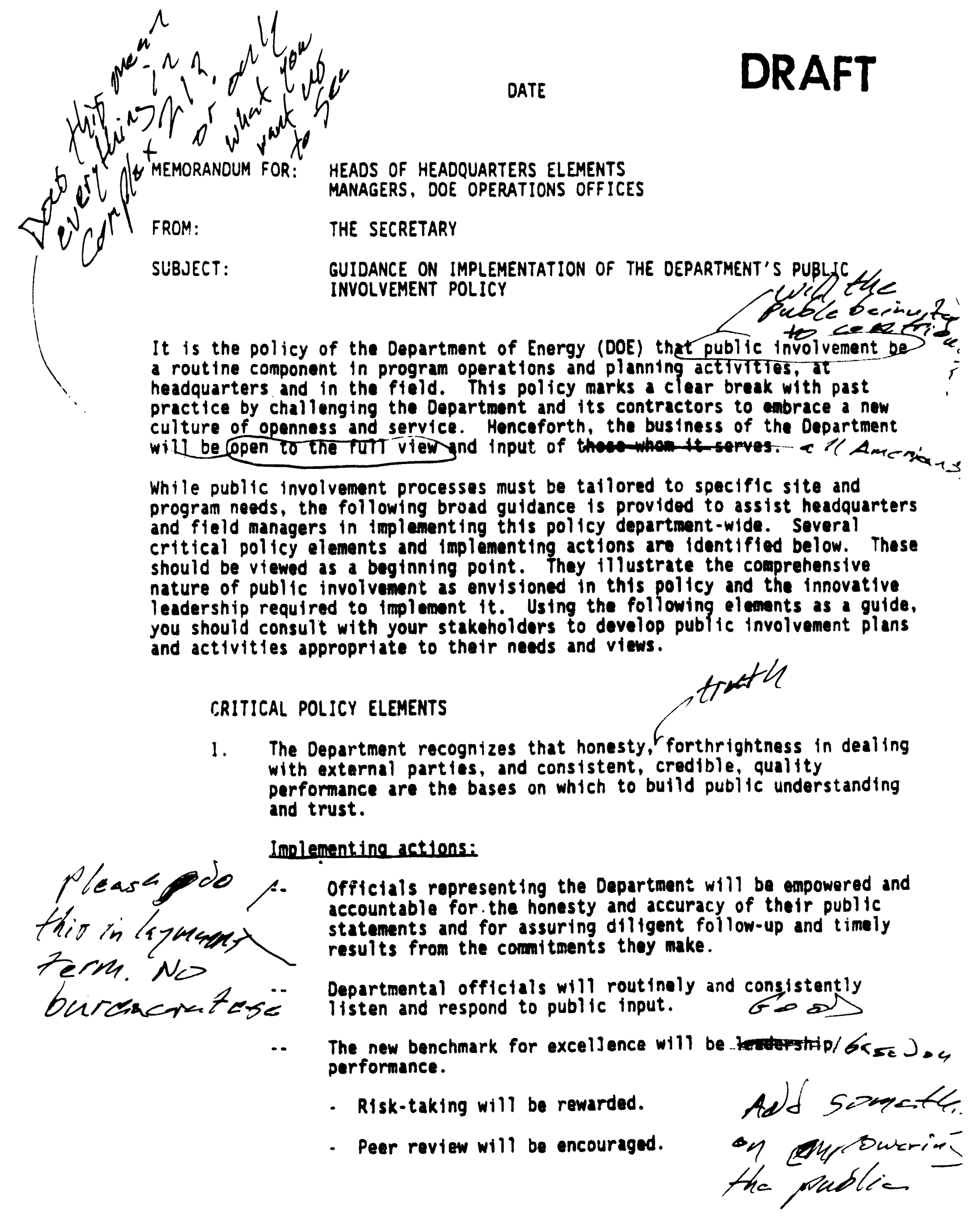




\section{DRAFT}

2. Departmental program development, planning, and decision processes must be clearly jefingd, with regular, well-known access points for public input.

\section{Imolementing actions:}

- Principal Secresarial officer and other senior departmental managers $w i ? l$ ensure that other affected program officials, site managers, and stakeholders are appropriately integrated into their planning and decision-making processes.

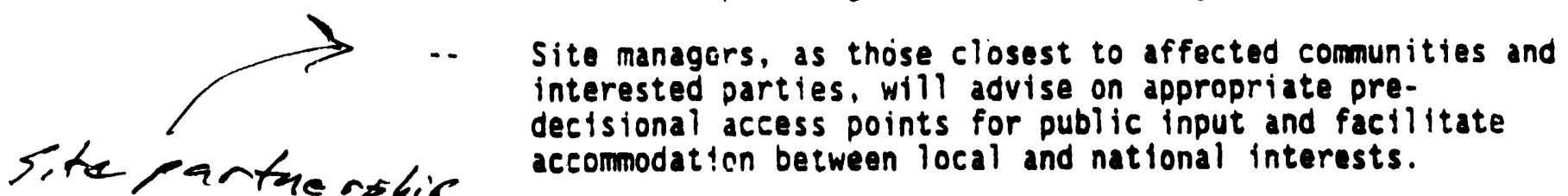
w pecblik

3. Headquarters, latoratories, facilities, and field offices will operate as an integrated team in planning public involvement activities, combining resources, sharing information, and coordinating schedules.

. Cooperation will be rectortor

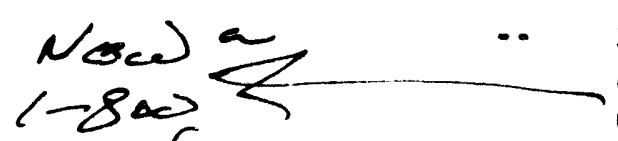

Site managers and local progran offtcials will routinely advise headquarters on local stakeholder needs/concerns and on the appropriateness/adequacy of public information/ nerator involvement efforts in their areas.

-. The Director of Public and Consumer Affairs, working with the Programmatic Assistant Secretaries, will develop reduce consistent formats and clearance procedures for public riof Tet information materials.

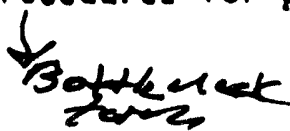

4. The Department must establish and support training/education programs to meet evolving public involvement needs, both internal and external.

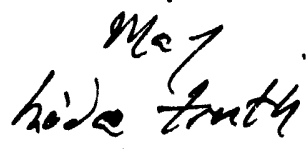

un whatio.

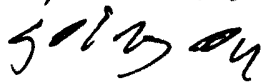

Imolementing actions: qeartar/y

-. The Director of Public and Consumer Affairs will assess on an anarios basis the effectiveness of the Department's communications efforts and recongend improvements.

.. The Director of Public and Consumer Affairs and the Assistant Sucretary for Human Resources and Administration, working with the Programmatic Assistant Secretaries, will identify and coordinate communication/public involvement treining on a priority basis until all appropriate headquarters and site personnel are trained.

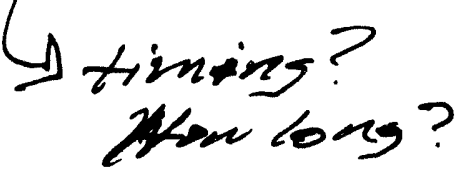


UAR

5. The Department must foster candid information exchanges directed at reaching a common understanding of options and risks and developing consensus.

Implementing actions:

- Whether formal or informal, all public involvement activities will be conducted in a spirit of openness, respect for different perspectives, and a genuine quest for information and ideas. F

-. The Department will work to establish, announce, and manage a data base of real-time information available to the pubic ic through telephone and computer access points.

include 
FAx To 6651718 .

Rt 4 BOX 57E

Santa Fe, NM 87501

January 12 th 1994

Christina Armijo, A316

Los Alamos Area Ofice

USDOE

Los Alamos, NM 87545

Dear Christina,

I have just seen the Draf Public Involvement Pollcy which is being circulated for comment Thank you for the opportunity to give input on this draft. My comments are

1 If the public is to have a meaningful interaction on policy and other lesues, it is vital that more than all the relevant information is available in some areas this will conflict with national securty iesues and classincation. I did not see this addressed in the document This particularly applies to members of the future SSAB

2. In the guldance document first paragraph, I would like the strategic plan to be particularly called out in the second line

3 In the last line of the same paragraph, and with security issues in mind, add "of Americans" after "view"

4. Under Critical Policy Elements, item 1, first implementing action, add "completeness" after "honesty". In dealing with the lay public who are often not trained in legal and technical issues, one wants to ensure that this is not taken actvantage of.

5. Under Critical Polioy Elements, item 3 change "Cooperation will be rewarded" to "Cooperation will be recognizzed". This gives the DOE and contractor management more flexibility. The document is saying that acting as an integrated team is a new part of the job and the use of the word "reward" implies raises for doing the job when I believe that raises above cost of living should be for an exceptional job.

6. Under Critical Policy Elements, item 5, add ". and understanding values" after "information and ideas" I think that this better expresses the attitudes that are being promoted in the document

As a general point, I do worry that the new policy is very broad and will come at a high cost On the other hand, I think that public involvement at the right level will potentially help the DOE and laboratories like LANL wth fresh outlooks, perspectives and community understanding instead of suspicion

Sincerely,

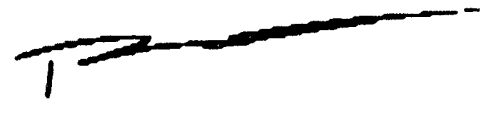


To: Department of Energy, Los Alamos Area Office and Los Alamos National Laboratory

From: Gloria Gilmore-House, Los Alamos citizen and member of the Working Group to Address Los Alamos Community Health Concerns

RE: Comments on the Draft Public Involvement Policy for the Department of Energy

As a resident of Los Alamos county and a member of the Working Group to Address Los Alamos Community Health Concerns, I admire the risk-taking aspect demonstrated by this bold Public Involvement Policy drafted by DOE leadership. From my point of view, DOE and LANL need to reassert themselves as leaders with pride in their product, faith in their ethics, and the ability to share it with the public. I remain skeptical, though, that they can change this much this fast.

One of my concerns is that changing a 50 year old culture from a closed, "no questions asked without a need to know" mentality to "an open, participatory culture that values diversity and innovation" will not happen quickly. An immense amount of time and energy will be needed to change mind sets. It necessitates a long-term commitment from everyone involved, DOE, LANL, and the public. How deep is this commitment to change? Is it simply a fad or will it continue beyond the present administration? If such an initiative begins and dies before it can take root, the public will grow even more skeptical and cynical. Therefore, before I take this initiative too seriously, I need a better understanding of how broad its support is.

DOE wants public involvement but DOE/LANL needs to understand that the burden of this transformation is on them. Why, for example, are risk-taking and peer review the only core values singled out as benchmarks for performance assessment in this document? Why aren't the other laudable values listed of accountability, fairness, openness, respect, sincerity, consistency, honesty, responsiveness, and scientific credibility also included as a measure of one's performance? They need to be.

Why when diversity is valued as an asset does LANL disband all special interest groups that had been created under the Work Force 2000? Diversity needs to be nurtured until it's routinely accepted at LANL and in our society in general. Such groups can help achieve this. By summarily disbanding them, then asking for the groups' input, LANL is operating in its business as usual, command-oriented hierarchy. Such actions don't support the words of the Public Involvement Policy.

I applaud your new commitment to making real-time information available to the public. This is basic; Environmental Surveillance reports that require 18 months from data to public suggests misplaced priorities.

With every best wish that this new policy can become a reality!

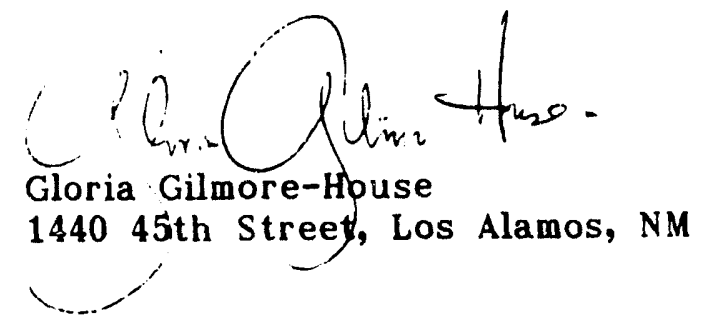


Chrestura Armijo

$\operatorname{Van} 10,1994^{84}$ vept of sinerged.

Gecertins Armio

we thane seceived yover segued for conmert on top aleneor taboretoips pane for the futare. We ose in favorof of soseres peduction and wacte minimizalion ant are net in favor of expanding the whe of the labosatory fy using phetonum!

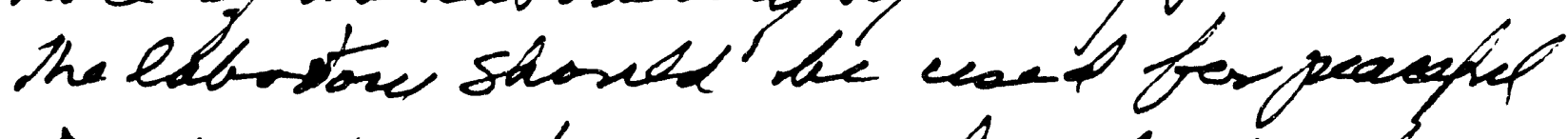

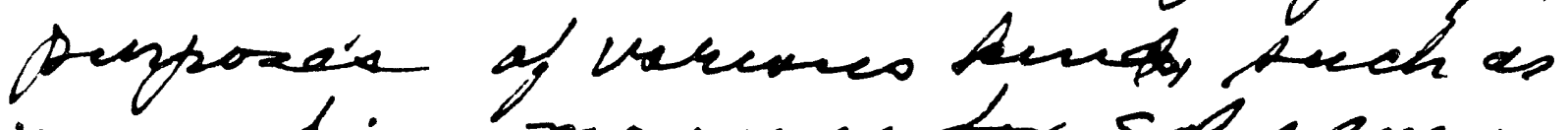

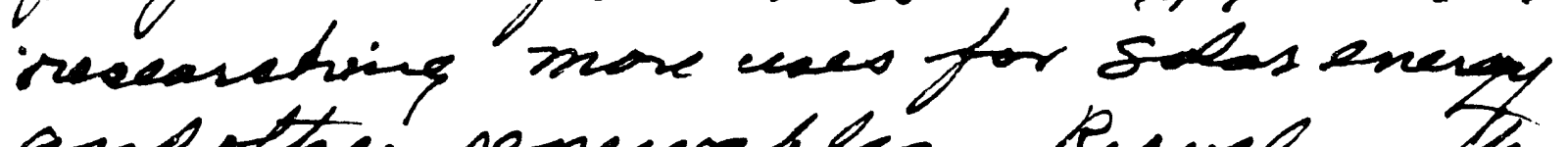
and other renewebles. Meyshng the weste stream, makury care mos frel. efferient, factores lea porentiry -

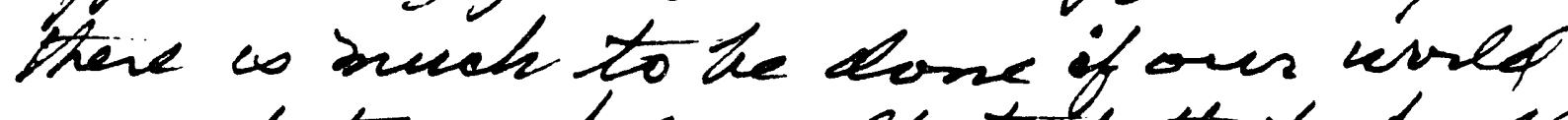
is nat to get so peelented that it well eventrall ${ }^{\prime}$ be the med of hermentind.

Sincueley

Carolyn Tapulh Arnola Teaturla 
Pg. 1

85

Ma elnustina Ormajo

DOE, fAO

12 gan 1994

m.. Ari..jo:

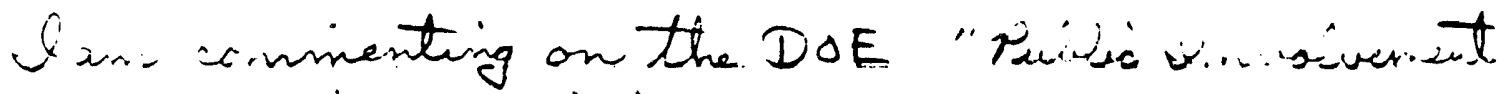
Dirivion. Maiming Paine".

For input on environmental clear -up, pollution prevention, contamination, ste., the public should be irseshed. So accurate, effective solutions can be found for contamination deanup, the public should be given the recusing behind the contaminating process and the composition of the contaminants. In short, people have a right to how what is contaminating the areas where they wok live and play. Thesis the point why DOE mut shift to a more guarded position. So r example; couches pourer slant spent fuel nods can be used ac an illustration. Fou educate the pubic on the mining process of arsmum and thorium, the release of energy in the reactor and the change - ant of the spent sods. you do most publicize the route of the new fuel node or of the spent a ode to the storage facility. 
Pg. 2

You do not puivieing emplnaize the fact that tis.x is enough uranium and tirasim le gt in spent rods to create a nuclear weapon.

Their same reasoning could he used on de-cianifid information. Cace-in-point: Mn Mite of the Soc Diane Study rouge. He and hie group have the right to information comesning cristamination, clear-upe, the rockies canning the contamination and the DOE policy on lean -up. Ot e and hin group trave no reason uhatracuen to sit their hands or weapisic' production poroccwer, uts, composition, tinting ste. LANL Security dictates dissemination. of information on a "Need to Thrown" basis. Io nationalization in the world sur corrunce me that a "group" has the right to sensitive information concerning the place, prover,

-. component e and testing of strategic vapors. The "Cold War" may be over, bat there in an even greater the st coming from the " J hind Would" countries. DOE must be casigul that in its effort to build a better relationalipe with the public it doesit release information that could aid terrorists in the making of high -tech weapons. 
Pg. 3

Public input on clean-eys, environment, te., could be welcomed. Public input comeanning ducioponint, tasering and valuation of high -tech weapons should not be implemented. again, dissemination of thin information ta lay-people would only play into the hands of thirdworld terrorists and their quit for high -tech weapon information.

DOE and its effort to open up deserve much audit. Hover, when the question of puli information v. National Society comes use, National e iscisity should be of paramount privity and concern.

Iamb you for your time.

Sunciseliy,

Sand $\Sigma, 3$ mine

$\alpha A N L$ J CI 
Comment on draft Public Involvement Policy

Received by LAAO verbally, 1/13/94

From: John F. Darke, Citizen, Los Alamos County

In terms of input with respect to public information, I cam currently looking at in my capacity as a document researcher, a proposed D\&D plan for TA-21, Buildings 3\&4. That document proposes to be substantiated by many other contractor documents which I have requested. I have had excellent cooperation with the Reading Room, the Report Library (Oppenheimer) and OS-1. Repeat ... excellent, prompt and timely response to my request for documents.

That cooperation notwithstanding, numerous primary references proposed by way of substantiation by the TA-21 D\&D plan have been classified documents. The section 148 review has been timely; however, certain documents remain classified and are unavailable. The gist of my comment is that proposed plans submitted for public comment should not rely upon "secret" references by way of substantiation.

In winter of $85 / 86$, had interface which overlapped TA-21. Area Office attorney and staff were very helpful. I would welcome cooperation with the DOE at this time to mitigate the problems which are rapidly accruing due to the failure of the contractor to declassify documents required for a hard look at the TA-21 D\&D proposal, dated 8/28/93 (DADEM13-93-004). 
Comment on draft Public Involvement Policy

Received by LAAO verbally, $1 / 12 / 94$

From: Erwin Binder, NIS-8, LANL (667-2940)

"Based on witnessing false and deceptive statements made recently by the Secretary of Energy, I have no confidence that the proposed public involvement process will not be subverted by political considerations." 
Jay Edgeworth

The purpose statement should contain a statement how more stakehoider involvement can reduce costs (e.g. stakeholder involvement in the planning stages of an Environmental Restoration project could reduce delays and legal issues later).

If we are truly committed to openness and public involvement, DOE personnel other than branch chiefs and above have to be involved. Goal 1 refers to every employee sharing in public involvement, but no responsibilities are listed for all employees, and no mention is made of employee involvement in the secretary's implementation memo. By employee involvement I mean when the public meets a DOE person, he/she will be considered by the public as a DOE representative. No consideration will be given as to the DOE person's qualifications to be a DOE representative; by virtue of their employer all DOE employees are its representatives to the public. Front-line personnel (facility reps, inspectors, etc.) will have the most face-to-face contact with lab personnel as well as interacting with representatives at their level from the public, and state and local authorities. It is thus important they be apprised of their responsibilities and be given the instructions necessary to adequately carry out their roles in the new era of openness. This means everyone (not just 'appropriate personnel') should be given public involvement training (see guidance memo part 4 bullet 2 ).

In addition, the public involvement issue does not only occur during work hours. DOE personnel at every level should always consider themselves representatives of the $U$. S. government and respond to questions raised by concerned individuals or groups. This response is not necessarily to provide detailed information; it may be to simply refer them to the appropriate public affairs person.

In short, the draft seems only to address the roles of public affairs officers and area managers and above. It is a mistake not to empower all employees to respond to the public's concerns since all employees will be dealing with the public on a daily basis, whether or not they are officially representing the department at that moment. 


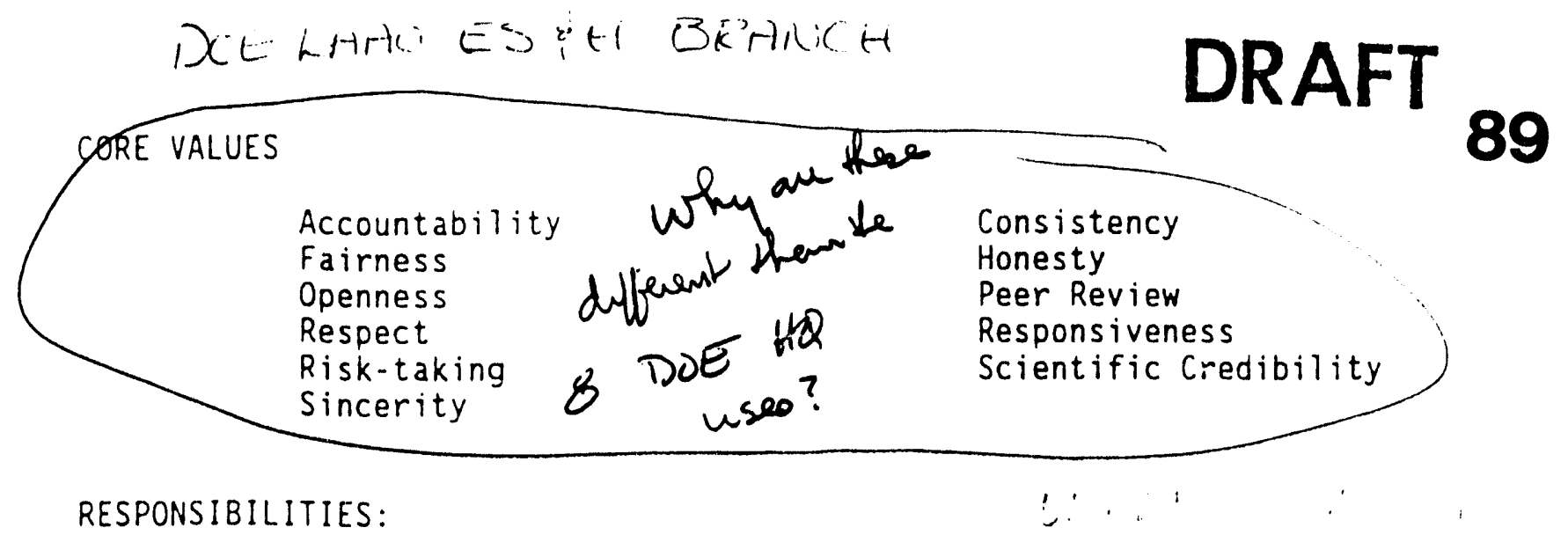

Under this policy, public involvement will be a discrete performance element for senior departmental and program managers directly responsible for its effective implementation.

To assure a consistent approach throughout the agency and with its contractors and to avoid unreasonable demands on site personnel or the public's time, Program and Staff offices will coordinate their public involvement activities through the Office of Public and Consumer Affairs, $a^{ \pm}$headquarters and in the field. This coordination role in no way limits or dilutes program managers' responsibility to plan, fund, and support appropriate levels of public involvement in their programs.

The Principal Secretarial Officer and Senior Departmental Managers will ensure that public involvement principles, values, and processes are fully understood and practiced within their programs and that necessary training and resources (human, information, systems, and financial) are provided.

Program Managers are responsible for identifying, planning, budgeting, and implementing the appropriate level and scope of public involvement activities in their programs, and routinely coordinating activities through the Office of Public and Consumer Affairs. Program managers will assure that their staff receive basic communication training and, where appropriate, advanced public involvement training.

The Director of Public and Consumer Affairs, headquarters, will establish a point of contact and mechanisms to coordinate public involvement activities Department-wide, and to assure that initiatives, as identified and implemented by secretarial officers and program managers, are carried out in a consistent, equitable, integrated manner. Public and Consumer Affairs will provide advice and support to program offices in developing and implementing effective communications/pubiic involvement strategies and information materials for local communities, stakeholders, employees, and the media.

Managers of Field Organizations are responsible for assuring that public involvement activities at their respective facilities and sites meet local needs, are appropriately coordinated, and reflect Departmental principles and values. Field managers will regularly advise headquarters on public involvement issues/needs of regional or national importance and recommend appropriate courses of action. 
Comment on draft Public Involvement Policy

Received by LANL electronically, 1/3/94

From: Laboratory Director, Sig Hecker

"I think this is a very important policy. One comment that I have is that where it says that the public is empowered to participate, we face the classic problem of 1) who is the public? 2) Accountability is the flip side of empowerment. How do we get the public to be accountable?" 
Comment received on Public Involvement Policy by LANL 1/5/94

From: LANL Public Affairs Director, Scott Duncan

"I have no problems with the draft policy as outlined. In theory it should work. However, as a practical matter, I'm not too sure just how we "empower" and "include" the public in the decision making process. 
Comments received verbally by LANL $1 / 11 / 93$

From John Ussery, FAX 581-4551

"Two days is uot enough time to comment. This seems to be noise from DOE headquarters. Enough time must be allowed for the public to truly respond." 


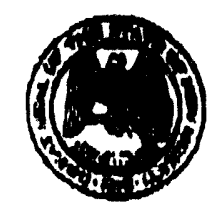

Dnver kina GOVIRNOA

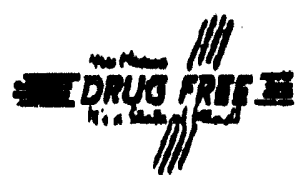

Aurra Loexwoor CAUINTT BEOROTAP

93

January 18,1994

hu'linis..

Chrietine Aratjo, A316

Los Alamos Area OeE100

U.8. Dopartiont of inergy

Loa Alamos, NA 87545

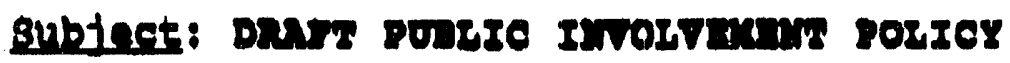

Danr Me. Asmijos

Thank you tor anding us a copy of the draet Publ1o Involvement pol1cy. On bohalf of the state of Now Hexico' Radionctive Havte Conoultation Task Foree (section 74-4A-6 Naw Mexico statutes Annotated 1978), wa ofear the following comments and recormandations on the polloy.

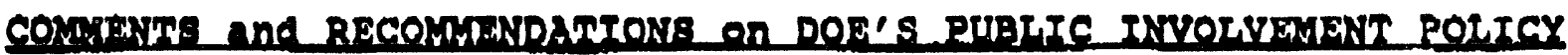

The U.8. Departmant of sncrey (DOE) 18 commanded for thia Inttiativa to enhance publde involvoment in ite planning ectivitios and program operationa. ve belleve a comprebenelve, effootive policy governing public informeton and participation wild ylold signifloant benet fta for all atakeholders, but partleularly for the DoE 1tuals.

ioje deciaion by DOE to develop a Department-wid public involvamant polley comes at a critlcal tiwe. The WIPP projoot is currently in the ardy stages of a major craneition. This situation presents DOI with an opportunity tor application of the now public involvement policy. The planning and conduct of WIPp oporations and activities mist prooed in a manner whioh provides ald

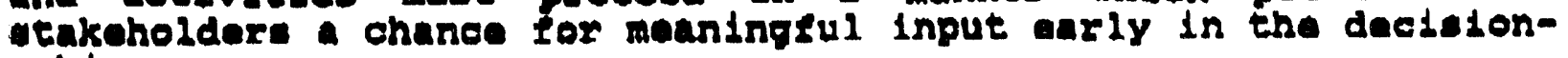
raking procene.
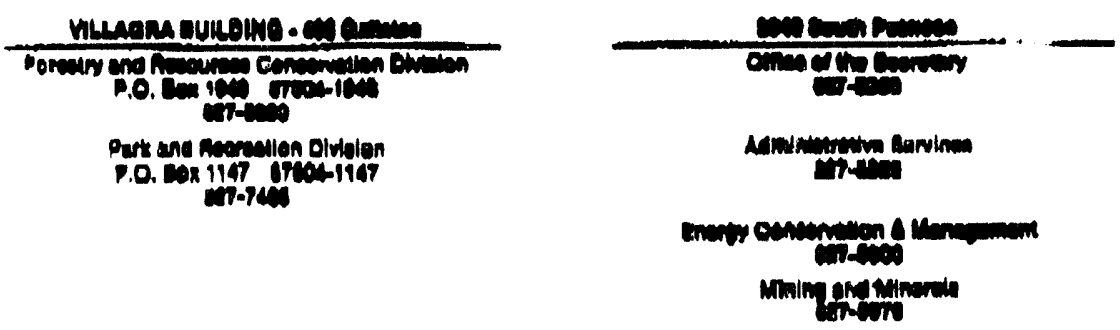

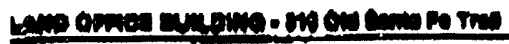

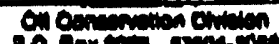

0.0. Con linen on 
Christina Armijo

Dos Public Involvemene. Pollcy

January 18, 1994

The timing of this polloy initlative also relates to DOE's ongoing effort to clean up and reoonelgure the nuclear weapone complex. Theos efforts are diffloult tanks in and of themselves. Howover, in light of racant and continuing rovelations of huran radiation experiments, complex cleanup and reconeiguration way become oven a more elgniflcant challenge.

DOz to encouragad to move expeditiounly toward adoption and implementation of a credible public involvomant polloy. such a polloy will be a demonntrable flret otap toward earning the publ10' trumt and confldence. It will be useful in gulding the procese for public partiolpation in developant of the programmatic Invironmental Impact staiement (s) on environmental restoration, waste managament, and reconflguration of U.S. nuelear wapons racil1tias.

In finalizing this flrst draft or a polloy, DOE should carafully reviow a recontly released report of tha secretary of Energy Advisory Board Turk Force on Radioactive Wauta Managemant entitled "Earning pubile Trust and Cone1denco: Roquisites for Managing Radloactive Wastes," November 1993, In particular, the IIndings and recommendetions of the rask Force provide many valuable Inslgnts whloh are diractly relevant to the formulation of a Doswide public involvement policy. Dor could be well-served if this policy embodies the gulding principles outilned in the Tadk Force ronort for intaracting with exteroul parties.

It 10 strongly recosmended DOE pay partioular attantion to impementation of the polley in the field. Often a wall-thoughtout plan or pollcy concalved in good falth falle to achleve 1 ts objeotive beoause of poor implomantation. In a large and geographlcally disperse organization suah as Dos, oven greater attention to effect1ve poliey implenantation is varranted.

In addition, we recommend DOE take the necossary stope to monitor and ovaluate the effectivanose of 1ta publio Isvolvament Polloy. varlous tools, Including roous groups and time-sartes surveys, can be used to detarmine whother the policy is offective in achieving 1te atated objectives. InIs is an important element of the ovarali polley developmant process.

Finally, we offor a conotruative oritielan of the nolioitation of utakehoidex Input on this draft public Involvement polloy. A notlce from the DOE IOS Alamos Ara offlea about the polloy was postmarked January 6 and recelved in this offlee on January 7 , 1994. A copy of the draft polley was not included with the notioe. 
Notwithstanding these circumstances, comments were requested "NO LATER THAN JANUARY 13." PYOViding lese than flve working days to acquire a copy of the policy, review it, and develop substantive comments sends the wrong moceage to the public about DOE's -incerity and commitment to meaninglul stakeholdar involvemant. It 1. especially the wrong mescage to be sending when tra lasue $1 \mathrm{~g}$ publie participation. Wo urge DOR to take corractive action to andure DOE handles tuture solieltatione mora appropriately.

Thank you for this opportunity to comment on the Dor's draft publio Involvement Pol1cy. Please contact Chris Wentz of ay stafl at 8275950 should you have any questione concerning these commants.

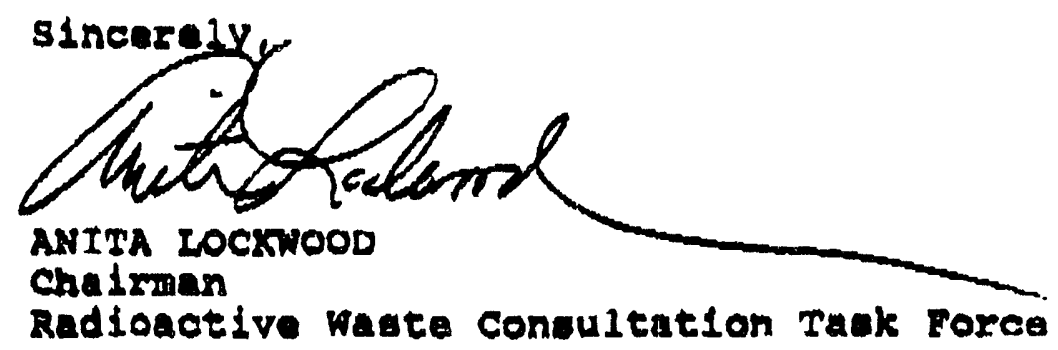

c: John Mekean, oflice of the Governox Task Force Cabinat Doeretarjes

Patricia Trujillo-oviedo, stakeholder Involvamont office, IANL 
DATE: JAN 141994

ATPN OD: CAO: PAO: PBS $94-0098$

sulect. Review of Draft Public Involvement Policy

To: Leroy Apodaca, OIEA-AL

The Carlabad Area office (CAO) performed an internal review of the subject document and provided it to otakeholders in Carlsbad and Hobbs for comment. As of this date no comments have been received from the stakeholders and CAO did not have any changes to suggent.

If you have any additional questions, please call me at 234-7313.

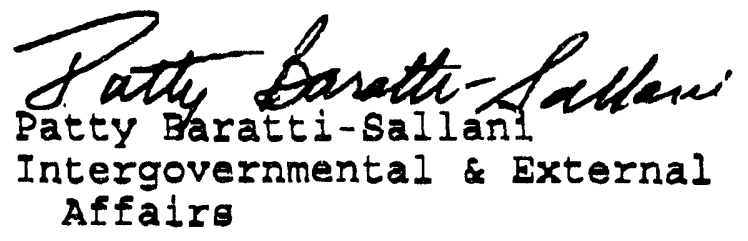


DATE: $\quad$ January 14,1994

TO: $\quad$ Lerov E. Apodoco

FROM: Jane Malogon

SUBJECT: Review of Droft Publlc Involvement Policy couple of comments for your conslderation. The completed. There are just a Purpose: Public involvement brings a full values into the Departments decision-maknge of diverse stakeholder viewpoints and Department to make better decisions and building in the process, enabling the between the Department and the public it serves.

GOALS: III. The publc is informed about and encouraged to participate in
Departmental decision-making. (Final declsions rest with the Department.)

If further information is needed, please feel free to contoct me of

Shirley Cheatham at (813) 541-8253.

cc: Gene Pressoir 


\section{UMTRA:GF}

Leroy E. Apodaca, Lirector, OIEA, AL

Review of Draft Public Involvement Policy

The following is our review of the Draft Public Involvement Policy which you distributed for comment December 17.1993. The policy conveys a strong commitment to involve the public in decision making at all levels of the Department.

\section{COMMENTS}

\section{Specitic:}

The last sentence under the heading "DEFINITION" is a strong one. It might be more effectively placed under the first heading "POLICY." The sentence reads: "The Department will actively seek, incorporate, or otherwise respond to the views of its stakeholders."

\section{General:}

1. Implementation of the policy will require complementary training for senior managers in the field, and public affairs management and staff.

a. Senior management, in addition to developing complementary new values and assumptions, must leam to involve public affairs early at the strategic planning level.

b. Public affairs professionals tend to come froin media relations/communication technician backgrounds. Public participation requires that they learn new roles with a stronger emphasis in strategic counseling lu senior management. The transition is a substantive one requiring development of new values, assumptions, and skills.

2. Public participation impacts schedules and entails costs. Public participation requires more interaction between management and stakeholders. It also requires more public affairs support time. While the end result of public participation is likely to be decisions which are more easily implemented due to public acceptance, a resource investment is required to achieve the long-term gain. Public participation is likely to impact schedules when the public does not 
accept pianned actions. This means that public participation must be included in schedules with sufficient time allowed for response to stakeholder input.

Should you have any questions, please do not hesitate to contact Gaeton Falance of my staff at $845-5636$.
Albert R. Chernoff
Project Manager
Uranium Mill Tailings Remedial Action
Project Office

cc:

F. Morgan, TAC 


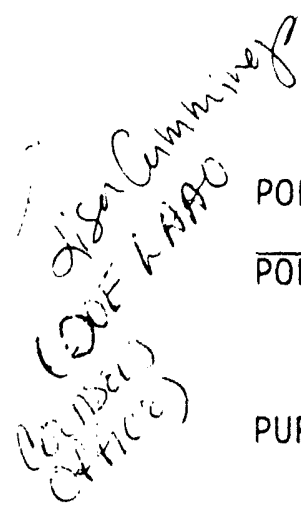

DATE

POLICY ON PUBLIC INVOLVEMENT

POLICY: The policy of the Department of Energy (DOE) is that public involyement must be a routine component in program operations and planning activities, at headquarters and in the field.

PURPOSE: Public involvement brings a full range of diverse stakeholder viewpoints and values early into the Department's decision-making process, enabling the Department to make better decisions and building mutual understanding and trust between the Department and the public it serves.

BACKGROUND: The Energy Department is relatively new at encouraging public involvement in its affairs. The Department grew largely out of the highly regimeited Cold War culture of two of its predecessor agencies, the Atomic Energy Commission and the Energy Research and Developmer Admiristration. The focus was on national defense through nuclear deterrence \%, the priority $\%$ on design and production of nuclear weapons:, and the emphasis on classified information and legally-required secrecy.

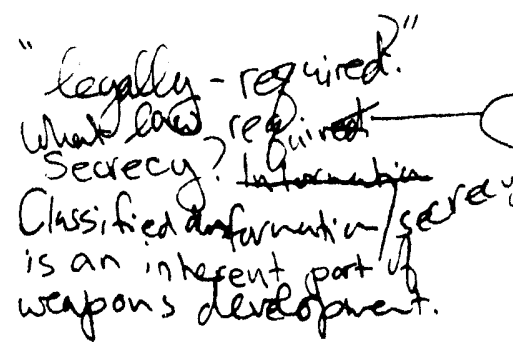

Changing this 50-year-old culture from a closed, command-oriented hierarchy into an open, participatory culture that values diversity and innovation requires special attention and leadership from the top down. Such leadership and change are essential if the Department is to succeed in meeting the economic and environmental challenges of the next century.

OEFINITION: Public involvement provides a means for Americans to influence difference decisions made by their government. It requires routine, whats $f^{\text {the diffece }}$ " substantive two-way communication between the Department of Energy tueen "individublic?" and other governmental entities, organized groups, Gndividuals, and "gneral gublic Department's decisions and activities. This communication will vary widely in nacure and scope, from informal conversations

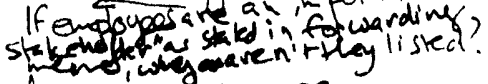
fopreewents are not a form of between individuals to scheduled meetings and workshops, to legally-required public meetings and hearings and [federal-statelocal-Tribal agreements. The Department will actively seek, incorporate, or otherwise respond to the views of its stakeholders.

GOALS: I. Credible, effective public involvement processes are routinely incorporated into the Department's daily program operations and long-term planning activities, at headquarters and in our laboratories, facilities, and field offices, with every employee sharing responsibility to practice and improve public involvement.

II. A clearly defined, coherent internal decision-making process with known access points for public involvement is routinely followed.

III. The public is infurmed about and/empowered to participate in Departmental decisign-making. I - Im concened much too broad a statement. I realize that the policies put 


\author{
Accountability \\ Fairness \\ Openness \\ Respect \\ Risk-taking \\ Sincerity \\ Taking risks is a corevalue? Such as the risks taken in \\ RESPONSIBILITIES: "jeching people with radioactive isotopes w/o thieir \\ Under this policy, public involvement will be a discrete performance \\ element for senior departmental and program managers directly \\ responsible for its effective implementation.
}

To assure a consistent approach throughout the agency and with its contractors and to avoid unreasonable demands on site personnel or the public's time, Program and Staff offices will coordinate their public how do you involvement activities through the office of Public and Consumer

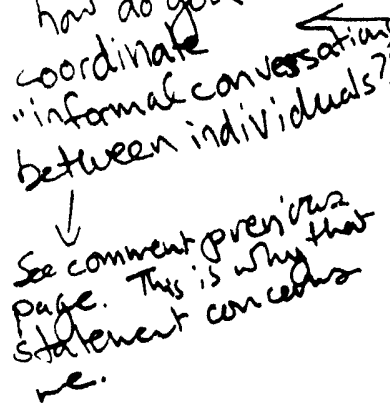

affars, at headquarters and in the field. way limits or dilutes program managers' responsibility to plan, fund, and support appropriate levels of public involvement in their programs.

The Principal Secretarial Ufficer and Senior Departmental Managers will ensure that public involvement principles, values, and processes are fully understood and practiced within their programs and that necessary training and resources (human, information, systems, and financial) are provided.

Program Managers are responsible for identifying, planning, budgeting, and implementing the appropriate level and scope of public involvement activities in their programs, and routinely coordinating activities through the Office of Public and Consumer Affairs. Program managers will assure that their staff receive basic communication training and, where appropriate, advanced public involvement training.

The Director of Public and Consumer Affairs, headquarters, will establish a point of contact and mechanisms to coordinate public involvement activities Department-wide, and to assure that initiatives, as identified and implemented by secretarial officers and program managers, are carried out in a consistent, equitable, integrated manner. Public and Consumer Affairs will provide advice and support to program offices in developing and implementing effective communications/public involvement strategies and information materials for local communities, stakeholders, employees, and the media.

Managers of Field Organizations are responsible for assuring that public involvement activities at their respective facilities and sites meet local neecs, are appropriately coordinated, and reflect Departmontal principles and values. Field managers will regulariy advise headquarters on public involvement issues/needs of regionai or national importance and recommend appropriate courses of action. 
Field Public Affairs/External Relations Directois will work with field managers to provide the same coordinating/integrating role for site pubiic involvement activities as the Director of Public and Consumer Affairs provides department-wide. 
MEMORANDUM FOR: HEADS OF HEADQUARTERS ELEMENTS

MANAGERS, DOE OPERATIONS OFFICES

FROM:

THE SECRETARY

SUBJECT:

GUIDANCE ON IMPLEMENTATION OF THE DEPARTMENT'S PUBLIC INVOLVEMENT POLICY

It is the policy of the Department of Energy (DOE) that public involvement be a routine component in program operations and planning activities, at headquarters and in the field. This policy marks a clear break with past practice by challenging the Department and its contractors to embrace a new culture of openness and service. Henceforth, the business of the Department will be open to the full view and input of those whom it serves.

While public involvement processes must be tailored to specific site and program needs, the following broad guidance is provided to assist headquarters and field managers in implementing this policy department-wide. Several critical policy elements and implementing actions are identified below. These should be viewed as a beginning point. They illustrate the comprehensive nature of public involvement as envisioned in this policy and the innovative leadership required to implement it. Using the following elements as a guide, you should consult with your stakeholders to develop public involvement plans and activities appropriate to their needs and views.

\section{C.RITICAL POLICY ELEMENTS}

1. The Department recognizes that honesty, forthrightness in dealing with external parties, and consistent, credible, quality performance are the bases on which to build public understanding and trust.

\section{Implementing actions:}

- Officials representing the Department will be empowered and accountable for the honesty and accuracy of their public statements and for assuring diligent follow-up and timely. results from the commitments they make.

- Departmental officials will routinely and consistently listen and respond to public input.

- The new benchmark for excellence will be leadership/

performance.
- Risk-taking will will be rewarded. $\rightarrow$ see comment p.2.

- Peer review will be encouraged. 
2. Departmental program development. planning, and decision processes must be cleariy jefined, with regular, well-known access points for public input.

Implementing actions:

- Principal Secretarial Officer and other senior departmental managers will ensure that other affected program officials, site manayers. and stakeholders are appropriately integrated into their planning and decision-making processes.

- Site managers, as those closest to affected communities and interested parties, will advise on appropriate predecisional access points for public input and facilitate accommodatinn between local and national interests.

3. Headquarters, latoratories, facilities, and field offices will operate as an integrated team in planning public involvement activities, combining resources, sharing information, and coordinating schedules.

- Cooperation will be rewarded.

- Site managers and local program officials will routinely advise headquarters on local stakeholder needs/concerns and on the appropriateness/adequacy of public information/ involvement efforts in their areas.

- The Director of Public and Consumer Affairs, working with the Programmatic Assistant Secretaries, will develop consistent formats and clearance procedures for public information materials.

4. The Department must establish and support training/education programs to meet evolving public involvement needs, both internal and external.

Implementing actions:

- The Director of Public and Consumer Affairs will assess on an annual basis the effectiveness of the Department's communications efforts and recommend improvements.

- The Director of Public and Consumer Affairs and the Assistant Secretary for Human Resources and Administration, working with the Programatic Assistant Secretaries, will identify and coordinate communication/public involvement training on a priority basis until all appropriate headquarters and site personnel are trained. 
5. The Department must foster candid information exchanges directed at reaching a common understanding of options and risks and developing consensus.

Implementing actions:

- Whether formal or informal, all public involvement activities will be conducted in a spirit of openness, respect for different perspectives, and a genuine quest for information and ideas.

- The Department will work to establish, announce, and manage a data base of real-time information available to the public through telephone and computer access points. 


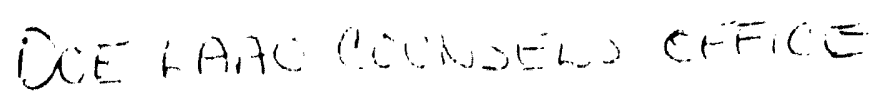

DATE

POLICY OAS PUBLIC INVOLVEMENT

POLICY: The policy of the Department of Energy (BOE) is that public invol'ement must be a routine component in program operations and planning activities, at headquarters and in the field.

PIJRPOSE: Public involvement biings a, full range of diverse stakeholder viewpoints and values earlý into the Department's decision-making process, enablirig the Départment to make better decisions and building mutual understanding and trust between the Department and the public it serves.
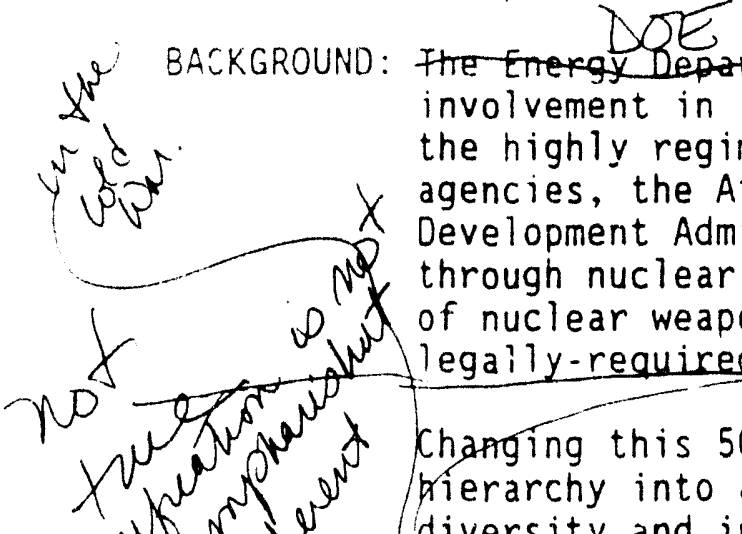

The energy bep is relatively ney at encouraging public involvement in its affairs. The Department grew largely out of the highly regimented Cold War eutture of two of its predecessor agencies, the Atomic Energy Commission and the Energy Research and Development Admiristration. The focus was on national defense through nuclear deterrence; the priority, on design and production of nuclear weapons; and the emphasis on classified information and legally-required secrecy

Changing this 50 year old culture from a closed, command-oriented Mierarchy into an open, participatory culture that values diversity and innovation requires special attention and leadership $\$$ (1) Non the top down. Such leadership and change are essential if (1) $y^{r}{ }^{r} d f^{\prime}$ the Department is to succeed in meeting the economic and of onvironmental chal lenges of the next century.

DEFINITION: (Public involvement provides a means for Americans to influence decisions made by their government. It requires routine,

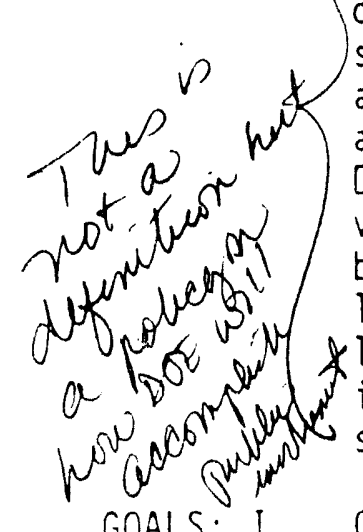
substantive two-way communication between the Department of Energy and other governmental entities, organized groups, individuals, and the general fublic interested in and/or affected by the Department's decisions and activities. This communication will vary widely in nature and scope. from informal conversations between individuals to scheduled meetings and workshops, to legally-required public meetings and hearings and federal-stateflocal-Tribal agreements. The Department will actively seek, incorporate, or otherwise respond to the views of its stakeholders.

Credible, effective public involvement processes are routinely incorporated into the Department's daily program operations and long-term planning activities, at headquarters and in our laboratories, facilities, and field offices, with every employee sharing responsibility to practice and improve public involvement.

II. A clearly defined, coherent internal decision-making process with known access points for public involvement is routinely followed.

III. The public is informed about and empowered to participate in Departmental decision-making. 

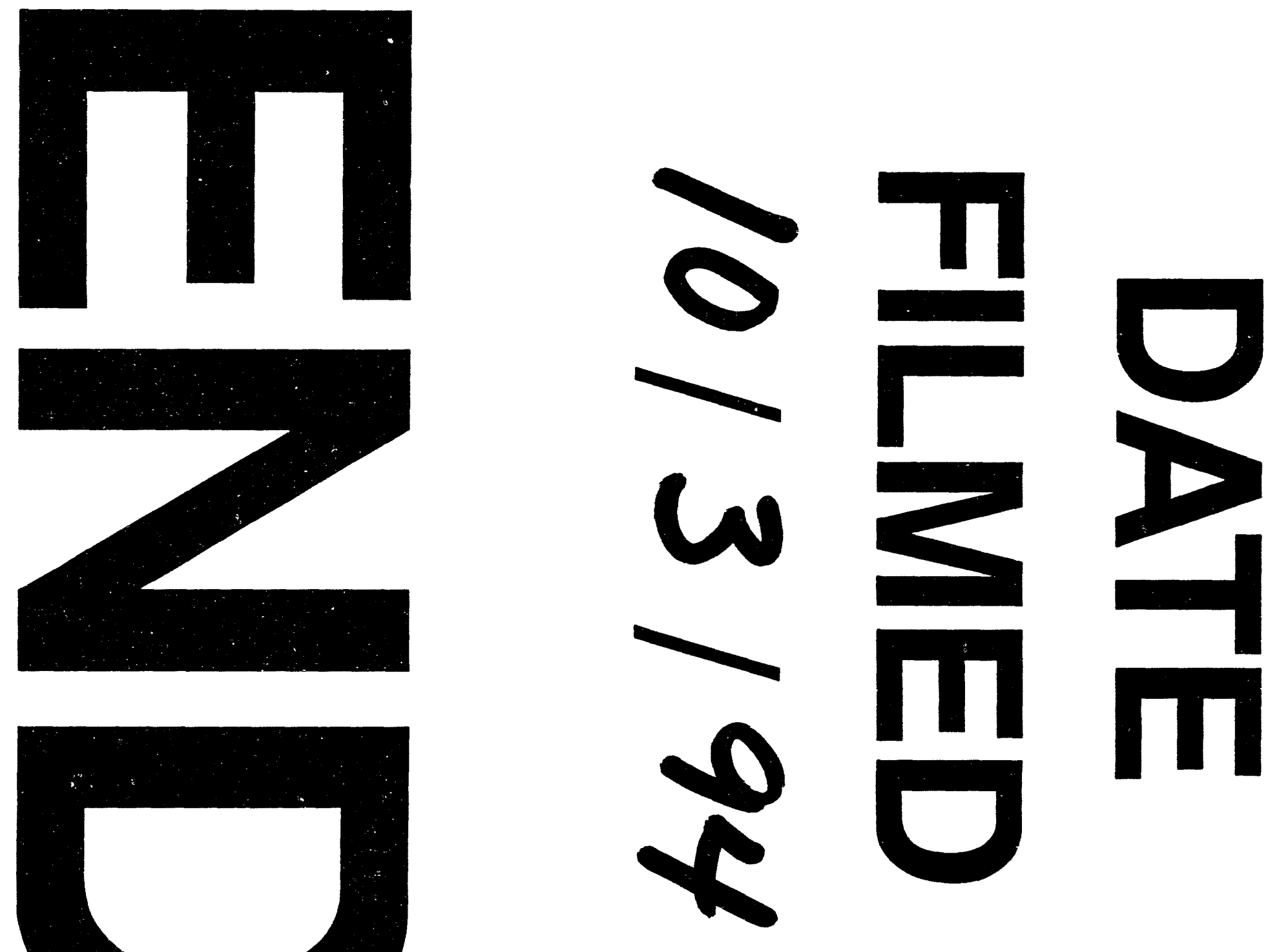
